Portland State University

PDXScholar

Dissertations and Theses

Dissertations and Theses

Spring 6-2-2014

\title{
Bridging the Future to Postsecondary Readiness
}

Brian Patrick Sien

Portland State University

Follow this and additional works at: https://pdxscholar.library.pdx.edu/open_access_etds

Part of the Educational Leadership Commons

Let us know how access to this document benefits you.

\section{Recommended Citation}

Sien, Brian Patrick, "Bridging the Future to Postsecondary Readiness" (2014). Dissertations and Theses. Paper 1858.

https://doi.org/10.15760/etd.1857

This Dissertation is brought to you for free and open access. It has been accepted for inclusion in Dissertations and Theses by an authorized administrator of PDXScholar. Please contact us if we can make this document more accessible: pdxscholar@pdx.edu. 
Bridging the Future to Postsecondary Readiness

by

Brian Sien

A dissertation submitted in partial fulfillment of the requirements for the degree of

Doctor of Education

in

Educational Leadership: Administration

\author{
Dissertation Committee: \\ Tom Chenoweth, Chair \\ Samuel Henry \\ Pauline Jivanjee \\ Amy Petti
}

Portland State University

2014 
(C) 2014 Brian Sien 


\begin{abstract}
Continuing education advances society. For every student, our educational system should provide a seamless transition from one level to the next until a degree or certificate is earned that reflects a mastery of skills needed to secure employment. This helps prepare each individual for a successful life after exiting the educational system and greatly benefit our society. Today, however, many students graduating from high schools are not ready for a postsecondary education. Transitioning students from high school to college is a complex process that requires many different approaches. Students making this transition are finding it more difficult to enter and succeed at a higher level of education because of the complexity of this process. Preparing students for postsecondary options is critical for every student. Students from low-income families and some ethnic and racial minority groups are most dependent on the ability of their high school to prepare them properly for college success (Conley, 2010). In what ways can schools better prepare students for postsecondary success? This study focuses on the creation of a Postsecondary Readiness Guidebook (PRG) which provides a comprehensive approach to help educational leaders prepare students for postsecondary success. The guidebook uses a problem-based learning design and follows the research and development process. The guidebook was field tested by educational leaders in a K-12 public school though a workshop using a qualitative methodology. During the field-testing of the guidebook, data were collected through assessments, interviews with educators, and questionnaires completed by educational leaders at the school. Data were analyzed using inductive
\end{abstract}


coding, facesheet coding, enumeration, and typology. The findings of the study reveal that using a guidebook with a comprehensive approach to postsecondary preparedness can help school leaders prepare students for postsecondary success. Educational leaders in the school collectively focused on best practices and programs aimed at preparing students for postsecondary options through the use and interaction of the PRG. The guidebook gave them a compass for which to navigate the complex process of preparing students for postsecondary success. 


\section{Dedication}

This work is dedicated to those who value the importance of education and how it transcends the world in which we live. I would like to thank my family who would not accept anything other than a college education. They pushed me and supported me in ways that, at the time, I did not understand. My grandparents, who are no longer around, surrounded me with the thought that not getting a postsecondary education would be the wrong road in life for me to take. My uncles, who benefitted greatly from higher education, provided the model from which to succeed. My mother, who made it a top priority to find a way to finance my education, would settle for nothing less than a college degree for me. It was through her vision that I devoted my life to education. My step-father, who also benefitted from a college degree, provided help and support along the way through encouragement and love for both my mother and me. My one-of-a-kind wife, Carla, who saw the sky as the limit for me, jumped on this opportunity to push me toward my potential through understanding, love, and knowledge of life. These players were critical in my journey toward helping others. It was their high expectations for me that pushed me and gave me the resilience to succeed.

To those who have pursued education and benefitted others through their journey, along with those who never had the opportunity due to educational barriers, I dedicate this to you. I am hoping that through my work, these barriers will be removed to make postsecondary education a reality for everyone. 


\section{Acknowledgements}

I would like to acknowledge my family for helping me get to this point in my life. Although they are miles away, their support and love has filled me during my Ed.D. journey. Your high hopes for me have helped to set the bar high, and allowed me the opportunity to influence others. I have always felt the pride you had in me and want to thank you for everything you have done to make this possible.

To my staff that helped to minimize any problems at school during my journey, I give you my thanks. My research and work allowed us to try out innovative and unique ideas, and because of this I feel we have all benefitted. You have been very understanding and I look forward to working with you to continually improve our school for our students.

To my friends in our educational leadership cohort (Teri, Paul, Peter, Linda, Dan and Carol), I cannot adequately express how much I enjoyed meeting you and getting to know you throughout our journey. When this process began, we had a deep passion for helping others in our jobs, and this has transcended into helping each other along the way. It is through your ambition, understanding, laughter, and hard work that I get my motivation to complete my work, and for that I thank you. I especially want to thank Teri for pushing me the final months to complete my work. Checking in with you during this process helped to clarify things and motivated me down the home stretch.

My journey would not have been possible without the help of all my professors. Dr. Karen Noordhoff provided me the opportunity to think about learning in a way I have 
never done. You challenged my critical thinking skills and your high expectations drove me to improve both my academic thinking and writing. I have never had an instructor like you, and because of this I was able to think and create to my potential.

Dr. Jackie Temple, thank you for teaching me the importance of organizational leadership and its role in running a school. During this class, your resources and insight were invaluable to me. Your generosity and compassion in class set the table for me to take risks. These risks allowed me to grow in job and in my other educational pursuits.

To my research professors, Dr. Swapna Mukhopadhyay, Dr. Emily de la Cruz, and Dr. Moti Hara; I want to thank you for teaching me about the different kinds of research and their origins. These late night classes of crunching thoughts, words, and numbers allowed me the opportunity to discover my core values and beliefs as they relate to research. Through your classes, I was able to connect research knowledge with these core values and beliefs toward my dissertation work. You also gave me the courage to move forward in my work with confidence and determination.

To my committee members, Dr. Amy Petti and Dr. Samuel Henry, thank you for teaching me how to navigate through policy, politics, and the world of academia. Your experience, knowledge, and resources in education have guided me in my journey. You have been great resources in my studies and my career. I also want to thank Dr. Pauline Jivanjee for her participation on my committee. I enjoyed working with you and am grateful to have you share your expertise with me. I truly appreciate your service on my committees. 
To come back to where I began in my world of educational leadership, I would like to sincerely thank Dr. Tom Chenoweth. You were the first professor I had in educational leadership, and I am really grateful for this. I could not have a better mentor and advisor throughout the years. Your educational experience and innovative thoughts are priceless. You never shy away from either educational change or reform; in fact, it is what motivates you. There are many people in education who are comfortable with the status quo, and I am very fortunate to have someone guide me who questions this thinking. Not only have you provided me with various resources, you have helped me transcend my thinking to challenge the educational system as a whole-and find comfort in this. You see my potential and drive me to reach it. I thank you for this, my advisor and friend.

Lastly, I would like to thank my wonderful wife, who has never stopped believing in me. I know that she is my ambition and drive. It is through her that I am able to get through this journey. She pushed me through understanding, guidance, knowledge and love. This process is very time consuming and I have sacrificed time with her. Because of this, her support and motivation has grown and she truly believes not only in what I am doing, but also in me. Thank you Carla! You are the best, and I could never have done this without you! 


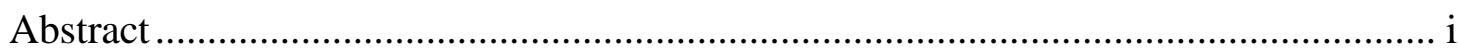

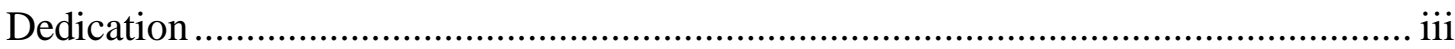

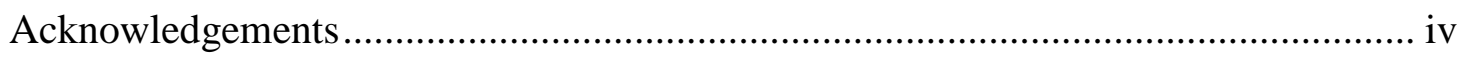

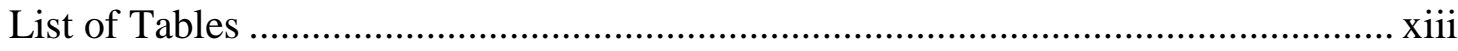

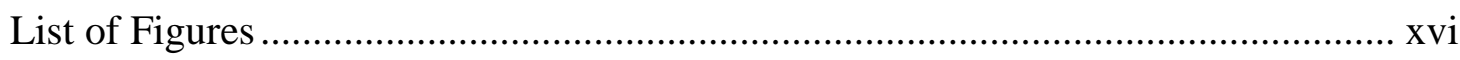

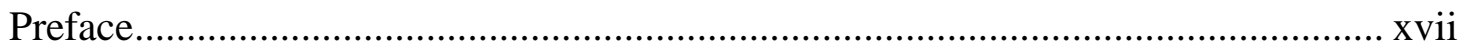

\section{CHAPTER}

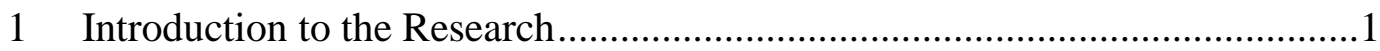

Background ..................................................................... 1

Statement of the Problem.......................................................... 4

Significance of the Study .......................................................... 6

Purpose of Study .................................................................... 11

The Advanced Placement Program ........................................ 12

Advancement Via Individual Determination ............................ 12

The International Baccalaureate Programme ............................ 13

Early and Middle College High School Models ...................... 14

Research Methodology ........................................................... 15

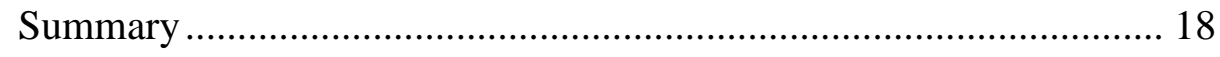

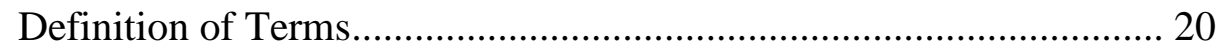




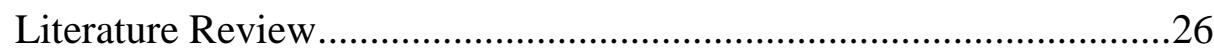

College and Career Readiness: Same or Different?............................33

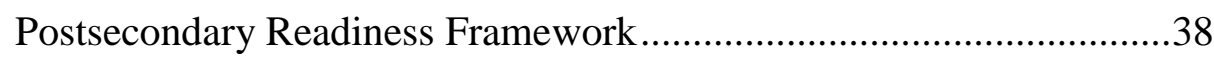

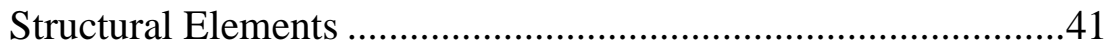

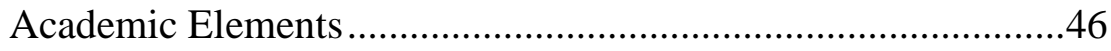

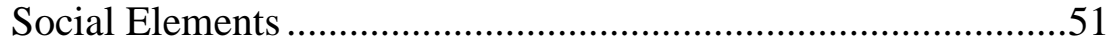

Early and Middle College High Schools .........................................662

Wallis Annenberg High School and Dayton Early College

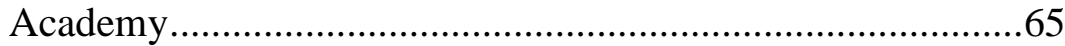

Middle College High School ....................................................68

Harbor Teachers Preparation Academy ..................................69

Conclusions and Recommendations ...............................................72

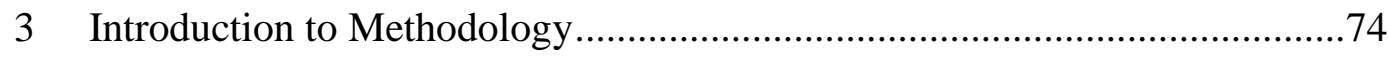

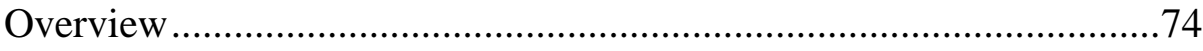

Research Design....................................................................... 77

Research and Information Collecting...................................80

Planning Objectives, Learning Activities, and Small-Scale

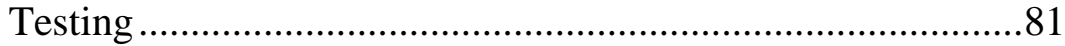

Develop Preliminary Form of the Product .............................82

Preliminary Field Testing .....................................................83

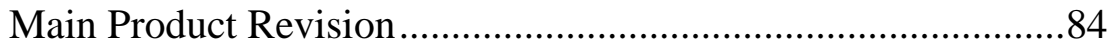

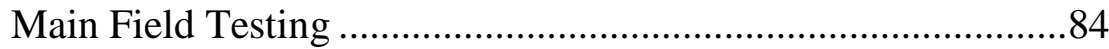

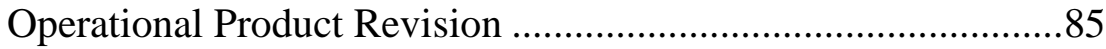

Operational Field Testing, Final Product Revision,

Dissemination, and Implementation...................................86

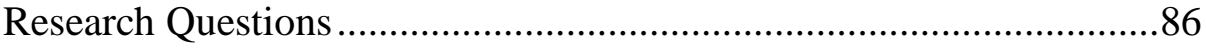

Data Collection Procedures..........................................................8 88 


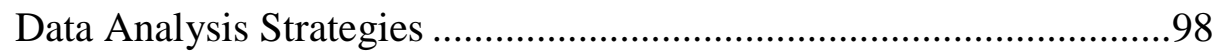

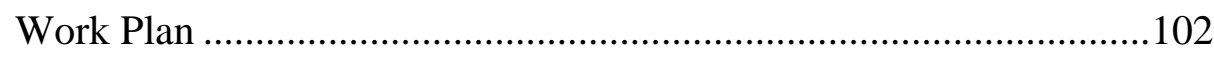

Research and Information Collecting.....................................102

Planning Objectives, Learning Activities, and Small-Scale Testing …….................................................................102

Develop Prelininary Form of the Project ...................................103

Preliminary Field Testing ..........................................................104

Main Product Revision.............................................................104

Main Field Testing ………………………………………......105

Operational Proudct Revision ..................................................105

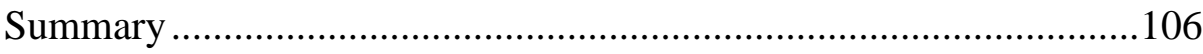

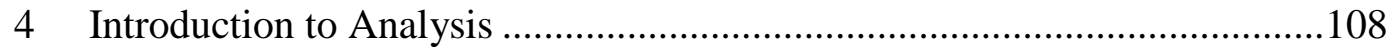

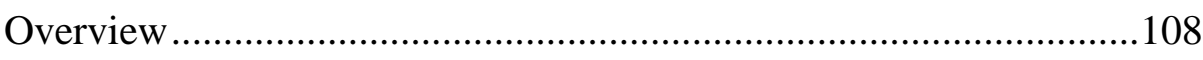

Seven Steps of the R\&D Process ......................................................110

Step 1: Research and Information Collecting ............................110

Step 2: Planning Objectives, Learning Activities, and Small-Scale Testing ......................................................111

Step 3: Develop Preliminary Form of the Product......................111

Step 4: Preliminary Field Testing ...............................................111

Step 5: Main Product Revision.....................................................112

Step 6: Main Field Testing ..........................................................112

Step 7: Operational Product Revision ..........................................113

Review of the Research Questions and Goals ..................................113

Research Questions .......................................................................114

Step 1: Research and Information Collecting ...........................115

Step 2: Planning Objectives, Learning Activities, and Small-Scale Testing ......................................................115

Step 3: Develop Preliminary Form of the Product.....................119

Step 4: Preliminary Field Testing..............................................121

Step 5: Main Product Revision.....................................................123

Step 6: Main Field Testing ...........................................................123 
Research Goals

Development and Implementation: Field Testing and the PBL

Project

Step 2: Planning Objectives, Learning Activities, and

Small-Scale Testing. 126

Step 3: Develop Preliminary Form of the Product....................149

Step 4: Preliminary Field Testing...........................................150

Step 5: Main Product Revision.............................................. 182

Step 6: Main Field Testing ...................................................184

Summative Evaluation of Results ...............................................231

Demographic Data Results ...............................................231

Workshop Survey Results .................................................232

Guidebook Survey Results ...................................................233

Knowledge of Postsecondary Readiness Results ....................234

Demographic Data Results of Interview Participants ...............235

Formative Evaluation of Results.................................................236

Workshop Results ......................................................236

Guidebook Functionality Results .......................................236

Guidebook Results (Knowledge) ......................................237

Interview Data Results ......................................................239

Product Development............................................................240

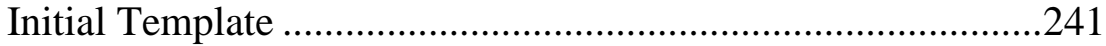

Preliminary Form of the Product..............................................2243

Main Product Revision..........................................................244

Operational Product Revision ...............................................246

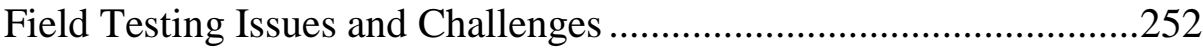

Accessibility .................................................................252

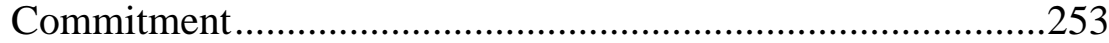

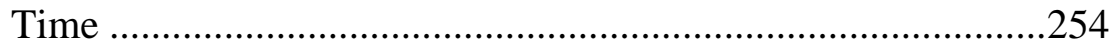

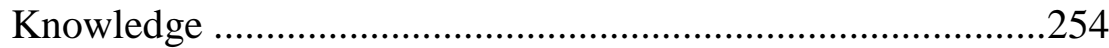

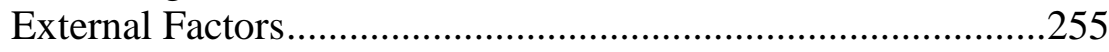


Summary 256

5 Conclusions, Speculations, and Recommendations for Leadership .............260

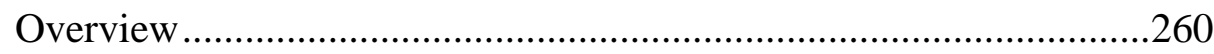

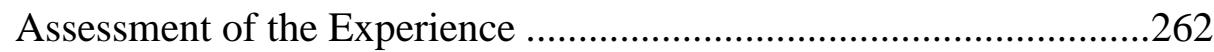

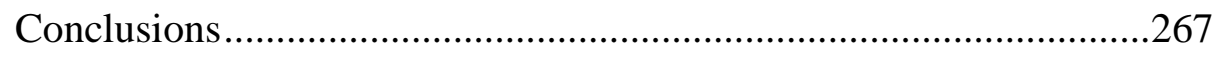

Speculations on Future Research .......................................................269

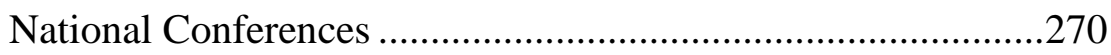

State-Level Conferences .........................................................271

Final Product Revision ............................................................272

Dissemination and Implementation..........................................273

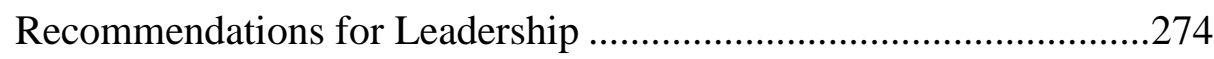

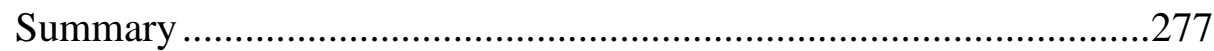

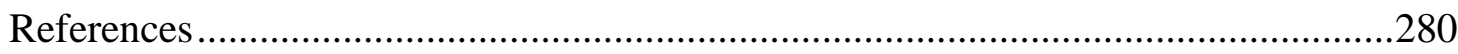

Appendices

A Workshop PowerPoint Presentation: Preliminary Field Testing ..................287

B Participants' Consent Form ………………..............................................293

C Interview Protocol: Small-Scale Testing ...................................................29

D Observational Protocol: Small-Scale Testing..............................................297

E Postsecondary Readiness Guidebook Workshop Questionnaire ...................299

F PrA and PoA on Postsecondary Readiness …………................................302

G Interview Protocol: Preliminary Field Testing ..............................................305

$\mathrm{H} \quad$ Letter of Introduction (Main Field Testing) …….........................................307 
I Participants' Consent Form (Main Field Testing) .........................................310

J Workshop Presentation (Main Field Test) ……………………....................312

K Guidebook Functionality Evaluation...........................................................323

L Interview Protocol: Main Field Testing ……………................................328

M Interview Protocol 1: Main Field Testing ………….................................330

N Interview Protocol 2: Main Field Testing ……….......................................332

O Interview Protocol 3: Main Field Testing ……………………………......334

P Interview Protocol 4: Main Field Testing …………...................................336

Q Interview Protocol 5: Main Field Testing …………....................................338

R Postsecondary Readiness Guidebook ………...............................................340 


\section{List of Tables}

Table

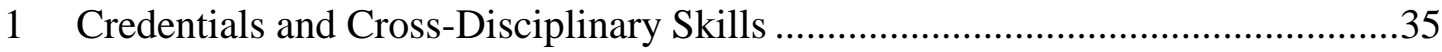

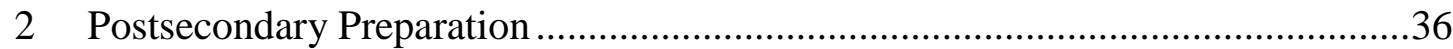

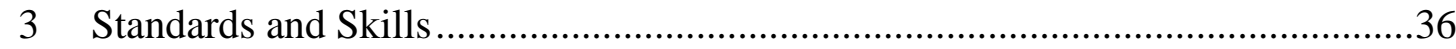

4 Setting the Infrastructure for College Readiness ...........................................46

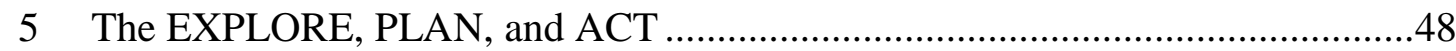

6 Four Keys to College and Career Readiness..................................................50

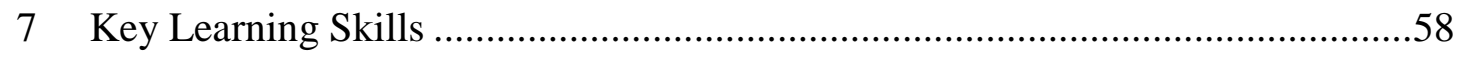

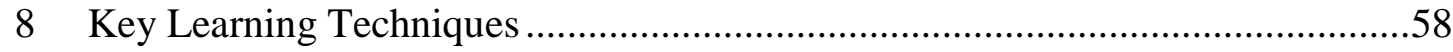

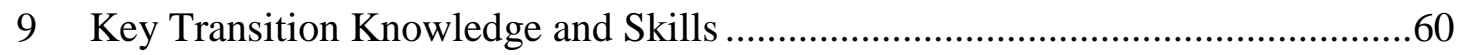

10 Comparing Specific Practices Within the Framework-I .................................67

11 Comparing Specific Practices Within the Framework-II..................................71

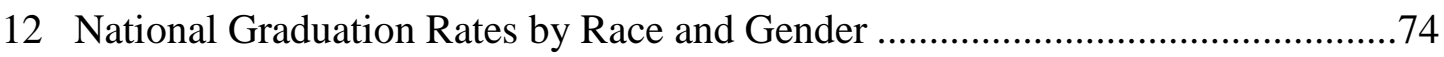

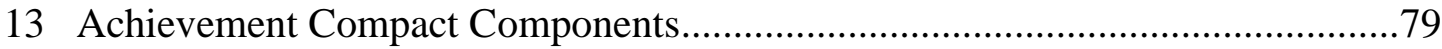

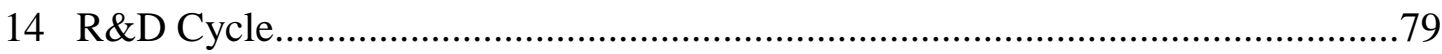

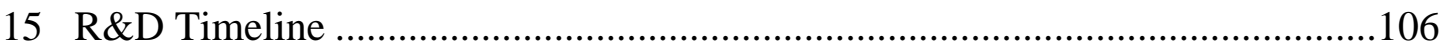

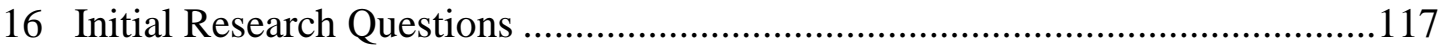

17 Preliminary and Guiding Research Questions ............................................119

18 Interview Questions Generated in Step 2 and Used in Step 3 of the R\&D Cycle

19 Small-Scale Testing: Design Team Demographic Information .........................128 
20 Small-Scale Testing: Professional Development-Meetings and Trainings

21 Small-Scale Testing: Educational Leader Interview Demographics

22 Small-Scale Testing: College Readiness Skills-Key Cognitive Skills...............136

23 Small-Scale Testing: Key Themes From Nine Coded Interviews..... 138

24 Small-Scale Testing: Key Themes on Participant's Role as Educational Leader

25 Small-Scale Testing: Formative Interview Feedback Template Advice/ Components

26 Small-Scale Testing: Key Themes From Eight Achievement Compact Advisory Committees

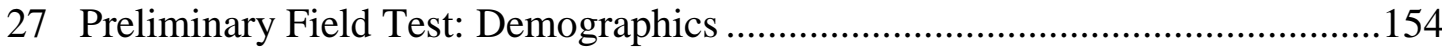

28 Preliminary Field Test: Evaluation of the Workshop ...................................156

29 Preliminary Field Test: Formative Results ................................................ 160

30 Preliminary Field Test: PrA and PoA and Formative Results on

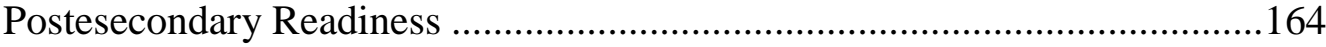

31 Preliminary Field Test: Educational Leaders Interview Demographics .............178

32 Preliminary Field Test: Key Themes From Two Coded Interviews ..................179

33 Preliminary Field Test: Formative Interview Feedback ................................181

34 Main Field Test: Participant Demographics ................................................188

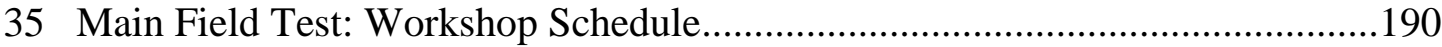

36 Main Field Test: Workshop Evaluation .....................................................195

37 Main Field Test: Workshop Formative Results ...............................................199

38 Main Field Test: Guidebook Evaluation.........................................................201 
39 Main Field Test: PrA and PoA and Formative Results on Postsecondary Readiness

40 Main Field Test: Educational Leaders Interview Demographics .......................225

41 Main Field Test: Key Themes From Six Coded Interviews ...............................227

42 Main Field Test: Formative Interview Feedback ...............................................228

43 Interview Data Results: Formative Interview Feedback.....................................240

44 Operational Product Revision 1: Supported by Data ...........................................247

45 Operational Product Revision 2: Supported by Data ..........................................248

46 Operational Product Revision 3: Supported by Data ...........................................249

47 Operational Product Revision 4: Supported by Data ...........................................250

48 Operational Product Revision 5: Supported by Data .........................................251 


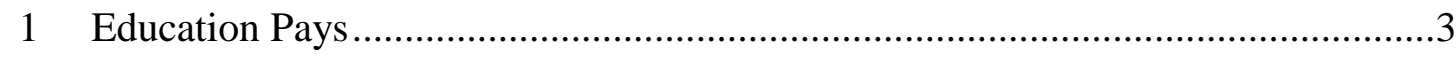

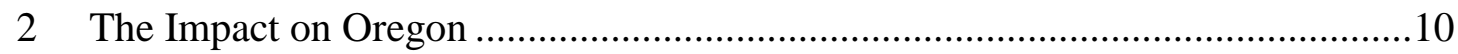

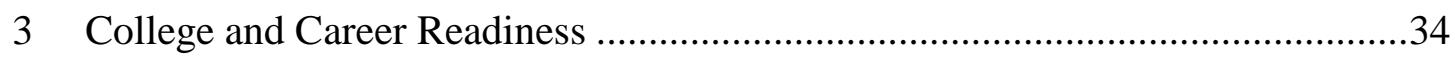

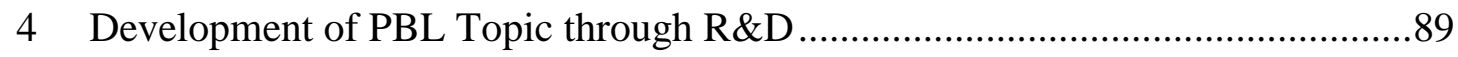

$5 \quad$ Workshop on Postsecondary Readiness.....................................................121

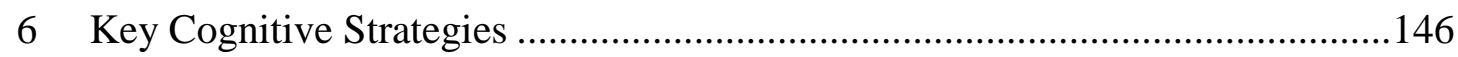

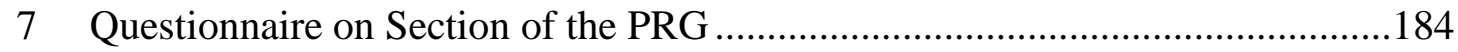




\section{Preface}

As an educator, I have the opportunity to travel around the country and observe different educational models. I do this because I believe that there are many ways to approach education; I do not have the market cornered on excellence. I also do this because I believe that any opportunity to collaborate will greatly help our educational process. This is no more evident than in the quote by Nelson Mandela, "Education is the most powerful weapon which you can use to change the world."

While traveling to Texas to visit a school model similar to ours, I was hoping to return with new, unique, and innovative approaches to education. Upon my return, I had the opportunity to reflect on what I had learned. While the intent of my visit was to gain knowledge on how to best serve students transitioning to postsecondary options, which I was able to do, I also realized that the educational culture of our country has limited collaboration between educational institutions.

When I first arrived for my visit, I was welcomed by the principal, who was in his first year with the school. As soon as I he greeted me, the first thing he asked me was: "Why are you here?" I responded that our two schools were similar in their mission and that I wanted to see what they were doing that was effective and what obstacles they have encountered along the way. He seemed surprised.

His reaction to my presence was disappointing. If the culture of education in our country were collaborative, his response to my visit would have been different. He would have welcomed me, and our two schools would have formed a professional partnership. 
We would have shared information about our obstacles and best practices in order to best serve our students.

While walking away from my visit, I did begin to lay the groundwork for collaboration. I realized that I have a great deal to share with this principal, and I am confident he could reciprocate with knowledge of his own. We shared contact information and hopefully, our journey toward our similar goal will continue.

It is through this work toward my dissertation that I am eager and willing to build a network of collaboration between educational institutions that are intent on preparing students for postsecondary success. This can begin through the creation of a Postsecondary Readiness Guidebook that will help high school leaders prepare students for postsecondary success through a comprehensive approach. Through the creation of this guidebook, I can begin to lay a foundation of collaboration. Hopefully, I can help to build a systematic sharing of knowledge among high schools aimed at successfully helping transition students from high school to postsecondary options. It is through this work that I am committed and motivated toward helping other educational leaders. 


\section{CHAPTER 1}

\section{INTRODUCTION TO THE RESEARCH}

\section{Background}

In November of 2009, President Barack Obama stated the necessity of making education America's national mission (U.S. Department of Education, 2009). During tough economic times, education plays a critical role in helping our citizens obtain the necessary skills to become contributing members of the work force. Oregon is realizing the importance of education and is committed to a "40-40-20" plan in which the state will: (a) ensure that at least $40 \%$ of adult Oregonians have earned a bachelor's degree or higher; (b) ensure that at least $40 \%$ of adult Oregonians have earned an associate's degree or postsecondary credential as their highest level of educational attainment; and (c) ensure that the remaining $20 \%$ or less of all adult Oregonians have earned a high school diploma, an extended or modified high school diploma, or the equivalent of a high school diploma as their highest level of educational attainment (Mission of Education Beyond High School, 2011). Unfortunately, in our educational system, many students graduating from high school are not ready for a postsecondary education; they are therefore unqualified to join the work force. Today, the goals of our educational system need to align with the goals of our society. We need to provide our students successful programs and schools that prepare them for a postsecondary education so that they can meet the demands of a global economy. Now more than ever, education must be the material from which the greatness of our country is shaped. Throughout this paper I assume that a 
postsecondary education prepared students for the work force. A postsecondary education includes studies completed at: community colleges (career certificates, associate's degrees) or universities (bachelor's, master's, professional, and doctoral degree). When looking at transitioning students from high school to postsecondary options, it is necessary to first look at the high school system. The evolution of high schools in our society is linked directly with the growth of our nation. Secondary schooling was developed from traditional village schools in the late $19^{\text {th }}$ and early $20^{\text {th }}$ centuries and was linked to the success of our country's economic and political future (Lee \& Smith, 1995). Large high schools were created for efficiency, differentiation, specialization, and standardization. This was done to prepare high school graduates to be productive members of the workforce and was a successful model of the production of human capital until the late 1960s (Lee \& Smith, 1995). As students earn their high school diploma, their unemployment rates decrease and their median weekly earnings increase compared to students who have not earned high school diploma. The more education one receives, the more one's earning potential and probability of employment increase, giving postsecondary education greater importance (Figure 1). 


\section{Earnings and unemployment rates by educational attainment}

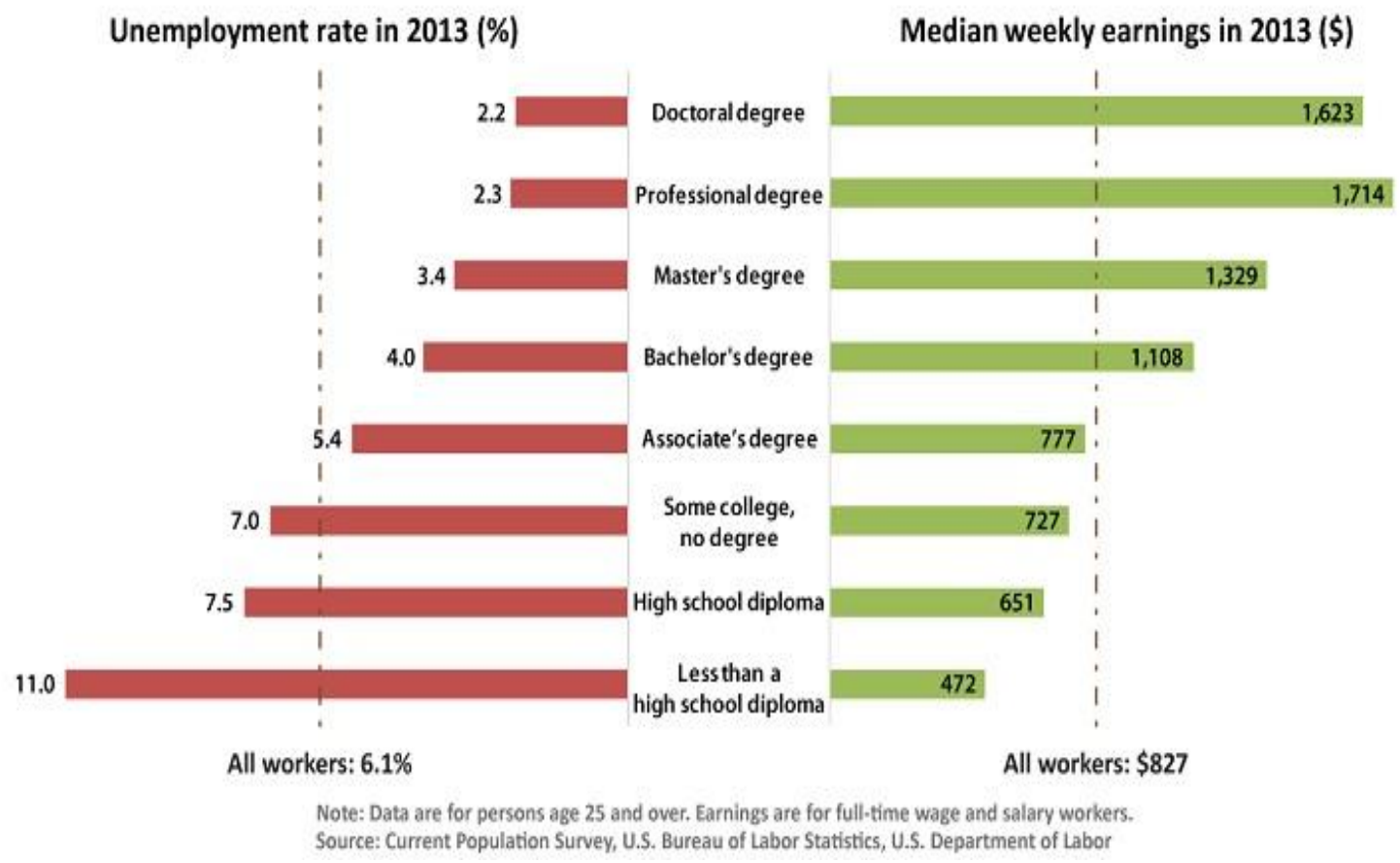

Figure 1. Education pays. This figure illustrates earnings and unemployment rates by educational attainment. Source U.S. Department of Labor, Bureau of Labor Statistics (2013), Current Population Survey.

In high schools today, there are many students who are not learning the necessary skills to succeed after high school. It is easy to avoid learning in today's high schools and still graduate believing that one has learned (Powell, Farrar, \& Cohen, 1985). Students from low-income families and some ethnic and racial minority groups are most dependent on the ability of their high school to prepare them properly for college success (Conley, 2010). Conley (2010) stated that while many high school graduates exceed expectations, many do not, and there is no real way to know the minimal level of skill that all diploma recipients have attained. High schools have continued to operate under 
older bureaucratic designs, even though our society and workforce have placed a greater importance on postsecondary education. High schools should be directly connected to elementary and middle schools, higher education, industry and business, state and federal government, and their communities that surround them (Boyer, 1983). In reality, high schools often become independent educational institutions that are isolated from the aforementioned stakeholders. There needs to be a bridge to connect the systems of education so our children do not suffer in the transition from one system to the next.

Because many students graduating high school are not ready for college, the following questions need to be answered: What can be done to our educational structure so that it successfully prepares students for a postsecondary education? What standards exist to help states, districts, schools, and educators prepare students for a postsecondary education? What program/schools currently exist to help students make a successful transition from high school to postsecondary education? It is up to educators to teach high school students the skills necessary to make a successful transition from high school to postsecondary education. If educators succeed in this, students will be able to reflect on their high school experience as constructive and positive toward helping them grow as individuals in our society. By answering the aforementioned questions, we begin to make education (America's national mission) a reality.

\section{Statement of the Problem}

In these uncertain economic times, parents from all racial, ethnic, and economic backgrounds are looking to high schools more than ever to prepare their sons and 
daughters well for life after high school. Many parents are hoping that this life after high school entails a successful entry into an institution of higher education to ensure that their sons/daughters can enjoy a life of happiness and prosperity. Studies show that students who earn a bachelor's degree are $33 \%$ more likely to become employed over students who earn a high school diploma (Pascarella \& Terenzini, 1991). Pascarella and Terenzini (1991) also showed that students obtaining an associate degree have a 9-17\% advantage of employment over students with a high school diploma.

Research confirms that many students graduating from high school are not ready for postsecondary education because high schools are not adequately preparing them. This lack of preparation requires remediation and can be attributed to the lack of alignment between high school and college regarding academic standards, communication, and collaboration. Some 2 -year colleges see $80 \%$ of their students taking remedial classes. Moreover, only $17 \%$ of students who must take remedial reading receive a bachelor's degree or higher (Conley, 2010). Better efforts must be made to transition students from high school to colleges and universities. The first year of college is the most important in regard to degree completion; $25 \%$ of these students drop out their freshman year (Carey, 2004). In my experience as a middle college principal, it has become a necessity for my high school to work closely with our local community college to provide a seamless transition from secondary to postsecondary education that will ensure student success. Both educational institutions have an investment in these students who will determine the future development and prosperity of our country. 


\section{Significance of the Study}

While not all students who finish high school go to college, nearly $70 \%$ will actually enroll in colleges or universities within two years of high school graduation (Haycock, Barth, Mitchell, \& Wilkins, 1999). As more and more students and families realize the importance of a postsecondary education, efforts must be made by both high schools and colleges to work on transitioning students successfully from one system to another. In order to facilitate this transition, the Bill and Melinda Gates Foundation (2009) has invested nearly $\$ 4$ billion to transform the levels of college-readiness and success for America's young people, particularly for low-income and minority youth. This foundation has helped demonstrate that with the right opportunities, all young people can achieve at high levels (Bill and Melinda Gates Foundation, 2009). As educational leaders are not emphasizing skills students need to be successful in college, it is difficult for students to make the transition from the public educational system (P-12) to the higher educational system (13-20).

The financial and economic implications of the current educational situation are difficult to ignore. The next decade will bring an economy where more than $60 \%$ of jobs will require a college degree; in Oregon only about a third of students will enter college the fall after graduating, and only about 10\% will earn a degree within 4 years (Carnevale, Smith, \& Strohl, 2010). As secondary schools and postsecondary institutions are not aligned, students are not acquiring the necessary skills to move from one system to the other. Of students who are admitted and enrolled into postsecondary institutions, 
$40 \%$ take at least one remedial course at a total cost of $\$ 1$ billion or more per year

(Conley, 2010). An effective transition for these students would provide savings to states and families and provide economic stability for the country.

Culturally, issues of social justice arise when we attempt to serve all members of our society within the current system. Social justice is defined as a dynamic state of affairs that is good for the common interest; this includes the good of each and all, in an acknowledgement that one depends on the other. The good depends on a correct distribution of benefits and responsibilities (Griffiths, 1998, p. 302). It is important, when referring to the aforementioned definition, to acknowledge that all students should have access to a postsecondary education. Conley (2010) reported that only $60 \%$ of students from minority groups and low-income families can expect to graduate from high school, only one in three will enroll in college, and only one in seven will earn a bachelor's degree. In 2005, the nation's governors held an educational summit to discuss the failure of high school to educate all students (Wolk, 2005). In this summit, some alarming statistics were addressed. According to Wolk (2005):

- Almost a third of students who start the ninth grade fail to graduate and twothirds are not prepared for college; only half of African-American, Latino, and Native-American youth earn a high school diploma.

- A solid majority of high school seniors are not proficient in reading, math, or science, and their scores decline from fourth to twelfth grade; U.S. students usually rank in the bottom half of global achievement, at a similar level as those in underdeveloped nations.

- Seventy-five percent of high school graduates enroll in college; more than a third need remedial courses, a third never make it to the sophomore year, and more than half do not complete the work necessary to earn a degree. 
- Eighteen percent of African Americans and 10 percent of Latinos complete a four-year college degree by the time they are 29: 34 percent of whites do.

- The percentage of U.S. students who earn a college degree is the same as it was 30 years ago. (p. 2)

It is clear from the research above that a sizeable portion of students moving to postsecondary education are not ready; there are specific groups of students who either never make it or are underrepresented in higher education. Leaders at the federal and state level are beginning to see the importance of creating an educational structure that successfully transitions students from high school to college or careers, and that it directly affects the growth of our country.

In February 2009, President Obama signed into law the American Recovery and Reinvestment Act of 2009. This federal legislation was created to help stimulate the economy, support job creation, and invest in critical sectors, including education (U.S. Department of Education, 2009). The U.S. Department of Education (2009) implemented American Recovery and Reinvestment Act to move education reform toward supporting investments in innovative strategies that would lead to improved student results, longterm gains in school and educational system capacity, and increased productivity and effectiveness. American Recovery and Reinvestment Act provided $\$ 4.35$ billion to create the Race to the Top Fund. This was a competitive grant program for States to reward and encourage innovation in education. This innovation would address the following conditions: achieving significant improvement in student outcomes, including making substantial gains in student achievement; closing achievement gaps; improving high 
school graduation rates; ensuring student preparation for success in college and careers; and implementing ambitious plans for educational reform (U.S. Department of Education, 2009).

To prepare students for success in postsecondary education, Race to the Top encouraged the adoption of standards and assessments that prepared students to succeed and to compete in the global economy. Race to the Top was based on six priorities to improve the quality of education in our country. Priorities one and five addressed successful transitions from high school to postsecondary education. Priority one, the Absolute Priority, focused on a comprehensive approach to educational reform where the Local Educational Agencies or school districts will use the funds from Race to the Top to increase stakeholder involvement and the rates at which students graduate from high school prepared for postsecondary education (U.S. Department of Education, 2009). Priority five, the Invitational Priority, focuses on early preschool-through-graduate school (P-20) coordination-vertical and horizontal alignment. Priority five stresses the importance of vertical alignment where a transition occurs (K-12 and postsecondary/careers) to ensure that students leaving one level are prepared for success, without remediation, in the next (U.S. Department of Education, 2009). As the federal government takes more of an active role in public education to improve the quality of education, it is working with states to set unifying educational guidelines and curriculum. In Oregon, the state legislature created the Oregon Education Investment Board (OEIB), a high-priority initiative of Governor John Kitzhaber. The OEIB (2011), chaired 
by the governor, is tasked with overseeing the effort to create a "seamless, unified system for investing in and delivering public education from early childhood through high school and college so that all Oregonians are well prepared for careers in our global economy" (p. 1). The goals of OEIB are: 100\% of Oregonians will earn a high school diploma or equivalent $-40 \%$ of Oregonians will obtain an associate's degree or postsecondary credential, $40 \%$ of Oregonians will obtain a bachelor's degree or higher, and $20 \%$ will obtain a high school diploma, an extended or modified high school diploma or the equivalent of a high school diploma (Figure 2).

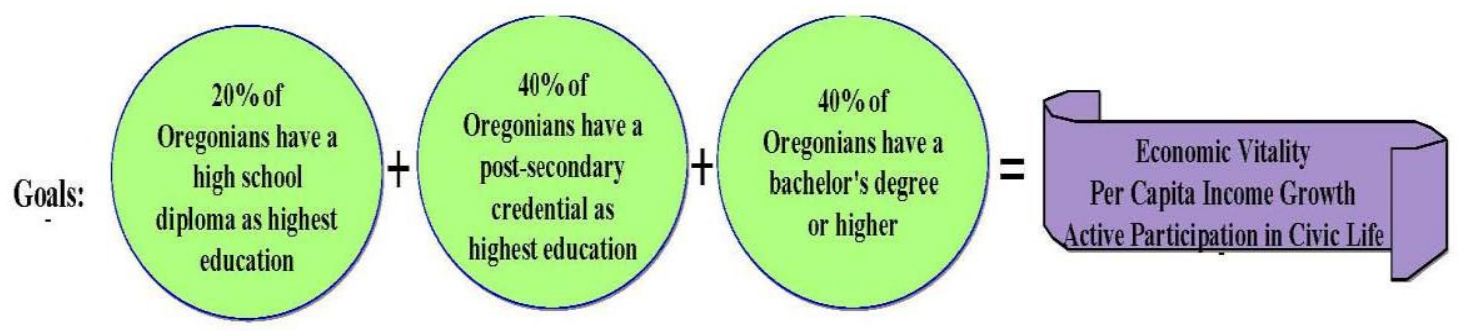

Figure 2. The impact on Oregon. This figure illustrates an aligned PK-20 education system. Source: OEIB (2011).

These goals will be achieved through a process of collecting, reviewing, and evaluating the efforts of groups with expertise in the areas of early learning, educational finance, and increasing K-12 efficiencies (Kitzhaber, 2011).

Today, both the federal and state governments are taking active roles in facilitating successful transitions from high school to college. The policies at both levels should help to reduce remediation and successfully prepare students for a postsecondary education through the creation of a seamless educational system. 


\section{Purpose of the Study}

There are several types of promising programs that appear to help address the problem of students not being prepared to transition from high school to postsecondary options. These are The Advanced Placement Program, Advancement Via Individual Determination, The International Baccalaureate Programme, and Early and Middle College High Schools. During the 2002-2003 school year, 1.2 million students were enrolled in courses that awarded dual high school and college credit, 1.8 million students were enrolled in Advanced Placement courses, and 165,000 students were enrolled in International Baccalaureate courses (Hoffman \& Vargas, 2010). Some of these approaches increase the chances of postsecondary student success. These programs can exist within secondary schools, or they can be individual schools. I briefly look into Conley's (2012a) four key approaches high schools have used to prepare students for postsecondary success. These four keys are: (a) key learning skills and techniques, (b) key cognitive strategies, (c) key content knowledge, and (d) key transition knowledge and skills (Conley, 2012a). I then use my research to frame postsecondary readiness. From this postsecondary readiness framework, I created a Postsecondary Readiness Guidebook (PRG) to help educational leaders prepare students for postsecondary success. The purpose of this study is to determine how useful the guidebook is in building the capacity and confidence of educational leaders to successfully facilitate student transitions from secondary to postsecondary education. For the purposes of this study, educational leaders are defined as educational policy advisors, teachers, parents, community members, state, 
district, and building educational administrators focused on improving current educational systems and practices.

\section{The Advanced Placement Program}

Advanced Placement (AP) Programs in high schools around the country work to prepare high school students for college level work and to address higher-level concepts and skills in specific courses. They require a certain level of collaboration between the two distinct educational systems. AP Programs address key cognitive strategies, key content knowledge, and can touch on key learning skills and techniques through their courses. AP Programs do not, however, always fulfill key transition knowledge and skills to prepare students for college. Also, not all students taking AP courses receive college credit. It is assumed that many underrepresented students are not enrolled in AP courses; instead students who are enrolled appear to already have the skills and capabilities to succeed at a postsecondary institution.

\section{Advancement Via Individual Determination}

The Advanced Via Individual Determination (AVID) Program targets students whose skills are in the middle to lower half of each grade and aims to give in-school supports to students who are traditionally underrepresented at postsecondary institutions, low-income families, and students who do not have a family tradition of college or college success. It also focuses on skills and strategies needed to succeed at the college level. It provides peer support, which can be an effective way to help students achieve personal management skills along with key content knowledge. AVID focuses on core 
skills such as reading and writing and helps students articulate personal and career goals. AVID begins for students the process of understanding how to: choose a college, fill out college paperwork, and prepare for college entrance tests. Students leaving the AVID Program do not obtain college credits for their high school classes, but they do learn key cognitive strategies, key content knowledge, key learning skills and techniques, and key transition knowledge and skills to a certain degree.

\section{The International Baccalaureate Programme}

The International Baccalaureate (IB) Programme was created to help meet the needs of students who were geographically mobile and needed some kind of academic worldwide standing. These students were the children of diplomats, students living abroad, native students returning from abroad, and children who travel extensively abroad (Poelzer \& Feldhusen, 1997). The IB Programme prepares students for college by imparting key cognitive strategies and key content knowledge through rigorous course offerings; it also touches on key learning skills and techniques through its theory of knowledge course. The IB Programme is limited in offering its students key transition knowledge and skills for success at the postsecondary level. Students must be enrolled in the IB Diploma Programme and score high on assessments in order to receive the IB Diploma. When students receive the IB Diploma, there is not a guarantee that their credits will transfer to every college or university. It is also assumed that the IB Programme caters to higher skilled students and does not focus on the underserved student. 


\section{Early and Middle College High School Models}

Early and Middle College High Schools work extensively with college campuses to transition all students to college through their unique configuration and structure. They are charged with making higher education more accessible and more affordable for underrepresented students (Wolk, 2005). Wolk (2005) stated that these schools "will ease the transition for students from high school to college and provide young people with a smoother pathway into adulthood and work" (p. 3). Early and middle college high schools help prepare students for postsecondary success through their mission and structure. One example of this is that college instructors teach students on college campuses. Thus, students receive key transition knowledge and skills by taking courses on the college campus and through their interaction with college support staff and students. Both of these models help to bridge the gap for student groups who in the past were underrepresented in postsecondary education.

Most high schools around the country have one of the aforementioned programs in place in an attempt to prepare their students for a postsecondary experience and create a successful transition from high school to college. Each program has positive attributes in addressing this transition successfully. Some high schools, however, are slow to adopt the programs that prepare students for college, as they do not fit easily into the original intent and structure of the traditional high school.

There are also social and cultural implications that must be considered to prepare all students for some kind of postsecondary education. Both through partnership and 
collaboration with postsecondary institutions and their structure, early/middle college high schools are able to address college and career readiness knowledge and skills and prepare all students for a successful transition to postsecondary options.

I examine more closely the elements of postsecondary readiness and how secondary schools prepare students for a successful transition to postsecondary options through a postsecondary readiness framework. I used my research on effective methods and practices that successfully prepare students for postsecondary success to create a PRG to help educational leaders address the question: In what ways can schools better prepare students for postsecondary success? The purpose of this study is to determine how useful the guidebook is in building the capacity and confidence of educational leaders to successfully facilitate student transitions from secondary to postsecondary education.

\section{Research Methodology}

Through my research of best practices and programs aimed at preparing students for postsecondary success, I found it necessary to create a postsecondary readiness framework to include the most successful practices. This framework was created by using the following questions to guide me in my review of the literature:

- What can be done to our educational structure so that it successfully prepares students for a postsecondary education?

- What standards exist to help states, districts, schools and educators prepare students for a postsecondary education?

- What do programs/schools currently do to help students make a successful transition from high school to postsecondary education? 
This resulted in the creation of a comprehensive approach to postsecondary preparedness; something I found had never been done with schools. This approach helped to address the following research question: In what ways can schools better prepare students for postsecondary success? My literature review helped me to create this framework around these successful practices around the country to address the problem of high school and college preparation and completion. The creation of a PRG addresses this problem, and this study measured ways the guidebook is useful to educational leaders.

Through the creation of the PRG, this study utilized qualitative methods and followed a problem-based learning (PBL) research design teamed with the research and development (R\&D) model. A complete discussion of the methodology of the study along with the PBL and R\&D approach follows in chapter 3. This methodology allowed me to: develop the capacity to apply my knowledge from theory and research to actual practice, and address the ways the guidebook was useful in helping schools and educational leaders prepare students for postsecondary success (Bridges \& Hallinger, 1995).

The guidebook was field tested by educational leaders in a variety of educational settings. During the preliminary field testing, I selected participants for these interviews and surveys, and distributed and collected consent forms. These educational leaders consisted of: an educational policy advisor, two transitional high school to college teachers, and two program directors for the same high school to college transitional 
program. These educational leaders work at the state level and in college programs from different states around the country. I obtained initial qualitative evaluations of the PRG by conducting interviews and surveys with these educational leaders who shared in the mission of preparing students for postsecondary success. Prior to identifying these educational leaders, I created interview protocols and questionnaires aimed at collecting data on ways the guidebook can be useful to them. The guidebook was then presented in its preliminary form through a workshop to the educational leaders to collect data around the following research questions:

1. In what ways can schools better prepare students for postsecondary success?

2. In what ways is the PRG useful in helping educational leaders prepare students for postsecondary success?

3. What improvements and changes to the PRG are needed to help educational leaders?

4. In what ways is the workshop useful in helping educational leaders navigate through the PRG?

The main field test for the PRG occurred at Oasis Academy (pseudonym), a K-12 public school using a qualitative methodology. During the field testing of the guidebook, data were collected through interviews with educators and questionnaires completed by educational leaders at the school. Data were analyzed using inductive coding, facesheet coding, enumeration, and typology.

The purpose of my research inquiry was to explore the usefulness of a comprehensive approach to preparing students for postsecondary options. In order for this approach to be most useful, all aspects of the PRG must be implemented. I have 
accumulated knowledge by measuring the ways this guidebook helped educational leaders through a qualitative approach to reach conclusions. This knowledge was used to create a final revision of a PRG to inform educational leaders on a comprehensive approach to prepare students for postsecondary success.

\section{Summary}

As our country begins to weave the importance of a postsecondary education into its mission, research has shown that both the individual and country as whole can economically benefit. This was not stressed when high schools were created, as the mission was focused on getting students prepared for the work force directly after high school. Today, however, our educational system has not adapted to our global economy. Many students graduating from high school are not ready for a postsecondary education; this makes them unqualified to join the work force and obtain a highly skilled and well paying job.

Because our educational systems are not connected, the transition for students from one system to another is very complex, and students often times are left caught between systems. A seamless transition for students will not only prepare them for the next level in their education, but also allow them the opportunity to obtain a degree or work certificate and become a contributing member to our work force and global economy. It will also advance the cause for social justice by integrating students who are underrepresented into our postsecondary system. As our federal and state governments see the value and importance of this to individuals and to our country, they have begun to 
address the structure of our educational system. They are beginning to make policy to align systems and to restructure outdated educational systems to provide opportunities to all students.

Currently there are many methods, programs, and practices that address the transition from high school to college. These address the problem on a smaller scale by implementing some of Conley's (2012a) four keys to college and career readiness within schools and can be effective. Programs like AVID help to teach key learning skills and techniques and touch on key transition knowledge and skills to give underrepresented students a foundation by which to transition successfully to a postsecondary education. Other programs, such as the AP Program and the IB Programme, expose students to key content knowledge and key cognitive strategies by awarding college credit and preparing them for postsecondary success. Lastly, early and middle college high schools address many components of Conley's four keys to college and career readiness. They do this through their structure and partnership with colleges and universities. This partnership allows them the opportunity to regularly offer dual high school and college enrollment. Research suggests that dual enrollment participation is positively related to outcomes such as high school graduation, college enrollment, and persistence in college (Hoffman \& Vargas, 2010). They also accomplish this through their mission of graduating students with significant college credit or a college degree/certificate.

In this study I was able to explore and research what methods, programs, and practices schools are using to prepare students for postsecondary success through the 
PBL research design. During this study I have moved from theory to hypotheses to data to conclusions. Based on these conclusions, I created a guidebook with a comprehensive approach to postsecondary readiness. Once the guidebook was created, I used a qualitative methodology to collect data to reach conclusions and build knowledge. By following the $R \& D$ process, I used this knowledge to refine the PRG for educational leaders to address the problem of transitioning high school students to postsecondary options.

\section{Definition of Terms}

Academic Behaviors. Noncognitive factors that include a range of attitudinal, behavioral, emotional, and personality characteristics that are necessary to function well in school and work.

ACT. A curriculum-based assessment program developed by ACT to help students prepare for the transition to postsecondary education while providing a measure of high school outcomes for college-bound students. The ACT is complemented by EXPLORE, ACT's eighth- and ninth-grade program, and by PLAN for tenth graders. The ACT tests will enable school personnel to confidently identify areas of strength and weakness (ACT, Inc., 2009).

Advisory Program. An effort to ensure that all students have at least one adult who knows them well and that all students belong to a small interactive group AP (Advanced Placement Program). Many high schools have Advanced Placement Programs designed to give students the opportunity to take college-level 
courses while in high school. These courses are taught by high school teachers and are developed by both secondary teachers and college and university professors. Students are able to demonstrate concepts and skills obtained through an exam given in May of each year. The tests are scored from 1-5 with 5 being the highest grade. If students score highly on the annual exams, then they may receive college credit, advanced placement in college courses, or both (Nugent \& Karnes, 2002). According to Nugent and Karnes (2002), more than one million AP tests were administered in May of 1998.

AVID (Advancement Via Individual Determination). AVID is a program implemented in high schools across the country aimed at giving in-school supports to students who are traditionally underrepresented at postsecondary institutions, low-income families, and students who do not have a family tradition of college or college success. An AVID program runs from fourth to twelfth grade and can be beneficial to all students achieving in the middle to lower half of each grade. There are two components to AVID: the AVID elective and the AVID curriculum. In the elective component students are taught essential skills in the area of self-management, study skills, and personal organization. It also focuses on cognitive strategies such as critical thinking and problem solving and is taught by an AVID-trained teacher. In order to give maximum support to students, there is a peer mentor system built in to the program where college students and former AVID students help current students improve the skills necessary to succeed in college (Conley, 2010). The AVID curriculum teamed with the elective classes touch on the following areas: reading, writing, study skills, test-taking skills, organization, goal 
setting, choosing a college, and preparing students for college entrance exams. The AVID program focuses on self-management and self-awareness to optimize student growth and prepare them for a postsecondary education.

College and Career Readiness. The completion of entry-level or core courses at a proficient level that allows students to take the next course in the sequence or the next level course in the subject area or complete the certificate.

College and Career Readiness Standards. Key cognitive strategies, key content knowledge, key learning skills and techniques, and key transition knowledge and skills (Conley, 2012a)

Common Core State Standards (CCSS). Standards aim to provide a consistent, clear understanding of what students are expected to learn.

Early College High School. Small schools that allow students to pursue not only a high school diploma but also an associate degree or up to two years of college credit toward a bachelor's degree (Hoffman \& Vargas, 2005).

Educational Planning and Assessment System (EPAS). Reflects the essential skills and understandings being taught in classrooms nationwide. ACT's EPAS includes three testing programs: EXPLORE for eighth and ninth graders, PLAN for tenth graders, and the ACT, a test taken by eleventh and twelfth graders. The three instruments are administered at three separate points in a student's secondary educational experience.

EXPLORE. A curriculum-based assessment program developed by ACT to help eighth and ninth graders devise a high school course work plan that prepares them to 
achieve their post high school goals. The results from EXPLORE provide educators with the means to structure high school planning and career exploration for students and parents and with a baseline to monitor students' progress. Through EXPLORE, a student's strengths and weaknesses can be identified early in his or her secondary educational experience (ACT, Inc., 2009).

IB (International Baccalaureate) Programme. A 2-year curriculum for high school 16-19 year old students. Students focus on one subject area from the following domains: Language, Individuals and Society, Mathematics, Arts and Electives, Experimental Sciences, and Second Language. Students then must take six subjects within each focus. Three or four of the subjects must be taken at the higher level (240 contact hours), while two or three courses are to be taken at the standard level (150 contact hours) (Nugent \& Karnes, 2002). Students take a theory of knowledge course, which focuses on critical thinking and examines the nature of learning and the acquisition of knowledge. Students will then complete an extended essay from 1 of 60 subjects. Student assessment is based on criterion-referenced examinations administered by the school but graded by international examiners on a scale from 1 (minimum) to 7 (maximum) in May of each year (Nugent \& Karnes, 2002). There are currently 742 schools offering the IB Diploma Program in the United States.

Key Cognitive Strategies. Problem formulation, research, interpretation, communication, checking for precision and accuracy (Conley, 2012a). 
Key Content Knowledge. Writing, reading, speaking, major theories and concepts in each content area (Conley, 2012a).

Key Learning Skills and Techniques. Time management, strategic study skills, persistence, ability to use study groups, self-control, intentionality, high degree of selfawareness (Conley, 2012a).

Key Transition Knowledge and Skills. The application process and the college cultural component. The key things to know are: how to apply to college, the differences among colleges, how to choose the right college, intricacies of the financial aid system, awareness of one's true performance, and tuition and book process. The cultural component of contextual and awareness skills include: how to approach a college instructor/advisor, how to interact with peers, and how to participate successfully as a member in an intellectual community (Conley, 2012a).

Middle College High School. Alternative high schools located on college campuses to help at-risk students complete high school and encourage college enrollment (“Middle College High School," 2009).

PLAN. A curriculum-based assessment program developed by ACT to help tenth graders plan their academic careers and prepare for entry into college or the world of work. PLAN is a midpoint review of progress that is being made in high school. For use by all tenth-grade students, PLAN provides direction for educational and career planning, and can guide adjustments in students' course work so as to better prepare them to achieve their goals after high school (ACT, Inc., 2009). 
Postsecondary. Refers to any formal setting in which an individual pursues instruction beyond high school. This might include two or four-year degree programs, certificate or licensure programs, apprenticeships, or training programs in the military. This definition is actionable and not identified by "cut scores" or in combination with other elements such as grade point average to predict college success. It describes what knowledge and skills students should know and have as defined through complex measures (Conley, 2012b).

Postsecondary Readiness Framework. Is built around methods, programs, and best practices high schools use to help students prepare for postsecondary success. This framework is comprehensive in nature and centers on three key elements: (a) structural elements, (b) academic elements, and (c) social elements.

Preparedness. Focuses on academic qualifications, which are measured by NAEP.

Readiness. Includes behavioral aspects of student performance such as time management, persistence, and interpersonal skills (Ford et al., 2006). 


\section{CHAPTER 2}

\section{INTRODUCTION TO RELATED LITERATURE}

\section{Literature Review}

By providing a review of the related literature, this chapter serves to provide a basis for developing and conducting this research study. Information is provided relative to college and career readiness, and two types of school models that focus on transitioning students from secondary schools to postsecondary options are examined. While the literature in this section focuses on the problem of students graduating from high school unprepared for postsecondary education, its primary use was to create a framework guided by the following questions: (a) What can be done to our educational structure so that students are successfully prepared for a postsecondary education? (b) What standards exist to help states, districts, schools, and educators prepare students for a postsecondary education? and (c) What program/schools currently exist to help students make a successful transition from high school to postsecondary education?

For many students, college attendance is a continuation of their life pattern, supported by parents who see it as a necessity and not an option. For others, however, attendance in college involves academic, social, and cultural transitions (Terenzini et al., 1994). We need to build systems in education that do not place undue pressure on students to make the transition from high school to college. We must instead create systems that integrate high school students into postsecondary education with meaningful 
prior involvement that ensures successful academic, social, cultural transitions. As Astin (1985) stated, "Students learn by becoming involved." (p. 133). Astin pointed out that a highly involved student is one who immerses himself/herself in the culture of college both academically and socially. For example, an involved student devotes considerable energy to studying, spends much time on campus, participates actively in student organizations, and interacts frequently with faculty members and other students (Astin, 1984). We must create a system that integrates every student with the next level until each is involved so that the academic, social, and cultural transitions are a success. Until we build or create such a system, many students graduating from high school will not be ready for a postsecondary education.

The literature examined in this section first addresses: (a) the similarities and differences between what it means to be college ready and career ready, (b) best practices and approaches aimed at preparing students for postsecondary success; these practices and approaches were used to create a framework for postsecondary success, and (c) how the framework of best practices and approaches work in early and middle college high schools.

Because there is so much societal value in having students enter and exit college successfully, it has become necessary to clearly define rigorous standards and implement them into each classroom in order to prepare all students for postsecondary success. I believe that a portion of high school success should be measured by how well the school prepares its students for postsecondary education. Conley (2010, p. 9) described this 
learning as the ability to engage in formal learning in any of a wide range of settings: university and college classrooms, community college 2-year certificate programs, apprenticeships that require formal classroom instruction as one component, and military training that is technical in nature and necessitates the ability to process information through a variety of academic skills, such as reading, writing, and mathematics.

To also apply this definition of learning to the high school, university, college classrooms, and community college 2-year certificate programs would mean that high schools will need to prepare students to enroll and succeed-without remediation-in courses at universities, programs that transfer students to universities, or certificate programs that allow students opportunities in career pathways (Conley, 2010). By researching and implementing successful practices/models aimed at preparing high school students for postsecondary options, high schools can better provide the proper education to help make the student transition from high school to postsecondary education a success.

The good news is that there are high schools that focus on college and career readiness standards and successfully transition all students from high school to postsecondary options. They do this directly by involving students in the transition process and providing the supports to make their success possible. These schools have a unique structure that allows them to address college and career standards as part of their mission and implement them to ensure a successful transition. 
Early and middle college high schools directly address the transition of high school graduates to postsecondary systems and fit in with federal and state programs such as Race to the Top and the Oregon "40-40-20" plan. Early and middle college high schools ensure a higher postsecondary success rate, improve the alignment of standards and curricula, and support high school and college teams in sharing accountability for the transition into college (Hoffman \& Vargas, 2010).

I am an advocate of both early and middle college high schools and postsecondary preparation in high schools because my experience has shown that these schools, when implemented correctly help prepare students for postsecondary education. As a middle college principal, I have worked diligently with teachers in my building to research what skills colleges or universities expect students to possess in order for them to succeed. Once these skills are identified, they need to be imparted through a framework of postsecondary readiness so that the process becomes systematic.

I began my research by reviewing familiar literature. My doctoral work and job as a middle college principal gives me knowledge of key theories and research. Because of this foundation, I gathered references and current educational information and researched organizations and leaders who have studied postsecondary readiness such as American College Testing (ACT), Educational Policy Improvement Center (EPIC), and David Conley. Finally, I was able to use the Portland State University library and online databases such as: ERIC (EBSCO interface), PSU WorldCat, and Google Scholar. Searches of these academic online databases yielded many recent articles on: college 
readiness (Bloom , 2011; Conley, 2010), career readiness (ACT, Inc., 2006), reform in education (Benson, Harkavy, Harkavy, \& Puckett, 2007), early colleges (Edmunds, 2010), and middle colleges ("Middle College High School," 2009). I tried to use literature that was published within the last three years, but had to use some older resources as well. I approached the literature this way because by using a narrow focus I was able to find resources that directly related to my topic and did not lead me astray. Since our society only now increasingly realizes the importance of postsecondary education, the research that is being done on how to prepare students for life after high school is relatively new, as is the research on specific educational models that seek to prepare students for a successful postsecondary education. As I began my research, I looked into the various program interventions in secondary schools that addressed the problem of students graduating from secondary schools not ready for a postsecondary education. My search became too broad and I had to narrow the focus to specific secondary school models whose mission addressed the aforementioned problem. Another problem with my original search was that I needed to define not only specific secondary school models, but also the aspects used to measure college and career readiness. This made it necessary to use the research to build a postsecondary readiness framework while looking at the unique structure of early and middle college high schools whose mission it is to transition high school students to a postsecondary education.

Most of the literature I reviewed was empirical. I was able to read research reports, journals, books, and articles on the best practices institutions use to help prepare 
students for postsecondary success. Descriptive articles were reviewed to explain processes and programs within postsecondary preparation and standards. There were a limited number of conceptual articles, which in the future need to be developed to gather alternative views on the importance of postsecondary transition. I also reviewed a variety of reports on the effectiveness of early and middle college reform models. This empirical data reported was collected during the last six years. The schools that reported the data received grants that allowed them the flexibility to approach school differently than traditional public schools. These grants fall under the Early College High School Initiative (Berger et al., 2005). The Early College High School Initiative is funded by The Bill \& Melinda Gates Foundation, and its purpose is to explore the effectiveness of these specific reform models (early and middle college high schools). The themes of preparedness vs. readiness, college readiness, career readiness, the state of education, best practices/policies, early and middle college high schools, and data in these models were intended to blend together smoothly, but gaps were evident in the research and need to be closed through further research. Some of the gaps I found lie in the area of comprehensive approaches and systems to postsecondary readiness. As Conley (2007) pointed out, a lot of information is collected on how to prepare a student to successfully transition to postsecondary options, but rarely, if ever, is the information combined into a comprehensive profile or system.

This review allowed me to challenge my own assumptions regarding postsecondary success. I was enlightened to find that some schools used best practices 
and approaches I did not think prepared students for postsecondary success. However, after reading in detail how schools implemented these best practices and approaches; I was convinced of their effectiveness. In future research, this review could be strengthened through descriptive and empirical articles on how successfully traditional public high transition students to postsecondary options. An added bonus from reviewing the literature on postsecondary readiness was the gathering of empirical articles to support my own assumptions on early and middle college high schools. It was enlightening to reflect on the educational system and see that college transitional reform models can complement and improve traditional public schooling by improving the transition from high school to college. The new knowledge I took away from the review was that schools across the country implement some best practices and approaches aimed at preparing students for postsecondary success, but there were no schools which used a comprehensive approach of best practices. The best practices being used were random and not organized around central themes to provide a necessary comprehensive approach toward postsecondary readiness for all students.

The chapter concludes with conclusions/recommendations about what can be done to successfully transition students to postsecondary options/institutions. My review suggests potential development for future research on college and career readiness as it relates to secondary students. Finally, I reflect on what I learned from this research in terms of gaps in the literature or limits in my own approach at facilitating student transition from secondary schools to postsecondary options. 


\section{College and Career Readiness: Same or Different?}

The literature on the topic of college and career readiness is vast, and the question arises: is college ready and career ready the same thing? Before answering this question, it is important to differentiate between preparedness and readiness. The National Assessment Governing Board defines preparedness as a subset of readiness (Ford et al., 2006). The National Assessment Governing Board is an organization that oversees the NAEP, also known as The Nation's Report Card. NAEP is the largest nationally representative continuing assessment of student knowledge in various subject areas. Preparedness focuses on academic qualifications, which are measured by the NAEP (2006). Readiness includes behavioral aspects of student performance such as time management, persistence, and interpersonal skills. These behavioral aspects are not measured by NAEP (Ford et al., 2006).

Conley (2012b) reinforced NAEP's work on differences between readiness and preparedness and attributes these skills to the various aspects of life. For example, he has linked readiness skills to being work ready and to some extent being job ready. As individuals move toward postsecondary options, they not only have to possess readiness skills, but they also need to acquire preparedness skills to become career and life ready. Figure 3 distinguishes among different types of readiness, displays the interconnectedness between college and careers, and reveals the importance in developing student skills for both college and careers. 


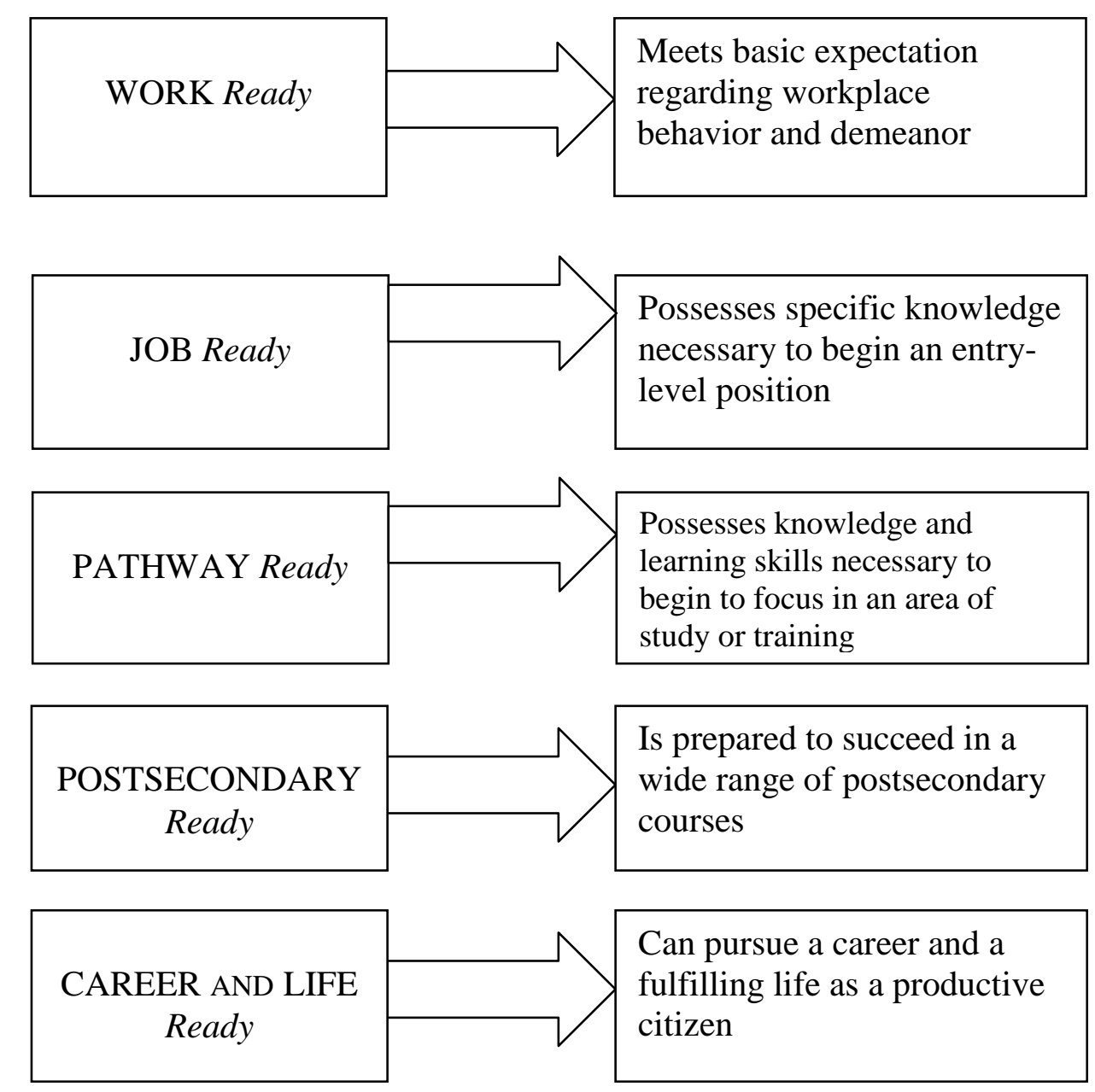

Figure 3. College and career readiness. This figure distinguishes among different types of readiness. Source: Conley (2012b).

In another study, Waters and Williams (2011) stated that college ready is for four to six years, but career ready is for 40 years. They continued, noting that college and career ready are similar but the goals are different. College readiness focuses on academic skills, whereas career readiness focuses on employability and job-specific skills along with the acquisition of college readiness skills (Waters \& Williams, 2011). 
In 2006, however, ACT published a study that claimed that college and career readiness were the same and comparable (Conley \& McGaughy, 2012). ACT's studies show that both college and workforce training require a certain level of readiness in both reading and math. As students graduate from high school they "need this level of readiness to succeed in college-level courses without remediation and to enter workforce training programs ready to learn job-specific skills” (ACT, Inc., 2006, p. 1). Conley (2012b) pointed out that academic skills and learning strategies required to pursue technical training are converging with those necessary to pursue a bachelor's degree.

Over the past six years, EPIC studied 500 two- and four-year postsecondary institutions and learned about requirements students face upon entry into beginning postsecondary courses. EPIC collected and analyzed syllabi, assignments, readings, and tests and found that both college and career readiness rely on the acquisition of specific standards, strategies, and skills. These factors are not limited to just specific content in academic areas. They are both academic and social. The findings from this study (Conley, 2012b) show standards, strategies, and skills needed for both college and career pathways (see Tables 1-3).

\section{Table 1}

Credentials and Cross-Disciplinary Skills

\begin{tabular}{|l|l|}
\hline Postsecondary Credentials & Cross-Disciplinary Standards/Skills \\
\hline Bachelor's Degrees & $\begin{array}{l}\text { Key cognitive strategies, learning skills, } \\
\text { foundational knowledge across all subject } \\
\text { areas }\end{array}$ \\
\cline { 1 - 2 } Career Certificates & \\
\hline Associate's Degrees &
\end{tabular}


As students graduate and move to careers, they benefit from having skills that will allow them to be successful in the workforce (Table 2).

\section{Table 2}

Postsecondary Preparation

\begin{tabular}{|l|l|}
\hline Career-Oriented Courses & Cross-Disciplinary Standards/Skills \\
\hline Accounting & \multirow{2}{*}{$\begin{array}{l}\text { Study skills, problem solving, critical } \\
\text { thinking, goal setting }\end{array}$} \\
\cline { 1 - 1 } Drafting & \\
\cline { 1 - 1 } Introduction to Computers & \\
\cline { 1 - 1 } Marketing & \\
\hline
\end{tabular}

Source: Conley (2012b)

There is also a link to core classes on literacy and math. Students who receive specific skills in these courses can succeed in jobs where these skills are a necessity. Table 3 shows what key skills overlap into careers.

Table 3

Standards and Skills

\begin{tabular}{|l|l|}
\hline Common Core Connection & Cross-Disciplinary Standards/Skills \\
\hline Reading literature specific to English courses & $\begin{array}{l}\text { Speaking, listening, reading informational texts, } \\
\text { and writing in a variety of genres }\end{array}$ \\
\hline $\begin{array}{l}\text { Statistics specific to science readiness, computer } \\
\text { technology courses specific to higher math skills }\end{array}$ & $\begin{array}{l}\text { Math-reasoning and problem solving (for both } \\
\text { academic and career-oriented courses }\end{array}$ \\
\hline
\end{tabular}

Source: Conley (2012a)

"Whether they're headed for college or a career, students need a solid foundation of academic knowledge combined with crucial thinking and learning skills" (Conley \& 
McGaughy, 2012, p. 1). Initially, educators need to lose the immediate focus on the words college and career and focus instead on the skills students need for each pathway. As they do this, they will be able to see an overlap of skills that every student needs despite long term goals. As these skills are being developed, a more targeted and personalized approach to individual goals becomes necessary for the planning of either a college or career pathway. As Conley and McGaughy (2012) pointed out, all students should be challenged with rigorous academic content while building skills toward personalized goals. As students learn basic foundational content knowledge, it allows them the flexibility to choose a pathway that fits best. Once they identify their pathway, then more targeted knowledge and skills prepare them for postsecondary success in specific areas. By focusing on both, secondary schools can enable all students to prepare for successful futures (Conley \& McGaughy, 2012).

In this study, I created a framework that will help guide schools to create a systematic approach to preparing students for postsecondary success. This framework includes elements from research proven to be successful in schools that prepare students for postsecondary success. The framework also includes foundational content knowledge along with more targeted knowledge and skills specific to each student's identified pathway. I refer to this framework as a postsecondary readiness framework. I am also assuming that a postsecondary education will prepare students for the work force.

By reviewing the literature relating to high school graduates being unprepared for postsecondary education, I was able to refine my search to look at schools and 
approaches aimed at addressing this problem. By collecting data on these specific schools and best practices, I was able to create a framework that provided a comprehensive approach to successfully prepare students for postsecondary success. The knowledge gained from this review allowed me to build on my own knowledge and experience as a middle college principal, while confirming some of my assumptions on approaches to postsecondary preparedness.

\section{Postsecondary Readiness Framework}

This section of the literature review grounds my research on the many aspects of postsecondary readiness and allows me to create a framework to help guide high schools in preparing students for college and careers. As one can imagine, the research on preparing students for postsecondary success is complex and comprehensive. The high school system must have a structure and mechanisms put in place where students can understand and become integrated into both the academic and social systems of postsecondary education. Terenzini et al. (1994) referred to a three-step process of separation, transition, and incorporation.

For many students who come from parents who attended college, separation from family and transitioning to postsecondary options is a logical next step after completion of high school, therefore academic and cultural issues are minimized. The biggest obstacle for these students is the social aspect of making friends and not academic competition. For first-generation college students, however, separation and transition can be more difficult as they have to adapt to academic, social, and cultural issues (Terenzini 
et al., 1994). For example, a first generation African-American student described his reasons for going to college:

I have a lot of reasons, but I guess, basically, because of where I live, a lot of kids are killed often, and you know, I decided to further my education just to get away from it. I don't like the fact that people are, you know, constantly shooting at you. It, it's, uh, it's bothersome. You don't want to be bothered with these gang bangers getting' you, rising up, so I said, "Either I make a difference or I get out of here.” And I said, "I'll do both." (Terenzini et al., 1994, p. 63)

It must be noted, however, that more research needs to be done on the process of separation among first-generation students, as not all students need or want to separate totally from their culture to attain success. For these non-traditional students, the academic transition to college was the most challenging.

To provide a successful transition and incorporation into postsecondary options, college students identified the importance of real learning. Real learning is identified as learning about oneself and developing survival skills in such areas as money and time management, personal goal setting, and self-efficacy (Terenzini et al., 1994). Students also identified a social culture as an important component of transition and incorporation into postsecondary life. College students need to experience a "we are all in this together" attitude and a social network where they work to help one another meet and make new friends. While this culture is very social, there is an academics-first priority where fun should not interfere with getting schoolwork done. In introductory freshman classes, one way to build this culture is through exercises where students learn about and introduce each other and engage in cooperative learning through group assignments (Terenzini et al., 1994). For example: as students enter the classroom for the first time, they are paired 
with another student. While paired, they introduce themselves and answer a topic such as: what were the biggest obstacles you have had to overcome to get to this point in your life? After each person answers the topic as it relates to him/her, questions are asked and a discussion takes place within the pair. The class then comes together and it is the responsibility of the partner to introduce the other person to the whole class, including elements from their earlier discussion. After this is done, then they engage in a group assignment related to the content of the class. This type of activity helps to build a comfortable learning environment/culture where students feel comfortable taking academic risks.

Pascarella and Terenzini (1991) indicated that if students negotiate the postsecondary transition successfully, the likelihood of student change, academic growth, and persistence significantly increase. Terenzini et al. (1994) described several themes that high schools can address to make the postsecondary transition a successful one.

1. Identify and promote cultural awareness of all students among students, parents, faculty members, and administrators-what students will be traditional college students and what students will be non-traditional

2. Validation (academic or social)-students need to be reassured that they can succeed, that they can do college-level work, that their ideas and opinions have value, and that they are worthy of the attention and respect of faculty, staff, and other students (this is very important for possible first-generation college students)

3. Involve faculty in orientation to postsecondary options-graduates of high school should be introduced to attitudinal and behavioral norms of the new academic and social setting expectations

4. Parent orientation-parents/spouses of all students (this is very important for possible first-generation college students) must be helped to understand the 
nature of the academic and time demands that will be placed on student and how to deal with the stresses all stakeholders will be experiencing.

5. Involves both in- and out-of-class experiences; in- and out-of-class experiences must relate to the academic/intellectual mission of each postsecondary institution

6. Institutional accommodations are required-the burden of responsibility for taking advantage of transition support mechanisms cannot rest with the student alone

7. Sense of caring-a successful transition for any given student is a cooperative activity, involving the individual and the will to succeed and a variety of other people willing to make success for that student possible. (pp. 69-72)

In order to prepare all students for postsecondary education, high schools must look to a postsecondary readiness framework in order to provide academic and social mechanisms to help all students transition successfully to postsecondary options. Within this framework, there are many aspects that must be addressed to help students make this transition successful. The following framework was created from the aforementioned research in order to help educators successfully prepare students for postsecondary education. The postsecondary readiness framework centers on three key elements: (a) structural elements, (b) academic elements, and (c) social elements.

\section{Structural Elements}

To prepare students for postsecondary success, educational leaders must look at the structural makeup of their schools to address successful transitions for every high school student to postsecondary options. In this chapter, structure is defined as the organizational makeup of a school. Strategy and goals shape structure, but the process is 
often complex and subtle (Bolman \& Deal, 2008). The research in this section addresses structural elements that high schools can focus on to successfully transition students to postsecondary options. These elements are: school mission and vision, transitions and infrastructure, and the development of college knowledge. After briefly introducing these structural elements, I provide a few examples of how schools can prepare students for successful transitions. One example is from the Institute of Education Sciences and the other is from the Annenberg Institute for School Reform. Both serve as guides for high schools to prepare all students for postsecondary success, and they address the structural postsecondary readiness framework component.

Research suggests that the major transition points in the educational continuum present students with particular social and academic challenges that can throw them off course (Bloom, 2011). ACT (2008) reported the transition from elementary to middle school is important and challenging, especially with regard to behavior. This same study suggests that eighth grade is more of a leverage point in a student's academic achievement and progress toward college and career readiness than any measure of high school achievement (ACT, Inc., 2008). By recognizing the importance of these transitions, educational leaders will be able to strategize to create approaches and programs to support students both socially and academically during these transitions. These approaches and programs can then be integrated into the structure of the school, so that students can navigate these transitions successfully throughout their educational experience. 
The goals and expectations of college and career readiness for all students must be embedded into the mission and vision of the school. The mission and vision should be shared and created around individual values and beliefs of all staff members. These individual values and beliefs should integrate into the core values and beliefs of the school. Once these are agreed upon, then the purpose for the school is created. The purpose of the school should include the goals and expectations of college and career readiness for all students. This purpose is important for creating a mission statement that everyone sees, knows, and uses (Bernhardt, 2002). Creating a shared mission and vision is important for a healthy "college-going" culture and is necessary for preparing students for postsecondary success.

Conley (2007) noted: "Many students fail to apply to college simply because the process seems so daunting, and they feel intimidated or overwhelmed by all of the requirements and activities associated with the application process" (p. 22). In order to create this "college-going" culture, schools must go through a process of "reculturing." Reculturing is defined as challenging current practices, patterns, and norms by examining them and implementing change when it is appropriate for the success of all students. Schools serious about creating significant changes that will positively impact student achievement and direction-especially in getting students ready for the postsecondary transition-must go through this process (Chenoweth \& Everhart, 2002).

Bloom (2011) stated that schools need to be able to identify students who are struggling and who lack the necessary skills as early as possible to provide targeted and 
research-based interventions. I assume that when this mechanism is put into place in every high school and the structure is aligned to the goals and expectations of college and career readiness for all students, then remediation will be less frequent and the transition to postsecondary options will be more successful.

The next structural component of the postsecondary readiness framework is that of resources. As both economic and human resources are becoming increasingly limited in schools and school districts, it is necessary to use these resources in a different and unique manner. Today, the school counselor to student ratio is alarmingly high, and counselor duties often are unrelated to college and career advising (Bloom, 2011). Another difficulty that Bloom (2011) noted is that counselors often lack the training and resources necessary to provide college and career advising. In order to provide the proper support and guidance to students, we must redefine how we use personnel in schools. Getting students ready for postsecondary options should not rest on counselors alone. As schools and students strive for college and career readiness, educators must acknowledge that this is a complex process and the answers do not lie in test scores. A big part of this process is for the school to develop a partnership or relationship with local postsecondary institutions. This partnership gives schools an opportunity to offer its students college-like experiences, such as: senior seminars on college readiness, college placement tests, advanced placement classes, college campus visits, and summer bridge programs to help prepare students for the transition (Conley \& McGaughy, 2012). The partnership also allows schools to offer dual enrollment programs to students. This gives 
high schools an opportunity to align courses offered with college course expectations and to share data for continuous school improvement.

In 2009, the Institute of Education Sciences, the research arm of the U.S. Department of Education, published a practice guide on what high schools can do to prepare all students for postsecondary success (Bloom, 2011). Below are the five targeted areas from the practice guide that can be embedded into the structure of each high school to successfully transition students to postsecondary options.

1. Rigorous, College-Preparatory Curriculum and Aligned Instruction and Assessments-the foundation for college- and career-readiness is an aligned, rigorous curriculum

2. Create a College-Going Culture-research suggests that teachers, administrators, parents, and peers play critical roles in supporting postsecondary aspirations (Corwin \& Tierney, 2007)

3. Targeted Supports, Particularly at Critical Transition Points-in addition to general strategies related to creating a relevant, engaging learning environment, targeted supports include programs that provide academic supports for students who are not prepared for the rigors of high school coursework

4. Indicators of Student Progress-AP course-taking, dual credit courses, percentage of high school graduates who go to college, college remediation rates of public high school graduates, college GPA, credit attainment, SAT, $\mathrm{ACT}$, or AP scores, one year college retention rates

5. Effective Educators-provide professional development to improve instruction in core subject areas as well as to help practitioners advance a college-going culture in the school. (Bloom, 2011, pp. 13-17)

From fall 2010 through summer 2011, the Annenberg Institute for School Reform received a 3-year grant from the Bill and Melinda Gates Foundation to develop the 
College Readiness Indicator System. This initiative looked to research and collect indicators that measured the dimensions of college readiness. It also served to help districts develop strategies based on these indicators (McAlister, Mevs, Lee, Rodriguez, \& Kim, 2012). Table 4 shows some strategies and dimensions that high schools can implement aimed at addressing college readiness.

Table 4

Setting the Infrastructure for College Readiness

\begin{tabular}{|l|l|}
\hline Dimension & Strategies \\
\hline Academic Preparedness & - Use data to drive postsecondary readiness policies \\
& - Align standards, curricula, and assessments to college-ready \\
& expectations \\
& - Intervene early to keep students on a college-ready track \\
\hline Academic Tenacity & $\begin{array}{l}\text { - Expose students to tenacity-building activities } \\
\text { - Provide accelerated learning opportunities that promote persistence } \\
\end{array}$ \\
& and attainment \\
\hline
\end{tabular}

Source: McAlister et al. (2012)

\section{Academic Elements}

One of the most important aspects of the postsecondary readiness framework focuses on academics. In order for students to be prepared for postsecondary education, high schools must align rigorous academic standards with those of postsecondary institutions. If this is not done, then it is unlikely that the curriculum will be rigorous enough to prepare students for a successful transition. Once this alignment is in place, then instructions and assessments must also be aligned in order to impact student learning and outcomes (Bloom, 2011). This alignment is reinforced through both federal and state 
policy. As individual states apply for No Child Left Behind waivers, the focus shifts to college and career readiness standards. Along with college and career readiness standards, most states are implementing CCSS. These standards aim to provide a consistent, clear understanding of what students are expected to learn. They are designed to help teachers and parents support students in their educational journey. The CCSS are intended to be rigorous, relevant and reflect the knowledge and skills that students need for success in college and careers.

Assessment of academic ability. The first step in addressing the academic elements of the postsecondary readiness framework is to look at sources of information to identify student skills and their progress throughout high school toward postsecondary success. Schools across the nation that aim to prepare students for postsecondary success use standardized assessments such as EXPLORE, PLAN, and ACT (see Table 5) as part of the educational planning. EXPLORE prepares eighth- and ninth-graders for their high school coursework and their post-high school choices. EXPLORE includes four multiple-choice tests covering English, mathematics, reading, and science. PLAN serves as the midpoint check of academic progress in high school. It is designed to improve students' preparation for education, training, and work after high school while they still have time to adjust their high school courses. The ACT is America's most widely accepted college entrance exam. It assesses high school students' general educational development and their ability to complete college-level work. The multiple-choice tests cover four skill areas: English, mathematics, reading, and science. The Writing Test, 
which is optional, measures skills in planning and writing a short essay. The three assessments are administered at three separate points in a student's secondary educational experience. These assessments are part of ACT's EPAS. EPAS reflects the essential skills and understandings being taught in classrooms nationwide (ACT, Inc., 2009).

\section{Table 5}

The EXPLORE, PLAN, and ACT

\begin{tabular}{|c|c|c|c|}
\hline \multicolumn{4}{|c|}{ Overview of EXPLORE, PLAN, and the ACT } \\
\hline Testing Program & Target Grades & Components & Content Areas \\
\hline EXPLORE & $\begin{array}{l}\text { Transition to High School } \\
\text { Grades } 8 \text { or } 9\end{array}$ & $\begin{array}{l}\text { - Student Planning } \\
\text { - Assessment } \\
\text { - Instructional Support } \\
\text { - Evaluation }\end{array}$ & $\begin{array}{l}\text { - English } \\
\text { - Math } \\
\text { - Reading } \\
\text { - Science }\end{array}$ \\
\hline PLAN & $\begin{array}{l}\text { Midpoint High School } \\
\text { Review } \\
\text { Grade } 10\end{array}$ & $\begin{array}{l}\text { - Student Planning } \\
\text { - Assessment } \\
\text { - Instructional Support } \\
\text { - Evaluation }\end{array}$ & $\begin{array}{l}\text { - English } \\
\text { - Math } \\
\text { - Reading } \\
\text { - Science }\end{array}$ \\
\hline $\mathrm{ACT}$ & $\begin{array}{l}\text { Final Measure of High } \\
\text { School Outcomes } \\
\text { Transition to College } \\
\text { Grades } 11 \text { and/or } 12\end{array}$ & $\begin{array}{l}\text { - Student Planning } \\
\text { - Assessment } \\
\text { - Instructional Support } \\
\text { - Evaluation }\end{array}$ & $\begin{array}{l}\text { - English } \\
\text { - Math } \\
\text { - Reading } \\
\text { - Science } \\
\text { - Writing (optional) }\end{array}$ \\
\hline
\end{tabular}

Source: ACT, Inc. (2009)

By beginning to evaluate students' strengths and weaknesses early in Grades 8 and 9 and continuing to assess progress through Grade 12, educators gain the information necessary to monitor and guide students as they prepare for their high school and postsecondary goals. EPAS provides schools, parents, and students with:

- a student planning component that looks at career and educational exploration and planning and prepares students for life after high school 
- an assessment component which measures knowledge in areas of English, Mathematics, Reading, and Science (and Writing in the ACT)

- an instructional support component that offers instructional support to teachers in each content area related to core subjects and college readiness standards

- an evaluation component which provides information that allows schools to research and monitor student performance over time and to assess the strengths and potential weaknesses of school programs

Most students $(70 \%)$ taking the aforementioned assessments indicated that information from these reports helped them identify necessary high school classes (Wimberly \& Noeth, 2005). Wimberly and Noeth (2005) noted that many students reported that teachers or counselors explained how these assessment results reflected their academic strengths and identified areas needing improvement. These reports also help teachers to develop challenging curricula for all students and link assessment results with corresponding skills (Wimberly \& Noeth, 2005).

After years of studying faculty members in many subject areas at two- and fouryear postsecondary institutions across the country, EPIC has developed four keys to college and career readiness. Table 6 shows these keys. As students move toward mastery in each of these keys, they will be increasingly postsecondary ready (Conley, 2012a).

While all of these keys are interrelated, two of the four keys (key cognitive strategies and key content knowledge) fall primarily within the academic elements of the postsecondary readiness framework. The key transition knowledge and skills and the key learning skills and techniques are explained below in the social elements section of the postsecondary readiness framework. 
Table 6

Four Keys to College and Career Readiness

\begin{tabular}{|c|c|c|c|}
\hline \multicolumn{4}{|c|}{ College and Career Readiness } \\
\hline $\begin{array}{l}\frac{\text { Key Cognitive }}{\text { Strategies }} \\
\text { 1. Problem } \\
\text { Formulation } \\
\text { 2. Research } \\
\text { 3. Interpretation } \\
\text { 4. Communication } \\
\text { 5. Precision and } \\
\text { Accuracy }\end{array}$ & $\begin{array}{l}\quad \underline{\text { Key Content }} \\
\text { Structure of Knowledge } \\
\text { 1. Facts } \\
\text { 2. Key terms } \\
\text { 3. Linking ideas } \\
\text { 4. Organizing concepts } \\
\text { Student Relation to } \\
\text { Content } \\
\text { 1. Attribution } \\
\text { 2. Effort vs. Aptitude } \\
\text { 3. Academic Value } \\
\text { 4. Challenge }\end{array}$ & $\begin{array}{l}\frac{\text { Key Learning }}{\underline{\text { Skills and }}} \\
\text { 1. Ownniques } \\
\text { Ownership of } \\
\text { Learning } \\
\text { 2. Learning } \\
\text { Techniques }\end{array}$ & $\begin{array}{l}\text { Key Transition } \\
\text { Knowledge and Skills } \\
\text { 1. Postsecondary } \\
\text { Awareness } \\
\text { 2. Postsecondary } \\
\text { Costs } \\
\text { 3. Matriculation } \\
\text { 4. Career Awareness } \\
\text { 5. Role and Identity } \\
\text { 6. Self-advocacy }\end{array}$ \\
\hline
\end{tabular}

Source: Conley (2012a)

Key Cognitive Strategies include formulating hypotheses, developing problemsolving strategies, identifying sources, and collecting information. They also involve analyzing findings or conflicting viewpoints and organizing and constructing work products in a variety of formats. Once this process is done, then students must confirm the precision and accuracy of all the work they produced (Conley, 2012b). Key Content Knowledge involves the conceptual ideas from core subjects. It requires an understanding of the structure of knowledge in these core subject areas that helps student insight and retention. In this key, students will link core subject knowledge with career aspirations to give relevance to each subject matter (Conley, 2012b).

Each one of these keys contains skills that college-level students need to have in order to complete college-level work. These keys to college and career readiness can serve as a guide for high schools to use in order to prepare students for postsecondary 
success. Teaming these keys with the CCSS, high schools can develop college and career readiness standards for all students. Because the process of preparing students for postsecondary success is a complex one, assessing postsecondary readiness becomes more and more challenging. Even with the implementation of the CCSS, it is difficult to address proficiency in each standard. The CCSS are intricate and lengthy and often measure multiple skills within each standard (Conley, 2012b). Conley (2012b) recognized the complexity of postsecondary readiness and addresses it through the following thoughts and recommendations:

- No single test can gauge every standard needed for postsecondary readiness.

- Cut scores are appropriate at a system level, but become more error-prone and inappropriate at each sublevel: state, district, school, classroom, and individual.

- Scores from a single measure of college and career readiness may be misused.

- Systems of assessment need to be set up (rather than one test or score) to address: grades, student self-reports, complex curriculum-embedded performance tasks, behavioral assessments, and non-content-based measures.

To address some of the points listed above, EPIC recommends that courses use embedded assessments tied to key cognitive strategies, key content knowledge, and key learning skills and techniques. Examples of this include, but are not limited to, extended essays, demonstrations and culminating projects, research papers, and inquiry-based experiments and investigations (Conley, 2007).

\section{Social Elements}

Because of changes to our economy, competition in a global market, and increasing demand for a skilled labor force, postsecondary training in today's world is 
critical. Obtaining a college education is generally accepted as both a goal and value among students today (Wimberly \& Noeth, 2005). The reality, however, is that for many students, aspirations do not end up aligning with outcomes (Conley, 2012b). Conley (2012b) referred to this as an "aspirations gap." Students most likely to experience the aspirations gap are those from groups traditionally underrepresented in postsecondary education. For every 100 students, 93 want to go to college; 70 graduate from high school. Out of those 70 students graduating from high school, 44 of them (63\%) enroll in postsecondary options. Out of those 44 students, 26 of them (60\%) earn a college degree within six years of enrolling (Conley, 2012a). According to these statistics, 74 students out of the original 100 enter the workforce with limited skills.

Wimberly and Noeth (2005) noted that, as the importance of postsecondary options grow, educational organizations and the U.S. Department of Education recommend that planning for postsecondary success begin as early as sixth grade. As schools play a key role in this planning and early preparation for postsecondary education, the literature in this section focuses on the social elements that can help schools facilitate effective early educational and postsecondary planning. The social elements in this section involve: including parents and school staff in educational planning; identifying and building academic behaviors of students; and improving both students' and parents' transition knowledge and skills.

Including parents and school staff. The encouragement of parents is one of the strongest factors in helping students develop their educational plans (Cabrera \& La Nasa, 
2000). Most parents expect their children to earn college degrees and enter rewarding careers (Wimberly \& Noeth, 2005). Parents are key when it comes to shaping their children's college-going behaviors (McAlister et al., 2012). A study done in the late 1980s shows that more than three quarters $(78 \%)$ of all parents surveyed expected their children to attend college and over half of them (58\%) expected them to finish (Ingels, Curtin, Kaufman, Alt, \& Chen, 2002). With this foundational piece in place, it is important to involve parents in planning the future of their child. Parents who have timely information about educational planning increase their child's school success, facilitate college planning, and increase the likelihood that their child will attend college (CotaRobles \& Gordan, 1999). The problem begins when students enter middle and high school. There is a disconnect between parents' educational expectations for their children and their postsecondary planning activities (Wimberly \& Noeth, 2005). This is especially true for parents who have not attended college. Wimberly and Noeth (2005) noted that these parents may lack the necessary skills and resources to assist their children with educational planning. Some parents are never or rarely informed or involved in educational decisions, and as a result students have to rely on school personnel and peers to help them through this process of educational planning (Wimberly \& Noeth, 2005). Schools today are beginning to realize that parental involvement is critical in the development of students and are taking steps to inform and involve parents. This is happening through informational nights, where schools provide students and parents 
information about workplace and college admission requirements, high school classes, and postsecondary options (Wimberly \& Noeth, 2005).

Early involvement. Another social element to help to help students with postsecondary planning is the involvement of school personnel as early as middle school. Counselors, teachers, and principals often influence students' educational goals and postsecondary planning (Wimberly \& Noeth, 2005). The National Association of Secondary School Principals recommends that every high school have an individual adult coach to help students through their educational journey and transitions. These adult mentors monitor students' academic progress and social development and guide them through the educational planning process (Wimberly \& Noeth, 2005). Wimberly and Noeth (2005) pointed out that school counselors also play a significant role in developing educational goals, identifying educational opportunities, and informing students and their parents about postsecondary options. Sometimes, however, counselors do not get involved in postsecondary planning until twelfth grade, which may be too late to help students (Wimberly \& Noeth, 2005). Wimberly and Noeth noted that due to the low counselor-student ratio in our high schools, counselor roles and time are limited. Because of this, teachers often help students with educational planning activities. Teachers develop strong relationships with students and advise them to take specific, challenging courses and to set educational goals to succeed both in and out of the classroom (Singh \& Granville, 1999). 
Because the involvement of parents and school staff is necessary to the postsecondary success of every student, schools must find systematic ways to include this involvement in their educational programs. Research has shown that an effective way to do this is through advisory programs. An advisory program is defined as an effort to ensure that all students have at least one adult who knows them well and that all students belong to a small interactive group (Manning \& Saddlemire, 1998). Manning and Saddlemire (1998) pointed out that educators and counselors in these advisory groups work collaboratively with students to improve their educational experiences and overall well-being. Educators for Social Responsibility (ESR, 2012) have done work on designing and implementing effective programs in high school. Advisory programs play an important role in a school's overall academic and student support services plan. They help to create a personalized learning environment where all students are well known by at least one adult. ESR (2012) stressed how advisory programs provide a structure and a set of practices for monitoring and supporting students' academic progress and college and career readiness throughout their time in high school. Advisory programs allow opportunities for parental involvement through student-led conferences, where the focus is on the student and his/her educational and postsecondary planning.

Academic behaviors. Another social element important to postsecondary readiness focuses on academic behaviors. Academic behaviors can be defined as noncognitive skills or a set of qualities that includes persistence, self-control, curiosity, conscientiousness, grit, and self-confidence (Tough, 2009). Casillas et al. (2011) stated that these noncognitive factors include a range of attitudinal, behavioral, emotional, and 
personality characteristics that are necessary to function well in school and work. Conley (2012b) included these academic behaviors as one of his four keys to college and career readiness. He referred to them as key learning skills and techniques. This key involves the ownership of learning (goal setting, persistence, self-awareness, etc.) and specific learning techniques (time management, study skills, collaborative learning, etc.). For the purposes of this chapter, I use the term "academic behavior" to categorize the full range of noncognitive factors.

Research shows that a combination of noncognitive factors, academic performance, and standardized achievement factors are predictive of first-year college academic success and retention (Robbins et al., 2004). The first step toward building academic behaviors in schools is to identify at-risk students and provide supports to assist them in their educational development.

A tool was developed to identify these academic behaviors and help educators these skills. Schools across the nation are using ENGAGE, developed by ACT, to identify youth who are at academic risk by supplementing standardized achievement testing with measures of important academic behaviors (Casillas et al., 2011). Casillas et al. (2011) pointed out that ENGAGE is a low-stakes, self-report inventory organized into three categories shown to be indicators of academic performance and persistence (Robbins et al., 2004). The three categories are:

- Motivation-includes personal characteristics that help students to succeed academically by focusing and maintaining energies on goal-directed activities.

- Social engagement-includes interpersonal factors that influence students' successful integration into their environment. 
- Self-regulation-includes the thinking processes and emotional responses of students that govern how well they monitor, regulate, and control their behavior related to school and learning. (Casillas et al., 2011, p. 3)

ENGAGE is available for use with grades 6-9 and grades 10-12 and captures students' perceptions of themselves, their families' commitment to education, schoolrelated factors, and important behavioral indicators (Casillas et al., 2011). Results from ENGAGE (grades 6-9) produce a report that provides an academic success index; this index estimates the probability that a student will be academically successful (defined as obtaining a high school GPA of 2.0 or above; Casillas et al., 2011). Results from ENGAGE (grades 10-12) also provide a retention index that estimates the probability of a student returning to college for a second year. Casillas et al. (2011) noted that with the student-level information provided by ENGAGE, educators can identify students who may be at risk of experiencing academic difficulties and connect them to interventions based on their areas of need.

Conley (2012b) also realized the importance of building academic behaviors to prepare students for postsecondary success. As noted above, he referred to these behaviors in his key learning skills and techniques. Conley broke up key learning skills and techniques into two broad categories: student ownership of learning-which includes goal setting, persistence, self-awareness, motivation, progress monitoring, help seeking, and self-efficacy-and learning techniques, such as time management, study skills, strategic reading, memorizing techniques, collaborative learning, technology skills, and self-monitoring (Conley, 2012b). Tables 7 and 8 show this categorization of key learning skills and techniques. 


\section{Table 7}

Key Learning Skills

\begin{tabular}{|l|}
\hline \multicolumn{1}{|c|}{ Ownership of Learning } \\
\hline$\frac{\text { Know Yourself }}{\bullet \text { Be self-aware-Find out your interests, passions, skills, and ambitions. }}$ \\
$\frac{\text { Set Goals }}{\bullet \text { Know what you need to achieve based on self-awareness. }}$ \\
$\frac{\text { Be Motivated }}{\bullet \text { Have the mindset to achieve your goals. }}$ \\
$\frac{\text { Monitor Performance }}{\bullet \text { Know how well you are really doing. Gauge your true skill level. }}$ \\
$\frac{\text { Ask for Help }}{\bullet \text { Know when you are stuck, then get help. Don't view this as a weakness. }}$ \\
$\underline{\text { Show Self-Efficacy }}$ \\
$\bullet$ Learn how to control the things you can control. Then control them.
\end{tabular}

Source: Conley (2012b)

\section{Table 8}

\section{Key Learning Techniques}

\section{Key Learning Techniques}

- Manage Time

- Take Notes

- Study for Tests

- Memorize

- Read Strategically

- Learn Collaboratively

- Use Technology

Source: Conley (2012a) 
The aforementioned skills in Table 7 are critical to build amongst students in secondary schools. Building these skills as early as fifth grade will help ensure that students are making a successful transition from elementary school to secondary schools and from secondary schools to postsecondary options.

Postsecondary instructors at a wide range of 2- and 4-year institutions stress the importance of these key learning skills and techniques across subject areas and programs (Conley \& McGaughy, 2012).

Transition knowledge and skills. The last aspect of social elements within the postsecondary readiness framework is working with parents and students to build knowledge and skills around the theme of life beyond high school. Conley (2012a) referred to this as key transition knowledge and skills. This key is necessary to navigate the transition from high school to postsecondary institutions. This information is knowledge that is not often accessible to all students (Conley, 2012a). Families that are historically under-represented in higher education or certain career pathways usually get left out of this knowledge. Some of the themes within this key are: knowing which courses to take in high school to be admitted to an appropriate postsecondary program (postsecondary awareness and matriculation), understanding financial aid options and procedures (postsecondary costs), being focused on a career pathway or major (career awareness), understanding college-level and workforce norms and expectations (role and identity), and knowing how to be a self-advocate within the institutional framework of 
postsecondary programs (self-advocacy) (Conley, 2012b). Table 9 shows the aspects involved in this key to postsecondary readiness.

\section{Table 9}

Key Transition Knowledge and Skills

\begin{tabular}{|l|}
\hline \multicolumn{1}{|c|}{ Key Transition Knowledge and Skills } \\
\hline $\begin{array}{l}\text { Postsecondary Awareness } \\
\text { • Aspirations } \\
\text { • Norms and culture }\end{array}$ \\
\hline $\begin{array}{l}\text { Postsecondary Costs } \\
\text { • Tuition } \\
\text { • Financial Aid }\end{array}$ \\
\hline $\begin{array}{l}\text { Matriculation } \\
\text { • Eligibility } \\
\text { - Admissions } \\
\text { • Program }\end{array}$ \\
\hline $\begin{array}{l}\text { Career Awareness } \\
\text { • Requirements } \\
\text { • Readiness }\end{array}$ \\
\hline $\begin{array}{l}\text { Role and Identity } \\
\text { • Role models }\end{array}$ \\
\hline $\begin{array}{l}\text { Self-Advocacy } \\
\text { • Resource acquisition } \\
\text { • Institutional advocacy }\end{array}$ \\
Source: Conley (2012b)
\end{tabular}

Source: Conley (2012b)

Grants are available to address the knowledge and support (key transition knowledge and skills) some students lack when applying for, funding, and enrolling in college. The U.S. Department of Education launched the College Access Challenge Grant Program, which aims to increase the number of low-income students who are ready for college (McAlister et al., 2012). McAlister et al. (2012) noted that other programs such as 
Project Grad USA and College Goal Sunday look to develop the college knowledge students and their families need for postsecondary success.

Community-based organizations play an active role in supporting students with key transition knowledge and skills (McAlister et al., 2012). As McAlister et al. (2012) noted that Community-based organizations step in to bridge gaps in college knowledge for students in high-needs schools where few of their peers apply to college. The College Board also does a great job of addressing key transition knowledge and skills by keeping parents informed and equipped to make college decisions (McAlister et al., 2012). A partnership between The College Board, the American Council on Education, and the Ad Council has developed the KnowHow2Go Initiative, which serves as a resource to help students and parents plan for postsecondary success (McAlister et al., 2012).

In creating a "postsecondary readiness framework," I was able to focus on literature that addresses both the academic and social mechanisms to help prepare students for postsecondary success. I was also able to go deeper into the key elements within this framework. As the transition from high school to college is a complex one for many students, schools would better serve students if they looked into improving current systems or creating systems that address structural, academic, and social elements aimed at addressing this transition for students. Creating a postsecondary readiness framework would ensure a systematic process to successfully prepare students for postsecondary options. 


\section{Early and Middle College High Schools}

Today, in our educational system, many students graduating from high school are not ready for a postsecondary education. I focus on two types of schools that currently exist to help students make a successful transition from high school to postsecondary education-early and middle college high schools. These schools have a structure that allows them to address and implement college and career standards as part of their mission and collaborate with postsecondary institutions to ensure a successful transition for all students. In this section I define each school model, review the research on early and middle colleges, and offer portraits of four schools (three early college models and one middle college) within the postsecondary readiness framework. I have chosen to research postsecondary readiness in early and middle college high schools because I feel that improvement needs to be made in helping students transition from high school to postsecondary education for the greater good of our workforce and nation.

Early college high schools are small schools with enrollment from 100-500 students. They allow students to pursue not only a high school diploma but also an associate degree or up to two years of college credit toward a bachelor's degree (Hoffman \& Vargas, 2005). Middle college high schools differ slightly from early college high school in that they are usually alternative high schools located on college campuses, help at-risk students complete high school, and encourage college enrollment ("Middle College High School,” 2009). Factors that place students at risk include, but are not limited to, poverty, homelessness, neglect, abuse, poor health and nutrition, pregnancy, 
potential language and cultural barriers, substance abuse, gang membership or delinquency, changing family structure, cognitive, emotional and other disabilities, and behavioral problems. Early and middle college high schools blend high school and college in rigorous, supportive programs, compressing the time it takes to complete a high school degree and the first 2 years of college (Berger et al., 2005). Recently, some middle college high schools have converted to early college high school models, which offer a five-year course of study toward a high school diploma and an associate degree or 2 years of college credits ("Middle College High School,” 2009). Early and middle college high schools are created in many ways: through partnerships of public school districts with private and public 4- year and 2-year postsecondary institutions or as public charter schools, for example (Berger et al., 2005).

Early and middle college high schools are charged with making higher education more accessible and more affordable for underrepresented students (Wolk, 2005). Wolk (2005) stated that early and middle college high schools "will ease the transition for students from high school to college and provide young people with a smoother pathway into adulthood and work" (p. 3). Both early and middle college high school models have key features: students are motivated by the opportunity to move to college-level work as soon as they are ready for it, students are rewarded for hard work through opportunities to earn 2 years of college credit (paid for by the school), learning takes place in small, personalized learning environments that demand rigorous, high quality work with extensive support, and the physical transition between high school and college is 
eliminated (Berger et al., 2005). Berger et al. (2005) showed how both early and middle college high schools demonstrate their full potential and close the gap between high school and college through six best practices.

1. Dual Enrollment/Dual Credit-college courses taken count for both high school and college credit.

2. Eligibility for College Courses-students who show "college readiness" skills are eligible for college courses.

3. Transfer Credits-students can transfer their college credits obtained to another two or four year institution.

4. Teacher Certification-high school teachers meet requirements to teach high school courses for dual high school and college credit and college instructors are permitted to teach high school students.

5. Funding-funding streams from high school to college can be combined

6. Autonomy-schools can make decisions to integrate secondary and post secondary education (Berger et al., 2005, p. 11)

The empirical literature I read demonstrates that early and middle college high schools are outperforming traditional high school student populations (Jobs for the Future, 2009). Attendance rates for early and middle college students average more than $90 \%$, which indicates high levels of student engagement and commitment to the academic program; grade-to-grade promotion rates exceed $90 \%$; and students outperform students in their districts on state math (by nearly 10\%) and language arts exams (by nearly 5\%). In 2007, more than 900 students graduated from 18 early college schools (2009). Of these graduates: $85 \%$ earned at least a semester of transferable college credit, $10 \%$ earned 2 full years of college credit or an associate's degree, and more than $60 \%$ 
were accepted to 4-year colleges, exceeding national rates for similar populations (Jobs for the Future, 2009).

Early and middle college high schools have grown from 3 schools in 2002-2003 to 201 schools in 24 states in 2008-2009 (Jobs for the Future, 2009). These schools abide by five core principles: (a) committed to serving students underrepresented in higher education; (b) created and sustained by local education agencies, higher education institutions, and the community, who are all jointly accountable for student success; (c) develop an integrated academic program so all students can earn college credit or a degree; (d) provide comprehensive support to help students achieve "college readiness" skills; and (e) work and advocate for supportive policies (Jobs for the Future, 2009).

In my research, I reviewed four schools and applied a postsecondary readiness framework to each study. The postsecondary readiness framework centers on three key elements: (a) structural elements, (b) academic elements, and (c) social elements. The research focuses on two early colleges in Los Angeles, California, one early college in Dayton, Ohio, and one middle college in Queens, New York. All of these schools combine high school and college to help students enter and succeed in college.

\section{Wallis Annenberg High School and Dayton Early College Academy}

Wallis Annenberg High School (WAHS) is located in South Central Los Angeles, while Dayton Early College Academy (DECA) is located in Dayton, Ohio. WAHS opened in 2004 and is a K-12 charter school that partners with California State University, Los Angeles. DECA opened in the fall of 2003 and partners with Sinclair 
Community College and the University of Dayton. Each school is small (fewer than 400 students) and located on or near a college campus. In my findings, both schools focused on eight areas/best practices to close the achievement gap from high school to college: (a) An educational identity, (b) continuous support, (c) caring relationships, (d) support for staff, (e) challenging environment, (f) importance of learning spaces, (g) constructing knowledge, (h) widespread and intense commitment (Wolk, 2005).

Wolk (2005) stated that developing an educational identity involves redefining success in school by focusing on the future. Teachers help in this process by projecting high expectations for students so that they perceive education and their future in a positive light. Teachers at both of these schools see the importance of continuous support for student success in both of these models. They strive to convince their students that college success is always possible and that it is never too late to succeed (Wolk, 2005). At both schools caring relationships are created in a family-like atmosphere. Because of the comfortable learning environment, students describe learning as "fun." Wolk (2005) pointed to teacher turnover as a negative aspect among students' lives in both models and encourages regular staff check-in to avoid this loss and teacher burnout. Student interviews at both schools reveal that students are thriving because of the challenging environment. Teachers and students set the bar high for each other to motivate students to achieve their full potential (Wolk, 2005). Wolk stated that students in early college "construct" knowledge through guided experience rather than lecture. This experience is tied to state benchmarks and completing college-level coursework for a college degree or 
certificate (Wolk, 2005). In both schools there is a widespread and intense commitment

to education from both students and teachers. I presume that what make these schools

successful can also be a drawback. An example of this is that the intense commitment to

build long-term success can lead to teacher burnout.

Table 10 shows how each of these specific practices identified at WAHS and

DECA fit within each component/element of the postsecondary readiness framework.

Table 10

Comparing Specific Practices Within the Framework-I

\begin{tabular}{|c|c|c|}
\hline \multicolumn{3}{|c|}{ POSTSECONDARY READINESS FRAMEWORK } \\
\hline $\begin{array}{l}\text { Structural Elements } \\
\text { 1. transitions in education } \\
\text { 2. the mission/vision of schools } \\
\text { 3. providing academic student } \\
\text { support } \\
\text { 4. utilizing the necessary } \\
\text { resources to provide students } \\
\text { with the guidance and support } \\
\text { 5. developing a partnership with } \\
\text { local postsecondary institutions }\end{array}$ & $\begin{array}{l}\quad \text { Academic Elements } \\
\text { 1. creating a rigorous } \\
\text { curriculum } \\
\text { 2. college and career readiness } \\
\text { standards and practices } \\
\text { 3. instruction } \\
\text { 4. identification of skills and } \\
\text { progress }\end{array}$ & $\begin{array}{l}\text { Social Elements } \\
\text { 1. including parents and } \\
\text { school staff in educational } \\
\text { planning } \\
\text { 2. identifying and building } \\
\text { academic behaviors of } \\
\text { students } \\
\text { 3. improving both students' } \\
\text { and parents' transition } \\
\text { knowledge and skills }\end{array}$ \\
\hline \multicolumn{3}{|c|}{ SPECIFIC PRACTICES AT WAHS AND DECA } \\
\hline $\begin{array}{l}\quad \underline{\text { Structural Elements }} \\
\text { Developing an educational identity } \\
\text { (mission/vision-2) } \\
\text { Providing continuous support } \\
\text { (academic support-3) } \\
\text { Caring relationships } \\
\text { (mission/vision-2) } \\
\text { Support for staff (mission/vision-2) } \\
\text { Importance of learning spaces } \\
\text { (mission/vision-2) }\end{array}$ & $\begin{array}{l}\quad \text { Academic Elements } \\
\text { Challenging environment } \\
\text { (creating a rigorous curriculum- } \\
\text { 1) } \\
\text { Constructing knowledge } \\
\text { (college and career readiness } \\
\text { standards and practices-2) }\end{array}$ & $\begin{array}{l}\quad \text { Social Elements } \\
\text { Widespread and intense } \\
\text { commitment (including } \\
\text { parents and school staff in } \\
\text { educational planning-1) }\end{array}$ \\
\hline
\end{tabular}


It is important to note that many of the best practices listed in the research of WAHS and DECA overlap with other elements of the postsecondary readiness framework. It is also important to point out that while some of the practices at these early college high school models fit into the postsecondary readiness framework, there are many elements that are not included and would help to address a better transition to postsecondary options for all students.

\section{Middle College High School}

Middle College High School (MCHS) is located in Queens, New York and has been a middle college since 1974. It has 490 students and partners with and is located on the campus of LaGuardia Community College. Students at MCHS attend to help lessen the burden of college tuition and accelerate and complete college early (Born, 2006). They quickly learned the differences between college and high school cultures. For example, missing classes, time to revise papers, and second chances were common in high school, but at college, these behaviors were not tolerated and were considered failure (Born, 2006). As Born (2006) pointed out, college is a whole new world with its own set of norms, its own vocabulary, and its own forms of communication. Students either learn or fail. To help with the aforementioned problems, MCHS created an Early College Seminar taught by high school teachers that meets two times each week during the initial summer orientation (Born, 2006). Students at MCHS enroll for college classes during their junior year, and the seminar increases to four weekly meetings of 70 minutes each. They receive one high school credit for attendance and participation (Born, 2006). 
The instructors of these seminars are expected to make contact informally with college instructors, gather college assignments, and address problems related to communication between students and instructors (Born, 2006). Born noted that as students move forward with their college experience, seminar support decreases to individual conferencing toward both high school and college completion. As students enter their fifth year of the program, there is no formal structure or support other than required daily check-ins. The average grade point averages for students in their fifth year are higher than those of the general population of students at the college (Born, 2006). A key to the success of MCHS is its culture where caring relationships between students and staff members are ingrained. Born noted that MCHS has an advisory group, mentors, and teachers who serve as counselors. Freshman orientation groups, conflict mediation, and programs such as Project Adventure build academic behaviors (Born, 2006). There is also support through an early college liaison to help with issues related to registration, testing, and record keeping (Born, 2006).

\section{Harbor Teachers Preparation Academy}

Harbor Teachers Preparation Academy (HTPA) is a fairly new school, as its first graduating class graduated in 2006. HTPA has 300 students and partners with and is located on the campus of Los Angeles Harbor Community College. Most students expect to complete their degree requirements by their senior year (fourth), a year earlier than their counterparts at MCHS (Born, 2006). To transition to the college, they enroll in a class called Personal Development taught by a college instructor. This class focuses on 
academic behaviors such as note taking, study skills, and time management. Born (2006) pointed out that students ease into college through "contract classes" for ninth and tenth graders. These classes are taught by college instructors and are attended exclusively by high school students. High school teachers accompany students to assist in behavioral issues and sometimes support those who are struggling (Born, 2006). These high school teachers can also help to fill in the gaps in the curriculum between high school and college. These "contract classes" are lecture driven and often crowded due to budget constraints (Born, 2006). The rigor of courses taken increases with each year of growth in high school. Born noted the philosophy behind this is that by the time students are in the eleventh grade, they will have the foundations and habits of mind (academic behaviors) to be ready for the college experience. Student support is provided at HTPA through AVID. AVID is a program aimed at giving in-school supports to students focusing on self-management and self-awareness to optimize student growth and prepare them for a postsecondary education. HTPA also engages in advisory sessions that are bimonthly, and students participate in discussing good study habits, credit checking, record-keeping, and postsecondary preparation (Born, 2006).

Table 11 shows how both MCHS and HTPA successfully bridge the gap from high school to college and how their approaches fit within each component/element of the postsecondary readiness framework. 


\section{Table 11}

Comparing Specific Practices Within the Framework-II

\begin{tabular}{|c|c|c|}
\hline \multicolumn{3}{|c|}{ POSTSECONDARY READINESS FRAMEWORK } \\
\hline$\underline{\text { Structural Elements }}$ & $\underline{\text { Academic Elements }}$ & $\underline{\text { Social Elements }}$ \\
\hline 1. transitions in education & $\begin{array}{l}\text { 1. creating a rigorous } \\
\text { curriculum }\end{array}$ & $\begin{array}{l}\text { 1. including parents and school } \\
\text { staff in educational planning }\end{array}$ \\
\hline 2. the mission/vision of schools & 2 college and career readinecs & identifyino and building \\
\hline $\begin{array}{l}\text { 3. providing academic student } \\
\text { support }\end{array}$ & standards and practices & $\begin{array}{l}\text { academic behaviors of } \\
\text { students }\end{array}$ \\
\hline $\begin{array}{l}\text { 4. utilizing the necessary } \\
\text { resources to provide students } \\
\text { with the guidance and support }\end{array}$ & $\begin{array}{l}\text { 3. identification of skills and } \\
\text { progress }\end{array}$ & $\begin{array}{l}\text { 3. improving both students' } \\
\text { and parents' transition } \\
\text { knowledge and skills }\end{array}$ \\
\hline $\begin{array}{l}\text { 5. developing a partnership with } \\
\text { local postsecondary } \\
\text { institutions }\end{array}$ & & \\
\hline \multicolumn{3}{|c|}{ SPECIFIC PRACTICES AT MCHS AND HTPA } \\
\hline$\underline{\text { Structural Elements }}$ & $\underline{\text { Academic Elements }}$ & $\underline{\text { Social Elements }}$ \\
\hline $\begin{array}{l}\text { Academic and personal guidance } \\
\text { supports (academic support-3) } \\
\text { Bridge gaps between Institutions } \\
\text { (developing partnerships-5) }\end{array}$ & $\begin{array}{l}\text { Rigorous courses (creating a } \\
\text { rigorous curriculum-1) }\end{array}$ & $\begin{array}{l}\text { College information and key } \\
\text { terms (improving both students' } \\
\text { and parents' transition } \\
\text { knowledge and skills-3) }\end{array}$ \\
\hline $\begin{array}{l}\text { Developing a college-going } \\
\text { culture (mission/vision-2) }\end{array}$ & & $\begin{array}{l}\text { AVID (identifying and building } \\
\text { academic behaviors of students- } \\
\text { 2) }\end{array}$ \\
\hline $\begin{array}{l}\text { Develop structure to } \\
\text { accommodate transition } \\
\text { (transitions in education-1) }\end{array}$ & & $\begin{array}{l}\text { Widespread and intense } \\
\text { commitment } \\
\text { (including parents and school } \\
\text { staff in educational planning-1) }\end{array}$ \\
\hline
\end{tabular}

As mentioned above with WAHS and DECA, it is important to note that many of the best practices listed in the research of MCHS and HTPA overlap with other elements of the postsecondary readiness framework. It is also important to point out that while 
some of the best practices at these early and middle college high school models fit into the postsecondary readiness framework, there are many elements that are not included and would help to address a better transition to postsecondary options for all students. There are more elements from MCHS and HTPA that fit into the postsecondary readiness framework, and I would assume that these schools successfully transition students to postsecondary options because of this richness.

\section{Conclusions and Recommendations}

In order to help address the fact that many students graduating from high school are not ready for a postsecondary education, we need to do two things: (a) include postsecondary readiness standards in high schools and (b) facilitate the growth of early and middle colleges around the nation.

With the implementation of CCSS throughout most of the nation, schools are looking to increase the focus and rigor of curriculum and instruction to help prepare students for postsecondary success. However, these CCSS do not address the structural or social elements aimed at helping with this transition. States need to pass laws to require schools to address elements of postsecondary readiness standards. Today, many schools are not addressing these elements to prepare all students for this transition. Until they do, many students will continue to graduate from high school unprepared for postsecondary education.

Effective policies at the state level must be implemented to spur the growth of schools aimed at preparing students for postsecondary success. Public high schools 
should offer equal access to dual high school and college enrollment opportunities and provide support through early and middle college high schools. Postsecondary institutions such as colleges and universities must be given incentives to partner with local school districts to implement early and middle college designs. If students demonstrate proficiency in particular advanced subject areas, they should be given dual college and high school credit. Funding must be provided for both secondary and postsecondary institutions to create a system where the student can transition at no cost. This transition should offer incentives to both educational institutions for the purpose of creating pathways for academic, social and financial supports (Hoffman \& Vargas, 2010). States must also collect individual student, district, and state data on early and middle college high schools for transparency and improved outcomes.

When postsecondary readiness standards are taught and implemented in all high schools teamed with the development of early and middle colleges around the nation, we will be able to improve the success of high school students transitioning to postsecondary education. It would also increase the chances of our educational system in creating "the holy grail of college readiness," which Conley (2007) described as an integrated system that imparts postsecondary readiness knowledge to students in an appropriate way so that they have a sense of how well they are being prepared and are preparing themselves for college. 


\section{CHAPTER 3}

\section{INTRODUCTION TO METHODOLOGY}

\section{Overview}

As I pointed out earlier in my research, postsecondary training in today's world is critical, as there is an increasing demand for a skilled labor force in order to compete in a global market. Therefore, the consequences of dropping out of high school are devastating to individuals, communities, and our national economy. Adults, at an absolute minimum, need a high school diploma if they want to earn a living wage. One problem with this is that nationally, many students are not graduating with a high school diploma, and, as Table 12 shows, the majority of these students are minority groups, particularly males.

Table 12

National Graduation Rates by Race and Gender

\begin{tabular}{|l|l|l|l|}
\hline \multicolumn{4}{|c|}{ National Graduation Rates By Race and Gender } \\
\hline Race/Ethnicity & Nation & Female & Male \\
\hline American Indian/AK Nat & 51.1 & 51.4 & 47.0 \\
\hline Asian/Pacific Islander & 76.8 & 80.0 & 72.6 \\
\hline Hispanic & 53.2 & 58.5 & 48 \\
\hline Black & 50.2 & 56.2 & 42.8 \\
\hline White & 74.9 & 77 & 70.8 \\
\hline All Students & 68 & 72 & 64.1 \\
\hline
\end{tabular}

Source: Orfield (2004) 
There is also the aspirations gap, as mentioned in chapter 2 . Out of $68 \%$ of students who graduate from high school, only $63 \%$ of these enter postsecondary options, and only $60 \%$ of these earn a postsecondary degree within six years of enrolling. This means that approximately 74\% enter the workforce with limited skills (Conley, 2012b). High schools either award a high school diploma that relies on state testing and limited skill building, or they attempt to prepare students for postsecondary success through approaches that are not comprehensive, grounded in research, or equitable for all student success. Based on these statistics, I have identified the research problem that many students graduating from high school are not ready for a postsecondary education. This problem is very complex and our educational system needs current approaches that: are equitable for all students and contain comprehensive approaches to postsecondary readiness skills to prepare all students for postsecondary success.

I believe that as a country we can do better. We should not allow our citizens to earn just a living wage; we should set the bar high and aim to build an abundance of skills for all of our citizens, so that they can live happier and we can compete at a higher level in this global economy. In order to accomplish this, we must look to improve how we prepare students for postsecondary options. As the statistics above point out, the current methods and approaches are not working.

To address the problem that many students graduating from high school are not ready for a postsecondary education, in chapter 2 , I researched methods, programs, and best practices secondary schools are using to prepare students for postsecondary success. 
Through my research, I was able to create a comprehensive PRG. The creation of this guidebook will help educational leaders look at more than one method of preparing all students for postsecondary success. The methods, programs, and best practices within the guidebook can be implemented in secondary schools across the nation. The PRG was the main tool used in a workshop for secondary leaders in a K-12 public charter school. These leaders were looking for ways in which they could better prepare their students for postsecondary success. I shared these methods, programs, and best practices and measured the guidebook's usefulness and collected data on ways I could improve the guidebook for other educational leaders to use. Educational leaders are defined as educational policy advisors, teachers, parents, community members, state, district, and building educational administrators focused on improving current educational systems and practices.

Chapter 3 addresses the research design used throughout my research. It also addresses the methodology of my study guided by the research questions that my PRG focuses on through its implementation in a K-12 public charter school. Data collection procedures are described through the use of the guidebook to reach conclusions and build knowledge around the aforementioned problem. My next steps cover data analysis strategies I used to guard against bias and my possible influence on the study outcomes to ensure the viability of this study. I conclude with an action plan of the implementation and management of the development of the product I field tested. 


\section{Research Design}

The research method and design structure that I used to address my research problem is a PBL approach that uses the $R \& D$ process. PBL is a research approach that begins with a problem that requires a critical synthesis of knowledge, the application of this knowledge, the development of problem-solving skills, the implementation of solutions, the facilitation of collaboration, and the development of self-directed learning skills. This approach is systematic and meets various challenges in life and career (Bridges \& Hallinger, 1995). Bridges and Hallinger (1995) aligned the goals (critical synthesis, systematic inquiry, and application of domain-relevant knowledge) for professional doctoral students with the PBL process. For this reason among others, it is the best research method for me to use with this study.

In order to use PBL for my study, I applied the R\&D model as it allowed me to apply my study to my job as an educational leader. The purpose of the R\&D model is to generate original contributions to knowledge, improve educational practice, and contribute new knowledge through research while raising new theoretical and empirical questions (Borg \& Gall, 1989). R\&D bridges the gap between research and practice. It takes the results of research and builds products to be applied in schools. This ability to not only contribute to my practice, but to also research knowledge, perfectly suits me as both a principal and a doctoral student. By going through the PBL and R\&D process, I was able to provide a solution to the problem that many high school graduates are not ready for postsecondary education through the creation of a guidebook for educational 
leaders. I field tested this guidebook and provided other educational leaders with a tool to help them prepare all students for postsecondary success. This tool gave educational leaders a comprehensive approach to methods, programs, and best practices high schools can use to address the problem at hand. This study impacted educational leaders, high schools, postsecondary educational institutions, and most importantly all students who plan to meet the demands of a global economy.

As the OEIB oversees efforts to create effective educational systems in Oregon to help students prepare for careers through postsecondary education, schools must address how to ensure students are college and career ready following the completion of high school (Table 13). To ensure this, in 2012, OEIB entered into achievement compacts with every K-12 school district, education service district, community college, the university system and individual university, and Oregon Health Sciences University (Oregon SB 1581, 2012).

States across the nation are using similar approaches in building systematic approaches to helping students thrive in a global economy. Because of this, there is a unique and timely opportunity to assist school leaders and schools in improving their efforts of preparing students for postsecondary options. In order to address elements of the aforementioned achievement compacts and to help educational leaders prepare high school students for postsecondary success, I created a product (PRG) by following Borg and Gall's (1989) cycle of R\&D (see Table 14). 


\section{Table 13}

\section{Achievement Compact Components}

\begin{tabular}{|l|l|}
\hline \multicolumn{2}{|l|}{ Completion: Are students completing high school college and career ready? } \\
\hline $\begin{array}{l}\text { 4raduation } \\
\text { Rate }\end{array}$ & $\begin{array}{l}\text { The percentage of students that earn a regular high school diploma within four years } \\
\text { of first entering ninth grade. Includes students who transfer into the district after } \\
\text { ninth grade and excludes students transferring out of the district. }\end{array}$ \\
\hline $\begin{array}{l}\text { 5-Year } \\
\text { Rate }\end{array}$ & $\begin{array}{l}\text { The percentage of students who earned a regular diploma, modified diploma, } \\
\text { extended diploma, adult high school diploma or GED within five years of entering } \\
\text { high school. Calculated as the percentage of students who earned such diploma or } \\
\text { certificate within five years of entering ninth grade divided by the size of the cohort. }\end{array}$ \\
\hline $\begin{array}{l}\text { Earning 9+ } \\
\text { College }\end{array}$ & $\begin{array}{l}\text { Percentage of students who have received, or earned the right to receive, nine or } \\
\text { more college credits while enrolled in high school or earlier. Credits can be earned } \\
\text { through any means approved by local school board policy, including but not limited } \\
\text { to AP exam, IB course completion, dual credit course completion, and community } \\
\text { college or university enrollment. Calculated as the percentage of students who } \\
\text { earned at least nine college credits by the end of their fifth or final year in high } \\
\text { school divided by the size of the cohort. }\end{array}$ \\
\hline $\begin{array}{l}\text { Postsecondary } \\
\text { Enrollment }\end{array}$ & $\begin{array}{l}\text { Number of students enrolled in a postsecondary institution (community college, } \\
\text { technical certificate program, or 4-year institution) within 16 months of high school } \\
\text { completion. Defined as the number of completers in a particular cohort that enroll in } \\
\text { postsecondary education divided by the number of completers in that cohort. }\end{array}$ \\
\hline
\end{tabular}

Source: OEIB (2011)

\section{Table 14}

\section{$R \& D$ Cycle}

1. Research and information collecting

2. Planning objectives, learning activities, and small-scale testing

3. Develop preliminary form of the product

4. Preliminary field testing

5. Main product revision

6. Main field testing

7. Operational product revision

8. Operational field testing

9. Final product revision

10. Dissemination and implementation

Source: Borg and Gall (1989) 
I used the research I collected to plan objectives, learning activities, and did some small-scale testing to create a preliminary form of the PRG. I then set up preliminary field tests of this guidebook with school leaders. Tools from this product were used to assess areas of systematic weaknesses based on the postsecondary readiness framework mentioned in chapter 2. Information was gathered and collected from the preliminary field test, and this data helped me to revise the PRG for my main field test. The main field test for the PRG used a qualitative methodology. Data were collected through interviews with educators and questionnaires completed by educational leaders at a K-12 public charter school intent on preparing students for postsecondary success. The guidebook focused and was refined through the feedback of the R\&D process to disseminate and implement at a later date (steps 8-10).

\section{Research and Information Collecting}

Step 1 was accomplished from the information and data gathered from my literature review (chapter 2) on preparing students for college and careers. As a principal of Highland Preparatory School (pseudonym) in an urban area, this step was critical for me because my passion is to help students with the transition from high school to postsecondary options. I found the literature review to be very helpful in my quest to provide a comprehensive approach to postsecondary readiness. During this step, I was able to dig deep into the area of preparing students for postsecondary success. I looked into methods, best practices, and programs aimed at building students' skills to smooth the transition from high school to postsecondary options. From this research and 
information collection, I saw some common themes and came up with a framework that would provide a comprehensive approach to postsecondary readiness. This postsecondary readiness framework gave me insight and ideas about creating a tool to help school leaders and schools prepare students for postsecondary success. Once I had the framework established, I was able to put together a template of a guidebook. As I moved through the R\&D cycle, the process of gathering information and research continued to help me refine and create a guidebook that was operational for educational leaders.

\section{Planning Objectives, Learning Activities, and Small-Scale Testing}

Step 2 began through the formation of a design team, and through participation in a district achievement compact advisory committee. This committee's purpose was to align our district's goals with those of the state to support each student graduating ready for college, career and citizenship. I participated in trainings led by members of EPIC that focused on elements from the postsecondary readiness framework mentioned in chapter 2. I visited schools from around the nation that had programs aimed at preparing students for college and careers. I interviewed educational leaders at these schools to get their input and perspectives toward preparing students for postsecondary options. In these visits I asked questions related to the postsecondary readiness framework I created from my review of literature on postsecondary readiness. From this I began to small-scale test the idea of a comprehensive approach to postsecondary readiness. This small-scale testing allowed me to improve on the template created in step 1. 


\section{Develop Preliminary Form of the Product}

Step 3 began through analyzing research and information from steps 1 and 2 of the R\&D cycle. The postsecondary readiness framework from chapter 2 along with the small-scale testing served as a compass for me to conceptualize a PRG. As the leader of a school whose mission it is to prepare students socially and academically for college and career-related programs helped me build a bridge between my school and other schools who shared our mission. Through this process, I was able to create a focus and direction for a comprehensive approach to postsecondary preparedness. The guidebook is called Bridging the Future to Postsecondary Readiness (Appendix R). Throughout the R\&D cycle the title of the guidebook has undergone many changes. Every person involved has had input in a title that would be the most effective. I wanted educators to see this product as a support to help them in their journey toward postsecondary preparedness for their students. As I mentioned earlier, this process is very complex and the preliminary form of the guidebook was to serve as a broad compass to help educational leaders navigate the transition from secondary schools to postsecondary options.

The guidebook begins with: an introduction, an explanation of the structure of the guidebook, a section on how to use the guidebook, and the purpose of the guidebook. It is divided into six sections: Research and Data addressing the Problem, Structural Elements, Academic Elements, Social Elements, and Resources focused on preparing students for postsecondary success. Feedback from the small-scale testing helped me 
organized the guidebook this way to make it more helpful for educational leaders to use and implement with their schools.

In step 3, I was able to take the template from the small-scale testing and develop it into a preliminary form of the final product. This step really helped me organize the guidebook by creating sections that would make it easier for the readers to navigate. Preliminary field testing would give me a better evaluation and assessment into each section of the guidebook.

\section{Preliminary Field Testing}

Step 4 was done with the help of educational leaders in different roles. These educational leaders consisted of an education policy advisor, two teachers from a high school to college transitional program, and two program directors of the same dual high school and college credit program. They work at the state level and from different states around the country. I was able to present the PRG through a workshop where I obtained initial qualitative evaluations of the PRG by conducting interviews and surveys with school leaders who shared in the mission of preparing students for postsecondary success. Prior to identifying these educational leaders, I created interview protocols and questionnaires aimed at collecting data on ways the guidebook can be useful to them. The guidebook was then presented in its preliminary electronic form to the aforementioned school leaders to collect data around the following research questions: 
1. In what ways can schools better prepare students for postsecondary success?

2. In what ways is the PRG useful in helping educational leaders prepare students for postsecondary success?

3. What improvements and changes to the PRG are needed to help educational leaders?

4. In what ways is the workshop useful in helping educational leaders navigate through the PRG?

\section{Main Product Revision}

Step 5 occurred after the preliminary field test and focused heavily on the data collected through interviews and surveys with educational leaders. I continued to work with the design team (step 2 above) to address the data gathered for preliminary product revision. I was very aware to get specific feedback from the interviews and surveys so I could avoid generalizations on the usefulness of the product. Through this feedback I revised the PRG by adding recommendations, assessments, and resources to each section of the guidebook. After the completion of this step, I felt confident in the product and eager to use it to be main field tested.

\section{Main Field Testing}

Step 6 was where I would get a more critical assessment and evaluation of the PRG. In this step I took the new product derived from step 5 and conducted main field testing. I selected a school that shared the mission of preparing students for postsecondary success and test the PRG. During this step, 26 educational leaders from Oasis Academy, a K-12 public charter school, took part in a workshop on how to use the guidebook along with sessions to guide them through the PRG. The educational leaders 
consisted of administrators from elementary to high school, teachers from elementary to high school, and other school support staff (Special Education Specialists, Career Center Coordinators etc.). The data I collected during this step was qualitative in nature. I conducted a pre- and post-survey to determine the participants' understanding of postsecondary readiness and to see how the PRG deepened their understanding. I also collected data from interviews and questionnaires based on the workshop and sessions from my time with Oasis Academy. The data gathered allowed me to understand the usefulness of the PRG in helping school leaders address my research problem (many students graduating from high school are not ready for a postsecondary education) in their schools. The guidebook served to add to the current research on this topic and gave a more in-depth understanding on Oasis Academy's approach to postsecondary readiness through this point-in-time study.

\section{Operational Product Revision}

Step 7 focused my attention to the PRG with the design team so that I could make other necessary modifications and improvement. I looked at the formative and summative data to refine the guidebook in order to make it ready for use with other educational leaders in schools (Bridges \& Hallinger, 1995). Through the main field test, I was able to add specific language to the recommendations, revise the assessments, and refine the resources to the PRG. I was also able to add learning activities that focused on the targets in each section. 
Through these revisions and professional editing, I made the PRG more effective and operational for school leaders whose school focus and mission is to help prepare students for postsecondary success. Going through the R\&D cycle provided me and other school leaders a tool with which to prepare high school students for postsecondary success.

\section{Operational Field Testing, Final Product Revision, Dissemination, and Implementation}

Steps 8, 9, and 10 were not tested at this time. They are intended to prepare others to implement the product in a variety of settings and collect data from instructors and student participants, leading to a final revision of the product (Borg \& Gall, 1989). These steps also allow educators the ability to incorporate the product into educational programs, publications, and presentations. Considerations for steps 8-10 are discussed in chapter 5 .

\section{Research Questions}

As a high school principal of a school whose mission it is to prepare students for college and career-related programs, I have always wanted to see how successful our educational system is at accomplishing this mission. In my journey through experience and research, I have found that many students graduating from high school are not ready for a postsecondary education. There were five essential questions that helped to address

this issue and guide this study. The first one was: In what ways can schools better prepare students for postsecondary success? This question helped me create a PRG aimed at helping school leaders address this problem within their schools. The second essential 
question created after researching the first essential question was: In what ways is the PRG useful in helping educational leaders prepare students for postsecondary success? The third question that helped me in the creation of the PRG was: What improvements and changes to the PRG are needed to help educational leaders in their quest toward postsecondary readiness. The next question was: What is the perceived impression of the guidebook's usability, applicability, and accessibility? Lastly, I used the following question to finish out my research: In what ways is the workshop useful in helping educational leaders navigate through the PRG?

By using the aforementioned questions to guide me through the R\&D cycle I was able to create a tool for educational leaders to explore their own approaches in preparing students for postsecondary success. The PRG offers schools a comprehensive approach to prepare students for postsecondary success. This approach is based on a postsecondary readiness framework created through the research of methods, programs, and best practices of successful schools. The research questions were a guide and critical for selfreflection before the guidebook and workshop was to be evaluated by others. Through this process, I deepened my knowledge of my topic and helped other educational leaders in their quest to prepare all students for postsecondary success. As I close out my journey with this topic, I hope the knowledge I gained will help me to continue to perfect the PRG. This guidebook created will inform educational leaders across the country of a comprehensive approach to best prepare students for postsecondary success. 


\section{Data Collection Procedures}

In my experience as a school leader, I have seen many cases where students cannot graduate high school because they lack the skills to earn a diploma. I have witnessed many students graduate high school only to enroll in remedial classes at the college level. I also have had conversations with students who enroll in an entry level college course only to get a poor grade due to a lack of skills necessary to pass the class. All of these scenarios can and will lead to frustration and students dropping out of college. The United States has dropped from first to twelfth among Organizations for Economic Cooperation and Development countries in college graduation rates, and signals the urgency of the college completion problem (Hoffman \& Vargas, 2010). The purpose of this proposal is to explore best practices and successful programs that high schools use to prepare students for postsecondary success. Through my experience, research, and observations I have not found a guidebook for educational leaders that addresses a comprehensive approach to postsecondary readiness. Many schools implement minimal best practices or programs aimed at preparing students for postsecondary success, but lack the structure, buy-in, or direction to provide students with all of the necessary support for postsecondary preparedness. By using PBL and the R\&D cycle, I am hoping to apply research, theory, and craft knowledge to this important problem that currently exists in secondary and postsecondary schools (Bridges \& Hallinger, 1995). This exploration will help to create a PRG that will focus on a 
comprehensive approach to postsecondary preparedness. The following flowchart (Figure 4) represents the development of my research idea.

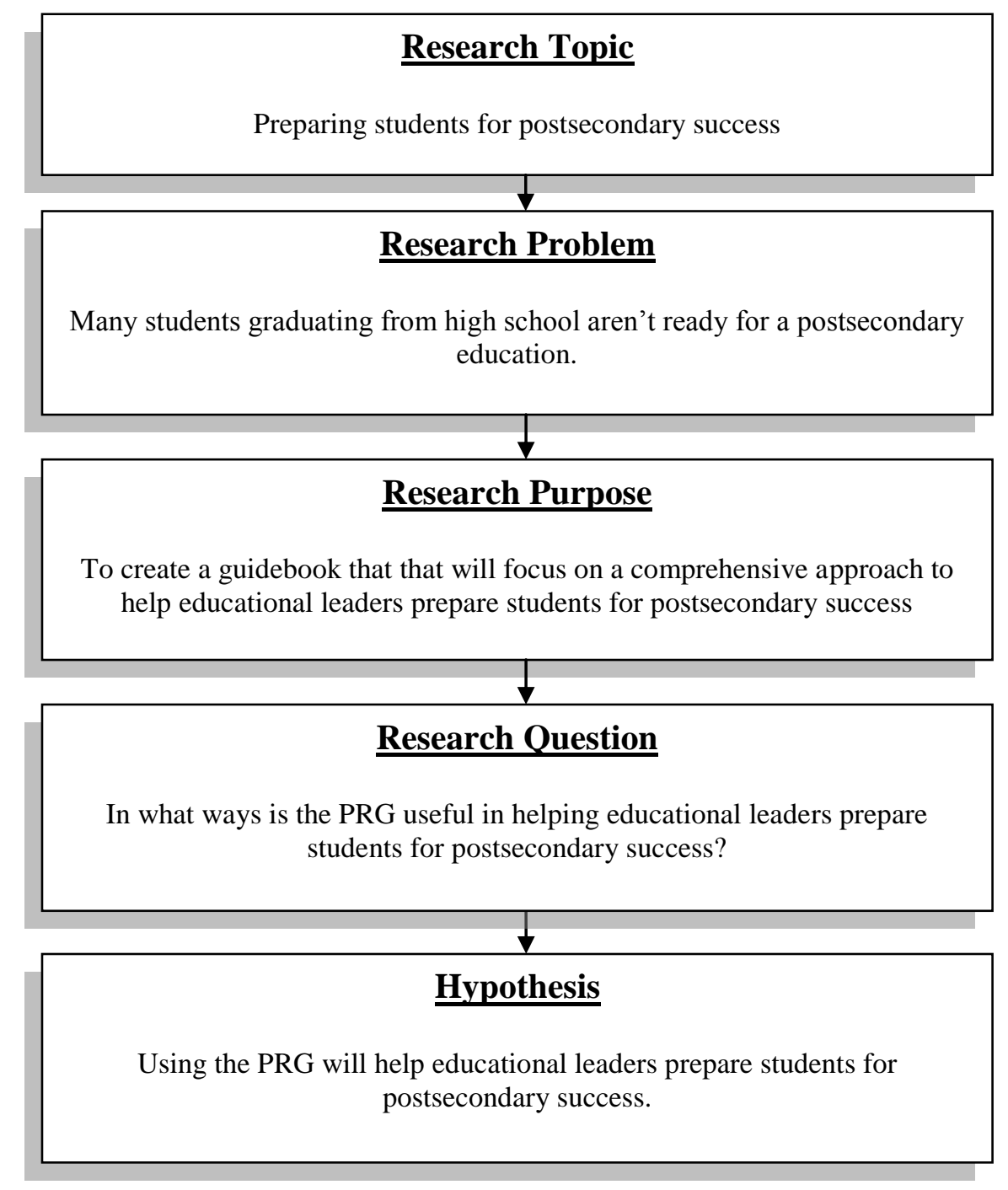

Figure 4. Development of PBL topic through R\&D. This figure follows my research idea from topic to product.

I accumulated knowledge by collecting facts or probable facts relating to the usefulness of the guidebook and build on these facts to give me knowledge with which to 
measure my hypothesis. My research was "value free" and the ethicality of behavior was policed by the PSU Human Subjects Research Review Committee. The Human Subjects Research Review Committee waived my research as they have determined that the project does not fall under the federal regulations pertaining to research with human subjects because the focal point of my research was the PRG and not human subjects.

Since the objective of my research was to measure how useful the PRG is for educational leaders in preparing students for postsecondary success, the scientific method behind my study was exploratory and the methodology was qualitative in nature. This methodology fit best with the PBL research design and the R\&D cycle because the focus of my research was a product measured by educational leaders. Since my research questions were set up to explore, discover, construct, and describe the initiation and perceived usefulness of my product (workshop and PRG) through this "single point in time" study, qualitative methods such as interviews, participant observation, and field notes best served this purpose (Johnson \& Christensen, 2007).

To collect the data for the interviews, I followed the basic procedures identified by Creswell (2007).

- Identify interviewees.

- Determine what type of interview is practical.

- Use adequate recording procedures.

- Design and use an interview protocol.

- Refine the interview questions and the procedures further through pilot testing. - Determine the place for conducting the interview. 
- Obtain consent from the interviewee to participate in the study.

- During the interview, stay to the questions, complete the interview within the time specified. Be respectful and courteous, and offer few questions and advice. (pp. 133-134)

As I collected the data through the observation process, I used Creswell's (2007) steps for observing to serve as a guide.

- Select a site to be observed.

- At the site, identify who or what to observe, when, and for how long.

- Determine, initially, a role to be assumed as an observer.

- Design an observational protocol as a method for recording notes in the field.

- Record aspects such as portraits of the informant, the physical setting, and your own reactions.

- During the observation, have someone introduce you if you are an outsider.

- After observing, slowly withdraw from the site. (pp. 134-135)

Since collecting data on the usefulness of my PRG, it became necessary to define the term usefulness as it related to my research. As I mentioned earlier (through Figure 4), my research topic is preparing students for postsecondary success. Therefore, I defined the usefulness of the PRG as that which provides a comprehensive approach to help educational leaders prepare students for postsecondary success. I measured this by collecting data on the usefulness of the PRG. This was done by collecting qualitative data from educational leaders through interviews, observations, and surveys. I collected a representative sample through a parallel sequential mixed sampling design. In a parallel sequential mixed sampling, the qualitative data gathered on the PRG was gathered 
sequentially from different participants who represented educational leaders. After I collected the aforementioned data, I was able to analyze the data to determine the usefulness of the PRG being studied.

Focusing on data collection in my R\&D, I collected data in many ways. All of the data collected was qualitative in nature. After identifying the problem: many students graduating from high school are not ready for a postsecondary education, and researching literature related to this problem, I worked with my design team to focus on the following questions pertaining to the creation of a product:

1. Does the proposed product meet an important educational need?

2. Is the educational environment sufficiently advanced that there is a reasonable probability that a successful product can be created?

3. Are personnel available who have the skills, knowledge, and experience necessary to build this product?

4. Can the product be developed within a reasonable period of time? (Bridges \& Hallinger, 1995)

After discussion and positive answers to the aforementioned questions, I moved forward with a level of confidence that I could create and test a product that could impact education.

The next step I took was to conduct small-scale research. I did this through observations in schools and interviews with leaders in schools preparing students for postsecondary success. I visited five charter schools and one traditional comprehensive high school in the Southern and Western United States that had postsecondary preparedness within their mission and vision. While there, I observed classrooms and 
interviewed school leaders to see if the PRG and its components would be useful in their journey of preparing students for postsecondary success. I collected this data through field notes, and interview protocols centering on my essential research questions. I developed a broader and deeper understanding of the problem and how I would address it through the development of a product. I was also able to collect data through meetings at my school with educational leaders from around the country.

The findings from the literature review and the data from my small scale research helped to center and create the components of my product or guidebook. I added the reflections, learning activities, and assessments to the postsecondary readiness framework and created a preliminary form of the PRG to be tested. I then focused on my target audience and began thinking about sites/venues that could field test my guidebook.

The preliminary field test was done with an educational policy advisor and teachers and program directors from the Achieve Higher through College Network (pseudonym). The Achieve Higher through College Network (AHCN) builds the capacity of colleges, school districts, and states to revolutionize education for high school dropouts and underprepared college students so that all young people can achieve college credentials. Their strategies include:

- Creating and replicating innovative programs

- Building partnerships that connect K-12 and higher education institutions and communities

- Influencing systems by creating change agents who are transforming instruction and student support practices from the inside out 
- Conducting research and sharing what we know about successfully serving high school dropouts and academically underprepared college students

- Helping effect policy and regulatory changes to ensure that AHCN and other alternative education models are available in every community that needs them

- Providing customized consulting services to colleges and school districts

Participants from AHCN included two teachers, the Associate Vice-President of Policy and Partnership Development and Manager of AHCN's Training and Partner Support. They went through a workshop on how to use the guidebook and looked at the components of the guidebook. They provided feedback on the workshop, design of the PRG, learning activities, assessments, and ways the PRG could be useful to a college program such as theirs. I collected this data through interviews, field notes, and surveys. The data collected in this step gave me a qualitative evaluation of how the PRG could be useful to other secondary schools. This critical feedback helped me revise and fully develop my guidebook into a tool ready to be implemented at a school site for the main field test.

The main field test was conducted with educational leaders from a K-12 public charter school in another state that serves underrepresented youth. Oasis Academy is a Pre-Kindergarten-12 public conversion charter school located in the rural area of Meadowview (pseudonym). Meadowview is home to socioeconomically and ethnically marginalized citizens. Rates in Meadowview show that $20.0 \%$ of families with children and $15.6 \%$ of individuals were below the poverty level. At Oasis Academy, $78.7 \%$ of students live in economic hardship, and $14.1 \%$ of students at the school have been identified as homeless or residing in emergency/transitional housing. On state tests, only 
$35.7 \%$ of Oasis' students were proficient in reading and only $23.2 \%$ in math. The mission of Oasis Academy is to prepare self-directed, self-aware, college-ready learners who will embrace the challenges of obstacles, experience the pride of perseverance and accomplishments, and demonstrate the strength of family and community.

In order to get the feedback to address my research questions, I presented the components and elements of the PRG in a workshop, and then facilitated the use of the PRG with the group. I sent a copy of the PRG two weeks before my visit and sent the participants a pre-survey of based on themes from my research questions. The data collected served to measure the ways the PRG was useful in helping educational leaders prepare students for postsecondary success. The following data sources were used in this study:

- Interviews with the educational leaders: (numbers of participants and their roles)

- Surveys on the usefulness of the PRG and its components

- Background and demographic data on schools/programs and neighborhoods The data collected reflects the application of the PRG with educational leaders in an environment focused on preparing students for postsecondary success. This data helped me to revise the PRG further, and created an educational product that will potentially be ready for use in schools.

As the researcher, I was the primary data-collection instrument as I observed the participants (educational leaders) interact with my product (PRG). I asked the questions, collected the data, made the interpretations, and recorded what was observed. Because of 
this I became a participant-as-observer and took on the role of an insider into my research. A participant-as-observer is when the researcher spends extended time with a group as an insider and tells participants that research is taking place (Johnson \& Christensen, 2007). As a participant-as-observer, I spent a great deal of time with educational leaders of Oasis Academy. Since Oasis Academy, the site where I field tested the PRG, was in another state, it provided me the neutrality to avoid issues that could influence the study. Also, since I was not personally involved with my own site, I avoided power and influence over participants, and avoided biasing the study. The advantage of this approach was that I made it clear to them that I was studying the PRG and its usefulness, and that I was not a bona fide group member. Another advantage of this was that I was able to get their permission to collect and record data as it pertained to the PRG. After my project is completed, I plan on sharing my tentative conclusions with the members of Oasis Academy who participated in my study for further feedback. One weakness to being a participant-as-observer was that participants may not have behaved naturally because they were aware they were part of a study. Fortunately, I was able to gain the trust of participants as I got to meet them and they adjusted to my presence.

When I approached the Human Subjects Research Review Committee or the Institutional Review Board, my study fell under "Waived Review" within federal regulations and was in the Exempt category (4.1). This ensured both minimal risk, and that research met one of the following categories for exemption (as they pertain to my research study). 
Exempt categories: (Quoted from 45 CFR 46.101)

1. Research conducted in established or commonly accepted educational settings, involving normal educational practices, such as (i) research on regular and special education instructional strategies, or (ii) research on the effectiveness of or the comparison among instructional techniques, curricula, or classroom management methods.

2. Research involving the use of educational tests (cognitive, diagnostic, aptitude, achievement), survey procedures, interview procedures or observation of public behavior, unless: (i)information obtained is recorded in such a manner that human subjects can be identified, directly or through identifiers linked to the subjects; and (ii) any disclosure of the human subjects' responses outside the research could reasonably place the subjects at risk of criminal or civil liability or be damaging to the subjects' financial standing, employability, or reputation.

3. Research involving the use of educational tests (cognitive, diagnostic, aptitude, achievement), survey procedures, interview procedures, or observation of public behavior that is not exempt under paragraph (b)(2) of this section, if: (i) the human subjects are elected or appointed public officials or candidates for public office; or (ii) federal statute(s) require(s) without exception that the confidentiality of the personally identifiable information will be maintained throughout the research and thereafter.

I picked the participants of the study in the preliminary and field testing stages because they shared the interest and mission of preparing students for postsecondary success. There were approximately 35 educational leaders who participated in the study. They were notified and assured that their participation in the study was completely voluntary. Their participation in this study had no effect on their relationship with their programs/schools or the researcher. Participants were not offered compensation of any kind. Any participant was advised that they could withdraw from the study at any time without any effect, either positive or negative, with their programs/schools or with the 
researcher. They were notified that their responses, and data collected would be kept confidential.

The purpose of this study was to examine more closely elements/components of postsecondary readiness, and how secondary schools prepare students for a successful transition to postsecondary options through a PRG. I was able to use my research on the usefulness of a PRG to help educational leaders address the question: In what ways is the PRG useful in helping educational leaders prepare students for postsecondary success? I presented and discussed with each educational leader who participated in this study the research findings and revisions to identify any inaccuracies or oversights. They validated the strengths and usefulness of the handbook through their insight and interpretations, which is included in the study.

\section{Data Analysis Strategies}

As I followed the PBL research design, it was necessary for me to collect data, analyze data, collect additional data, and analyze the additional data throughout the R\&D cycle. This process is called interim analysis (Miles \& Huberman, 1994). I used interim analysis because I was able to get data that helped refine my developing theories and tested my hypotheses developed from examining my data when I was in the field (Johnson \& Christensen, 2007). I also collected many sources of data, interviews, and observations to establish reliability and validity. This fits with Creswell's characteristics of a "good" qualitative study (Creswell, 2007). 
After collecting the data it became necessary to begin coding my data. I used many forms of coding in order to make sense and analyze my data. I first generated inductive codes by directly examining the data. This allowed me to create a master list through my interviews, observations, and surveys. The inductive codes provided good, clear, descriptive words to characterize segments of my data. I also used facesheet coding to account for group differences (e.g., female and male to each interview to signify the participant's gender). Facesheet codes apply to a complete document or case (Johnson \& Christensen, 2007). While coding, I found it necessary to quantify or enumerate my data throughout the data analysis process. Johnson and Christensen (2007) pointed out that enumeration helps qualitative researchers communicate concepts such as amount or frequency when analyzing and writing up the results. Another type of coding I used to analyze my data was hierarchical categorization. This was used when I looked at the observation and interview data and broke the words and sentences into themes and relationships that helped to address my research question. I then organized these sentences and themes into different levels or subcategories. For example, when participants in my study referred to goals and objectives in the classroom, I organized these into the category of learning targets and standards. I then classified this as a subcategory under quality instructional practices. Lastly, I put quality instructional practices under the main topic of academic elements which is one of the components of the postsecondary readiness framework which guides the PRG. The different types of coding used in my study are be addressed further in chapter 4 . 
In order to check and establish validity in my study, I relied heavily on triangulation. More specifically, I used data and methodological triangulation. Data triangulation involves using different sources of information in order to increase the validity of a study (Guion, 2011). In my study, these sources were an education policy advisor, district administrators, building administrators, teachers from different grade levels, and multiple school support personnel in steps 2,4 , and 6 of the R\&D cycle. I interviewed and observed each of these groups to gain insight into their perspectives of the PRG and my research questions. As Guion (2011) pointed out, during the analysis stage, feedback from the stakeholder groups would be compared to determine areas of agreement as well as areas of divergence. I also used methodological triangulation. Methodological triangulation involves the use of multiple qualitative methods in a study (Guion, 2011). For example, in my study during steps 2,4 , and 6 of the R\&D cycle, I used the results from surveys, interviews and observations to compare to see if similar results are being found. When conclusions from each of the aforementioned methods are the same or similar, then validity is established. Triangulation in my study is addressed more in-depth in chapter 4.

The advantages of triangulation include "increasing confidence in research data, creating innovative ways of understanding a phenomenon, revealing unique findings, challenging or integrating theories, and providing a clearer understanding of the problem" (Thurmond, 2001, p. 254). These are benefits because of the diversity and quantity of data that is used for analysis. 
The disadvantage of triangulation is that it can be time-consuming. As I collected more data, I needed to spend more time planning and organizing. Another disadvantage includes the "possible disharmony based on investigator biases, conflicts because of theoretical frameworks, and lack of understanding about why triangulation strategies were used" (Thurmond, 2001, p. 256).

When I interviewed participants in my study, I recorded their answers to my questions and transcribed their responses. I also recorded my observations to minimize any personal bias of my research. I used the aforementioned coding techniques with the interviews and observations so I could better analyze the data. During the main field test of the PRG, I interviewed: two building administrators, two secondary school teachers, and two elementary school teachers. After the workshop sessions I collected data on the usefulness of these sessions. These sessions covered the research problem, structural, academic, and social elements, along with resources to help with postsecondary preparedness. At the end of the week I collected data on the usability, applicability, and accessibility of the guidebook. I also administered and used a pre- and post-survey focusing on my research questions as they pertain to postsecondary readiness.

In my analyses of any survey data, I developed questionnaires on SurveyMonkey. SurveyMonkey is a web survey development company that allows researchers to build, distribute, collect, and analyze these surveys to get results. It broke the results down into question summaries, data trends, and individual responses. SurveyMonkey allowed me to see only the questions and responses that I wanted to analyze. I used cross tabulation to 
compare questions and answers to see how they were interrelated. Finally, I used their text analysis to breakdown open-ended responses to better categorize and analyze the results.

\section{Work Plan}

This research proposal was submitted to Portland State University's Human Subjects Research Review Committee or the Institutional Review Board along with the informed consent document, the survey questions, and individual interview questions. For validity purposes, this section provides a detailed work plan and timeline that I followed as I conducted this research study.

\section{Research and Information Collecting}

Step 1 began in September 2012 and helped to provide context around postsecondary preparation. During this time, I was able to dig deep into looking at the methods and programs aimed at preparing students for postsecondary success. This gave me the opportunity to create a framework from my research. This framework gave me insight and ideas about creating a tool to help school leaders and schools prepare students for postsecondary success.

\section{Planning Objectives, Learning Activities, and Small-Scale Testing}

Step 2 occurred throughout the 2012-2013 school year. I began small-scale testing of ideas through conversations, meetings, and discussions with school leaders around the nation. I focused on a comprehensive approach to postsecondary readiness. During this time I was able to visit schools from around the nation and attend conferences to see how 
educational leaders were addressing my research problem (many students graduating from high school are not ready for a postsecondary education) in their schools. I administered informed consent forms and let participants know that this process was completely voluntary. The collected consent forms gave me permission to gather data from observations, reflections, questionnaires/surveys, and the tools within the guidebook. The consent forms were to assure that participants had the option not to participate in the study and that they could withdraw from the study at any time without consequence. All participants were left with forms and instructions that included my contact information along with that of Professor Chenoweth in case they were to revoke consent. The data used from small-scale testing included: field notes and informal interview questions. This small-scale testing allowed me to conceptualize a product I could create to help prepare students for postsecondary success.

\section{Develop Preliminary Form of the Product}

Step 3 happened during the summer of 2013 I created a preliminary form of the product from the data and feedback from my small-scale testing. The guidebook was revised following steps one and two of the R\&D cycle. Through these steps, I was able to add a workshop, activities, assessments, and resources to the postsecondary readiness framework and create a preliminary form of the PRG to be tested. Having gone through step 2 of the R\&D process provided me feedback to create a guidebook from an initial template of my product. 


\section{Preliminary Field Testing}

Step 4 was done in September 2013, to provide information on the guidebook's usefulness to educational leaders focused on preparing students for postsecondary success. I provided a workshop on how to use the guidebook to participants, and I obtained an initial evaluation of the PRG by conducting interviews and administering surveys with educational leaders who shared in the mission of preparing students for postsecondary success. Prior to identifying school leaders, I created an interview protocol, and questionnaires aimed at testing the usefulness of the PRG. This served as the basis for preliminary product revision during October 2013.

\section{Main Product Revision}

Step 5 occurred from October through November 2013. I took the new product derived from the process above and worked with my design team consisting of a K-12 principal, a program coordinator, and a high school charter school teacher. They were familiar with my study as I had worked with them during the small-scale testing phase of my research. The design team had already discussed my research questions and approach, and consent forms were collected prior to this time period meeting. When I met with the members of my design team, they were briefed about the progress of the study and received information about and a description of the data collection activities. After going through this process, I followed with revisions to the PRG from their data and planned a main field test of the PRG at Oasis Academy in February 2014. 


\section{Main Field Testing}

Step 6 took place in February 2014. I presented the PRG through a workshop and sessions with a K-12 public charter school (Oasis Academy) for the main field test. The information collected was coded to protect the identities of study participants. This coding ensured that the data collected had no impact on participants' relationship with school/programs, colleagues, or supervisors. This coding system protected the identities of the participants by listing each individual as a number and each grade level as a symbol. I did not reveal the symbol for the school or the number of each participant. All surveys, reflections, product notes, codling lists, and field notes are secured in my home office. The coding list was kept separate from the data so as not to inadvertently reveal the identity of any participant. After 3 years from the dissertation defense, the coding list will be destroyed.

\section{Operational Product Revision}

I focused on step 7 from February-April 2014. I analyzed the data collected in the main field test in order to revise the PRG. These data were both formative-pointing out ways I could improve the guidebook-and summative, to assess the efficacy of my product (Bridges \& Hallinger, 1995). I then determined whether the PRG was fully ready for use in schools whose mission is connected to postsecondary readiness. This process required the collection of additional data for the final revision of the guidebook. Table 15 shows my R\&D proposed timeline. 
Table 15

R\&D Timeline

\begin{tabular}{|l|l|l|}
\hline \multicolumn{1}{|c|}{ When } & \multicolumn{1}{|c|}{ What } & \multicolumn{1}{c|}{ Action } \\
\hline September 2012 & $\begin{array}{l}\text { Research and Information } \\
\text { Collection }\end{array}$ & Review of Relevant Literature \\
\hline 2012-2013 school year & Small-Scale Testing & $\begin{array}{l}\text { Site Visits, Informal Conversations, } \\
\text { Meetings, and Discussions }\end{array}$ \\
\hline Summer 2013 & $\begin{array}{l}\text { Develop Preliminary Form of } \\
\text { the PRG I }\end{array}$ & A PRG with Tools was Created \\
\hline September 2013 & $\begin{array}{l}\text { Preliminary Field Test of PRG } \\
\text { I }\end{array}$ & $\begin{array}{l}\text { Partner with Educational Leaders for } \\
\text { Guidebook Review }\end{array}$ \\
\hline October-December 2013 & Creation of PRG II & Revision of PRG I \\
\hline February 2014 & Main Field Test of PRG II & $\begin{array}{l}\text { Partner with Oasis Academy for } \\
\text { Guidebook Field Test } \\
\text { (Initial Meeting, Consent Forms, Coding, } \\
\text { Facilitation and Implementation) }\end{array}$ \\
\hline February-April 2014 & Creation of PRG III & Revision of PRG II \\
\hline
\end{tabular}

\section{Summary}

This chapter looked into the problem that many students graduating from high school are not ready for a postsecondary education and described the process I went through in order to address this problem. I was researched relevant literature, carried out small-scale testing with educational leaders who shared in my passion to prepare students for postsecondary success, and picked a research design (PBL) through the R\&D cycle. By focusing on the problem, I came up with research questions to guide me through this process. The process gave me direction to build a product aimed at addressing the problem. This chapter described not only the what (creation of a guidebook), but also how (methods to measure efficacy) it would be perfected. It also gave me the opportunity 
to further research and revise my product to be an important tool in preparing students for postsecondary success.

Because of the research outlined in this chapter, I talked to many educational leaders who have voiced interest in a comprehensive approach to postsecondary preparation. Their interest was spurred because they saw the need to provide students with successful programs. They also believed in schools that prepared all for a postsecondary education in order to meet the demands of a global economy.

I am dedicated to helping educational leaders and schools to provide a comprehensive approach to postsecondary readiness. This process has helped me and will continue to help me build the skills necessary to apply what I have learned to the field of education. I will take my findings and research and share them with current and future educational leaders. Chapter 4 addresses how the steps of the R\&D cycle led to the refinement of my guidebook through field testing and analysis. As a result, the guidebook helped educational leaders create programs to successfully transition students to postsecondary options. 


\section{CHAPTER 4}

\section{INTRODUCTION TO ANALYSIS}

\section{Overview}

What can educational leaders do to help prepare students for postsecondary success? This exploration is based on the guidebook titled: Bridging the Future to Postsecondary Readiness. The purpose of this study is to determine how useful the guidebook is in building the capacity and confidence of educational leaders to successfully facilitate student transitions from secondary to postsecondary education. The guidebook was created using Borg and Gall's (1989) R\&D cycle through Bridges and Hallinger's (1995) PBL research design. Following the steps of the R\&D cycle, the guidebook was evaluated by a group of 35 educational leaders, including a K-12 public charter school whose mission is to prepare its students for college and careers. The guidebook was developed because educational leaders from around the country have emphasized the importance of preparing students for college and careers. As mentioned in chapter 1, if educational leaders use this as their compass, then the goals of our educational system will align with the goals of our society. This will then produce contributing members of the work force, enabling our country to meet the needs of the global economy.

As I gained more and more experience in education, a passion grew to look at how we prepare students for life after high school. Teaching in a high school in Montana, 
a rural town in Arizona, and my experience in Oregon, I was able to see first-hand many different scenarios in the education and preparation of students for life after high school. Through this experience, I saw first-hand students: who did not acquire the skills to earn their high school diploma, who did graduate high school, but had to enroll in remedial courses in college, who enrolled in entry level college courses only to fail one or more of these courses, and who got frustrated with their college experiences and dropped out of college. Presently, I am a leader of a small high school-to-college transitional program whose mission and vision is tied directly to preparing students for postsecondary success. This educational foundation and research allowed me to create a guidebook with a comprehensive approach to postsecondary readiness for educational leaders. I believe this guidebook will help these leaders better prepare their students for the challenges for life after high school.

This chapter follows steps 1-7 of the R\&D cycle, and includes a description of what happens at each step along with the outcome. This description will include the input from the key participants so that I can improve both the workshop and my product (guidebook). The five research questions and goals that guided this study are reviewed. The research and design used in this study will be explained in this chapter along with the development and field testing of the guidebook. This chapter describes my experience as researcher as I progressed through the first seven steps of the R\&D cycle. Finally, this chapter explains the results and discuss the field testing issues and challenges. 


\section{Seven Steps of the R\&D Process}

The PBL approach that employs R\&D was used as the design structure, and was the most beneficial for collecting the qualitative data for my study. Bridges and Hallinger (1995) pointed out that the PBL option is different from other research options. This is because the research includes a set of steps that result in the development of a PBL project. Borg and Gall (1989) also pointed out that educational R\&D is used to develop educational products. I engaged in the R\&D cycle and used the findings to create, revise and refine a tested product (guidebook) to potentially be implemented in a secondary school setting. My following is a brief overview of the study's R\&D cycle that includes steps $1-7$.

\section{Step 1: Research and Information Collecting}

As I looked at the literature and research on my topic, I immediately found a need for a tool (guidebook) to help educational leaders prepare students for postsecondary success. The literature review revealed approaches schools use to help prepare students for life after high school, and gave me a better understanding of these best practices. However the literature review also revealed that there was no existing tool that offered a comprehensive approach to postsecondary preparedness. This became the goal of my study and helped to address my main research question: In what ways can schools better prepare students for postsecondary success? 


\section{Step 2: Planning Objectives, Learning Activities, and Small-Scale Testing}

In order to create a tool with a comprehensive approach to postsecondary readiness, I formed a design team consisting of a: K-12 administrator, a high school teacher, and a member of my school support team. This team would help in the planning, and objectives of the tool. Other ideas were generated through my participation in committees, district and school-wide trainings, conferences, and school visitations. Small-scale testing consisted of interviewing educational leaders who were involved in implementing educational best practices and programs to prepare students for postsecondary options. I also used observational field notes from my participation in trainings to capture descriptive and reflective data relative to my topic.

\section{Step 3: Develop Preliminary Form of the Product}

After interviewing participants, I was able to create a focus and direction for a comprehensive approach to postsecondary preparedness through the creation of a product: PRG: Bridging the Future to Postsecondary Readiness. In step 3, I was able to take the template from the small-scale testing and develop it into a preliminary form of the final product. This step really helped me organize the guidebook by creating sections that would make it easier for the readers to navigate.

\section{Step 4: Preliminary Field Testing}

In step 4, I conducted a preliminary field test with an education policy advisor and educational leaders in transitional high school to college program. These educational leaders participated in a workshop which outlined how to use the PRG. They were 
interviewed and surveyed on the usefulness of the workshop and guidebook. Because the participants were geographically from different areas and different states, I presented the workshop and PRG to them individually and at different times.

\section{Step 5: Main Product Revision}

Interview and survey data were used to revise the PRG. I continued to work with the design team (step 2 above) to address the data gathered for preliminary product revision. I tried to get specific feedback from the interviews and surveys so I could avoid generalizations on the usefulness of the product. Through this feedback I revised the PRG by improving the recommendations, assessments, and resources to each section of the guidebook.

\section{Step 6: Main Field Testing}

In step 6, I offered a workshop for a K-12 public charter school that included school administrators, high school, middle and elementary teachers, and school support personnel. I conducted a pre- and post-survey to determine the participants' understanding of postsecondary readiness and see how the PRG deepened their understanding. I also collected data from interviews and questionnaires based on the workshop and sessions from my time with the K-12 public charter school. The data gathered allowed me to understand the usefulness of the PRG in helping school leaders address my research problem (many students graduating from high school are not ready for a postsecondary education) in their schools. 


\section{Step 7: Operational Product Revision}

During this step, I used the summative and formative assessment data from step 6 for the final editing and revisions to the workshop and guidebook. The formative data from this step allowed me to improve the product while the summative data shed light on the product's efficacy (Bridges \& Hallinger, 1995).

In this chapter, I analyze the first seven steps in the R\&D cycle. These steps helped me create, develop, field test, revise and refine the guidebook: Bridging the Future to Postsecondary Readiness. This chapter reviews my research questions and goals that helped guide my research. It also provides a description of the general design of the project. Next I address the information, data collection, and data analysis of the small-scale testing, along with the preliminary and main field testing. I then discuss the summative and formative evaluation of results of the field testing of my project. I then discuss how these results lead to the development of the product throughout the small scale, preliminary and main field testing. Finally, I focus on field testing issues and challenges that came up during the field tests.

\section{Review of the Research Questions and Goals}

The research method and design structure that I used in my study is a PBL approach that uses the $R \& D$ process. The purpose of this study is to determine how useful Bridging the Future to Postsecondary Readiness is in building the capacity and confidence of educational leaders to successfully facilitate student transitions from secondary to postsecondary education. My analysis follows Borg and Gall's (1989) steps 
1-7 of the R\&D cycle. This process takes the results of research and builds products to be applied in schools. In my study, this process includes input from educational leaders to help improve the PRG.

Steps 1-7 were used to help me create, test, refine and revise my guidebook. The purpose of the R\&D model is to generate original contributions to knowledge, improve educational practice, and contribute new knowledge through research while raising new theoretical and empirical questions (Borg \& Gall, 1989). R\&D helped me to bridge the gap between research and practice. It took the results of my research and built a product (PRG) to be applied in schools by educational leaders. By going through the PBL and $\mathrm{R} \& \mathrm{D}$ process, I can provide a tested product that is used in schools to address the problem that many high school graduates are not ready for postsecondary education.

\section{Research Questions}

I used the following research questions to guide me through steps 1-7 in order to create and develop the PRG.

1. In what ways can schools better prepare students for postsecondary success?

2. In what ways is the PRG useful in helping educational leaders prepare students for postsecondary success?

3. What improvements and changes to the PRG are needed to help educational leaders?

4. What is the perceived impression of the guidebook's usability, applicability, and accessibility?

5. In what ways is the workshop useful in helping educational leaders navigate through the PRG? 
Participants in the study described useful as it relates to the PRG in different ways. This was based on their job as educational leaders, and how they interacted with the PRG. The ways the PRG was useful was analyzed and will be described later in this chapter and the next. Improvements and changes directly related to way participants saw the PRG as useful. Improvements and changes were implemented to make the PRG more useful for educational leaders. For the purposes of this study and the guidebook: usability relates to the quality, relevance, and appropriateness of the guidebook; applicability relates to the application of the contents, and the introduction of the guidebook; and accessibility relates to the method, form and structure of the guidebook.

\section{Step 1: Research and Information Collecting}

This step began informally when I began a career in education more than 18 years ago. However, I began focusing on the topic of postsecondary preparedness when I entered the doctoral program and became interested in accruing more knowledge on the subject through research. In the winter of 2012, I dove deep into the research to collect information through literature, school visits, and discussions with students, staff and other educational leaders and came up with an approach or template that would eventually become my product.

\section{Step 2: Planning Objectives, Learning Activities, and Small-Scale Testing}

This is where I developed a formal research proposal of my study. Bridges and Hallinger (1995) described how in this step the researcher must not only identify the product and plan for development, but for the assessment of this product. The target 
audience was identified as well as sites in which the product was tested. The search for resources related to the problem along with people knowledgeable of the problem continued in this step (Bridges \& Hallinger, 1995). I used this knowledge of the PBL research design along with the $\mathrm{R} \& \mathrm{D}$ cycle and formed a design team. This team consisted of a: K-12 administrator, a high school teacher, and a member of my school support team. This team would help answer questions I had on the problem I was focusing on: many students graduating from high school are not ready for a postsecondary education, and help me generate ideas about a solution to help address the aforementioned problem. Once a solution was generated, the design team helped in the planning objectives and development of a tool/template.

After working with the design team, I participated in a district achievement compact advisory committee. The observations from participating in this committee captured a district's approach toward goal alignment to support each student graduating ready for college, career and citizenship. I used my conceptual framework around this comprehensive approach derived from my research of current literature to guide my observation field notes. Out of this committee I was able to see how our district schools implement promising practices aimed at preparing students for college and careers. These observations helped me to focus and develop interview questions and assessments tied to sections within the PRG.

I then took part in trainings led by members of EPIC that focused on elements from the postsecondary readiness framework mentioned in chapter 2. EPIC is an 
organization based on the research, and knowledge of David Conley, who has a vast array of experience with postsecondary preparedness. These trainings helped me to develop the Academic Elements section of the PRG. More specifically, it also helped to further develop my initial research questions used to guide me through my research of the current literature tied to the topic of postsecondary preparedness.

Next, I was able to use the questions I developed through conversations with educational leaders and in trainings to interview secondary teachers to get their input and perspectives toward preparing students for postsecondary options. As stated above, these questions (Table 16) were my initial research questions used to guide my literature review.

Table 16

\section{Initial Research Questions}

Initial Questions Linked to the Postsecondary Readiness Guidebook (PRG) Framework

1. What can be done to our educational structure so that it successfully prepares students for a postsecondary education?

2. What standards exist to help states, districts, schools and educators prepare students for a postsecondary education?

3. What do programs/schools currently do to help students make a successful transition from high school to postsecondary education?

Next, I took the input from the initial research questions and began to draft interview questions and assessments to be used to help measure the usefulness of the PRG. My goal in this step was to gather the necessary information from the comments, and discussions/conversations/interviews, and field notes with the aforementioned 
educational leaders to develop a guidebook out of the template/tool. I also wanted to ensure that I had the necessary qualitative methods such as interview protocols and questionnaires to use in the preliminary and main field tests to further develop the guidebook.

Lastly, I was able to visit schools from states in the Southern and Western United States that had programs aimed at preparing students for college and careers. In these visits I presented them with the template/tool prior to my visit, and during my visit, I asked the questions (Table 17) that were developed earlier in this step and were generated out of my initial research questions. Their feedback to these questions was brought back to the design team. This process helped me develop the preliminary form of the guidebook. These visits with school leaders also convinced me to present this tool/guidebook in a workshop so that educators can maximize its usefulness.

Step 2 allowed me to small-scale test the idea of a comprehensive approach to postsecondary readiness. By doing this with a variety of educational leaders and in a variety of educational settings, I was able to see how educational leaders were addressing my research problem through my initial and preliminary research questions. This helped me to refine my research questions and create interview questions in order to improve the template created in step 1. It also led me to develop the preliminary form of the guidebook to be field-tested. 


\section{Table 17}

Preliminary and Guiding Research Questions

\begin{tabular}{|l|}
\hline \multicolumn{1}{|c|}{ Preliminary Research Questions } \\
\hline 1. How can educational leaders better prepare high school students for postsecondary \\
success? \\
2. Is the Postsecondary Readiness Guidebook effective in helping educational leaders prepare \\
students for postsecondary success? \\
\hline Guiding Questions \\
1. What can be done to our educational structure so that it successfully prepares students for a \\
postsecondary education? \\
2. What standards exist to help states, districts, schools and educators prepare students for a \\
postsecondary education? \\
3. What do programs/schools currently do to help students make a successful transition from \\
high school to postsecondary education?
\end{tabular}

\section{Step 3: Develop Preliminary Form of the Product}

After generating ideas, questions, and a direction for a solution to my research problem with a design team in step 2, I was able to develop a preliminary form of the guidebook. The information gathered from step 2, not only helped in the development of the guidebook, but it also gave me insight as to how I would measure its ability to provide a solution to my research problem. I looked at my research questions and began to develop an approach to the preliminary field test. The interview questions (Table 18) that were created out of my small-scale testing would be used in the preliminary field test to improve on the preliminary form of the guidebook. 
Table 18

Interview Questions Generated in Step 2 and Used in Step 3 of the R\&D Cycle

Interview Questions

1. How can educational leaders better prepare high school students for postsecondary success?

2. Is the Postsecondary Readiness Guidebook effective in helping educational leaders prepare students for postsecondary success?

3. Is the Postsecondary Readiness Workshop effective in helping educational leaders navigate through the Postsecondary Readiness Guidebook?

4. In what ways is the guidebook/workshop helpful?

5. What are some things that should be changed about the guidebook/workshop?

6. In what ways can the guidebook help educational leaders prepare students for a postsecondary education?

7. Are the approaches in the guidebook helpful for educational leaders to prepare students for a postsecondary education?

8. In what ways does the guidebook bring awareness to postsecondary awareness in secondary schools?

From the feedback in step 2, I also put together a presentation (Figure 5) on how to use the guidebook to help educational leaders maximize its usefulness. This would also be used in the preliminary field test to enhance the guidebook. The workshop (Appendix A) from this step consisted of data collection on postsecondary readiness knowledge and the usefulness of the workshop, navigation through the components of the guidebook, and dissemination of a comprehensive approach to postsecondary readiness. The agenda of the workshop had participants take a pre-assessment on postsecondary readiness knowledge, participate in a session on the problem, components, and activities of the 
guidebook. Next, there was a question and answer period for clarification, and finally, participants took an evaluation survey of the workshop.

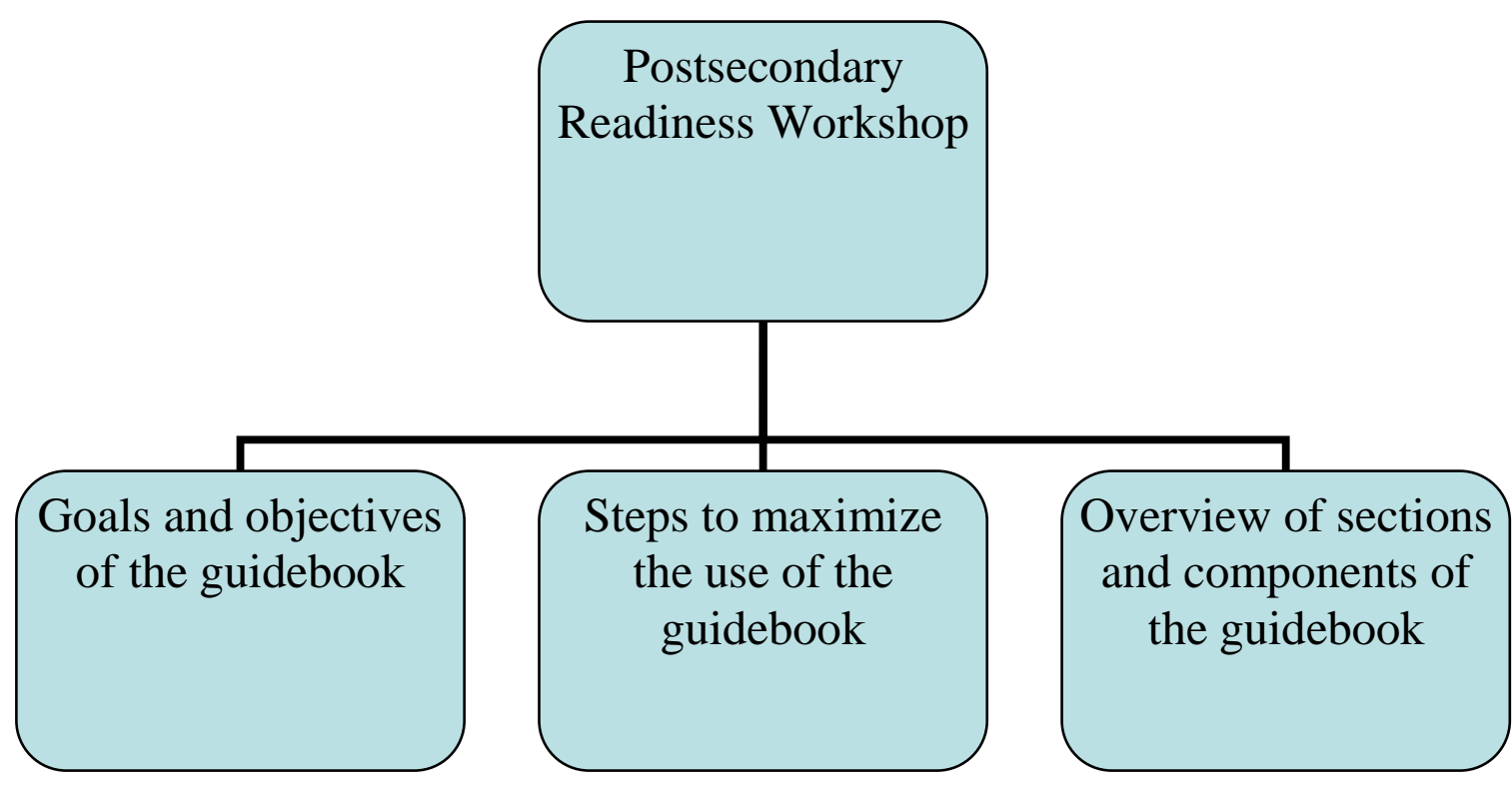

Figure 5. Workshop on postsecondary readiness. This figure shows the principal design and direction of my workshop to help educational leaders maximize the usefulness of the PRG.

\section{Step 4: Preliminary Field Testing}

During step 4, I gathered information that gave me insight on my approach to improve the preliminary form of my guidebook. I used the interview questions (Table 18) to guide the direction of my research. "The purpose of the preliminary field test is to obtain an initial qualitative evaluation of the new educational product" (Borg \& Gall, 1989). I focused my attention on revising current protocols and creating new, more specific protocols that collected data based on the workshop, usefulness of the guidebook, its content, and its resources. Bridges and Hallinger (1995) noted that formative 
evaluative feedback needs to be specific to avoid an overestimation of the effectiveness of the product. The feedback showed me where there were gaps not only in my approach to the research, but in the guidebook itself. This step was very important in my development as a researcher.

The information gathered in this step gave me insight and direction on how to refine my research. I revised and added to my interview questions (Table 18) and questionnaires to give me a better idea of how my guidebook addressed my research problem. For example, I changed the structure of my interview questions from a yes or no to an open ended approach to collect more information. I also changed specific words in the interview questions to collect better feedback from participants. The example below reflects the change in one of my interview question:

- Is the Postsecondary Readiness Guidebook effective in helping educational leaders prepare students for postsecondary success?

- In what ways is the Postsecondary Readiness Guidebook useful in helping educational leaders prepare students for postsecondary success?

I also expanded my data collection methods to include a pre-assessment (PrA) and postassessment (PoA) of the participants' understanding of postsecondary readiness and its components. This gave me a better understanding of how the guidebook impacted the participants' knowledge of postsecondary readiness through the research process.

The participants in the preliminary field test were educational leaders who showed interest in the topic of postsecondary readiness. This was important because as Bridges and Hallinger (1995) pointed out: "prior to any full administration of the product, the developer should schedule a 'dry run' with a group of 'students' that is representative 
of the target audience" (p. 121). This step gave me the confidence as a researcher to move forward, improve the guidebook, and conduct a main field test for educational leaders.

\section{Step 5: Main Product Revision}

After collecting information from the preliminary field test, I continued to work with the design team to improve my protocols and refine my research approach for the main field test. The feedback I received about the research process is addressed above, and the feedback on the guidebook itself was critical in refining the guidebook to be tested in the field. I revised the PRG by adding targets, recommendations, reflections, and an action plan guide to each section of the guidebook. I also added an assessment that would measure the usability, applicability, and accessibility of the guidebook. After the completion of this step, I felt confident in the product and eager to use it in the main field-test.

\section{Step 6: Main Field Testing}

In the work with my design team, I was able to revise and refine the research questions that guided my work with the field test. These research questions are listed below:

1. In what ways can schools better prepare students for postsecondary success?

2. In what ways is the PRG useful in helping educational leaders prepare students for postsecondary success?

3. What improvements and changes to the Workshop/PRG are needed to help educational leaders?

4. What is the perceived impression of the guidebook's usability, applicability, and accessibility? 
5. In what ways is the workshop useful in helping educational leaders navigate through the PRG?

Throughout the first five steps of the R\&D cycle, the aforementioned questions have been created, refined, and revised many times with the help of participants in my research study. All of the research questions were answered with data collected through interviews, observations, and in a workshop conducted in this step of the R\&D cycle.

\section{Research Goals}

This research study examines a comprehensive approach to postsecondary readiness which consists of best practices and methods secondary schools can use to prepare students for postsecondary success. It includes theoretical and practical approaches for educational leaders to accomplish this goal. The goal of this study is to look at the problem that many high school graduates are not ready for postsecondary education, and address it with a field-tested guidebook for educational leaders. The guidebook provides these leaders with essential knowledge, tools and a comprehensive approach to prepare all students for postsecondary success. A second goal of this study provided educational leaders workshops which helped these leaders better understand a comprehensive approach to postsecondary readiness and how it can impact their leadership, school and students. Both of these goals were accomplished. By going through the PBL and R\&D process, I generated a tested product that should be used to address postsecondary readiness. 


\section{Development and Implementation: Field Testing the PBL Project}

Implementing a PBL project links knowing and doing. In this study, I learned new knowledge through PBL because: (a) I had prior knowledge as an educational leader that was activated and incorporated with new knowledge through my research, (b) I had various opportunities to apply this knowledge through steps 1-7 of the R\&D cycle, and (c) I analyzed the new knowledge in an educational setting suitable to my research topic (Bridges \& Hallinger, 1995). Bridging the Future to Postsecondary Readiness is the guidebook I developed because many students graduating from high schools are not ready for a postsecondary education. This guidebook serves the purpose of addressing this need.

PBL is teamed with the R\&D process to validate educational products (Borg \& Gall, 1989). This is an appropriate research design to use with my study because of its potential impact on secondary schools. By following the 10 steps of the R\&D cycle, I am confident in the product I developed for educational leaders. In step 1 I researched and collected information on postsecondary readiness; During step 2 I planned objectives, learning activities, and small-scaled tested my ideas; step 3 I developed a preliminary form of the product; step 4 I was able to preliminary field test my product; step 5 allowed me to revise my product; step 6 I conducted a main field test; and step 7 was the operational product revision (Borg \& Gall, 1989). Through the PBL research design, I went through steps 1-7 for my research study. Bridges and Hallinger do not "demand that students carry out steps 8 and 9 of the R\&D process," and step 10 is implemented at the 
student's discretion (Bridges \& Hallinger, 1995, p. 123). I address these last three steps in chapter 5.

The seven steps of the R\&D cycle were implemented so that the product is ready to help educational leaders in the field. Steps in the R\&D cycle are listed below:

1. Research and information collecting

2. Planning objectives, learning activities, and small-scale testing

3. Develop preliminary form of the product

4. Preliminary field testing

5. Main product revision

6. Main field testing

7. Operational product revision

This section describes the small scale and field testing for the development and implementation of the guidebook: Bridging the Future to Postsecondary Readiness through the PBL research design. I provide detailed information on my experience in steps 2,4 , and 6 , and touch on how the product was developed and revised through the R\&D cycle.

\section{Step 2: Planning Objectives, Learning Activities, and Small-Scale Testing}

In step 1 I was able to conceptualize a framework around postsecondary readiness through my research and information collecting. This gave me a comprehensive approach to prepare students for postsecondary success. With this approach, I was able to propose a solution to my research problem that many students graduating from high schools are not ready for a postsecondary education. By using the postsecondary readiness framework 
from step 1, I developed a template of the guidebook for educational leaders. In my experience as an educational leader, I have witnessed this problem firsthand. I also have experience in addressing the problem in the school of which I am a principal. It is through this experience and research that I created the guidebook, Bridging the Future to Postsecondary Readiness. In step 2, I formed a design team to help guide me through the development of the guidebook. I also conducted small-scale testing of the template through field notes from trainings and through interviews with educational leaders. The purpose of this feedback was to gain insight from educational leaders who also have experience with my research topic. This was important because I wanted to include their ideas and strategies into the development of my guidebook. I discuss the findings from the small-scale testing at the end of this section. For the purposes of this study, educational leaders are defined as educational policy advisors, teachers, parents, community members, state, district, and building educational administrators focused on improving current educational systems and practices.

The design team consisted of a: K-12 administrator, high school teacher, and a member of my school support team. The data collected from the design team was though field notes and interviews. The field notes helped me record important ideas, insights and thoughts from my interaction with the participants. The interviews were informal conversational. I chose this type of interview because the participants were open to speak and share ideas. Informal conversational interviews are spontaneous and loosely structured and do not require an interview protocol (Johnson \& Christensen, 2007). 
Because of this, my field notes played an important role in my research. On my design team, the K-12 administrator is in charge of a suburban school with approximately 500 students. The high school teacher works in a suburban high school to college transition public charter school of 300 students. He teaches in the areas of language arts and math. The school support team member of my design team is a project coordinator in the same public charter school. I chose these three people because of their different job descriptions and their involvement with my research problem. My overall findings on the design team is addressed at the end of this section (see Table 19).

Table 19

Small-Scale Testing: Design Team Demographic Information

\begin{tabular}{|l|l|l|l|}
\hline Participant & \multicolumn{1}{|c|}{ Ethnicity } & \multicolumn{1}{c|}{ Role } & \multicolumn{1}{c|}{ Meeting Dates } \\
\hline Bill & Caucasian & K-12 Principal & $\begin{array}{l}\text { March 6, 2012, May 8, 2012, August 7, } \\
\text { 2012, October 17, 2014 }\end{array}$ \\
\hline Gary & Caucasian & $\begin{array}{l}\text { High school teacher of } \\
\text { Language Arts and Math }\end{array}$ & Monthly during 2012-2013 school year \\
\hline Mary & Caucasian & Project Coordinator & Monthly during 2012-2013 school year \\
\hline
\end{tabular}

Note. Pseudonyms were used to protect participants' identities.

I participated in district meetings which focused on increasing rates of graduates entering college. These meetings were called district achievement compact advisory meetings and consisted of educational leaders from within our district. I gathered information through observational field notes. I also participated in trainings and conferences that focused on postsecondary readiness. The trainings were led by members of EPIC, and centered on building key cognitive strategies in secondary students. The 
information gathered through my participation in these trainings was in the form of observational field notes. My overall findings on the professional development, meetings and trainings are addressed at the end of this section (see Table 20).

Table 20

Small-Scale Testing: Professional Development-Meetings, and Trainings

\begin{tabular}{|l|l|l|l|}
\hline \multicolumn{1}{|c|}{$\begin{array}{c}\text { Professional } \\
\text { Development }\end{array}$} & \multicolumn{1}{c|}{ Focus } & \multicolumn{1}{c|}{ Organization } & \multicolumn{1}{c|}{ Dates } \\
\hline $\begin{array}{l}\text { District Achievement } \\
\text { Compact Advisory } \\
\text { Committee }\end{array}$ & $\begin{array}{l}\text { Increasing rates for } \\
\text { graduates entering college } \\
\text { and earning college credit }\end{array}$ & $\begin{array}{l}\text { Harborview School } \\
\text { District }\end{array}$ & $\begin{array}{l}1^{\text {st }} \text { Thursday during the } \\
2012-2013 \text { school year }\end{array}$ \\
\hline $\begin{array}{l}\text { College Readiness } \\
\text { Training }\end{array}$ & $\begin{array}{l}\text { Building Key Cognitive } \\
\text { Skills }\end{array}$ & EPIC & $\begin{array}{l}\text { August 15, 2012, } \\
\text { December 4, 2013 }\end{array}$ \\
\hline
\end{tabular}

Lastly, I met with principals, directors, and staff members of schools who focus on college and career readiness. These educational leaders were from public schools all over the nation. With these educational leaders, I gathered data through one-on-one interviews. I used the interview guide approach where I explored specific topics through open-ended questions. These topics and questions are provided on an interview protocol written by the researcher before the interview sessions (Johnson \& Christensen, 2007). I interviewed three principals, one teacher, one counselor, and one program director. One principal was from an elementary public charter school serving low income students in the Western United States. Highline Prep (pseudonym) serves students in grades K-5 and has 638 students. The school has $84 \%$ of students receiving free and reduced price meals, and $71 \%$ of students are English Language Learners. The one teacher I interviewed was a 
$7^{\text {th }}$ grade language arts teacher from a public charter middle school in the Western United States as well. Starwood Academy Prep (pseudonym) is a free, open-enrollment, collegepreparatory public charter middle school outside of a metropolitan city in the Western United States. It serves students in grades 5-8 with 403 students. The school has $83 \%$ of students receiving free and reduced price meals, $21 \%$ of students are English Language Learners, and 5\% are students with special needs. Another educational leader I interviewed was a counselor at a public charter high school with students from diverse populations with a strong focus on postsecondary readiness. Riverdale Early College (pseudonym) serves students in grades 9-12 with 271 students. The school has $44 \%$ of students receiving free and reduced price meals, $13 \%$ of students are English Language Learners, and 2\% are students with special needs. In the Southern United States I interviewed a program director in a public charter high school within a metropolitan city. Green Valley College Prep (pseudonym) serves low-income students from underserved areas and its focus is university and college preparatory. It serves students in grades 9-12 with 339 students. The school has $77 \%$ of students receiving free and reduced price meals, 20\% of students are English Language Learners, and 11\% are students with special needs. The next principal I interviewed was from an early college high school program in the Southern United States. El Rey Early College (pseudonym) is a small schools designed so that students can earn both a high school diploma and an associate degree or up to two years of credit toward a bachelor's degree. The school has $81 \%$ of students receiving free and reduced price meals, $3.7 \%$ of students are English Language 
Learners, and $1 \%$ are students with special needs. The last educational leader I interviewed during the small-scale testing was a principal of a large comprehensive high school with an early college embedded into the school. West County High School (pseudonym) enrolls 2,700 students in a rural area outside of a metropolitan city in the Southern United States. West County High School is the educational, social, and economic center for a community of diverse ethnic and socioeconomic backgrounds. It is the only high school in a district that spans 260 square miles. It is focused on the needs of students from urban areas as well as those from rural areas. The school has $43 \%$ of students receiving free and reduced price meals, $2.4 \%$ of students are English Language Learners, and $8.4 \%$ are students with special needs. My overall findings on the site visits and interviews with educational leaders are addressed at the end of this section (see Table 21).

The first of my interviews was with my design team. This was done for planning purposes and helped me with my approach with professional development around my topic and with the interviews with educational leaders from around the country. When I interviewed Bill, he helped me focus on the themes pertinent to educational leadership. For example, what is the role of the principal in leading an effort toward improving instructional practices? This was important because of his experience as the leader of a K-12 school. These interviews were approximately one hour in length and occurred over a time period of 2 years. The second interview with a member of my design team was with Mary, a project coordinator at a public charter school. She helped me organize my 
Table 21

Small-Scale Testing: Educational Leader Interview Demographics

\begin{tabular}{|c|c|c|c|c|c|}
\hline Participant & Role & Ethnicity & School & Location & Demographics \\
\hline Sue & Principal & Caucasian & $\begin{array}{l}\text { Highline Prep } \\
\text { Elementary }\end{array}$ & $\begin{array}{l}\text { Western } \\
\text { United States }\end{array}$ & $\begin{array}{l}\text { 81\%-Latino } \\
\text { 9\%-Asian Am. } \\
\text { 5\%-Caucasian } \\
\text { 3\%-African Am. }\end{array}$ \\
\hline Isabel & $\begin{array}{l}7^{\text {th }} \text { Grade } \\
\text { Language Arts }\end{array}$ & Latina & $\begin{array}{l}\text { Starwood } \\
\text { Academy Prep } \\
\text { Middle School }\end{array}$ & $\begin{array}{l}\text { Western } \\
\text { United States }\end{array}$ & $\begin{array}{l}\text { 81\%-Latino } \\
\text { 16\%-Asian Am. } \\
2 \% \text {-Other } \\
1 \% \text {-African Am. }\end{array}$ \\
\hline Jose & Counselor & Latino & $\begin{array}{l}\text { Riverdale Early } \\
\text { College High } \\
\text { School }\end{array}$ & $\begin{array}{l}\text { Western } \\
\text { United States }\end{array}$ & $\begin{array}{l}\text { 56\%-Latino } \\
\text { 18\%-Caucasian } \\
\text { 13\%-Asian } \\
\text { 4\%-African Am. } \\
\text { 4\%-Filipino } \\
\text { 3\%-Two or More }\end{array}$ \\
\hline Marcy & $\begin{array}{l}\text { Program } \\
\text { Director }\end{array}$ & $\begin{array}{l}\text { African } \\
\text { American }\end{array}$ & $\begin{array}{l}\text { Green Valley } \\
\text { College Prep } \\
\text { High School }\end{array}$ & $\begin{array}{l}\text { Southern } \\
\text { United States }\end{array}$ & $\begin{array}{l}\text { 91\%-Latino } \\
\text { 5\%-African Am. } \\
\text { 3\%-Caucasian } \\
\text { 1\%-Other }\end{array}$ \\
\hline Rodrigo & Principal & Latino & $\begin{array}{l}\text { El Rey Early } \\
\text { College High } \\
\text { School }\end{array}$ & $\begin{array}{l}\text { Southern } \\
\text { United States }\end{array}$ & $\begin{array}{l}95 \% \text {-Latino } \\
2 \% \text {-Caucasian } \\
1.7 \% \text {-African Am. } \\
1 \% \text {-Asian }\end{array}$ \\
\hline Juan & Principal & Latino & $\begin{array}{l}\text { West County } \\
\text { High School }\end{array}$ & $\begin{array}{l}\text { Southern } \\
\text { United States }\end{array}$ & $\begin{array}{l}\text { 64\%-Latino } \\
\text { 24\%-Caucasian } \\
\text { 9\%-African Am. } \\
\text { 1\%-Asian } \\
\text { 1\%-Pacific Islander } \\
\text { 1\%-Two or More }\end{array}$ \\
\hline
\end{tabular}

Note. Pseudonyms were used to protect participants' identities. 
approach around the research I collected from my review of the literature on postsecondary readiness. This would be critical to frame all of my interviews to follow. These interviews were approximately one hour in length, and they occurred monthly over a period of 2 years. The last member of my design team I interviewed was Gary, a classroom teacher. He was able to give me perspective on my approach that centered around a teacher's perspective on my topic. Again, these interviews were approximately one hour in length, and they occurred monthly over a period of 2 years.

The trainings and professional development I attended gave me insight and helped me focus on different aspects of preparing students for postsecondary success. The first professional development session I participated in was with our district's achievement compact advisory committee centering on district and state alignment of postsecondary readiness goals. These meetings were held once a month throughout the 2012-2013 school year and served the purpose of providing the state with information on how our district will improve in many categories, including but not limited to: reading, attendance, and students earning college credit. In these meetings I took field notes on how educational leaders from schools within our district were preparing students to earn college credit. These meetings were 2 hours in length for each session. During the months of August and December, I participated in trainings around building key cognitive skills. These trainings were conducted by EPIC and based on the research, knowledge and experience of David Conley, a professor at the University of Oregon, who is the foremost expert on postsecondary readiness. These were two 4-hour sessions on the indicators, 
rubrics, and stages of cognitive skills. I took notes during each session, and it helped me gain insight on building cognitive skills.

My next set of interviews was with educational leaders from around the nation. All of these visits and interviews were done while school was in session. My first visit was to three schools in September of 2012 that were in close proximity of each other in the Western United States. I first visited Sue, an elementary principal of Highline Prep Elementary. Her school focuses on getting its students the skills necessary to enter college. I was able to tour her school and interview her about her school's approach to postsecondary readiness. I spent 2 hours with her during this process. The tour and questions about the school took one hour, and the interview after the tour took one hour as well. Later the same day, I visited Isabel, a seventh grade teacher at Starwood Academy Prep Middle School. This gave me the opportunity to see how a middle school teacher prepared her students for postsecondary success. I spent 2 hours with Starwood Academy Prep. As before with Highline, tour and questions about the school took one hour, and the interview after the tour took 1 hour. The next day, I went to Riverdale Early College High School in the same area as the two aforementioned schools. While there I toured the school and interviewed their counselor, Jose for 2 hours. This school was located on the campus of a community college.

The last set of interviews occurred in another part of the country. I visited and interviewed three schools in February 2013 that were in close proximity of each other. The first interview in this set of interviews was at Green Valley College Prep in the 
Southern United States. I toured the campus and interviewed Marcy who was the program director for the college prep high school. The tour and interview took about an hour and a half. The next interview was the same day with Juan, the principal of West County High School. The tour and interview took about two and one half hours. The next day, I concluded with the last tour and interview of Rodrigo, the principal of El Rey Early College High School. El Rey is located across the street from a local community college. He briefly showed me around and I interviewed him in approximately an hour.

For the interviews, I collected data following the basic procedures identified by Creswell (2007) and created a protocol (Appendix C). Prior to visiting the educational leaders, I sent down the protocol so that the participants could be aware of the themes when I arrived. For the participating individuals, I thanked them for their time and assured them of confidentiality of responses and potential future interviews. I also reminded them that the information will be used in the creation and revisions of a guidebook to help educational leaders better prepare students for postsecondary success.

During the interviews, I collected data through voice memos. I then transcribed the data, verbatim, from the voice memos to begin coding. I used inductive coding by examining the data. This provided good, clear, descriptive words to characterize segments of my data. An example of this was when a participant in an interview used the terms quality instruction, curriculum design, and clear communication. I coded this as "educational best practices." I then used facesheet coding to establish the demographic variables such as the participants gender, race, or role (see Tables 19-21). I also 
enumerated the data from the interviews to identify amount or frequency. Lastly, to make sense of the data from my interviews and professional development, I used the hierarchical categorization of typology. An example of this is when a participant used the terms college readiness and cognitive skills. This was broken down into a onedimensional typology listed in Table 22.

Table 22

Small-Scale Testing: College Readiness Skills-Key Cognitive Skills

I. College Readiness Skills

a. Key cognitive strategies

i. Problem formulation

ii. Research

iii. Interpretation

iv. Communication

v. Precision and accuracy.

During the observations for each professional development opportunity, I followed Creswell's (2007) observational protocol which follows the steps below:

- Select a site to be observed

- At the site, identify who or what to observe, when, and for how long.

- Determine, initially, a role to be assumed as an observer.

- Design an observational protocol to record notes

- Record the surroundings 
- Have someone introduce you if you are an outsider

- After observing, withdraw from the site

My role in this step of the $R \& D$ process is that of the observer-as-participant. I was in this role because I had a limited time and brief interactions with the participants (Johnson \& Christensen, 2007). As mentioned above, I followed Creswell's (2007) observation protocol (Appendix D) to record my field notes. These field notes capture a single event and interactions relating to my research topic. My field notes in this study relate to events and interactions connected to the postsecondary readiness framework created in step 1 of Borg and Gall's R\&D cycle (Borg \& Gall, 1989). For example, in this step, I focused on the structural, academic and social elements that would be the foundation of my guidebook. My field notes were open-ended, and by using an observation protocol, I was able to record both descriptive and reflective data. I liked this method because I was able to capture data in a chronological fashion. The reflective data allowed me to capture data about the process, reflections on activities, and summary conclusions about activities for later theme development (Creswell, 2007). The downside to this type of data collection is that it is still subject to the biases of the writer. The observational field notes used in this section followed a two column format with a line down the center of the page dividing the descriptive notes from the reflective notes. A visual sketch of the setting and a label for it provided additional useful information.

As I collected and began to analyze the data from the interviews, I used inductive coding and broke the interviews down into themes using clear descriptive words to 
characterize the segments of my data (Table 23). I did this to reveal important and common themes to focus on in my analysis.

Table 23

Small-Scale Testing: Key Themes from Nine Coded Interviews

\begin{tabular}{|l|c|}
\hline \multicolumn{1}{|c|}{ Themes } & Number of Pieces of Information Coded \\
\hline Mission & 84 \\
\hline Leadership & 75 \\
\hline Culture & 106 \\
\hline Communication & 146 \\
\hline Data & 105 \\
\hline Best Practices & 75 \\
\hline Quality Instructional Strategies & 60 \\
\hline Curriculum Design & 54 \\
\hline Standards & 87 \\
\hline Assessments & 102 \\
\hline Professional Development & 72 \\
\hline Family Involvement & 129 \\
\hline Academic Behaviors & 144 \\
\hline Transition Knowledge & 147 \\
\hline Technology & 84 \\
\hline
\end{tabular}

I enumerated the data to show the frequency, and when possible, I classified the data using a typology. For example, the themes and frequencies (in parentheses) centered on: transition knowledge (147), communication (146), academic behaviors (144), family involvement (129), and culture (106). The participants also showed an interest in a comprehensive approach to preparing students for postsecondary success. They were really interested in a tool that would focus on the structural, academic, and social elements in my initial template of the guidebook. Participants identified transition 
knowledge (147) as a key component in preparing students for postsecondary readiness. The topics that made up the transition knowledge theme that were mentioned by the participants were academic awareness, expectations at the next level of education, alignment of systems, registration and admission process, tuition/fees/financial aid.

The data from the interviews was also broken down using facesheet coding. Facesheet coding establishes the demographic variables such as the participant's gender, race, or role. For the purpose of this study, I used facesheet coded based on the participant's role as an educational leader. The role of teacher represents an educator delivering content and curriculum through instruction. The role of support personnel represents counselors and coordinators. The roles of administrators include principals or directors. The number represents the frequency of responses during the interviews (see Table 24).

The interviews gave me a great opportunity to test the idea of the postsecondary readiness framework that I created in step 2 of the R\&D cycle. Each participant had specific strengths within different components of the framework, and it was great to get their perspective on these strengths. For example, administrators mentioned the theme of mission 62 times. This showed me that mission should be included in the guidebook. However, the teachers only touched on mission nine times and support personnel mentioned it 13 times. Nonetheless, I felt it was an important piece to include in the development of the guidebook. Their feedback definitely helped me take my initial template and create the preliminary form of my guidebook. 
Table 24

Small-Scale Testing: Key Themes Based on Participant's Role as Educational Leader

\begin{tabular}{|l|c|c|c|c|}
\hline \multicolumn{1}{|c|}{ Themes } & $\begin{array}{c}\text { Teacher } \\
(n=2)\end{array}$ & $\begin{array}{c}\text { Support Personnel } \\
(n=2)\end{array}$ & $\begin{array}{c}\text { Administrator } \\
(n=5)\end{array}$ & Total \\
\hline Mission & 9 & 13 & 62 & 84 \\
\hline Leadership & 25 & 29 & 21 & 75 \\
\hline Culture & 29 & 34 & 43 & 106 \\
\hline Communication & 47 & 49 & 50 & 146 \\
\hline Data & 15 & 36 & 51 & 105 \\
\hline Best Practices & 32 & 19 & 24 & 75 \\
\hline Quality Instructional Strategies & 34 & 10 & 16 & 60 \\
\hline Curriculum Design & 24 & 9 & 21 & 54 \\
\hline Standards & 42 & 10 & 35 & 87 \\
\hline Assessments & 24 & 38 & 40 & 102 \\
\hline Professional Development & 36 & 16 & 20 & 72 \\
\hline Family Involvement & 36 & 41 & 52 & 129 \\
\hline Academic Behaviors & 42 & 55 & 47 & 144 \\
\hline Transition Knowledge & 34 & 57 & 56 & 147 \\
\hline Technology & 37 & 26 & 21 & 84 \\
\hline
\end{tabular}

As I transcribed the data from the interviews, I included some of the comments that helped me refine and improve my guidebook. Table 25 shows the feedback the interviewees gave regarding the necessary components and approach to a guidebook. 
Table 25

Small-Scale Testing: Formative Interview Feedback Template Advice/Components

\begin{tabular}{|c|c|}
\hline Participants & Template Advice/Components \\
\hline Bill-DT & $\begin{array}{l}\text { - Make sure to create a pre- and post-survey for your next step to help measure the } \\
\text { effectiveness of the guidebook. } \\
\text { - I would highlight the problem and include this into your guidebook to give the } \\
\text { user context. } \\
\text { - Try to make the guidebook not only a resource for how to approach } \\
\text { postsecondary readiness, but a tool in assessing where the user's school is } \\
\text { regarding this approach. }\end{array}$ \\
\hline Gary-DT & $\begin{array}{l}\text { - If you can, I would try to present the information in a way that represents good } \\
\text { teaching. Make the layout of the book conducive to learning. } \\
\text { - Provide concrete examples of quality instructional practices and successful tools } \\
\text { schools use to prepare students for success. } \\
\text { - Break information up in chunks so that the guidebook is manageable and } \\
\text { efficient. }\end{array}$ \\
\hline Mary-DT & $\begin{array}{l}\text { - Keep your focus on the postsecondary readiness framework to guide your } \\
\text { product. } \\
\text { - Allow users the opportunity to reflect on their practices. } \\
\text { - Include resources for users to get in-depth knowledge on critical components in } \\
\text { your guidebook. }\end{array}$ \\
\hline Sue & $\begin{array}{l}\text { - If this is for educational leaders from all levels, make it applicable to this } \\
\text { audience. }\end{array}$ \\
\hline Isabel & $\begin{array}{l}\text { - I would include activities for users to internalize the knowledge you are } \\
\text { disseminating. } \\
\text { - Include a variety of text, pictures, and activities. }\end{array}$ \\
\hline Jose & $\begin{array}{l}\text { - Your guidebook needs to be very organized to be effective. If you are proposing } \\
\text { a comprehensive approach with many different strategies, then this material must } \\
\text { be reliable and usable for the educator. If you do not do this, it can be a wasted } \\
\text { opportunity. }\end{array}$ \\
\hline Marcy & $\begin{array}{l}\text { - I would create a workshop for users on how to use the guidebook once it is } \\
\text { completed. } \\
\text { - I would also give users an introduction to the strategies with some effective tools, } \\
\text { and allow the educational leaders and schools to chart their own learning and } \\
\text { course based on this. This should guide them and not provide all of the answers. }\end{array}$ \\
\hline Rodrigo & $\begin{array}{l}\text { - Definitely include a PrA and PoA. } \\
\text { - The more sections you have, the less likely educators will want to go through it. } \\
\text { Make it organized. } \\
\text { - To make it worth their time, include activities that connect their practices with } \\
\text { the guidebook. This will add relevance to the process. }\end{array}$ \\
\hline
\end{tabular}


Table 25 (continued)

\begin{tabular}{|l|l|}
\hline Participants & \multicolumn{1}{c|}{ Template Advice/Components } \\
\hline Juan & $\begin{array}{l}\text { - This approach to getting students' college and career ready is an excellent one. } \\
\text { We do great things at WCHS, but having a guidebook to include successful } \\
\text { things other schools are doing would be extremely helpful. } \\
\text { - Create your interview protocols for your interviews to include more specific } \\
\\
\text { questions relating to your guidebook and its effectiveness. I would revise your } \\
\text { research questions to include this. }\end{array}$ \\
\hline
\end{tabular}

Note. DT represents members of the design team

Note. Pseudonyms were used to protect participants' identities.

In dealing with my design team, Bill really liked the approach toward a comprehensive tool for educational leaders. He said this approach can "be a compass that can provide educational leaders with an approach to help all students for college and careers." Mary thought that the framework would be an excellent guide to help with the interviews and observations during the small scale and field testing of the guidebook. "The three components of your template (structural, academic, and social elements) should give you direction and help you create a preliminary form of your guidebook from the data collected." Gary was excited to see this approach contain a solid approach to teaching and learning within the classroom. "I would love to apply your academic elements as a school to provide consistency around curriculum, instruction and assessment."

The six interviews with the different educational leaders from around the nation also gave me formative feedback of my template during the small-scale testing. Sue loved the idea of including all areas of the K-12 system in preparing students for postsecondary success. "All too often we assume this process begins at the high school 
level, and by that time, it is too late for the initial steps of preparation." Isabel gave me great information as to the inclusion of academic behaviors in her classroom and at her school, and was excited to see this included in my framework. "Educators in all levels assume that students come to them with the necessary academic behaviors, and this is not so. We need to teach and build these skills at every grade and every level to give our students the tools necessary to succeed at the next level." Jose gave me a counselor's perspective around educating the whole student and not just through academics. "Our students need to be aware of how our educational system works at every level. They need to connect the dots between the academics they are learning in the classroom with how it fits into the world they will be entering after they leave us." When interviewing Marcy, she expressed the need for community involvement. "There are established members of the community of all races, creeds and colors who have successfully navigated through our educational system. These individuals need to get involved and mentor our future leaders.” Rodrigo expressed the need for choices and options in education. "There needs to be many approaches to help students succeed after high school. However, these approaches must follow the practices from successful schools around the country and world." The last interviewee, Juan, stressed the need for family involvement in education. "Schools can't do this alone. We need to include our families and communities in helping our students prepare for life after high school. This must be the top priority in closing the gap from high school to college." This constructive 
feedback by all of the participants helped me to plan out the preliminary form of my guidebook.

During the small-scale testing, I used my observational field notes as the tool for data collection in the professional development opportunities. To analyze this data I used inductive coding, enumeration and typology. The major themes that came out of my experience with the achievement compact advisory committee involved promising practices that our district schools use to prepare students for college and careers (see Table 26). These themes and frequencies were: communication (42), vertical alignment (34), data (29), educator collaboration (24), and college awareness (23). Collecting this data provided me insight toward a district's approach to college and career preparation. This was very important because this approach and the themes generated were similar and reinforced the comprehensive approach to postsecondary readiness I created from step 1 of the R\&D cycle.

The field notes I collected during the training led by members EPIC focused on one of Conley's (2012a) college readiness standards. This was key cognitive strategies. Key cognitive strategies involve the steps of research: problem formulation, research, interpretation, communication, and checking for precision and accuracy. After collecting this data, I used typology to break down the components of the cognitive strategies to make sense of the process. These data describe the concepts of the training (see Figure $6)$. 
Table 26

Small-Scale Testing: Key Themes From Eight Achievement Compact Advisory Committees

\begin{tabular}{|l|c|}
\hline \multicolumn{1}{|c|}{ Themes } & Number of Pieces of Information Coded \\
\hline Leadership meetings & 12 \\
\hline Vertical alignment & 34 \\
\hline Character education & 15 \\
\hline Curriculum & 16 \\
\hline Instruction & 22 \\
\hline Technology & 17 \\
\hline College awareness & 23 \\
\hline After school programs & 14 \\
\hline Communication & 42 \\
\hline Attendance & 20 \\
\hline Health and wellness & 19 \\
\hline Educator collaboration & 24 \\
\hline Data & 29 \\
\hline Assessments & 15 \\
\hline Summer school & 12 \\
\hline
\end{tabular}




\section{Key Cognitive Strategies}
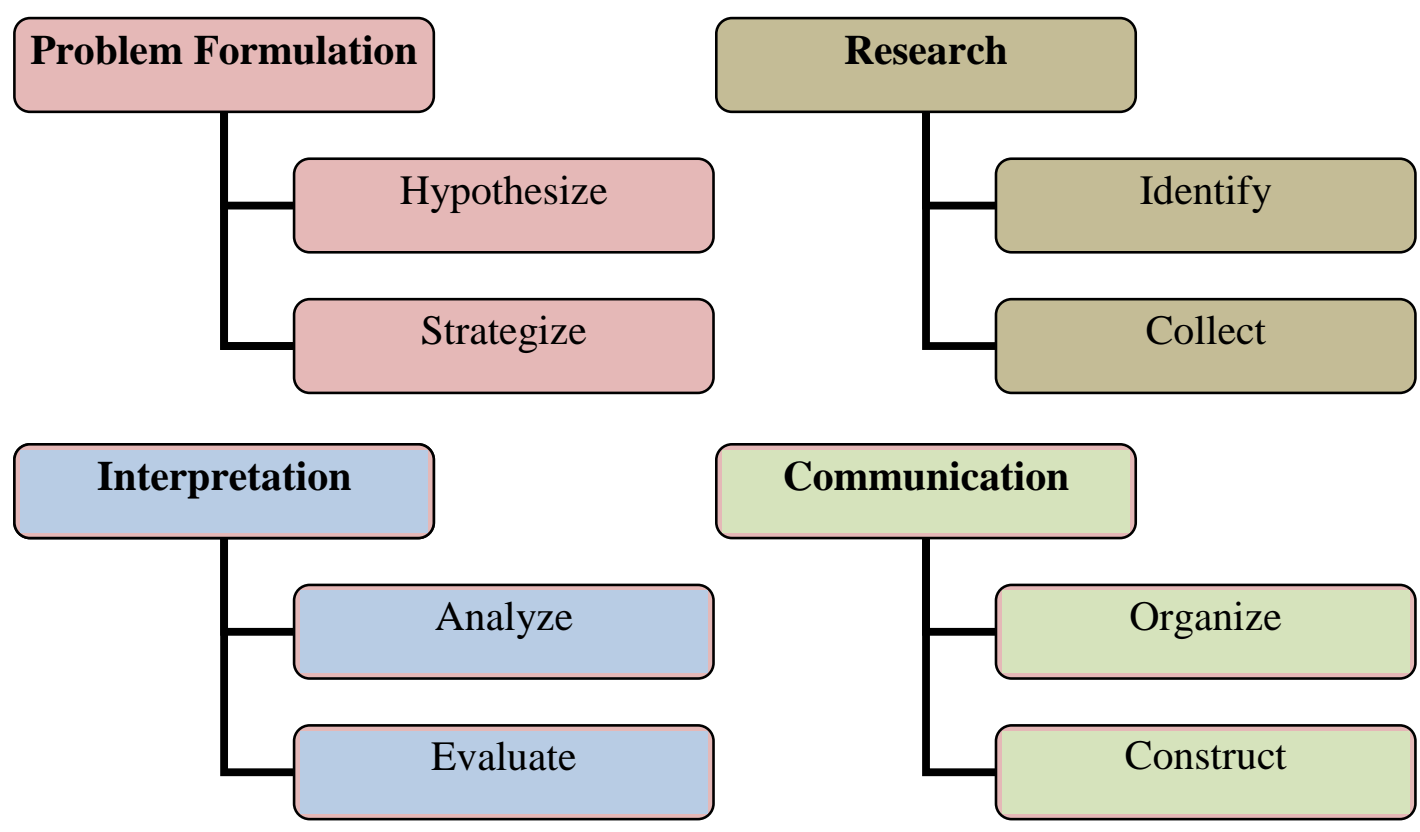

\section{Communication}

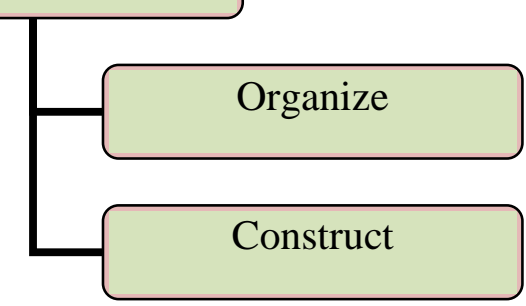

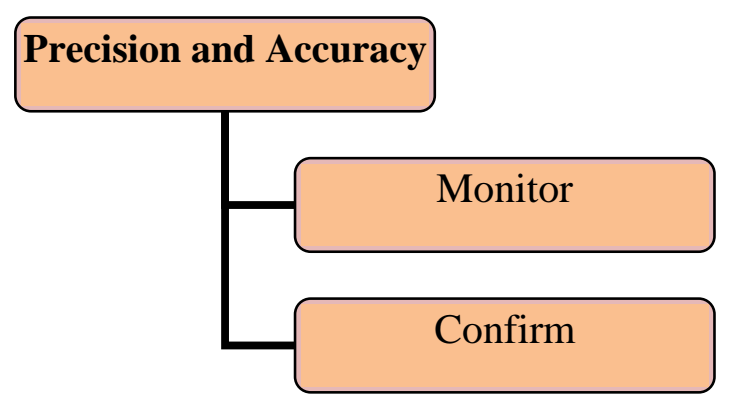

Figure 6. Key cognitive strategies. This figure shows the components to Conley's (2012a) key cognitive strategies.

The design team kept me on track by continually asking the following questions:

(a) Does the proposed product meet an important educational need? (b) Is the educational environment sufficiently advanced that there is a reasonable probability that a successful product can be created? (c) Are personnel available who have the skills, knowledge, and 
experience necessary to build this product? and (d) Can the product be developed within a reasonable period of time? These questions provided me with a compass with which to keep my research project realistic and attainable. I did not meet with them too often due to scheduling and job duties. This proved to be both a positive and negative because as I got deep into information collecting and revising my guidebook, they were able to keep perspective and give me valuable feedback to answer the aforementioned questions. A common question from them was, "Are you sure that participants of the field test have the knowledge to help you build a successful product.” As I went through the R\&D cycle in our meetings, it became clear to them that any educator could provide valuable feedback to create a successful product. A negative to meeting with them on such few occasions was that they did not completely understand the complexity of the process and the guidebook. This limited the depth of their feedback to just the process and not the content. Overall, I believe the design team was a necessity in helping me create and refine my guidebook, but I would try to encourage more meetings to develop their understanding of the complexity of the R\&D process and guidebook.

The professional development, meetings, and trainings gave me perspective of how different educational leaders in our district and professionals approached my research problem. I learned of some great approaches that schools in our district are using to help prepare students for postsecondary readiness such as: implementing the CCSS in elementary and middle school; creating peer mentorship for sixth graders and ninth graders to help with the transition from one level to the next; and opening up summer 
school opportunities for freshman that have fallen behind in credits. I also witnessed some schools that are not addressing many important factors such as creating a mission and vision around shared values and beliefs, and implementing consistent instructional practices school-wide. The trainings gave me a better understanding of the key cognitive strategies and how to implement them in schools, but the training fell short with teachers. This was due to the fact that the trainers were professionals of the research and not practitioners of the content with students. This left a disconnect between the trainers and the participants. Overall, participating in professional development, meetings, and trainings helped with the understanding of some of the content and practices in my guidebook, but fell short of how to effectively implement this content and these practices within the school setting. It did not help too much with the development of my guidebook.

By far the most impactful aspect of my small-scale testing was the site visits and interviews with educational leaders from around the country. The site visits and interviews gave me the perspective and insight toward improving the template of my guidebook. I was able to see firsthand how some of the best practices were applied at an elementary, middle and high school site. I was also able to get information on how each site implemented some of these best practices as well as the obstacles that popped up along the way. For example, one educational leader discussed how she implemented the $\mathrm{ACT}$ as an indicator for career exploration. She also outlined the steps of what went wrong along the way. I took these ideas and used them to refine my guidebook. Another 
educational leader discussed steps he took to create a college and career going culture. I took these steps and included them into my postsecondary readiness framework. Not only did I get ideas from practitioners, but I was able to share my template with them. Overall, this experience was very helpful in the creation of my preliminary product. I address the components added in the next section.

Step 2, small-scale testing, was a critical step for me in the R\&D process because it allowed me to collect and analyze important information from a variety of educational leaders from all over the country. While not all of the experiences helped in the refinement of my guidebook, it was beneficial nonetheless. Improvements to my guidebook came about through the rich formative feedback shown in the aforementioned tables and figures. After my experience with the small-scale testing, I had the data necessary to move to step 3 of the R\&D cycle.

\section{Step 3: Develop Preliminary Form of the Product}

After completing step 2, I took the template of my guidebook and revised it to include the data collected from my site visits, interviews and trainings. My template consisted of the postsecondary readiness framework generated from the review and research on the literature central to my research topic. This template gave me a great approach to creating a guidebook, but the information from step 2 allowed me to add more components to the template. The guidebook was revised to include: an introduction, a section on the problem, the three sections from the postsecondary readiness framework, and a section of resources. I was also able to add activities and assessments into each 
section to make the guidebook more interactive. The last piece I needed to add to my guidebook with the preliminary form of the product was a workshop on how to use the guidebook. I could not assume that users would be able to go through it without some direction. This was added from the feedback from step 2. By going through the first three steps of the $R \& D$ process, the preliminary form of my guidebook came to life. I was now eager to test and improve it during step 4 with other educational leaders.

\section{Step 4: Preliminary Field Testing}

Now that I had a preliminary form of my guidebook, I was eager to collect data on its usefulness. This usually occurs with a small group of participants that are asked to review the project and provide feedback (Bridges \& Hallinger, 1995). Having gone through step 2 of the $R \& D$ process allowed me to create life to my guidebook by including a workshop, activities, assessments, and resources. I then looked for participants who had experience with my topic, and who were interested in collaborating with me to preliminary test the guidebook. Bridges and Hallinger (1995) noted that the participants of the preliminary field testing provide feedback on the "clarity and unity of the project, as well as the suitability of the resources and the guiding questions. Their comments often lead to another round of revision prior to the main field-test" (p. 48).

My guidebook now included a comprehensive approach to postsecondary readiness, and provided ways for users to interact with it while connecting it to their learning environments. Step 2 of the R\&D process gave me feedback through site visits, 
trainings, and interviews on the importance of the guidebook in helping educational leaders prepare students for postsecondary success.

In this step, in order to maximize the usefulness of the guidebook, the data collected during the small-scale testing required me to implement a workshop, and a PrA and PoA, along with interviews. The workshop (Appendix A) consisted of data collection on postsecondary readiness knowledge and the usefulness of the workshop, navigation through the components of the guidebook, and dissemination of a comprehensive approach to postsecondary readiness. The workshop had participants take a PrA on postsecondary readiness knowledge. I gathered this information in order to assess what knowledge participants held toward a comprehensive approach to postsecondary readiness. The workshop also had participants involved in a session on the problem, components, and activities of the guidebook. Next, there was a question and answer period for clarification, and finally, participants took an evaluation survey of the workshop. After the workshop I conducted interviews with newly refined interview protocols, and I developed the following surveys which were administered through SurveyMonkey:

1. Survey of the workshop-This questionnaire provides information on how useful the workshop was in helping participants navigate through the guidebook (Appendix E). PrA of postsecondary readiness-This questionnaire covers the content and approaches within the guidebook and provides overall information of the participants' knowledge on the elements of the guidebook (Appendix F).

2. PoA of postsecondary readiness-This questionnaire covers the content and approaches within the guidebook and provides information on ways the guidebook was useful (Appendix F). 
The preliminary field test required two meetings with all of the participants. Because of location and scheduling issues, I had to provide three hour long workshops for our first meeting with all participants. In this first meeting, I administered the PrA of postsecondary readiness, gave them electronic and hard copies of the guidebook, presented the workshop, and scheduled the second meeting. For the second meeting, I met with two participants individually for 1 hour each via teleconference. In this meeting, I administered the PoA and conducted a formal interview about the process. For the three other meetings, I conducted three separate 30-minute teleconferences discussing the guidebook and administering the PoA. Because these meetings were shortened, I did not get the opportunity to formally interview these participants.

This section covers the: participants, workshop and workshop evaluation, $\operatorname{PrA}$ and PoA, and interview data. This section also covers ways the guidebook is useful from summative and formative data collected during the preliminary field test. I was pleased to find the participants' comments to be positive and constructive toward improving the guidebook for the main field test.

Participants of preliminary field test. In step 2, I gained insight from educational leaders from elementary, middle and high school. In this step, I wanted to broaden my audience to include educational leaders from the college and state levels. This was important to do because in this study educational leaders are defined as educational policy advisors, teachers, parents, community members, state, district, and 
building educational administrators focused on improving current educational systems and practices.

The participants of the field test were: an education policy advisor, two teachers, and program directors from the $\mathrm{AHCH}$. The educational policy advisor is a lead policy advisor, has decision-making authority and plays an important administrative leadership role. The AHCN builds the capacity of colleges, school districts, and states to revolutionize education for high school dropouts and underprepared college students so that all young people can achieve college credentials.

During the preliminary field test, I collected data at different times due to the conflicting schedules and location of the participants. The first participant I knew throughout my experience in education, and she was very interested in unique and innovative approaches to helping students succeed in college and careers. She serves as an education policy advisor and has been in education for the last 10 years and in her current position for the last 4 years. One teacher of the high school to college transitional program has been in education for the last 10 years and in her current position for the last 3 years. The other teacher in the same program has been in education for 6 years and in her current position for the last 2 years. The program director of AHCN has been in education for more than 10 years and in his current position for the last 8 years. The other director has been in education for the last 7 years and with AHCN for the last 3 years (see Table 27). 
Table 27

Preliminary Field Test: Demographics

\begin{tabular}{|c|c|c|c|c|c|}
\hline \multicolumn{6}{|c|}{ Preliminary Field Test Demographics } \\
\hline & Susie & Erin & Sam & Tiffany & Linda \\
\hline 1. Ethnicity & Caucasian & Caucasian & Caucasian & Caucasian & $\begin{array}{l}\text { Black } \\
\text { (African } \\
\text { American) }\end{array}$ \\
\hline 2. Gender & Female & Female & Male & Female & Female \\
\hline 3. Role & Teacher & Teacher & $\begin{array}{l}\text { Program } \\
\text { Director }\end{array}$ & Policy Maker & $\begin{array}{l}\text { Program } \\
\text { Director }\end{array}$ \\
\hline $\begin{array}{l}\text { 4. I have been in } \\
\text { education for: }\end{array}$ & 4-6 years & $7-10$ years & $\begin{array}{l}11 \text { or more } \\
\text { years }\end{array}$ & $7-10$ years & $7-10$ years \\
\hline $\begin{array}{l}\text { 5. I have been in } \\
\text { my current } \\
\text { position for: }\end{array}$ & $1-3$ years & $1-3$ years & $7-10$ years & $4-6$ years & $1-3$ years \\
\hline $\begin{array}{l}\text { 6. Describe your } \\
\text { school's location: }\end{array}$ & Suburban & Suburban & Urban & N/A & Urban \\
\hline $\begin{array}{l}\text { 7. What is the total } \\
\text { racial/ethnic } \\
\text { minority } \\
\text { percentages? }\end{array}$ & $\begin{array}{l}\text { Over } 10 \% \text { but } \\
\text { less than } 50 \%\end{array}$ & $\begin{array}{l}\text { Over } 10 \% \\
\text { but less than } \\
50 \%\end{array}$ & $\begin{array}{l}\text { Over } 50 \% \text { but } \\
\text { less than } 75 \%\end{array}$ & N/A & $\begin{array}{l}\text { More than } \\
50 \% \text { but less } \\
\text { than } 75 \%\end{array}$ \\
\hline $\begin{array}{l}\text { 8. Are you familiar } \\
\text { with } \\
\text { postsecondary } \\
\text { readiness? }\end{array}$ & I know a little & Yes & Yes & Yes & Yes \\
\hline $\begin{array}{l}\text { 9. Does your } \\
\text { school/program } \\
\text { offer a } \\
\text { comprehensive } \\
\text { approach to } \\
\text { postsecondary } \\
\text { readiness? }\end{array}$ & I am not sure & No & No & N/A & No \\
\hline $\begin{array}{l}\text { 10.Are you } \\
\text { interested in } \\
\text { learning about a } \\
\text { comprehensive } \\
\text { approach to } \\
\text { postsecondary } \\
\text { readiness? }\end{array}$ & Yes & Yes & Yes & Yes & Yes \\
\hline
\end{tabular}

Note. Pseudonyms were used to protect participants' identities. 
The participants' location of work was split between urban and suburban settings. The total racial/ethnic minority percentages of their schools vary from as low as $10 \%$ to as high as $75 \%$. They all seem to have some knowledge regarding postsecondary readiness, while at the same time; they feel their schools do not provide a comprehensive approach. They all were interested in finding more about a comprehensive approach to postsecondary readiness.

Preliminary field test postsecondary readiness workshop. For the workshop I had to administer it at different times due to the location and scheduling conflicts. I held the workshop at my school in our conference room for the two program directors. During this workshop, I provided them with a laptop to take the PrA on postsecondary readiness. This PrA took 15 minutes to complete. The purpose of the PrA was to connect the participant and their experiences with their schools/sites to the information and practices from the guidebook. All of the participants took the PrA survey during the workshop phase. After the PrA, I gave them a copy of the preliminary form of the guidebook and continued with the workshop on how to use the guidebook. This workshop took approximately 30 minutes. As I presented, they followed my presentation by looking through the corresponding sections. A 10-15 minutes question and answer period on postsecondary readiness minutes followed. When we finished with the workshop, participants took the PRG workshop survey (Table 28). This took them 10 minutes to complete. When they left, they took the preliminary form of the guidebook and would go through it together. I then scheduled a time to reconnect with them to administer the PoA 
survey. One of the participants agreed to a longer meeting to conduct a formal interview, and one participant agreed to a shorter meeting to take the PoA.

Table 28

Preliminary Field Test: Evaluation of the Workshop

\begin{tabular}{|c|c|c|c|c|c|c|}
\hline Workshop & Questions & $\begin{array}{l}\text { Strongly } \\
\text { Disagree }\end{array}$ & Disagree & Neutral & Agree & $\begin{array}{l}\text { Strongly } \\
\text { Agree }\end{array}$ \\
\hline \multirow[t]{3}{*}{$\begin{array}{l}\text { Workshop } \\
\text { Content }\end{array}$} & $\begin{array}{l}\text { I was well } \\
\text { informed about } \\
\text { the goals and } \\
\text { objectives of this } \\
\text { workshop. }\end{array}$ & & & & & 5 \\
\hline & $\begin{array}{l}\text { This workshop } \\
\text { lived up to my } \\
\text { expectations. }\end{array}$ & & & & & 5 \\
\hline & $\begin{array}{l}\text { The content is } \\
\text { relevant to my } \\
\text { job. }\end{array}$ & & & & & 5 \\
\hline \multirow[t]{3}{*}{$\begin{array}{l}\text { Workshop } \\
\text { Design }\end{array}$} & $\begin{array}{l}\text { The workshop } \\
\text { activities } \\
\text { stimulated my } \\
\text { learning. }\end{array}$ & & & & 4 & 1 \\
\hline & $\begin{array}{l}\text { The difficulty } \\
\text { level of this } \\
\text { workshop was } \\
\text { appropriate. }\end{array}$ & & & & & 5 \\
\hline & $\begin{array}{l}\text { The pace of this } \\
\text { workshop was } \\
\text { appropriate. }\end{array}$ & & & & & 5 \\
\hline \multirow{2}{*}{$\begin{array}{l}\text { Workshop } \\
\text { Facilitator/ } \\
\text { Instructor }\end{array}$} & $\begin{array}{l}\text { The instructor was } \\
\text { well prepared. }\end{array}$ & & & & & 5 \\
\hline & $\begin{array}{l}\text { The instructor was } \\
\text { helpful. }\end{array}$ & & & & & 5 \\
\hline \multirow[t]{2}{*}{$\begin{array}{l}\text { Workshop } \\
\text { Results }\end{array}$} & $\begin{array}{l}\text { I accomplished } \\
\text { the goals of this } \\
\text { workshop. }\end{array}$ & & & & 1 & 4 \\
\hline & $\begin{array}{l}\text { I will be able to } \\
\text { use what I learned } \\
\text { in this workshop. }\end{array}$ & & & & & 5 \\
\hline Delivery & $\begin{array}{l}\text { The workshop } \\
\text { was a good way } \\
\text { for me to learn } \\
\text { this content. }\end{array}$ & & & & & 5 \\
\hline
\end{tabular}


For the two teachers, I was able to visit their site and follow the same procedures as described in the aforementioned paragraph. I administered the PrA on postsecondary readiness. They were instructed to have laptops to use and provide a projector for the workshop. After 10-15 minutes, I presented the workshop on the guidebook while providing them a hardcopy of the guidebook. It took me approximately 35 min to go through the workshop. After the workshop, they took the survey on the workshop. Afterward, we scheduled a time for to take the PoA on postsecondary readiness. Much like the participants from above, one of the participants agreed to a longer meeting to conduct a formal interview, and one participant agreed to a shorter meeting to take the PoA.

My last participant was difficult to schedule as a result of her job. To get her feedback, I was able to schedule a time and host a distance learning session via GoToMeeting. Prior to the meeting, I sent her an electronic copy of my guidebook along with the link to the PrA on postsecondary readiness on the SurveyMonkey website. Then I was able to go through the workshop. I only had 30 minutes to go through this process with her, but I was able to finish. I was not able to host a question/answer session on the workshop due to the time constraints. Within a month, this participant completed the PoA, but I did not get the opportunity to conduct a formal interview with her.

To organize the workshop, I created a PowerPoint presentation that consisted of: goals, the session's agenda, overview on the data collection, and overview of the sections of the guidebook, the problem, an overview of the postsecondary readiness framework 
and its elements, and the components that make up the guidebook (Appendix A). Prior to this workshop, I collected the informed consent forms ensuring the confidentiality of all participants. This workshop was an important element to begin the preliminary field testing because the goals, objectives and activities were outlined during the workshop.

Results of the survey on the workshop. In this section, participants were asked to rate the level of agreement based on the questions about the workshop (Table 28). The questions from the workshop were broken down into the following categories: content, design, facilitator/instructor, results and delivery. The last piece of data collection asked participants how they would improve the workshop. The survey used a Likert scale of 1-5. The scale served the purpose of collecting participants' level of agreement to a series of statements in each section. On the Likert scale 1 equaled Strongly Disagree and 5 equaled Strongly Agree.

Under the Workshop Content category, all participants strongly agreed with how the workshop informed them of the goals and objectives. I had this on the first slide and went into great deal covering the goals and objectives of the workshop. They also strongly agreed that the workshop lived up to their expectations. One participant commented that the workshop was very important and timely. I attribute this to the fact that I had prior discussions about my journey into postsecondary readiness and what I was trying to accomplish. The last question under the Workshop Content category they also strongly agreed that the content was relevant. I believe this was true because I had 
picked these participants as they were involved in this process at some level with their current jobs.

The data under the Workshop Design category showed promising results on the workshop as well. However, four of the participants marked agree on the workshop activities stimulated my learning, while one participant strongly agreed. One participant commented he wanted more activities. I feel the results under this question were justified because I saw the workshop as informative and due to time constraints; I did not put in any activities. As far as the difficulty level and pace of the workshop; participants all strongly agreed that it was appropriate.

Data collected under the Facilitator/Instructor category revealed that I was well prepared as all participants strongly agreed. They also strongly agreed that I was helpful with the workshop and questions regarding the workshop. This was great to see as this was the first attempt at presenting such a big concept in such a short period of time.

The data on the Results of the workshop was positive as well. Four participants strongly agreed that the goals were accomplished during the workshop and one participant agreed. The one participant that agreed wanted the workshop to be longer.

The last piece of positive data was that all participants strongly agreed that this workshop was a good way for them to learn this content. I was very encouraged to see this, and I believe when I use this data to improve the workshop, that it will be even more effective at disseminating the content of postsecondary readiness. 
The next section of data from the survey of the workshop (Table 29) allowed participants to give information on how they would improve the workshop followed by what is most valuable and least valuable about this workshop.

Table 29

\section{Preliminary Field Test: Formative Results}

\begin{tabular}{|c|c|}
\hline How would you improve this workshop? & Results \\
\hline Provide better information before the workshop. & 0 \\
\hline Clarify the workshop objectives. & 0 \\
\hline Reduce the content covered in the workshop. & 0 \\
\hline Increase the content covered in the workshop. & 4 \\
\hline Update the content covered in the workshop. & 0 \\
\hline Improve the instructional methods. & 0 \\
\hline Make workshop activities more stimulating. & 1 \\
\hline Improve workshop organization. & 0 \\
\hline Make the workshop less difficult. & 0 \\
\hline Make the workshop more difficult. & 0 \\
\hline Slow down the pace of the workshop. & 0 \\
\hline Speed up the pace of the workshop. & 0 \\
\hline Allow more time for the workshop. & 4 \\
\hline Shorten the time for the workshop. & 0 \\
\hline Improve the tests used in the workshop. & 0 \\
\hline Add more video to the workshop. & 0 \\
\hline What is least valuable about the workshop? & $\begin{array}{l}\text { - The workshop could be longer to help take us } \\
\text { through each section of the guidebook. } \\
\text { - Too short. } \\
\text { - This workshop could be a week long to take } \\
\text { us through the guidebook. } \\
\text { - We just scratched the surface. }\end{array}$ \\
\hline What is most valuable about the workshop? & $\begin{array}{l}\text { - Relative to my job. } \\
\text { - Very important information. } \\
\text { - The importance of the topic. } \\
\text { - Excellent approach to preparing educational } \\
\text { leaders. } \\
\text { - Excellent and relevant topic. }\end{array}$ \\
\hline
\end{tabular}


Participants were given a list of improvements from which to mark to help improve the workshop. The results were fairly positive and constructive. Only three improvements were noted. One participant marked that the workshop activities needed to be more stimulating. This feedback added to the aforementioned survey results as I did not plan for any activities in the workshop due to time constraints. Four participants marked that the content needed to be increased in the workshop. I feel this was due to the fact that the workshop just introduced the components and did not go into detail. The workshop may have left more questions than answers due to its brevity. The last improvement that was marked was that the workshop needed more time. I believe this feedback was accurate due to the scope of the guidebook, and that a workshop cannot cover all of the concepts in 30 minutes.

The last piece of information to improve the workshop was what was valuable and least valuable about the workshop. This was an open-ended question and the feedback was very valuable for improvements to the workshop. Focusing on the least valuable comments, one participant stated, "The workshop could be longer to help take us through each section of the guidebook." Another participant echoed this statement by saying the workshop was "too short." Another valuable piece of information was, "This workshop could be a week long to take us through the guidebook." To add to these themes, one participant stated, "We just scratched the surface." The most valuable comments listed the topic as "excellent and relevant," with one participant stating the topic was "relative to my job." Two participants revealed that the most valuable piece 
was the topics importance. Another participant stated something similar. Finally one participant noted it was an "excellent approach to preparing educational leaders."

Overall, the workshop needed to be refined along with the dissemination of the workshop. Unfortunately, due to scheduling conflicts, I had to create the workshop around the schedules of the participants and this proved to be limiting. I did accomplish some of the goals from the workshop which were:

1. Collect data on your understanding of postsecondary readiness

2. Help you navigate through the guidebook

3. Understand the components of postsecondary readiness

4. Become more familiar with a comprehensive approach to postsecondary readiness

5. Collect data on the usefulness of the workshop

I was able to collect data from the PrA, but I had to reschedule another meeting with the participants to collect the interview data and the PoA data. The workshop did bring to light the components and was a good introduction to the guidebook, but the time spent with in the workshop and with the participants was too short. I also believe that participants were more familiar with a comprehensive approach to postsecondary readiness, although their knowledge about this was limited due to the length of the workshop and time with the guidebook. The last goal was met because I was able to collect data on the usefulness of the workshop.

PrA and PoA of postsecondary readiness. I administered all of the PrA surveys to all participants in the aforementioned workshop. During the workshop, the participants 
were given both a hardcopy of the guidebook as well as an electronic version of the guidebook. The PrA and PoA were based on the same questions (Appendix F). Both assessments used a Likert scale of 1-5. The scale served the purpose of collecting frequency with 1 being Never, and 5 being Always. Participants rated how often the theme on postsecondary readiness in each question occurred at their site/school. The content of the PrA and PoA was used to gauge the participants' understanding and knowledge of the topic-postsecondary readiness. The questions from the PrA and PoA are meant to serve two purposes: (a) discover information and practices from the guidebook, and (b) connect the information from the guidebook to their own sites. I did this by posing questions which allowed the participants to include relative data from their own schools/programs. I then used questions connected to the material from each section of the guidebook to measure their understanding and knowledge of the components within these sections. The PoA was used to capture the participant's new knowledge gained from using the guidebook.

I administered the PoA during a second and final meeting with the participants. These meetings were at different times due to location and scheduling conflicts. All of the participants had approximately one month to individually go through the guidebook. Within this time, I scheduled a meeting with each of them regarding the PoA of the guidebook and to conduct an interview on the process. These meetings were conducted via teleconference and lasted approximately one hour. 
Open-ended comments. There was a comment box at the end of each survey question for participants to complete (this was optional). During the PrA there were no comments. However, there were comments after each question in the PoA. These comments provided excellent qualitative data from which to assess the usefulness of the workshop, guidebook and postsecondary readiness process. They also add context to the Likert scale responses. The questions and results from the PrA and PoA are listed in Table 30. The interview data are discussed later in this section as well.

Table 30

Preliminary Field Test: PrA and PoA and Formative Results on Postsecondary Readiness

\begin{tabular}{|c|c|c|}
\hline Postsecondary Readiness & $\operatorname{PrA}$ & PoA \\
\hline $\begin{array}{l}\text { 1. We prepare students for postsecondary } \\
\text { options at my school. }\end{array}$ & $\begin{array}{l}\text { - } 20 \% \text {-Sometimes } \\
\text { - } 40 \% \text {-Often } \\
\text { - } 40 \% \text {-Always }\end{array}$ & $\begin{array}{l}\text { - } 80 \% \text {-Hardly ever } \\
\text { - } 20 \% \text {-Sometimes }\end{array}$ \\
\hline \multicolumn{3}{|c|}{$\begin{array}{l}\text { Open-Ended Comments from the PoA } \\
\text { - Getting better } \\
\text { - Needs to be systematic } \\
\text { - At a state level, no } \\
\text { - I thought we did, but we need more work on this } \\
\text { - Not in an appropriate, systematic fashion }\end{array}$} \\
\hline $\begin{array}{l}\text { 2. Preparing students for postsecondary } \\
\text { options is a top priority for our school. }\end{array}$ & $\begin{array}{l}\text { - } 20 \% \text {-Often } \\
\text { - } 80 \% \text {-Always }\end{array}$ & $\begin{array}{l}\text { - } 80 \% \text {-Hardly ever } \\
\text { - } 20 \% \text {-Sometimes }\end{array}$ \\
\hline $\begin{array}{l}\text { Open-Ended Comments from the PoA } \\
\text { - We are committed } \\
\text { - No, because it is not systematic } \\
\text { - Not consistent enough } \\
\text { - I thought it was, but we are missing } \mathrm{n} \\
\text { - It needs to be comprehensive }\end{array}$ & y elements & \\
\hline
\end{tabular}




\section{Table 30 (continued)}

\begin{tabular}{|c|c|c|}
\hline Postsecondary Readiness & $\operatorname{PrA}$ & PoA \\
\hline $\begin{array}{l}\text { 3. Our mission and vision was created } \\
\text { through shared values and beliefs of all } \\
\text { stakeholders involved with the school. }\end{array}$ & $\begin{array}{l}\text { - } 20 \% \text {-Never } \\
\text { - } 40 \% \text {-Hardly ever } \\
\text { - } 40 \% \text {-Sometimes }\end{array}$ & $\begin{array}{l}\text { - } 20 \% \text {-Never } \\
\text { - } 80 \% \text {-Hardly ever }\end{array}$ \\
\hline \multicolumn{3}{|l|}{$\begin{array}{l}\text { Open-Ended Comments from the PoA } \\
\text { - I did not have input } \\
\text { - Very little input from all } \\
\text { - Very little of this } \\
\text { - Very little input from all stakeholders } \\
\text { - Teachers were not involved }\end{array}$} \\
\hline $\begin{array}{l}\text { 4. Data is used to create and drive } \\
\text { postsecondary readiness programs and } \\
\text { policies. }\end{array}$ & $\begin{array}{l}\text { - } 40 \% \text {-Sometimes } \\
\text { - } 40 \% \text {-Often } \\
\text { - } 20 \% \text {-Always }\end{array}$ & $\begin{array}{l}\text { - } 80 \% \text {-Hardly ever } \\
\text { - } 20 \% \text {-Sometimes }\end{array}$ \\
\hline \multicolumn{3}{|l|}{$\begin{array}{l}\text { Open-Ended Comments from the PoA } \\
\text { - Needs improvement } \\
\text { - Not enough of this } \\
\text { - Not systematic } \\
\text { - } \quad \text { Vary rarely. It is not systematic } \\
\end{array}$} \\
\hline $\begin{array}{l}\text { 5. Standards, curriculum and assessments } \\
\text { are aligned to college readiness } \\
\text { expectations. }\end{array}$ & $\begin{array}{l}\text { - } 80 \% \text {-Sometimes } \\
\text { - } 20 \% \text {-Often }\end{array}$ & $\begin{array}{l}\text { - } 80 \% \text {-Hardly ever } \\
\text { - } 20 \% \text {-Sometimes }\end{array}$ \\
\hline \multicolumn{3}{|c|}{$\begin{array}{l}\text { Open-Ended Comments from the PoA } \\
\text { - We need to use the expectations from the guidebook } \\
\text { - Not as defined by the guidebook }\end{array}$} \\
\hline $\begin{array}{l}\text { 6. Interventions are in place at my school } \\
\text { to keep students on track for } \\
\text { postsecondary success. }\end{array}$ & $\begin{array}{l}\text { - } 40 \% \text {-Hardly ever } \\
\text { - } 60 \% \text {-Sometimes }\end{array}$ & $\begin{array}{l}\text { - } 80 \% \text {-Hardly ever } \\
\text { - } 20 \% \text {-Sometimes }\end{array}$ \\
\hline \multicolumn{3}{|c|}{$\begin{array}{l}\text { Open-Ended Comments from the PoA } \\
\text { - Not enough resources } \\
\text { - We need to develop programs to help with this } \\
\text { - Not enough support given to struggling students }\end{array}$} \\
\hline $\begin{array}{l}\text { 7. Tenacity-building activities are } \\
\text { systematic and implemented across all } \\
\text { grade levels. }\end{array}$ & - $100 \%$-Hardly ever & $\begin{array}{l}\text { - } 80 \% \text {-Never } \\
\text { - } 20 \% \text {-Hardly ever }\end{array}$ \\
\hline $\begin{array}{l}\text { Open-Ended Comments from the PoA } \\
\text { - This needs to occur } \\
\text { - Not as defined by the guidebook }\end{array}$ & & \\
\hline
\end{tabular}


Table 30 (continued)

\begin{tabular}{|c|c|c|}
\hline Postsecondary Readiness & $\operatorname{PrA}$ & PoA \\
\hline $\begin{array}{l}\text { 8. My school has developed a college- } \\
\text { going culture. }\end{array}$ & $\begin{array}{l}\text { - } 20 \% \text {-Hardly ever } \\
\text { - } 20 \% \text {-Sometimes } \\
\text { - } 60 \% \text {-Often } \\
\end{array}$ & $\begin{array}{l}\text { - } 80 \% \text {-Hardly ever } \\
\text { - } 20 \% \text {-Sometimes }\end{array}$ \\
\hline \multicolumn{3}{|c|}{$\begin{array}{l}\text { Open-Ended Comments from the PoA } \\
\text { - I thought we had, but we are providing the comprehensive approach } \\
\text { - I feel this is hit and miss } \\
\text { - Now that we have a comprehensive approach, we will work on this } \\
\text { - We are missing many elements }\end{array}$} \\
\hline $\begin{array}{l}\text { 9. My school has developed partnerships } \\
\text { with local colleges and universities. }\end{array}$ & $\begin{array}{l}\text { - } 20 \% \text {-Sometimes } \\
\text { - } 80 \% \text {-Always }\end{array}$ & $\begin{array}{l}\text { - } 20 \% \text {-Hardly ever } \\
\text { - } 20 \% \text {-Sometimes } \\
\text { - } 60 \% \text {-Always }\end{array}$ \\
\hline \multicolumn{3}{|c|}{$\begin{array}{l}\text { Open-Ended Comments from the PoA } \\
\text { - Need to work on communication in this step } \\
\text { - Not enough of this } \\
\text { - We have one, but it needs transparency }\end{array}$} \\
\hline 10. Curriculum at my school is rigorous. & $\begin{array}{l}\text { - } 40 \% \text {-Sometimes } \\
\text { - } 60 \% \text {-Often }\end{array}$ & $\begin{array}{l}\text { - } 20 \% \text {-Hardly ever } \\
\text { - } 80 \% \text {-Sometimes }\end{array}$ \\
\hline \multicolumn{3}{|l|}{$\begin{array}{l}\text { Open-Ended Comments from the PoA } \\
\text { - We are working on this }\end{array}$} \\
\hline $\begin{array}{l}\text { 11. Our teachers and school align } \\
\text { curriculum, instruction, assessment, } \\
\text { and programs to college and career } \\
\text { readiness standards. }\end{array}$ & $\begin{array}{l}\text { - } 20 \% \text {-Hardly ever } \\
\text { - } 80 \% \text {-Sometimes }\end{array}$ & $\begin{array}{l}\text { - } 80 \% \text {-Hardly ever } \\
\text { - } 20 \% \text {-Sometimes }\end{array}$ \\
\hline \multicolumn{3}{|c|}{$\begin{array}{l}\text { Open-Ended Comments from the PoA } \\
\text { - We can do better } \\
\text { - Teachers need to implement a consistent set of best practices } \\
\text { - We need more collaboration } \\
\text { - Not much collaborating }\end{array}$} \\
\hline $\begin{array}{l}\text { 12. Quality instructional practices are } \\
\text { consistently integrated into each class } \\
\text { offered at my school. }\end{array}$ & $\begin{array}{l}\text { - } 40 \% \text {-Hardly ever } \\
\text { - } 60 \% \text {-Sometimes }\end{array}$ & $\begin{array}{l}\text { - } 80 \% \text {-Hardly ever } \\
\text { - } 20 \% \text {-Sometimes }\end{array}$ \\
\hline \multicolumn{3}{|c|}{$\begin{array}{l}\text { Open-Ended Comments from the PoA } \\
\text { - We can do better } \\
\text { - Teachers need to implement a consistent set of best practices } \\
\text { - We need more collaboration } \\
\text { - Different instruction with different instructors }\end{array}$} \\
\hline $\begin{array}{l}\text { 13. There is a structure set up at my school } \\
\text { for the systematic identification of } \\
\text { skills and progress. }\end{array}$ & $\begin{array}{l}\text { - } 60 \% \text {-Hardly ever } \\
\text { - } 40 \% \text {-Sometimes }\end{array}$ & - $100 \%$-Hardly ever \\
\hline $\begin{array}{l}\text { Open-Ended Comments from the PoA } \\
\text { - Not systematic } \\
\text { - This needs to be streamlined } \\
\text { - We need more collaboration } \\
\text { - Not systematic }\end{array}$ & & \\
\hline
\end{tabular}




\section{Table 30 (continued)}

\begin{tabular}{|c|c|c|}
\hline Postsecondary Readiness & $\operatorname{PrA}$ & PoA \\
\hline $\begin{array}{l}\text { 14. Parents and school staff are included in } \\
\text { educational planning. }\end{array}$ & $\begin{array}{l}\text { - } 60 \% \text {-Hardly ever } \\
\text { - } 40 \% \text {-Sometimes }\end{array}$ & - $100 \%$-Hardly ever \\
\hline \multicolumn{3}{|l|}{$\begin{array}{l}\text { Open-Ended Comments from the PoA } \\
\text { - Very difficult to achieve } \\
\text { - Should be mandatory } \\
\text { - This is imperative } \\
\text { - We need more collaboration } \\
\text { - Vary rarely }\end{array}$} \\
\hline $\begin{array}{l}\text { 15. There is a structure/program set up at } \\
\text { my school for identifying and building } \\
\text { academic behaviors of students. }\end{array}$ & $\begin{array}{l}\text { - } 80 \% \text {-Hardly ever } \\
\text { - } 20 \% \text {-Sometimes }\end{array}$ & - $100 \%$-Hardly ever \\
\hline \multicolumn{3}{|l|}{$\begin{array}{l}\text { Open-Ended Comments from the PoA } \\
\text { - We need to work on this } \\
\text { - This needs to be created } \\
\text { - Not consistent }\end{array}$} \\
\hline $\begin{array}{l}\text { 16. Systematically, my school improves } \\
\text { both students' and parents' transition } \\
\text { knowledge and skills with regard to the } \\
\text { transition from elementary to middle } \\
\text { school. }\end{array}$ & $\begin{array}{l}\text { - } 80 \% \text {-Never } \\
\text { - } 20 \% \text {-Hardly ever }\end{array}$ & $\begin{array}{l}\text { - } 80 \%-\text {-Never } \\
\text { - } 20 \% \text {-Hardly ever }\end{array}$ \\
\hline \multicolumn{3}{|l|}{$\begin{array}{l}\text { Open-Ended Comments from the PoA } \\
\text { • We need to help with vertical alignment }\end{array}$} \\
\hline $\begin{array}{l}\text { 17. Systematically, my school improves } \\
\text { both students' and parents' transition } \\
\text { knowledge and skills with regard to the } \\
\text { transition from middle school to high } \\
\text { school. }\end{array}$ & $\begin{array}{l}\text { - } 80 \% \text {-Never } \\
\text { - } 20 \% \text {-Hardly ever }\end{array}$ & $\begin{array}{l}\text { - } 80 \% \text {-Never } \\
\text { - } 20 \% \text {-Hardly ever }\end{array}$ \\
\hline \multicolumn{3}{|l|}{$\begin{array}{l}\text { Open-Ended Comments from the PoA } \\
\text { • We need to help with vertical alignment }\end{array}$} \\
\hline $\begin{array}{l}\text { 18. Systematically, my school improves } \\
\text { both students' and parents' transition } \\
\text { knowledge and skills with regard to the } \\
\text { transition from high school to college. }\end{array}$ & $\begin{array}{l}\text { - } 20 \% \text {-Hardly ever } \\
\text { - } 80 \% \text {-Sometimes }\end{array}$ & - $100 \%$-Hardly ever \\
\hline \multicolumn{3}{|l|}{$\begin{array}{l}\text { Open-Ended Comments from the PoA } \\
\text { - Working on this } \\
\text { - We need to help with vertical alignment } \\
\text { - Not enough of this } \\
\text { - Needs more of this }\end{array}$} \\
\hline
\end{tabular}


Table 30 (continued)

\begin{tabular}{|c|c|c|}
\hline Postsecondary Readiness & $\operatorname{PrA}$ & PoA \\
\hline $\begin{array}{l}\text { 19. I know how to implement a } \\
\text { comprehensive approach to } \\
\text { postsecondary readiness at my school. }\end{array}$ & $\begin{array}{l}\text { - } 40 \% \text {-Hardly ever } \\
\text { - } 60 \% \text {-Sometimes }\end{array}$ & - $100 \%$ Always \\
\hline \multicolumn{3}{|c|}{$\begin{array}{l}\text { Open-Ended Comments from the PoA } \\
\text { - Very insightful } \\
\text { - An excellent approach and very thoughtful } \\
\text { - Great approach } \\
\text { - Wow, I feel this guidebook gives direction with how to proceed } \\
\text { - Now we have a compass }\end{array}$} \\
\hline $\begin{array}{l}\text { 20. I am aware of resources to help } \\
\text { improve our process of postsecondary } \\
\text { preparedness. }\end{array}$ & $\begin{array}{l}\text { - } 20 \% \text {-Hardly ever } \\
\text { - } 80 \% \text {-Sometimes }\end{array}$ & - $100 \%$-Always \\
\hline $\begin{array}{l}\text { Open-Ended Comments from the PoA } \\
\text { - Thanks for the resources } \\
\text { - Thanks for the help } \\
\text { - These should help } \\
\text { - Great resources } \\
\text { - Thanks to the guidebook }\end{array}$ & & \\
\hline
\end{tabular}

\section{Results of the survey of the PrA and PoA. The PrA and PoA focused on}

postsecondary readiness and the components and elements from the guidebook. All of the PrA surveys were administered to all of the participants during the workshop. The PoA surveys were administered to each of the participants within a month's time in a second meeting. I wanted these surveys to serve two purposes for the participants: (a) to discover information and practices from the guidebook, and (b) to connect the information from the guidebook to their own sites.

The PrA and PoA questions were created and categorized from sections of the guidebook. This helped me assess where the participant knowledge was strong and where it needed to be strengthened. The sections that the questions were categorized from were: The Problem, Structural Elements, Academic Elements, Social Elements, Applied Best 
Practices, and Resources. Although I tried to keep each question limited to one category, they often overlapped into more than one category.

Survey questions. After reviewing the guidebook and participating in the workshop, participants rated how often the theme of postsecondary readiness occurred at their site/school. The participants' ratings were tallied in percentages and listed above in Table 30. Since the Likert scale measured five categories (1-Never, 2-Hardly ever, 3Sometimes, 4-Often, 5-Always). I broke these categories into two parts: low and high frequency responses. The high frequency responses (HFR) captured numbers 3Sometimes, 4-Often, and 5-Always. The low frequency responses (LFR) captured numbers 2-Hardly ever, and 1-Never. After participating in the workshop and using the guidebook, I assumed from the results that a growth of knowledge occurred with questions 1-18 in the following instances:

1. When data percentages decreased from HFR in the PrA to a data percentage increase of LFR; or a data percentage decrease from one HFR to a greater increase in a lower HFR (100\%-always in PrA to $100 \%$-sometimes in PoA)

2. When data percentages increased from LFR in the PrA to a greater data percentage increase of LFR; or a data percentage increase from one LFR to a greater increase in a lower frequency response (100\%-hardly ever in PrA to $100 \%$-never in PoA).

Fullan (2001) referred to this phenomenon as an implementation dip. He noted that like the perceived growth of knowledge from these assessments, the implementation dip is a dip in performance and confidence as one encounters an innovation that requires new skills and understanding (Fullan, 2001). It must be pointed out; however, that this growth 
of knowledge shifts in questions 19-20 where percentages decreased from LFR in the PrA to a data percentage increase of HFR in the PoA.

Self-assessment. The first and second questions provided a self-assessment on the priority of postsecondary readiness at the participants' sites, and how well these sites prepare their students for postsecondary success. Prior to participating in the workshop and going through the guidebook, $100 \%$ of the responses were HFRs: sometimes, often, or always. However, after the workshop and guidebook review, this number reduced significantly to LFR to $80 \%$, or hardly ever for both questions. This number showed a presumed growth of knowledge as to the key aspects of postsecondary readiness and their awareness of approach and implementation at the participants' sites.

Some of the open-ended comments that showed perceived growth of knowledge from the workshop and guidebook relating to this section were:

- "I thought we did (prepare students for postsecondary options), but we need more work on this."

- "I thought it was (preparing students for postsecondary options is a top priority), but we are missing many elements."

A few of the other comments show the lack of consistency with an approach that is not comprehensive. These comments reveal the lack of knowledge prior to their experiences with the workshop and guidebook to the knowledge acquired from these two experiences. The workshop and guidebook seemed to have a significant effect on their knowledge of postsecondary readiness as it relates to their sites. Participants thought they had an idea of the components to postsecondary readiness prior to the workshop and guidebook, however, after the components were addressed along with their experience 
with the guidebook, the results show that knowledge was gained. The data show their awareness of how these components are applied in their schools. This was valuable to my findings because it showed that the guidebook was a tool that imparted knowledge and connected that knowledge to their practice making it relative to the educational process.

Structural elements. The next seven questions have to do with the structural elements of the guidebook. Question three showed the presumed growth of knowledge on mission and vision created through shared values and beliefs. The PrA showed $60 \%$ of participants responded with LFR. This increased to $100 \%$ after they were exposed to the workshop and guidebook. Question four dealt with data driving postsecondary readiness revealed that $100 \%$ of the participants responded with HFR in the PrA, whereas in the PoA, this shifted to $20 \%$ HFR and $80 \%$ LFR. Question five on aligned standards shifted from $100 \%$ HFR in the PrA to $80 \%$ LFR in the PoA. Question six on interventions doubled from $40 \%$ LFR in the PrA to $80 \%$ LFR in the PoA. Question seven on tenacitybuilding activities went from $100 \%$ of responses marking hardly ever in the PrA to $80 \%$ of responses marking never in the PoA. Question eight on developing a college-going culture data showed $80 \%$ of responses as high frequency in the PrA to $80 \%$ as low frequency in the PoA. The last question on the Structural Elements was question nine. This question related to partnerships with local colleges and universities. In the PrA $100 \%$ of the responses were high frequency, and in the PoA this percentage reduced to $80 \%$ with an increase of $20 \%$ in LFR. Every question showed a presumed growth in 
knowledge with questions four and five showing the greatest jump in change of percentages from HFR to LFR (100\%-HFR to 80\%-LFR). Question nine, however, showed the smallest decline of percentages with $80 \%$ responding always and $60 \%$ responding sometimes in the PrA, to $60 \%$ responding always and $20 \%$ responding sometimes. Even though this showed a small decline, it still showed a presumed growth of knowledge from PrA to PoAs, and the implementation of the workshop and guidebook.

The open-ended comments from this section reveal that participants have learned key knowledge about postsecondary readiness. Many of the comments mention how their approaches to data are not systematic. They also mention how the guidebook provides a common language and approach for educational leaders. "We need to use the expectations (on standards, curriculum and assessments) from the guidebook." Other comments relating to a common approach are: "I thought we had (a college-going culture), but are we providing a comprehensive approach?" "Now that we have a comprehensive approach to follow, we will work on this." The data collected in the PrA and the PoA on the Structural Elements revealed a presumed growth of knowledge after participants went through the workshop and guidebook.

Academic elements. Questions numbered 10-13 fell under the Academic Elements section of the guidebook. Question 10 on rigorous curriculum had 100\% HFR in the PrA and this percentage declined to $80 \%$ HFR and $20 \%$ LFR in the PoA. Alignment of curriculum, instruction, assessment in question 11 swung from $80 \%$ HFR and $20 \%$ LFR 
in the PrA to $20 \%$ HFR and $80 \%$ LFR in the PoA. Responses on question 12 relating to quality instructional practices went from 60\% HFR and 40\% LFR in the PrA to $20 \%$ HFR and $80 \%$ LFR in the PoA. The last question under the Academic Elements section of the guidebook is question 13 which deals with the themes of identification of skills and progress. In the PrA $40 \%$ were HFR and 60\% were LFR, and this shifted to $100 \%$ LFR in the PoA. As with the questions from the Structural Elements, every question showed a presumed growth in knowledge. Question 11 revealed the greatest jump in change of percentages from HFR to LFR (80\%-HFR to 80\%-LFR). Question 10, however, showed an interesting pattern. Of the responses in the PrA, 40\% marked sometimes, and 60\% marked often. In the PoA, however, $80 \%$ marked sometimes, and 20\% marked hardly ever. The sometimes category doubled in responses. This was due to a change in responses from often to sometimes in the PrA and the PoA, and a change in responses from sometimes to hardly ever in the PrA and the PoA. As interesting as this pattern was, it still showed a presumed growth of knowledge.

The key words from the open-ended comments from the PoA from this section were: consistency, collaboration, and systematic. One participant noted in response to aligned curriculum, instruction and assessment: "We need more collaborating." Another participant echoed this statement: "Not much collaborating." Looking at quality instructional practices, one participant noted: "Teachers need to implement a consistent set of best practices." Two comments reflected how their sites identify skills and progress in a systematic manner: "Not systematic." The data collected in the PrA and the PoA on 
the Academic Elements revealed a presumed growth of knowledge after participants went through the workshop and guidebook.

Social elements. Questions 14-18 fell under the Social Elements section of the PRG. Question 14 dealt with the inclusion of parents and staff in planning and in the PrA, $40 \%$ marked HFR while $60 \%$ marked LFR. In the PoA, this shifted to $100 \%$ LFR. Building academic behaviors of students in question 15 showed $20 \%$ HFR and $80 \%$ LFR in the PrA, and once again this shifted to $100 \%$ LFR in the PoA. Questions 16 and 17 proved to be nonfactors because the majority of participants have no experience in their current job working with elementary and middle school programs. The data is the same for both of these questions, 100\% LFR in both the PrA and the PoA. Question 18, however, deals with the transition knowledge from high school to college. The data in the PrA shows $80 \%$ HFR and $20 \%$ LFR. In the PoA, this shifts to $100 \%$ LFR. Once again, every question showed a presumed growth in knowledge. Question 18 revealed the greatest jump in change of percentages from HFR to LFR (80\%-HFR to $100 \%$-LFR). Question 15 showed the smallest decline of percentages with $20 \%$ responding sometimes and $80 \%$ responding hardly ever in the PrA to $100 \%$ responding hardly ever in the PoA. Even though this showed a small decline, it still showed a presumed growth of knowledge.

Looking at the open-ended questions related to the Social Elements of the guidebook show a need for implementation, consistency and collaboration. When referring to parental and school staff involvement in educational planning, one participant 
noted: "This is imperative!" While another participant commented: "Should be mandatory." On the themes of student and parent transition knowledge and skills, participants voiced the need for vertical alignment. The data collected in the PrA and the PoA on the Social Elements revealed a presumed growth of knowledge after participants went through the workshop and guidebook.

Guidebook knowledge. This section of questions from the PrA and PoA required a change in analysis from questions 1-18. To show a presumed growth of knowledge after participating in the workshop and reviewing the guidebook, I assumed from the results that a growth of knowledge occurred with questions 19-20 in the following instances:

1. When data percentages decreased from LFR in the PrA to a data percentage increase of HFR; or a data percentage decreased from a lower LFR to a greater increase in a higher LFR (100\%-never in PrA to $100 \%$-hardly ever in PoA); or a data percentage increase from a lower HFR to a greater increase in a higher HFR (100\%-sometimes in PrA to $100 \%$-always in PoA).

Question 19 related to participants knowledge on how to implement a comprehensive approach to postsecondary readiness. This gave me more insight on the participants' growth knowledge after their experiences with the workshop and guidebook because it is directly asking the question. In the PrA $40 \%$ of the responses were LFR and $60 \%$ were HFR, and after the PoA, $100 \%$ of the responses were HFR. This showed a $40 \%$ jump in knowledge. The same pattern is true of question 20 relating to resources on postsecondary readiness. In the PrA, $20 \%$ of the responses were LFR and $80 \%$ were HFR. In the PoA, the responses jumped to $100 \%$ HFR, or a $20 \%$ jump in knowledge. 
The open-ended comments for the last two questions show a growth in knowledge to echo the results listed in the above sections. Reflecting on the knowledge during the PoA of how to implement a comprehensive approach to postsecondary readiness, one participant stated, "very insightful." Another said, "an excellent approach and very thoughtful." Two other positive comments on the guidebook and workshop are: "Wow, I feel this guidebook gives direction with how to proceed." "Now we have a compass." Looking at the last question dealing with resources to help, one participant stated, "thanks for the help." Another participant said, "Thanks to the guidebook."

After looking at all of the data on the PrA- and PoAs, I was very happy with the positive results and comments about the workshop and guidebook. All of the sections imparted knowledge on the participants and made them think about the process. Overall, I would say that the most impactful part of the surveys were the last two questions:

1. I know how to implement a comprehensive approach to postsecondary readiness at my school.

2. I am aware of resources to help improve our process of postsecondary preparedness.

These questions directly relate to the usefulness of the guidebook. Both the survey responses and the open-ended comments relating to these questions were extremely positive. It gave me confidence that the guidebook had the basic structure to give participants the knowledge of a comprehensive approach to postsecondary readiness along with resources to help them implement this approach at their school sites. Because the implementation dip can be confusing to analyze, I would have reconstructed the questions differently to help make the analysis of the data easier to connect knowledge 
gained from using the guidebook. Unfortunately, I did not do this for the main field test as it was a lesson learned throughout the process.

Interviews on postsecondary readiness. Bridges and Hallinger (1995) pointed out that formative data point to ways the researcher can improve the product. This was my goal as I began the interviews with the participants. Within a month, I was able to interview two participants from the preliminary field test to collect qualitative data on the workshop and guidebook. The first interviewee was Erin who is a teacher at AHCN. She has been in education for 10 years. She has currently been in her position for the last 3 years where she runs a leadership program for college and high school students on a college campus. In the past she has taught college reading, and human development courses at the college. The second person I interviewed was Linda. Linda is a program director for AHCN and has been involved in education for the last 7 years. She has currently been in her position for the last 3 years where she is working on developing a systematic approach to identify college readiness skills for students and help support them in their acquisition of these skills. Both participants have some knowledge regarding postsecondary readiness, while at the same time; they feel their schools/programs do not provide a comprehensive approach. They both were interested in finding more about a comprehensive approach to postsecondary readiness and wanted to share their ideas from their experiences with the workshop and guidebook. Table 31 reflects the demographic data of the participants in the interviews. 
Table 31

Preliminary Field Test: Educational Leaders Interview Demographics

\begin{tabular}{|l|l|l|l|l|l|l|}
\hline Participant & Role & Ethnicity & $\begin{array}{c}\text { School/ } \\
\text { Program }\end{array}$ & Location & $\begin{array}{c}\text { Experience in } \\
\text { Education }\end{array}$ & $\begin{array}{c}\text { Experience in } \\
\text { Current Position }\end{array}$ \\
\hline Linda & $\begin{array}{l}\text { Program } \\
\text { Director }\end{array}$ & $\begin{array}{l}\text { Black } \\
\text { (African } \\
\text { American) }\end{array}$ & AHCN & Texas & $7-10$ years & $1-3$ years \\
\hline Erin & Teacher & Caucasian & AHCN & Oregon & $7-10$ years & $1-3$ years \\
\hline
\end{tabular}

Note. Pseudonyms were used to protect participants' identities.

Both of the interviews were done via teleconference and I used voice memos to capture their words and thoughts. While they were talking, I took notes to capture my thoughts. Prior to the interview, each participant signed a consent form. The primary focus of this interview was to collect qualitative data to help refine the workshop and guidebook on postsecondary readiness. All the data collected measured the usefulness of the workshop and guidebook. The participants of this study were not the subjects of this study. I revised the interview protocol from step 2 and used the refined version in this step of the R\&D cycle to collect data from the interviews (Appendix G).

Results of interviews on postsecondary readiness. As in step 2 of the $R \& D$ process, I generated inductive codes which are defined as codes that are generated by a researcher by directly examining the data (Johnson \& Christensen, 2007). This helped to break the interviews down into themes using descriptive words to characterize segments of the data. As seen in Table 32, I also used facesheet coding which captures the demographic data from the interviews. I did not get to analyze the facesheet coding because my interview sample size was too small. 
Table 32

Preliminary Field Test: Key Themes From Two Coded Interviews

\begin{tabular}{|l|c|}
\hline \multicolumn{1}{|c|}{ Themes } & Number of Pieces of Information Coded \\
\hline Consistency & 8 \\
\hline Systematic Approach & 15 \\
\hline Guided Approach & 13 \\
\hline Communication & 11 \\
\hline Reflections & 9 \\
\hline Breadth and Length & 12 \\
\hline Streamlined & 6 \\
\hline Common Language & 8 \\
\hline Standards & 4 \\
\hline Targets & 4 \\
\hline Recommendations & 5 \\
\hline Design & 7 \\
\hline Compass & 8 \\
\hline Alignment & 11 \\
\hline Comprehensive & 12 \\
\hline
\end{tabular}

The main source of data analysis I used was enumeration. This reveals the themes and frequency of the data collected. Following the interview protocol, I generated and enumerated the following codes from the interviews: systematic approach (15), guided approach (13), breadth and length (12), comprehensive (12), and communication and alignment (10). The participants were excited about the possibility of a guidebook that will provide direction for their schools/programs in preparing students for postsecondary success. They identified systematic approach as the most positive, useful aspect of the guidebook. They also thought that it provided a guided approach for educational leaders 
and their teams. One concern they had was that they were worried about the breadth and length of the guidebook. They also thought the workshop was too brief for the comprehensive approach I was using with the guidebook. Linda liked the comprehensive approach and they mentioned that they have never seen an approach to postsecondary readiness this complete. Erin mentioned that she thought that the guidebook would help with system and level alignment and the communication that comes with it.

The constructive feedback by all of the participants during the interview phase helped me to look at the current state of my guidebook and plan out the next revisions for improvement of my guidebook. Table 33 shows the feedback the interviewees gave regarding the necessary components and approach to a guidebook.

The two interviews with the different educational leaders gave me formative feedback on both the workshop and guidebook. The formative feedback proved to be the most helpful of all. The participants were able to give me specifics about how to improve my approach to postsecondary readiness. Linda's pointed out, "This is an excellent approach to helping educational leaders in this topic." She also noted that there should be, "an assessment of the guidebook's usability." Another key piece of information she gave was that I should, "include in the presentation how the guidebook fits with where their (participating members) school is currently." Linda's formative feedback was specific to what I needed, and I believe this was due to the fact that she is a program director. Erin, the teacher, gave me some important formative feedback as well. She noted, "I do like how the guidebook serves as a guide and not an answer to school's problems." She also 
explained that I should extend the workshop into six session to match the sections in the guidebook. This would give participants an "incredible" experience with the guidebook. She thought I should, "Include targets and recommendations to the workshop and guidebook for clarity." This feedback was very helpful in the main product revision of the $R \& D$ process.

Table 33

Preliminary Field Test: Formative Interview Feedback

\begin{tabular}{|l|l|}
\hline Participants & \multicolumn{1}{|c|}{ Preliminary Guidebook Advice/Components } \\
\hline Linda & - This is an excellent approach to helping educational leaders in this topic. \\
- Create an assessment for each section and component of the guidebook. \\
- Modify the workshop to go with each section of the guidebook. \\
- I was really educated about all of the successful approaches and it was great to \\
- have them presented in such an organized manner. \\
- There needs to be an assessment of the guidebook's usability. \\
- I get to the end of each section and say, "so what?" Include an action plan with \\
- each section. \\
- It is difficult to measure effective. \\
- You might want to broaden the language to include language for all education \\
- levels \\
theik sure you include in your presentation how the guidebook fits with where \\
- Include targets and recommendations to the workshop and guidebook for clarity. \\
- I would also add a section for reflections and planning. \\
- I think the academic element section can be really powerful as it provides a \\
common language. \\
- The language is very K-12 \\
- I do like how the guidebook serves as a guide and not an answer to school's \\
problems. \\
- You should present the whole guidebook in a workshop that lasts either one full \\
- Create an easy guide to break into chunks to overcome the breadth of the \\
guidebook.
\end{tabular}

Note. Pseudonyms were used to protect participants' identities. 
The preliminary field test was another important step for revising and refining the workshop and guidebook. It gave me additional information from a group of educational leaders different than those in the small-scale testing phase. I received rich, specific formative and summative feedback from interviews and surveys to help in the main product revision. Despite the scheduling conflicts and limited time requirements to conduct the workshop and interviews, I took away many important things to improve my product and research approach. I learned that the workshop evaluation was valuable, because it exposed the limitations to the workshop agenda and timeline. The agenda needed to include a more in-depth workshop experience where sessions would dive into each section of the guidebook and allow time to process the information. I also gained confidence in my guidebook. The guidebook had the necessary components toward helping participants gain the knowledge to implement a comprehensive approach to postsecondary readiness. I just needed to make a few adjustments and additions to make it better. These adjustments will be addressed in the next sections. Through my experience with the small-scale testing and the preliminary field test, I felt I had the necessary data to move to step 5 of the R\&D cycle.

\section{Step 5: Main Product Revision}

The feedback in step 4 gave me more depth in assessing the impact of the workshop and guidebook. I took this feedback as the basis for product revision in this step of the R\&D cycle. Bridges and Hallinger (1995) added that this may entail revision of any or all of the guidebook's components. The development of my guidebook from 
template in step 1 to an initial form of a guidebook that was tested during the preliminary field testing gave me satisfaction with the progress of my research. In this step, I saw the guidebook take more of a functional form than ever before in this research project.

The first major revision was to the workshop itself. I added to my research questions to include a question that demanded specific feedback about the workshop: What improvements and changes to the workshop are needed to help educational leaders navigate more successfully through the guidebook? From the feedback in the previous step I needed to change how the workshop connected to the guidebook. The workshop in the preliminary field test provided an overview, but the workshop in the main field test needed to go deeper into the sections of the guidebook. This was important because of the breadth and depth of the topic and the fact that I was proposing a comprehensive approach to postsecondary readiness.

With the feedback from the preliminary field testing, I continued to revise and add to my research questions. The questions were revised to be open-ended and allow for more constructive and thoughtful feedback. I created and revised data collection protocols around the guidebook itself. These protocols centered on the perceived impression of the guidebook's usability, applicability, and accessibility. Within each section I added design questions and targets to give more of a focused approach. I also added a recommendation and reflection section to help users connect the material in the guidebook to their own practices. At the end of each section I added an action plan guide that helps users navigate through the next steps with their leadership teams. Lastly, I 
revised my interview protocols to contain specific questions to address the content of each section of the guidebook (Figure 7).

\section{Target 1}

\section{()}

\section{The Problem: Many Students Graduating from Secondary Schools Aren't Ready for a Postsecondary Education!}

\begin{tabular}{|l|c|c|c|c|c|}
\hline \multirow{2}{*}{$\begin{array}{l}\text { Indicate how much you agree with the following } \\
\text { statements about Target 1. }\end{array}$} & \multicolumn{5}{|c|}{ Please select only one response } \\
\cline { 2 - 6 } & $\begin{array}{l}\text { Strongly } \\
\text { Disagree }\end{array}$ & Disagree & Neutral & Agree & $\begin{array}{c}\text { Strongly } \\
\text { Agree }\end{array}$ \\
\hline This section clearly defined the problem. & $\bigcirc$ & $\bigcirc$ & $\bigcirc$ & $\bigcirc$ & $\bigcirc$ \\
\hline $\begin{array}{l}\text { The research in this section was relevant to the } \\
\text { problem. }\end{array}$ & $\bigcirc$ & $\bigcirc$ & $\bigcirc$ & $\bigcirc$ & $\bigcirc$ \\
\hline $\begin{array}{l}\text { This section helped me better understand the } \\
\text { problem. }\end{array}$ & $\bigcirc$ & $\bigcirc$ & $\bigcirc$ & $\bigcirc$ & $\bigcirc$ \\
\hline $\begin{array}{l}\text { This section helped me reflect on my current beliefs } \\
\text { and practices at my school as they relate to the } \\
\text { problem. }\end{array}$ & $\bigcirc$ & $\bigcirc$ & $\bigcirc$ & $\bigcirc$ & $\bigcirc$ \\
\hline $\begin{array}{l}\text { The recommendations in this section were helpful. } \\
\text { Assessing Current Knowledge at the end of the } \\
\text { section helped me understand what I need to do to } \\
\text { address the problem in my school. }\end{array}$ & $\bigcirc$ & $\bigcirc$ & $\bigcirc$ & $\bigcirc$ & $\bigcirc$ \\
\hline
\end{tabular}

Figure 7. Questionnaire on section of the PRG. This figure shows an assessment of one of the sections of the PRG.

\section{Step 6: Main Field Testing}

Now that I had a more functional product in my workshop and guidebook, I looked to implement and collect data on its usefulness. Bridges and Hallinger (1995) noted that, "it is at this stage that the researcher collects the key data concerning the 
products efficacy" (p. 122). The data collected during this step included both formative and summative data.

When I looked at the data from steps 2 and 4, I realized that educational leaders need a comprehensive approach to postsecondary readiness. Data from these steps confirmed the need for this approach. Feedback from participants revealed that the workshop and guidebook could provide a systematic, comprehensive approach and improve communication from one level of education to another. To maximize the use of both the workshop and guidebook, I implemented a workshop which took participants through every section of the guidebook along with its components. I adjusted the workshop agenda (Appendix J) to include: revised goals, the addition of objectives for the week, an agenda for each day of the week detailing activities and assignments, and added components from feedback and data collected in the prior step. These additions also include: an assessment to measure the usefulness of the workshop as well as a preand post- assessment of the postsecondary readiness process; and an assessment for participants to measure the perceived impression of the guidebook's usability, applicability, and accessibility. Lastly, I conducted interviews and gathered formative data to improve the product. The following surveys were administered during the main field testing through SurveyMonkey:

1. PrA of postsecondary readiness-This questionnaire covers the content and approaches within the guidebook and provides overall information of the participants' knowledge on the elements of the guidebook.

2. Survey of the workshop-This questionnaire provides information on how useful the workshop was in helping participants navigate through the guidebook. 
3. Survey of the guidebook-This questionnaire measures the perceived impression of the guidebook's usability, applicability, and accessibility.

4. PoA of postsecondary readiness-This questionnaire covers the content and approaches within the guidebook and provides information on ways the guidebook was useful.

This section covers the: participants, workshop and workshop evaluation, guidebook and guidebook's evaluation on usability, applicability, and accessibility, PrA and PoAs, and interview data. This section describes summative and formative data collected during the main field test. As with the preliminary field test, I was pleased to find the participants' comments to be positive and constructive toward improving the guidebook for the main field test. However, the process was not ideal for the implementation of the workshop and guidebook which is discussed later in this chapter and in chapter 5 .

Participants of main field test. In order to find a site that could provide me with the information on the usefulness of my workshop and guidebook, I looked for a school that was unique and provided an innovative approach to education. This site had to focus on postsecondary readiness, and it would be ideal if this site contained more than one level of education. This was important to me because key transition knowledge and alignment were components of my guidebook. Fortunately, I knew an educational leader at a school that matched these criteria. I contacted him to see if he and his school would like to participate in the main field test of my workshop and guidebook. I had met the administration of this school previously, while visiting this acquaintance, so they knew who I was along with my role in education. After initial interest, I sent a letter of introduction to the administrative team (Appendix H). A few months later they contacted 
me, agreed to be part of my study, and we scheduled a time for the field test. As I proceeded with the next steps, my acquaintance, an assistant administrator at the school served as a "gatekeeper." A gatekeeper is an individual who has inside status with a group and serves as the initial contact for the researcher and leads the researcher to other participants (Creswell, 2007).

Oasis Academy. The main field test was conducted with educational leaders from a K-12 public charter school in another state that serves underrepresented youth. Oasis Academy (pseudonym) is a Pre-Kindergarten-12 public conversion charter school which enrolls 900 students located in the rural area of Meadowview (pseudonym). Oasis Academy is the largest charter school in the state. Meadowview is home to socioeconomically and ethnically marginalized citizens. Rates in Meadowview show that $20.0 \%$ of families with children and $15.6 \%$ of individuals were below the poverty level. At Oasis Academy, $78.7 \%$ of students live in economic hardship, and $14.1 \%$ of students at the school have been identified as homeless or residing in emergency/transitional housing. On state tests, only $35.7 \%$ of Oasis' students were proficient in reading and only 23.2\% in math. The mission of Oasis Academy is to prepare self-directed, self-aware, college-ready learners who will embrace the challenges of obstacles, experience the pride of perseverance and accomplishments, and demonstrate the strength of family and community.

Oasis Academy was a great site to field test the workshop and guidebook because it serves four levels of education: elementary, middle school, high school, and college. It 
serves a diverse group of students from the community. The participants were open to a comprehensive approach to postsecondary readiness, and because of this I was able to get excellent feedback from participants in all of these areas. I met with the administrative team throughout the week. I met with the secondary team on the second and third day of my visit. I met with the sixth grade team on the third and fourth days. Lastly, I met with the fifth grade team on the fifth and last day of my visit. In all, the field test included 26 participants. Table 34 shows these participants and their demographics.

Table 34

Main Field Test: Participant Demographics

\begin{tabular}{|c|c|c|c|}
\hline \multicolumn{4}{|c|}{ Administrative Team } \\
\hline Participant & Ethnicity & Role & Meeting Dates \\
\hline Jill & Caucasian & $\begin{array}{l}\text { School Director and } \\
\text { High School Principal }\end{array}$ & $\begin{array}{l}\text { February 3, 2014- } \\
\text { February 7, 2014 }\end{array}$ \\
\hline John & Caucasian & $\begin{array}{l}\text { Middle School } \\
\text { Principal and Special } \\
\text { Education Coordinator } \\
\text { and Gatekeeper }\end{array}$ & $\begin{array}{l}\text { February 3, 2014- } \\
\text { February 7, 2014 }\end{array}$ \\
\hline Pete & Caucasian & $\begin{array}{l}\text { Elementary School } \\
\text { Principal }\end{array}$ & $\begin{array}{l}\text { February 3, 2014- } \\
\text { February 7, 2014 }\end{array}$ \\
\hline \multicolumn{4}{|l|}{ Secondary Team } \\
\hline Participant & Ethnicity & Role & Meeting Dates \\
\hline James & Caucasian & $\begin{array}{l}\text { High School } \\
\text { Humanities Teacher }\end{array}$ & $\begin{array}{l}\text { February 4, 2014- } \\
\text { February 7, 2014 }\end{array}$ \\
\hline Mark & Caucasian & $\begin{array}{l}\text { High School Science } \\
\text { Teacher }\end{array}$ & $\begin{array}{l}\text { February 4, 2014- } \\
\text { February 7, 2014 }\end{array}$ \\
\hline Noah & Pacific Islander & College Coordinator & $\begin{array}{l}\text { February 4, 2014- } \\
\text { February } 7,2014\end{array}$ \\
\hline Sarah & Caucasian & $\begin{array}{l}\text { High School Language } \\
\text { Arts Teacher }\end{array}$ & $\begin{array}{l}\text { February 4, 2014- } \\
\text { February 7, 2014 }\end{array}$ \\
\hline Victor & African American & $\begin{array}{l}\text { PE } \\
\text { High School Teacher }\end{array}$ & $\begin{array}{l}\text { February 4, 2014- } \\
\text { February 7, 2014 }\end{array}$ \\
\hline Amy & Hispanic/Latino & $\begin{array}{l}\text { High School Math } \\
\text { Teacher }\end{array}$ & $\begin{array}{l}\text { February 4, 2014- } \\
\text { February 7, 2014 }\end{array}$ \\
\hline Sarah & Caucasian & $\begin{array}{l}\text { High School Language } \\
\text { Arts Teacher }\end{array}$ & $\begin{array}{l}\text { February 4, 2014- } \\
\text { February 7, 2014 }\end{array}$ \\
\hline
\end{tabular}


Table 34 (continued)

\begin{tabular}{|c|c|c|c|}
\hline \multicolumn{4}{|l|}{ Secondary Team } \\
\hline Participant & Ethnicity & Role & Meeting Dates \\
\hline Leslie & Pacific Islander & $\begin{array}{l}\text { Middle School } \\
\text { Language Arts }\end{array}$ & $\begin{array}{l}\text { February 4, 2014- } \\
\text { February 7, } 2014\end{array}$ \\
\hline Mary & Caucasian & $\begin{array}{l}\text { Middle School } \\
\text { Language Arts }\end{array}$ & $\begin{array}{l}\text { February 4, 2014- } \\
\text { February 7, } 2014\end{array}$ \\
\hline Clark & Pacific Islander & $\begin{array}{l}\text { Middle School Math } \\
\text { Teacher }\end{array}$ & $\begin{array}{l}\text { February 4, 2014- } \\
\text { February 7, } 2014\end{array}$ \\
\hline Kathy & Other/Multicultural & $\begin{array}{l}\text { Middle School Science } \\
\text { Teacher }\end{array}$ & $\begin{array}{l}\text { February 4, 2014- } \\
\text { February 7, } 2014\end{array}$ \\
\hline \multicolumn{4}{|l|}{ Sixth Grade Team } \\
\hline Participant & Ethnicity & Years in Education & Meeting Dates \\
\hline $\begin{array}{l}\text { Paula } \\
\end{array}$ & Pacific Islander & $1 \frac{1}{2}$ years & $\begin{array}{l}\text { February 5, 2014- } \\
\text { February 7, } 2014\end{array}$ \\
\hline Richard & Pacific Islander & 12 years & $\begin{array}{l}\text { February 5, 2014- } \\
\text { February 7, } 2014\end{array}$ \\
\hline Colleen & Caucasian & 9 years & $\begin{array}{l}\text { February 5, 2014- } \\
\text { February 7, } 2014\end{array}$ \\
\hline Charles & Pacific Islander & 16 years & $\begin{array}{l}\text { February 5, 2014- } \\
\text { February 7, 2014 }\end{array}$ \\
\hline David & African American & 2 years & $\begin{array}{l}\text { February 5, 2014- } \\
\text { February 7, } 2014\end{array}$ \\
\hline \multicolumn{4}{|l|}{ Fifth Grade Team } \\
\hline Participant & Ethnicity & Years in Education & Meeting Dates \\
\hline Ryan & Caucasian & 4 years & February 7, 2014 \\
\hline Carla & Pacific Islander & 12 years & February 7, 2014 \\
\hline Luisa & Hispanic/Latino & 2 years & February 7, 2014 \\
\hline Eric & Caucasian & 8 years & February 7, 2014 \\
\hline Jill & Caucasian & 2 years & February 7, 2014 \\
\hline Kara & Asian & 5 years & February 7, 2014 \\
\hline Paul & Caucasian & 1 year & February 7, 2014 \\
\hline
\end{tabular}

Note. Pseudonyms were used to protect participants' identities.

Main field test postsecondary readiness workshop. I spent one week with the

participants during the main field test to present the guidebook through a series of workshops. During this week, I collected the necessary formative and summative data on both the workshop and guidebook. We met in classrooms, conference rooms, offices, and the library. Each meeting site was conducive to the workshop. Prior to my visit I sent all of the participants an electronic version of the guidebook, a PrA to gauge their 
knowledge on the postsecondary readiness process, and an informed consent document (Appendix I). All of these were sent one week in advance of my visit. I provided a series of five workshops with educational leaders of three to 10 members from each level of the school (elementary, middle, high and administrative teams). I met with the administrative team throughout the week. I met with the secondary teams the second, third, fourth and fifth days of my visit. I met with the sixth grade team on the third, fourth and fifth days of my visit, and I met with the fifth grade team on the last day of my visit. The workshops were tailored to each level group and their involvement in the postsecondary readiness process (Table 35).

Table 35

Main Field Test: Workshop Schedule

\begin{tabular}{|c|c|c|c|c|c|}
\hline \multirow[b]{2}{*}{$\begin{array}{l}\text { Oasis } \\
\text { Academy } \\
\text { Team }\end{array}$} & \multicolumn{5}{|c|}{ Postsecondary Readiness Workshop Schedule } \\
\hline & $\begin{array}{c}\text { Monday } \\
\text { February 3, } \\
2014\end{array}$ & $\begin{array}{c}\text { Tuesday } \\
\text { February 4, } \\
2014\end{array}$ & $\begin{array}{l}\text { Wednesday } \\
\text { February } 5 \text {, } \\
2014\end{array}$ & $\begin{array}{c}\text { Thursday } \\
\text { February } 6 \text {, } \\
2014\end{array}$ & $\begin{array}{c}\text { Friday } \\
\text { February } 7,2014\end{array}$ \\
\hline $\begin{array}{l}\text { Admin. } \\
\text { Team }\end{array}$ & $\begin{array}{l}\text { Workshop on } \\
\text { Section 1- } \\
\text { The Problem }\end{array}$ & & $\begin{array}{l}\text { Workshop on } \\
\text { Section 2- } \\
\text { Structural } \\
\text { Elements }\end{array}$ & $\begin{array}{l}\text { Workshop on } \\
\text { Section 5- } \\
\text { Application }\end{array}$ & $\begin{array}{l}\text { Workshop on } \\
\text { Section 6- } \\
\text { Resources }\end{array}$ \\
\hline $\begin{array}{l}\text { Secondary } \\
\text { Team }\end{array}$ & & $\begin{array}{l}\text { Workshop on } \\
\text { Section 1- } \\
\text { The Problem }\end{array}$ & $\begin{array}{l}\text { Workshop on } \\
\text { Section 3- } \\
\text { Academic } \\
\text { Elements }\end{array}$ & $\begin{array}{l}\text { Workshop on } \\
\text { Section 5- } \\
\text { Application }\end{array}$ & $\begin{array}{l}\text { Workshop on } \\
\text { Section 6- } \\
\text { Resources }\end{array}$ \\
\hline $\begin{array}{l}\text { Sixth Grade } \\
\text { Team }\end{array}$ & & & $\begin{array}{l}\text { Workshop on } \\
\text { Section 1-The } \\
\text { Problem }\end{array}$ & $\begin{array}{l}\text { Workshop on } \\
\text { Section 4- } \\
\text { Social } \\
\text { Elements }\end{array}$ & $\begin{array}{l}\text { Workshop on } \\
\text { Section 6- } \\
\text { Resources }\end{array}$ \\
\hline $\begin{array}{l}\text { Fifth Grade } \\
\text { Team }\end{array}$ & & & & & $\begin{array}{l}\text { Workshop on } \\
\text { Section 1-The } \\
\text { Problem }\end{array}$ \\
\hline
\end{tabular}


The workshops were based on a guidebook designed to provide schools with the tools to help all students transition successfully to postsecondary options following high school. Prior to the beginning of the first workshop I gave each participant a copy of the guidebook: Bridging the Future to Postsecondary Readiness. The workshops included: goals and objectives, agendas, self-assessments of postsecondary readiness, reflections on practice, recommendations, action plans, resources and information on a comprehensive approach to postsecondary readiness (Appendix J). The workshop provided an opportunity to assess the usefulness of the workshop, guidebook's usability, applicability, and accessibility (Appendix K).

Workshop introduction and the problem. I met with every team and went over the workshop format and The Problem from the guidebook. Because school was in session, I had to present this workshop four times over the course of the week. I began with the administrative team and finished the last day with the fifth grade team. During this workshop I went over the goals, agenda for the week, data collection procedures, and how to use the guidebook. Due to time constraints, each of these four sessions lasted for one hour.

Workshop on structural elements. For this section of the guidebook, I met only with the administrative team. The elements in this section were pertinent to their job descriptions and their times to meet were flexible. The elements in this session included:

- Developing a mission/vision.

- Infrastructure (academic preparedness, academic tenacity, use of data.) 
- Developing a college knowledge (developing a college-going culture and local partnerships).

I would have liked to meet with every team and hold a workshop on this section, but due to school being in session and time constraints, I was only able to meet with the administrative team. I only presented information from this workshop once during the week. I was able to go through the entire section and complete the activities. This session lasted one hour.

Workshop on academic elements. During this workshop session I met only with the secondary team. The elements of this section of the guidebook were relevant to this group over the others. The elements in this session included:

- Creating a rigorous curriculum.

- College and career readiness standards and practices.

- Quality instructional practices.

- Identification of skills and progress.

I would have liked to include the administrative and sixth grade team during this session; however, due to school being in session and time constraints, I was only able to meet with the secondary team. I only presented information from this workshop once during the week. I was able to go through the entire section and complete the activities. This session lasted one hour.

Workshop on social elements. During this workshop session I met only with the sixth grade team. The elements of this section of the guidebook were the most relevant to this group over the others. The elements in this session included: 
- Including parents and school staff in educational planning.

- Identifying and building academic behaviors of students.

- Improving both students' and parents' transition knowledge and skills.

I would have liked to include all teams during this session; however, due to school being in session and time constraints, I was only able to meet with the sixth grade team. I only presented information from this workshop once during the week. I was able to go through the entire section and complete the activities. This session lasted one hour.

Workshop on application. During this workshop session I met with the administrative and secondary teams. As in the workshops above, the application of postsecondary readiness was the most relevant to these groups over the others. This section showed how the elements in the guidebook were applied in a secondary school setting. Once again, I would have liked to include all teams during this session; however, due to school being in session and time constraints, I was only able to meet with two teams. I only presented information from this workshop once during the week. I was able to go through the entire section and complete the activities. This session lasted one hour.

Workshop on resources. During this workshop session I met with the administrative, secondary, and sixth grade teams. This was a great session to end the workshops. I was able to get the majority of the teams together and go over the resources; answer questions from prior to the week, and discuss how they would move forward with their work on postsecondary readiness. I only presented information from this workshop 
once during the week. I was able to go through the entire section, field questions and facilitate a discussion around postsecondary readiness. This session lasted one hour.

When participants finished one session of the workshop, they took the PRG workshop survey (Table 36). This took them approximately 10 minutes to complete. Because of time constraints, participants assessed only one workshop session. The administrative team assessed the workshop from Section 2-Structural Elements. The secondary team assessed the workshop from Section 3-Academic Elements. The sixth grade team assessed the workshop from Section 4-Social Elements. The fifth grade team assessed the workshop from Section 1-The Problem.

Results of the survey on the workshop. In this section, participants were asked to rate the level of agreement based on the questions about the workshop (Table 36). All participants took part in the workshop, and completed the survey. There were 25 participants in all. The questions from the workshop were broken down into the following categories: content, design, facilitator/instructor, results and delivery. The last piece of data collection asked participants how they would improve the workshop. The survey used a Likert scale of 1-5. The scale served the purpose of collecting participants' level of agreement to a series of statements in each section. On the Likert scale 1 equaled Strongly Disagree and 5 equaled Strongly Agree. 
Table 36

Main Field Test: Workshop Evaluation

\begin{tabular}{|c|c|c|c|c|c|c|}
\hline Workshop & Questions & $\begin{array}{l}\text { Strongly } \\
\text { Disagree }\end{array}$ & Disagree & Neutral & Agree & $\begin{array}{l}\text { Strongly } \\
\text { Agree }\end{array}$ \\
\hline \multirow[t]{3}{*}{$\begin{array}{l}\text { Workshop } \\
\text { Content }\end{array}$} & $\begin{array}{l}\text { I was well informed about the } \\
\text { goals and objectives of this } \\
\text { workshop. }\end{array}$ & & & 3 & 11 & 11 \\
\hline & $\begin{array}{l}\text { This workshop lived up to } \\
\text { my expectations. }\end{array}$ & & & 3 & 9 & 13 \\
\hline & $\begin{array}{l}\text { The content is relevant to my } \\
\text { job. }\end{array}$ & & & 6 & 8 & 11 \\
\hline \multirow[t]{3}{*}{$\begin{array}{l}\text { Workshop } \\
\text { Design }\end{array}$} & $\begin{array}{l}\text { The workshop activities } \\
\text { stimulated my learning. }\end{array}$ & & & 3 & 6 & 16 \\
\hline & $\begin{array}{l}\text { The difficulty level of this } \\
\text { workshop was appropriate. }\end{array}$ & & & 2 & 10 & 13 \\
\hline & $\begin{array}{l}\text { The pace of this workshop } \\
\text { was appropriate. }\end{array}$ & & & 2 & 10 & 13 \\
\hline \multirow{2}{*}{$\begin{array}{l}\text { Workshop } \\
\text { Facilitator/ } \\
\text { Instructor }\end{array}$} & $\begin{array}{l}\text { The instructor was well } \\
\text { prepared. }\end{array}$ & & & 1 & 8 & 16 \\
\hline & The instructor was helpful. & & & 1 & 8 & 16 \\
\hline \multirow[t]{2}{*}{$\begin{array}{l}\text { Workshop } \\
\text { Results }\end{array}$} & $\begin{array}{l}\text { I accomplished the goals of } \\
\text { this workshop. }\end{array}$ & & & 5 & 10 & 10 \\
\hline & $\begin{array}{l}\text { I will be able to use what I } \\
\text { learned in this workshop. }\end{array}$ & & & 4 & 8 & 13 \\
\hline Delivery & $\begin{array}{l}\text { The workshop was a good } \\
\text { way for me to learn this } \\
\text { content. }\end{array}$ & & & 8 & 9 & 8 \\
\hline
\end{tabular}

Workshop content. In this category, $88 \%$ of participants agreed or strongly agreed on being strongly informed about the goals and objectives of the workshop while the remaining 12\% marked neutral. One respondent commented, "very clear," while another responded, "Wondering if the topic applies to fifth grade." I assumed that this last comment may be indicative of the fact that fifth grade is many years from college and the relevance among these participants may not be as strong. On the question of whether the workshop lived up to expectations, $88 \%$ had favorable results. Out of the $88 \%, 52 \%$ 
strongly agreed. Two respondents commented that they did not have any expectations. This could be attributed to how well the participants were informed of my visit. The last question on Workshop Content revealed that $76 \%$ of respondents agreed or strongly agreed that the content was relevant to their jobs. The remaining $24 \%$ marked neutral on this question. Overall, the data collected on the Workshop Content was favorable. The content connected with the vast majority of participants with no negative categories being marked.

Workshop design. The data in this category showed improvements from the preliminary field test. The question relating to the workshop activities reveal that $88 \%$ of respondents marked agree or strongly agree. One of the comments stated, "It really got me thinking." Another comment revealed that the workshop activities had an, "interesting approach." The difficulty level of the workshop showed very favorable results with $92 \%$ of respondents agreeing or strongly agreeing. One participant commented, "Yes, perfect for the secondary team." The participants thought that the pace was appropriate with $92 \%$ agreeing or strongly agreeing. The $8 \%$ of respondents marked neutral on this question. I believe the results and comments of the Workshop Design improved because I incorporated the guidebook's activities into each workshop to connect more with the participants. I was happy to see improvement in this area.

Facilitator/instructor. Data from this category revealed that $96 \%$ of respondents thought I was well prepared while the remaining $4 \%$ marked neutral. A vast majority of respondents (96\%) marked that I was helpful during the workshop with one commenting, 
"Very knowledgeable on the topic." I was pleased to see that the participants saw me as an effective facilitator of the topic.

Workshop results. The workshop data were good, but not as high as the previous categories. On accomplishing the goals of the workshop, $80 \%$ agreed or strongly agreed while 20\% marked neutral. One comment state, "So much more to do." Another comment noted frustration, "I don't know how to proceed with fifth graders." $84 \%$ of respondents thought they could use what they learned from the workshop. One respondent commented, "I would like to continue with this work." Another stated, "Not enough time to do my job of teaching fifth graders to read.” Other than this last comment, the data from Workshop Results were positive. I felt there was a gap an attitude and learning gap from the fifth grade team responses. As stated above, this could be due to the fact that the fifth grade team's students have the longest period to graduation than any other participating team's students.

Delivery. The one question on the Delivery related to whether the workshop was a good way for participants to learn this content, $68 \%$ agreed or strongly agreed, whereas $32 \%$ marked neutral. These were the lowest figures of the survey. The comments attached to this question give context to the result of the data:

- "Could use this with the whole staff."

- "Needs to be for the whole staff in a retreat."

- "I loved this workshop."

- "Would have loved to have this as a PD opportunity for the whole staff together." 
This next section provided data on how participants would improve the workshop. They were given a list (Table 37) 16 choices along with two open-ended questions of what was most and least valuable about the workshop.

There were three areas where respondents marked that they would improve the workshop. The biggest percentage responded that more time should be allowed for the workshop. Eighty-eight percent of respondents (14) noted this. The next two categories tied for second with $13 \%$ of respondents (2). They wanted better information before the workshop, and to add more video to the workshop.

The open-ended comments on least and most valuable about the workshop were revealing to the context of the study. I used inductive coding on this and there were nine comments about the time of day and year of the workshop. Two respondents commented that they were looking or questioning the application to fifth grade. Two respondents wanted more sessions, and two respondents wished that other grades were included with them in the workshop. One comment revealed the lack of preparation, "I wished I read more of the guidebook prior to the workshop.” Another voiced frustration, "“"I am busy with other things besides taking on something new." With the most valuable comments, I was pleased to read the results. Six participants thought the workshop provided an organized, systematic approach. Six participants thought the topic, concepts, best practices and resources were most valuable. Three liked the communication and vertical alignment. Two liked that it provided common language. Two thought the comprehensive approach was the most valuable, and two participants like everything. 
Table 37

Main Field Test: Workshop Formative Results

\begin{tabular}{|c|c|c|}
\hline How would you improve this workshop? & Results & $\%$ \\
\hline Provide better information before the workshop. & 2 & 13 \\
\hline Clarify the workshop objectives. & 0 & 0 \\
\hline Reduce the content covered in the workshop. & 0 & 0 \\
\hline Increase the content covered in the workshop. & 0 & 0 \\
\hline Update the content covered in the workshop. & 0 & 0 \\
\hline Improve the instructional methods. & 0 & 0 \\
\hline Make workshop activities more stimulating. & 0 & 0 \\
\hline Improve workshop organization. & 0 & 0 \\
\hline Make the workshop less difficult. & 1 & 6 \\
\hline Make the workshop more difficult. & 0 & 0 \\
\hline Slow down the pace of the workshop. & 0 & 0 \\
\hline Speed up the pace of the workshop. & 0 & 0 \\
\hline Allow more time for the workshop. & 14 & 88 \\
\hline Shorten the time for the workshop. & 0 & 0 \\
\hline Improve the tests used in the workshop. & 0 & 0 \\
\hline Add more video to the workshop. & 2 & 13 \\
\hline $\begin{array}{l}\text { What is least valuable about the workshop? } \\
\text { - Time of day and year (9) } \\
\text { - Application to } 5^{\text {th }} \text { grade (2) } \\
\text { - More sessions needed (2) } \\
\text { - Wish other grades were with us (2) } \\
\text { - "I wished I read more of the guidebook prio } \\
\text { - "I am busy with other things besides taking }\end{array}$ & $\begin{array}{l}\text { xshop." } \\
\text { g new." }\end{array}$ & \\
\hline $\begin{array}{l}\text { What is most valuable about the workshop? } \\
\text { - Organized systematic approach (6) } \\
\text { - The topic, concepts, best practices and resol } \\
\text { - Communication and vertical alignment (3) } \\
\text { - Common language (2) } \\
\text { - Comprehensive approach (2) } \\
\text { - Everything (2) }\end{array}$ & & \\
\hline
\end{tabular}


The results from the data on the workshop were very favorable. This was due to the feedback and data collected from the preliminary field test. I will take this data and use it to improve the workshop even further if/when I pursue steps 8-10 of the R\&D cycle.

Survey of the guidebook. The one assessment that was added to the main field test that was not administered during the preliminary field test was that of testing and evaluating a guidebook. This was a critical component to add to my study because I wanted my guidebook to be usable, applicable and accessible. To meet these needs, I created a survey to capture this data (Table 38). My guidebook falls under the category of an instructional manual (Folmer, Moynihan, \& Schothorst, n.d.). According to an instructional manual: teaches new knowledge and skills, it shows how to do something, and it introduces new ways of looking at a task (Folmer et al., n.d.). When creating the guidebook I wanted to include appropriate material related to my topic. This included current research and appropriate resources. The guidebook also had to have a nice presentation. Potential users would have to want to engage with it. The last aspect I needed out of my guidebook was that it had to be available when and where it was needed. These criteria helped to achieve my goal of a useful guidebook. After engaging with the guidebook, participants of my field test were given a survey to test the overall guidebook based on these criteria. 
Table 38

Main Field Test: Guidebook Evaluation

\begin{tabular}{|c|c|c|c|}
\hline \multicolumn{2}{|r|}{ Overall Guidebook Evaluation } & No & Yes \\
\hline \multirow[t]{5}{*}{ Usability } & $\begin{array}{l}\text { Did the cover, Table of Contents and Introduction } \\
\text { encourage you to read further? }\end{array}$ & & $\begin{array}{c}17 \\
(100 \%)\end{array}$ \\
\hline & $\begin{array}{l}\text { Are the views, opinions and theories based on the best and } \\
\text { most up to date information/research? }\end{array}$ & & $\begin{array}{c}17 \\
(100 \%) \\
\end{array}$ \\
\hline & Is the guidebook free of hidden values or attitudes? & & $\begin{array}{c}17 \\
(100 \%)\end{array}$ \\
\hline & $\begin{array}{l}\text { Do you have sufficient existing knowledge to make sense } \\
\text { of the new information given? }\end{array}$ & $\begin{array}{c}3 \\
(18 \%) \\
\end{array}$ & $\begin{array}{c}14 \\
(82 \%)\end{array}$ \\
\hline & $\begin{array}{l}\text { Does the guidebook help you understand how the elements } \\
\text { of the postsecondary readiness framework will help your } \\
\text { school? }\end{array}$ & $\begin{array}{c}1 \\
(6 \%)\end{array}$ & $\begin{array}{c}16 \\
(94 \%)\end{array}$ \\
\hline \multirow[t]{5}{*}{ Applicability } & $\begin{array}{l}\text { Does the guidebook take into account the knowledge and } \\
\text { skills available to the K-12 educational leader? }\end{array}$ & $\begin{array}{c}2 \\
(12 \%) \\
\end{array}$ & $\begin{array}{c}15 \\
(88 \%)\end{array}$ \\
\hline & $\begin{array}{l}\text { Does the guidebook take into account the time and } \\
\text { motivation available to the K-12 educational leader? }\end{array}$ & $\begin{array}{c}9 \\
(53 \%) \\
\end{array}$ & $\begin{array}{c}8 \\
(47 \%)\end{array}$ \\
\hline & $\begin{array}{l}\text { Does the workshop on the sections, application and } \\
\text { resources of the guidebook help you understand how to use } \\
\text { the guidebook? }\end{array}$ & & $\begin{array}{c}17 \\
(100 \%)\end{array}$ \\
\hline & Is the information well-structured and easy to find? & & $\begin{array}{c}17 \\
(100 \%)\end{array}$ \\
\hline & Is the text readable? & & $\begin{array}{c}17 \\
(100 \%)\end{array}$ \\
\hline \multirow[t]{6}{*}{ Accessibility } & Are the colors used well? & & $\begin{array}{c}17 \\
(100 \%)\end{array}$ \\
\hline & $\begin{array}{l}\text { Can you list the six sections of the Postsecondary Readiness } \\
\text { Guidebook? }\end{array}$ & $\begin{array}{c}11 \\
(65 \%) \\
\end{array}$ & $\begin{array}{c}6 \\
(35 \%) \\
\end{array}$ \\
\hline & $\begin{array}{l}\text { Can you list the three elements of the Postsecondary } \\
\text { Readiness Framework? }\end{array}$ & $\begin{array}{c}1 \\
(6 \%) \\
\end{array}$ & $\begin{array}{c}16 \\
(94 \%)\end{array}$ \\
\hline & $\begin{array}{l}\text { Without looking it up, can you explain in your own words } \\
\text { what the guidebook means when it talks about 'the } \\
\text { problem'? }\end{array}$ & & $\begin{array}{c}17 \\
(100 \%)\end{array}$ \\
\hline & $\begin{array}{l}\text { Do the components of the guidebook (design questions, } \\
\text { targets, activity circles, recommendations etc.) really help } \\
\text { you gain information and skills on the topic? }\end{array}$ & & $\begin{array}{c}17 \\
(100 \%)\end{array}$ \\
\hline & $\begin{array}{l}\text { Is the reader given a way to assess his or her progress } \\
\text { toward postsecondary readiness elements? }\end{array}$ & & $\begin{array}{c}17 \\
(100 \%) \\
\end{array}$ \\
\hline
\end{tabular}


Table 38 (continued)

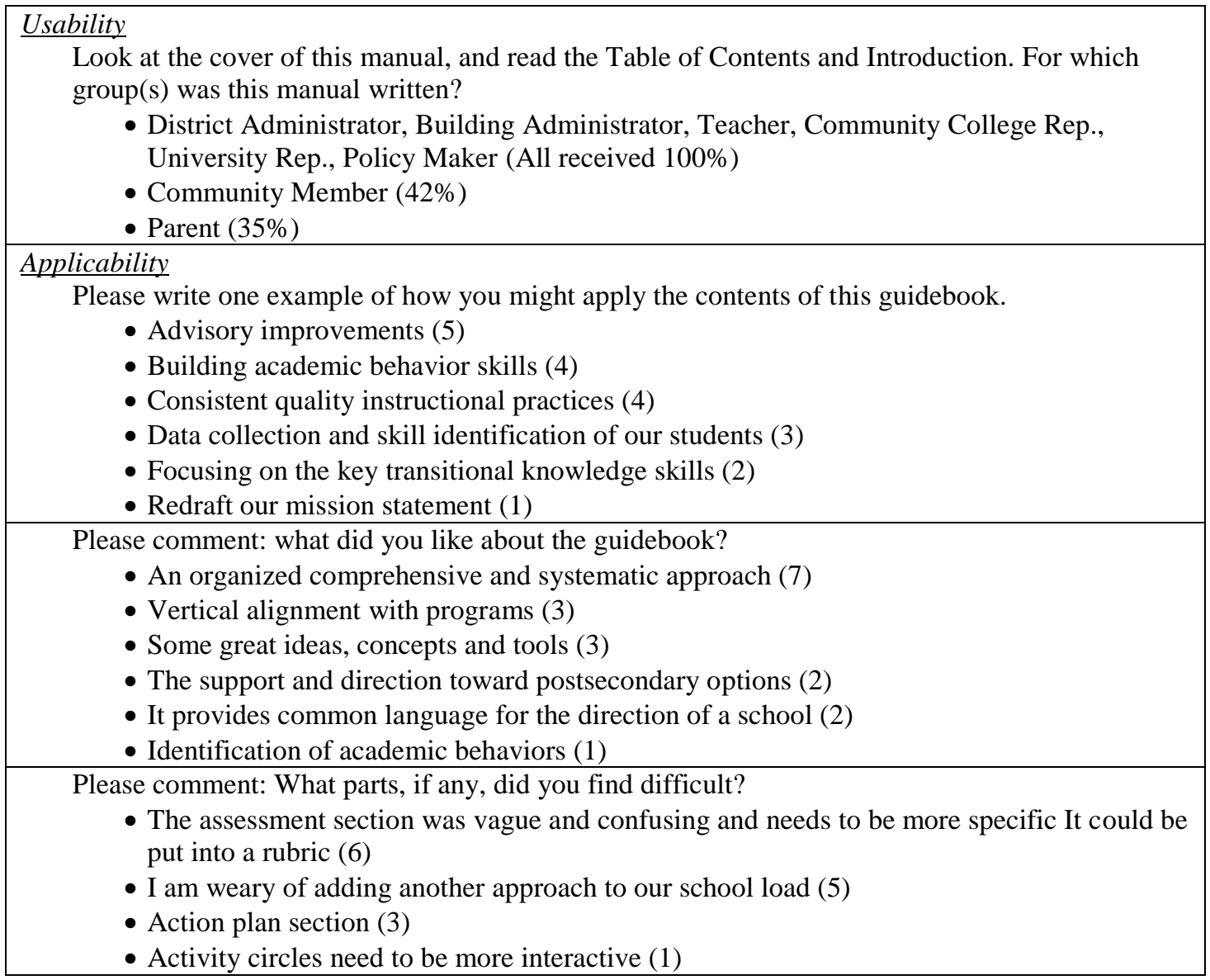

Results of the survey of the guidebook. Prior to my visit at Oasis Academy, I sent

all participant of the main field test an electronic version of the guidebook. On my first day at the site, I gave all participants a hard copy of the guidebook along with reading assignments throughout the week. The last day of my visit to Oasis Academy, I administered a survey to measure the usability, applicability, and accessibility of the guidebook. I did it on the last day to give the participants many opportunities to engage with the guidebook by participating in workshops throughout the week. The survey 
consisted of four questions on demographics, four open-ended questions, and 16 yes/no questions. From the staff of Oasis Academy, 17 participants took the survey. For the analysis of this data, I refer to the category yes as positive and the category no as negative.

The overall data collected on the Usability of the guidebook is revealing, yet positive. Questions on the cover, table of contents and introduction along with current views, opinions and theories both received $100 \%$ positive results. The respondents also marked $100 \%$ positive that the guidebook was free of hidden values and attitudes. The question about existing knowledge for the comprehension of new information received $82 \%$ (14) positive marks and 18\% (3) negative marks. Respondents felt that the guidebook helped to understand how the elements of the postsecondary readiness framework would help their school. These results were 94\% (16) positive and 6\% (1) negative. The one open-ended question about Usability revealed all respondents thought the audience of the guidebook included all of the following: district administrator, building administrator, teacher, community college rep., university rep., and policy maker. Only $42 \%$ (7) thought the audience would be community members, and 35\% (6) thought the audience would be parents. I address how these data impacted the operational product revision later in this chapter.

Concerning the data on the Applicability of the guidebook, the results were not as positive as the Usability section. Three questions, however, showed overwhelming positive responses. The questions on the helpfulness of the components of the guidebook, 
well-structured and easy to find information, and the readability of the guidebook all received $100 \%$ positive results. Respondents $(88 \%-15)$ marked that the guidebook took into account the knowledge and skills of K-12 educational leaders, while $2 \%$ (2) thought that the guidebook did not do this. The biggest split in this survey dealt with whether the guidebook took into account the time and motivation of K-12 educational leaders. The results of this question reveal 53\% (9) of the respondents thought the guide book ignored time and motivation of K-12 educational leaders. $47 \%$ (8) of the respondents thought the guidebook took time and motivation into account. The one open-ended question relating to the Applicability of the guidebook showed how respondents would apply concepts of the guidebook. Five respondents said that it would help with advisory improvements. Four said it would help build academic behavior skills. Another four revealed it provided consistent quality instructional practices. Three respondents would use it for data collection and skill identification, and two would use it to build key transitional knowledge skills. One administrator would use it to redraft the mission statement. I was pleased to see that the respondents thought the Applicability of the guidebook was useful, however I thought the data on time and motivation of educational leaders was disappointing. I was not surprised by the high percentage of respondents who thought the guidebook ignored the time and motivation of educational leaders. I address this later in this chapter under issues and challenges.

Lastly, the data on the Accessibility of the guidebook revealed that four questions received $100 \%$ positive results. These questions dealt with: the colors of the guidebook, 
identification of the problem, the components helped with increase the knowledge of the topic, and a self-assessment of postsecondary readiness elements. Almost all respondents (94\%-16) could identify the three elements of the postsecondary readiness framework. However, 65\% (11) of respondents could not list the six sections of the guidebook. The open-ended formative data on what respondents liked about the guidebook and what they found difficult really gave me the information with which to improve the workshop and guidebook. Seven participants liked that it provided an organized comprehensive and systematic approach. Three participants liked how the guidebook addressed the vertical alignment with programs and levels. Another three liked the ideas, concepts and tools. Two liked how the guidebook supported the direction toward postsecondary options. Another two thought it provided a common language for the direction of a school. Six participants though the assessment component at the end of each section was vague and confusing. They noted it needed specificity or a rubric. Five members were weary of adding more approaches to their school work loads. Three members thought the action plan section could be improved for sustainability. I disagree with the comments of the guidebook adding more approaches to their work loads. If planned properly and connected with school improvement plans, the guidebook will help to make best practices systematic and work more efficient. I do agree, however, with their comments pertaining to the action plan. If integrated into the workshop and enough time is planned for the facilitation of the action plan, then I believe that the practices in the guidebook can be sustainable. 
PrA and PoAs of postsecondary readiness. Prior to the main field test, I sent all participants a PrA. I administered the PoA at the site on my final day, and collected responses for one week after I had left. The PrA and PoA were based on the same questions. Both assessments used a Likert scale of 1-5. The scale served the purpose of collecting frequency with 1 being Never, and 5 being Always. Participants rated how often the theme on postsecondary readiness in each question occurred at their site/school. The content of the pre- and post- assessments was used to gauge the participants' understanding and knowledge of the topic-postsecondary readiness. The questions from the pre- and post- assessment are meant to serve two purposes: (a) discover information and practices from the guidebook, and (b) connect the information from the guidebook to their own sites. I did this by posing questions which allowed the participants to include relative data from their own schools/programs. I then used questions connected to the material from each section of the guidebook to measure their understanding and knowledge of the components within these sections. The PoA was used to capture the participants' new knowledge gained from using the guidebook.

All of the participants took part in a workshop that covered the sections of the guidebook. The workshop was created to help educational leaders increase their knowledge of the guidebook. The questions from the PrA and PoAs are listed in Table 39 and the results from these surveys follow. 
Table 39

Main Field Test: PrA and PoAs and Formative Results on Postsecondary Readiness

\begin{tabular}{|c|c|c|}
\hline Postsecondary Readiness & $\operatorname{PrA}$ & PoA \\
\hline $\begin{array}{l}\text { 1. We prepare students for postsecondary } \\
\text { options at my school. }\end{array}$ & $\begin{array}{l}\text { - } 36 \% \text {-Sometimes } \\
\text { - } 53 \% \text {-Often } \\
\text { - } 16 \% \text {-Always } \\
\end{array}$ & $\begin{array}{l}\text { - } 29 \% \text {-Hardly ever } \\
\text { - } 71 \% \text {-Sometimes }\end{array}$ \\
\hline \multicolumn{3}{|c|}{$\begin{array}{l}\text { Open-Ended Comments from the PrA } \\
\text { - We are having our first class graduate this year. } \\
\text { - Yes for the students that are motivated, others get left behind. } \\
\text { Open-Ended Comments from the PoA } \\
\text { - We aren't looking at this in elementary school } \\
\text { - Who is we; I don't know if this is school-wide } \\
\text { - This is our goal } \\
\text { - We try at the secondary level } \\
\text { - Not consistently }\end{array}$} \\
\hline $\begin{array}{l}\text { 2. Preparing students for postsecondary options } \\
\text { is a top priority for our school. }\end{array}$ & $\begin{array}{l}\text { - } 16 \% \text {-Sometimes } \\
\text { - } 58 \% \text {-Often } \\
\text { - } 26 \% \text {-Always } \\
\end{array}$ & $\begin{array}{l}\text { - } 59 \% \text {-Hardly ever } \\
\text { - } 41 \% \text {-Sometimes }\end{array}$ \\
\hline \multicolumn{3}{|l|}{$\begin{array}{l}\text { Open-Ended Comments from the PoA } \\
\text { - Not for elementary-maybe for secondary } \\
\text { - Not for all } \\
\text { - All need to get on board } \\
\text { - Ne are graduating our first class this year } \\
\text { - Not systematic } \\
\text { - It needs to be unified }\end{array}$} \\
\hline $\begin{array}{l}\text { 3. Our mission and vision was created through } \\
\text { shared values and beliefs of all stakeholders } \\
\text { involved with the school. }\end{array}$ & $\begin{array}{l}\text { - } 5 \% \text {-Hardly ever } \\
\text { - } 42 \% \text {-Sometimes } \\
\text { - } 42 \% \text {-Often } \\
\text { - } 11 \% \text {-Always }\end{array}$ & $\begin{array}{l}\text { - } 35 \% \text {-Never } \\
\text { - } 53 \% \text {-Hardly ever } \\
\text { - } 12 \% \text {-Sometimes }\end{array}$ \\
\hline $\begin{array}{l}\text { Open-Ended Comments from the PoA } \\
\text { - Yes, } 4 \text { years ago } \\
\text { - Not included } \\
\text { - We need to revisit this } \\
\text { - I've never been a part of this } \\
\text { - We don't look at our mission statement ever } \\
\text { - We haven't looked at our mission in } 4 \text { years }\end{array}$ & & \\
\hline
\end{tabular}


Table 39 (continued)

\begin{tabular}{|c|c|c|}
\hline Postsecondary Readiness & $\operatorname{PrA}$ & PoA \\
\hline $\begin{array}{l}\text { 4. Data are used to create and drive } \\
\text { postsecondary readiness programs and } \\
\text { policies. }\end{array}$ & $\begin{array}{l}\text { - } 11 \% \text {-Hardly ever } \\
\text { - } 50 \% \text {-Sometimes } \\
\text { - } 39 \% \text {-Often }\end{array}$ & $\begin{array}{l}\text { - } 12 \% \text {-Never } \\
\text { - } 64 \% \text {-Hardly ever } \\
\text { - } 24 \% \text {-Sometimes }\end{array}$ \\
\hline $\begin{array}{l}\text { Open-Ended Comments from the PrA } \\
\text { - There really isn't any data because we haven't } \\
\text { Open-Ended Comments from the PoA } \\
\text { - This is up to our teams } \\
\text { - Personality driven } \\
\text { - No structure for this } \\
\text { - No foundation for data-random collection } \\
\text { - It is random } \\
\text { - Random collection and analysis }\end{array}$ & ad a class graduate ye & \\
\hline $\begin{array}{l}\text { 5. Standards, curriculum and assessments are } \\
\text { aligned to college readiness expectations. }\end{array}$ & $\begin{array}{l}\text { - } 32 \% \text {-Sometimes } \\
\text { - } 58 \% \text {-Often } \\
\text { - } 11 \% \text {-Always }\end{array}$ & $\begin{array}{l}\text { - } 6 \% \text {-Never } \\
\text { - } 12 \% \text {-Hardly ever } \\
\text { - } 82 \% \text {-Sometimes }\end{array}$ \\
\hline \multicolumn{3}{|c|}{$\begin{array}{l}\text { Open-Ended Comments from the PoA } \\
\text { - We didn't know how to do this in elementary school } \\
\text { - Thanks to the Common Core } \\
\text { - Common Core }\end{array}$} \\
\hline $\begin{array}{l}\text { Interventions are in place at my school to keep } \\
\text { students on track for postsecondary success. }\end{array}$ & $\begin{array}{l}\text { - } 16 \% \text {-Hardly ever } \\
\text { - } 26 \% \text {-Sometimes } \\
\text { - } 58 \% \text {-Often }\end{array}$ & $\begin{array}{l}\text { - } 18 \% \text {-Hardly ever } \\
\text { - } 82 \% \text {-Sometimes }\end{array}$ \\
\hline \multicolumn{3}{|c|}{$\begin{array}{l}\text { Open-Ended Comments from the PoA } \\
\text { - I don't know what they are but I think we do this } \\
\text { - We need direction with this } \\
\text { - hit and miss } \\
\text { - We have money and resources for this }\end{array}$} \\
\hline $\begin{array}{l}\text { 7. Tenacity-building activities are systematic and } \\
\text { implemented across all grade levels. }\end{array}$ & $\begin{array}{l}\text { - } 47 \% \text {-Hardly ever } \\
\text { - } 35 \% \text {-Sometimes } \\
\text { - } 18 \% \text {-Often }\end{array}$ & $\begin{array}{l}\text { - } 18 \% \text {-Never } \\
\text { - } 65 \% \text {-Hardly ever } \\
\text { - } 18 \% \text {-Sometimes }\end{array}$ \\
\hline $\begin{array}{l}\text { Open-Ended Comments from the PoA } \\
\text { - We try } \\
\text { - Secondary needs to do this } \\
\text { - Not at the secondary level }\end{array}$ & & \\
\hline
\end{tabular}


Table 39 (continued)

\begin{tabular}{|c|c|c|}
\hline Postsecondary Readiness & $\operatorname{PrA}$ & PoA \\
\hline $\begin{array}{l}\text { 8. My school has developed a college-going } \\
\text { culture. }\end{array}$ & $\begin{array}{l}\text { - } 5 \% \text {-Hardly ever } \\
\text { - } 32 \% \text {-Sometimes } \\
\text { - } 53 \% \text {-Often } \\
\text { - } 11 \% \text {-Always }\end{array}$ & $\begin{array}{l}\text { - } 65 \% \text {-Hardly ever } \\
\text { - } 35 \% \text {-Sometimes }\end{array}$ \\
\hline \multicolumn{3}{|l|}{$\begin{array}{l}\text { Open-Ended Comments from the PoA } \\
\text { - Just saying it doesn't make it happen } \\
\text { - We are trying } \\
\text { - We don't know yet } \\
\text { - Not school-wide yet } \\
\text { - Not as a school } \\
\text { - This is random } \\
\text { - It is random }\end{array}$} \\
\hline $\begin{array}{l}\text { 9. My school has developed partnerships with } \\
\text { local colleges and universities. }\end{array}$ & $\begin{array}{l}\text { - } 16 \% \text {-Sometimes } \\
\text { - } 79 \% \% \text {-Often } \\
\text { - } 5 \% \text {-Always }\end{array}$ & $\begin{array}{l}\text { - } 18 \% \text {-Hardly ever } \\
\text { - } 82 \% \text {-Sometimes }\end{array}$ \\
\hline \multicolumn{3}{|c|}{$\begin{array}{l}\text { Open-Ended Comments from the PoA } \\
\text { - I don't know } \\
\text { - I believe so } \\
\text { - Through the navigation center } \\
\text { - This is personality driven through our navigation center }\end{array}$} \\
\hline 10. Curriculum at my school is rigorous. & $\begin{array}{l}\text { - } 47 \% \text { Sometimes } \\
\text { - } 53 \% \text {-Often }\end{array}$ & $\begin{array}{l}\text { - } 24 \% \text {-Hardly ever } \\
\text { - } 76 \% \text {-Sometimes }\end{array}$ \\
\hline \multicolumn{3}{|l|}{$\begin{array}{l}\text { Open-Ended Comments from the PoA } \\
\text { - I don't know } \\
\text { - Depends on the grade } \\
\text { - Personality driven } \\
\text { - Personality driven }\end{array}$} \\
\hline $\begin{array}{l}\text { 11. Our teachers and school align curriculum, } \\
\text { instruction, assessment, and programs to } \\
\text { college and career readiness standards. }\end{array}$ & $\begin{array}{l}\text { - } 67 \% \text {-Sometimes } \\
\text { - } 33 \% \text {-Often }\end{array}$ & $\begin{array}{l}\text { - } 71 \% \text {-Hardly ever } \\
\text { - } 29 \% \text {-Sometimes }\end{array}$ \\
\hline \multicolumn{3}{|c|}{$\begin{array}{l}\text { Open-Ended Comments from the PoA } \\
\text { - We don't use our time wisely } \\
\text { - No collaboration } \\
\text { - This should happen at all levels } \\
\text { - We didn't know how to do this until the guidebook } \\
\text { - I didn't know what these were until reading your guidebook }\end{array}$} \\
\hline
\end{tabular}


Table 39 (continued)

\begin{tabular}{|c|c|c|}
\hline Postsecondary Readiness & $\operatorname{PrA}$ & PoA \\
\hline $\begin{array}{l}\text { 12. Quality instructional practices are consistently } \\
\text { integrated into each class offered at my } \\
\text { school. }\end{array}$ & $\begin{array}{l}\text { - } 61 \% \text {-Sometimes } \\
\text { - } 33 \% \text {-Often } \\
\text { - } 6 \% \text {-Always }\end{array}$ & $\begin{array}{l}\text { - } 59 \% \text {-Never } \\
\text { - } 29 \% \text {-Hardly ever } \\
\text { - } 12 \% \text {-Sometimes }\end{array}$ \\
\hline \multicolumn{3}{|l|}{$\begin{array}{l}\text { Open-Ended Comments from the PoA } \\
\text { - This should happen } \\
\text { - Teacher fear this } \\
\text { - Everyone is different } \\
\text { - This needs to become systematic } \\
\text { - Very little } \\
\text { - Once again-personality driven }\end{array}$} \\
\hline $\begin{array}{l}\text { 13. There is a structure set up at my school for the } \\
\text { systematic identification of skills and } \\
\text { progress. }\end{array}$ & $\begin{array}{l}\text { - } 17 \% \text {-Hardly ever } \\
\text { - } 50 \% \text {-Sometimes } \\
\text { - } 33 \% \text {-Often }\end{array}$ & $\begin{array}{l}\text { - } 12 \% \text {-Never } \\
\text { - } 71 \% \text {-Hardly ever } \\
\text { - } 18 \% \text {-Sometimes }\end{array}$ \\
\hline \multicolumn{3}{|l|}{$\begin{array}{l}\text { Open-Ended Comments from the PoA } \\
\text { - Just within our teams }\end{array}$} \\
\hline $\begin{array}{l}\text { 14. Parents and school staff are included in } \\
\text { educational planning. }\end{array}$ & $\begin{array}{l}\text { - } 17 \% \text {-Hardly ever } \\
\text { - } 61 \% \text {-Sometimes } \\
\text { - } 22 \% \text {-Often }\end{array}$ & $\begin{array}{l}\text { - } 77 \% \text {-Hardly ever } \\
\text { - } 24 \% \text {-Sometimes }\end{array}$ \\
\hline \multicolumn{3}{|l|}{$\begin{array}{l}\text { Open-Ended Comments from the PoA } \\
\text { - Not enough collaborating with parents } \\
\text { - We are not ready for this yet }\end{array}$} \\
\hline $\begin{array}{l}\text { 15. There is a structure/program set up at my } \\
\text { school for identifying and building academic } \\
\text { behaviors of students. }\end{array}$ & $\begin{array}{l}\text { - } 17 \% \text {-Hardly ever } \\
\text { - } 34 \% \text {-Sometimes } \\
\text { - } 44-\text { Often }\end{array}$ & $\begin{array}{l}\text { - } 76 \% \text {-Hardly ever } \\
\text { - } 24 \% \text {-Sometimes }\end{array}$ \\
\hline \multicolumn{3}{|l|}{$\begin{array}{l}\text { Open-Ended Comments from the PoA } \\
\text { - Yes, at the elementary level } \\
\text { - Mostly at the elementary level } \\
\text { - Not at the secondary level } \\
\text { - Elementary does a better job with this }\end{array}$} \\
\hline $\begin{array}{l}\text { 16. Systematically, my school improves both } \\
\text { students' and parents' transition knowledge } \\
\text { and skills with regard to the transition from } \\
\text { elementary to middle school. }\end{array}$ & $\begin{array}{l}\text { - } 12 \% \text {-Never } \\
\text { - } 29 \% \text {-Hardly ever } \\
\text { - } 53 \% \text {-Sometimes }\end{array}$ & $\begin{array}{l}\text { - } 35 \% \text {-Never } \\
\text { - } 47 \% \text {-Hardly ever } \\
\text { - } 18 \% \text {-Sometimes }\end{array}$ \\
\hline $\begin{array}{l}\text { Open-Ended Comments from the PoA } \\
\text { - Too many gaps } \\
\text { - We should survey parents on this } \\
\text { - Very little communication }\end{array}$ & & \\
\hline
\end{tabular}


Table 39 (continued)

\begin{tabular}{|c|c|c|}
\hline Postsecondary Readiness & $\operatorname{PrA}$ & PoA \\
\hline $\begin{array}{l}\text { 17. Systematically, my school improves both } \\
\text { students' and parents' transition knowledge } \\
\text { and skills with regard to the transition from } \\
\text { middle school to high school. }\end{array}$ & $\begin{array}{l}\text { - } 6 \% \text {-Never } \\
\text { - } 29 \% \text {-Hardly ever } \\
\text { - } 53 \% \text {-Sometimes } \\
\text { - } 12 \% \text {-Often }\end{array}$ & $\begin{array}{l}\text { - } 38 \% \text {-Never } \\
\text { - } 50 \% \text {-Hardly ever } \\
\text { - } 13 \% \text {-Sometimes }\end{array}$ \\
\hline \multicolumn{3}{|l|}{$\begin{array}{l}\text { Open-Ended Comments from the PoA } \\
\text { - Too many gaps } \\
\text { - We should survey parents on this } \\
\text { - Very little communication }\end{array}$} \\
\hline $\begin{array}{l}\text { 18. Systematically, my school improves both } \\
\text { students' and parents' transition knowledge } \\
\text { and skills with regard to the transition from } \\
\text { high school to college. }\end{array}$ & $\begin{array}{l}\text { - } 6 \% \text {-Never } \\
\text { - } 12 \% \text {-Hardly ever } \\
\text { - } 35 \% \text {-Sometimes } \\
\text { - } 41 \% \text {-Often } \\
\text { - } 6 \% \text {-Always }\end{array}$ & $\begin{array}{l}\text { - } 35 \% \text {-Hardly ever } \\
\text { - } 65 \% \text {-Sometimes }\end{array}$ \\
\hline \multicolumn{3}{|l|}{$\begin{array}{l}\text { Open-Ended Comments from the PoA } \\
\text { - Too many gaps } \\
\text { - We should survey parents on this } \\
\text { - We are better with this at the secondary level }\end{array}$} \\
\hline $\begin{array}{l}\text { 19. I know how to implement a comprehensive } \\
\text { approach to postsecondary readiness at my } \\
\text { school. }\end{array}$ & $\begin{array}{l}\text { - } 35 \% \text {-Never } \\
\text { - } 52 \% \text {-Hardly ever } \\
\text { - } 6 \% \text {-Sometimes }\end{array}$ & $\begin{array}{l}\text { - } 12 \% \text {-Sometimes } \\
\text { - } 53 \% \text {-Often } \\
\text { - } 35 \% \text {-Always }\end{array}$ \\
\hline \multicolumn{3}{|c|}{$\begin{array}{l}\text { Open-Ended Comments from the PoA } \\
\text { - I've never seen an approach like this } \\
\text { - I hope our leaders adopt this approach to unite all levels toward postsecondary options } \\
\text { - Thanks for the organized approach } \\
\text { - This guidebook and workshop gave me direction and an awareness of how to approach this } \\
\text { - Your approach enlightened me to this process }\end{array}$} \\
\hline $\begin{array}{l}\text { 20. I am aware of resources to help improve our } \\
\text { process of postsecondary preparedness. }\end{array}$ & $\begin{array}{l}\text { - } 12 \% \text {-Never } \\
\text { - } 53 \% \text {-Hardly ever } \\
\text { - } 29 \% \text {-Sometimes } \\
\text { - } 6 \% \text {-Often }\end{array}$ & $\begin{array}{l}\text { - } 17 \% \text {-Sometimes } \\
\text { - } 77 \% \text {-Often } \\
\text { - } 6 \% \text {-Always }\end{array}$ \\
\hline \multicolumn{3}{|c|}{$\begin{array}{l}\text { Open-Ended Comments from the PoA } \\
\text { - Thanks for refocusing us on the important concepts } \\
\text { - I wish this occurred at the beginning of the year } \\
\text { - Thanks for the tools } \\
\text { - Thanks for the help }\end{array}$} \\
\hline
\end{tabular}

Results of the survey of the PrA and PoAs. For consistency and accuracy, I used the same data analysis techniques as I did in the preliminary field test. The purpose of 
the PrA and PoA were twofold: (a) to discover information and practices from the guidebook, and (b) to connect the information from the guidebook to their own sites.

The PrA and PoA questions were created and categorized from sections of the guidebook. This helped me assess where the participant knowledge was strong and where it needed to be disseminated. The sections that the questions were categorized from were: The Problem, Structural Elements, Academic Elements, Social Elements, Applied Best Practices, and Resources. Although I tried to keep each question limited to one category, they often overlapped into more than one category.

Survey questions. After reviewing the guidebook and participating in the workshop, participants rated how often the theme of postsecondary readiness occurred at their site/school. The participants' ratings were tallied in percentages and listed above in Table 39. Since the Likert scale measured five categories (1-Never, 2-Hardly ever, 3Sometimes, 4-Often, 5-Always). I broke these categories into two parts; LFR and HFR. The HFR captured numbers 3-Sometimes, 4-Often, and 5-Always. The LFR captured numbers 2-Hardly ever, and 1-Never. After participating in the workshop and using the guidebook, I assumed from the results that a perceived growth of knowledge occurred with questions 1-18 in the following instances:

1. When data percentages decreased from HFR in the PrA to a data percentage increase of LFR; or a data percentage decrease from one HFR to a greater increase in a lower HFR (100\%-always in PrA to $100 \%$-sometimes in PoA)

2. When data percentages increased from LFR in the PrA to a greater data percentage increase of LFR; or a data percentage increase from one LFR to a greater increase in a lower frequency response (100\%-hardly ever in PrA to $100 \%$-never in PoA). 
As pointed out earlier in this chapter, this perceived growth of knowledge from these assessments is known as an implementation dip. This implementation dip is a dip in performance and confidence as one encounters an innovation that requires new skills and understanding (Fullan, 2001). It must be pointed out; however, that this perceived growth of knowledge shifts in questions 19-20 where percentages decreased from LFR in the PrA to a data percentage increase of HFR in the PoA.

Open-ended comments. There was a comment box at the end of each survey question for participants to complete (this was optional). During thePrA there were three open-ended comments. However, there were many comments after each question in the PoA (Table 39). These comments provided excellent qualitative data from which to assess the usefulness of the workshop, guidebook and postsecondary readiness process. They also add context to the Likert scale responses.

Self-assessment. In the PrA and PoA, the first two questions were a selfassessment of knowledge on perceived approaches toward postsecondary readiness. The first question of preparing students for postsecondary options; prior to the workshop on the guidebook, $100 \%$ of the responses were HFR: 36\%-sometimes, $53 \%$-often, and 16\%always. After the workshop and their time with the guidebook, this shift of knowledge changed to $71 \%$ HFR (sometimes) and $29 \%$ LFR (hardly ever). This was a perceived growth of knowledge on the components and approach to prepare students for postsecondary options. 
The open-ended questions during the PrA, respondents said, "We are having our first class graduate this year." Another respondent replied, "Yes, for the students that are motivated, others get left behind.” From the PoA, participants responded, "We aren't looking at this in elementary school." Another stated, "I don’t know if this is schoolwide."

The second question focused on postsecondary readiness being a top priority at their site. In the PrA, $100 \%$ of the responses were HFR: 16\%-sometimes, 58\%-often, and $26 \%$-always. After the workshop, there was a perceived shift in knowledge with $41 \%$ of the respondents marking HFR or sometimes and $59 \%$ of respondents marking LFR or hardly ever.

There were no open-ended comments from the PrA, but the comments from the PoA show six responses on the lack of a systematic or unified approach. One of the comments stated, "All need to get on board." Another shared, "It needs to be unified." One commented on the split in approach between levels, "Not for elementary-maybe for secondary."

After looking at the data on the first two questions, there was a perceived shift in knowledge around these themes after the workshop and their work with the guidebook. The HFR decreased $29 \%$ in the first question and a $59 \%$ decrease in the second question.

Structural elements. The next seven questions have to do with the structural elements of the guidebook. The third question about a mission created through shared values and beliefs of all stakeholders showed $95 \%$ of responses were HFR: $11 \%$ - 
sometimes, $42 \%$-often, and 42\%-always. After the workshop and time with the guidebook, the HFR reduced to $12 \%$-sometimes, with $88 \%$ of the responses revealing LFR: 35\%-never, 53\%-hardly ever.

There were no open-ended questions from the PrA, but from the PoA it was clear that there was little connection to the mission statement. Below are some of the comments on the mission statement:

- "We haven't looked at our mission in 4 years."

- "We don’t look at our mission statement ever."

- "We need to revisit this."

- "I've never been a part of this."

The second question on using data to create and drive a postsecondary approach in the PrA revealed 89\% HFR: 50\%-sometimes, 39\%-often. In the PoA, however, the percentage of HFR decreased to $24 \%$-sometimes, and LFR increased from $11 \%$-hardly ever to $64 \%$-hardly ever and $12 \%$-never.

The open-ended comments from the PrA once again stated, "There really isn't any data because we haven't had a class graduate yet." After the workshop respondents shared, "No foundation for data collection." Another stated, "Personality driven." While two responses reflected that the process was "random".

From the PrA, the next question on the alignment of standards, curriculum, and assessments to college readiness expectations show 100\% HFR: 32\%-sometimes, 58\%- 
often, and $11 \%$-always. From the PoA, however, the HFR decreased to $82 \%$-sometimes with an increase of $18 \%$ LFR-6\%-never, $12 \%$-hardly ever.

There were no open-ended comments prior to the workshop. From the PoA, respondents gave praise to the CCSS, "Thanks to the Common Core." Another participant shared, "We didn't know how to do this in elementary school."

On the theme of interventions, prior to the workshop and time with the guidebook, $84 \%$ were HFR: $26 \%$-sometimes, and 58\%-often. From the PoA this decreased to $82 \%$-sometimes. Although this was only a $2 \%$ decrease, it was a decrease of $58 \%$ from a higher category within the HFR (often to sometimes). As stated above respondents marked 58\%-often from the PrA to 0\%-often from the PoA.

There were no open-ended comments in the PrA, but in the PoA participants noted the lack of direction and communication with the intervention process. "I don't know what they are but I think we do this." Another stated, "We need direction with this." One noted, "Hit and miss." While another stated the potential, "We have money and resources for this."

The next question on tenacity-building activities, before the workshop respondents answers were 53\% HFR: 35\%-sometimes, 18\%-often. After the workshop the HFR decreased to $18 \%$-sometimes. The LFR increased from $47 \%$-hardly ever, to $83 \%$ LFR: $18 \%$-never, 65\%-hardly ever.

There were no open-ended comments in the PrA, but in the PoA, respondents stated, "We try." One noted, "Secondary needs to do this." Another echoed this comment, 
"Not at the secondary level." This clearly showed a split in approaches from one level to the next.

The next two questions dealt with creating a college-going culture. Prior to the workshop, $96 \%$ of respondents marked HFR: 32\%-sometimes, 53\%-often, and 11\%always. From the PoA and after the workshop, this decreased to 35\% HFR: 35\%sometimes. The LFR increased from 5\%-hardly ever to 65\%-hardly ever. The other question focused on partnership development with postsecondary institutions. From the PrA, $100 \%$ of respondents marked HFR: 16\%-sometimes, $79 \%$-often, and 5\%-always. From the PoA, this decreased to $82 \%$ HFR: $82 \%$-sometimes. The LFR increased from $0 \%$ in the PrA to $18 \%$-hardly ever in the PoA.

There were no open-ended comments for either of these questions in the PrA, however, the comments from the PoA focus on effort to confusion. One respondent noted, "Just saying it doesn't make it happen." Another responded, "We are trying." Dealing with the partnership with postsecondary institutions, one response stated, "This is personality driven through our Navigation Center."

The responses, both summative and formative, pertaining to the Structural Elements reveal many interesting things. The summative data clearly shows a decrease in HFR in every question and an increase in LFR. The formative comments show a lack of coordination and systematic approach toward postsecondary readiness in this area. The participants showed a discovery of information and clearly connected the information from the guidebook to their own sites. Therefore, the data collected in the PrA and the 
PoA on the Structural Elements revealed a presumed growth of knowledge after participants went through the workshop and guidebook.

Academic elements. The next questions (10-13) were under the Academic Elements section of the guidebook. Question 10 on rigorous curriculum had $100 \%$ HFR in the PrA: 47\%-sometimes, 53\%-often. This percentage decreased to 76\%-sometimes HFR, and 24\%-hardly ever LFR in the PoA.

There were no open-ended comments for either of these questions in the PrA, however, the comments from the PoA reveal a lack of coordination and transparency, “Depends on the grade.” Another noted, "I don’t know." Two participants stated, "Personality driven."

From the PrA, alignment of curriculum, instruction, assessment in question 11, respondents showed 100\% HFR: 67\%-sometimes, 33\%-often. After the workshop and engaging the guidebook, the HFR declined to $29 \%$-sometimes, with $71 \%$-hardly ever of the responses showing LFR.

There were no open-ended comments from the PrA, but the PoA revealed lack of collaboration and coordination. One of the respondents stated, "We don't use our time wisely.” Another noted, "This should happen at all levels." One replied, "No collaboration." Two respondents made direct comments about the guidebook, "We didn't know how to do this until the guidebook." Another stated, "I didn't know what these were until reading your guidebook." 
Question 12 on quality instructional practices from the PrA showed 100\% HFR: $61 \%$-sometimes, $33 \%$-often, and 6\%-always. From the PoA, responses declined to $12 \%$ sometimes HFR and $88 \%$ were LFR: 59\%-never, 29\%-hardly ever.

There were no open-ended comments from the PrA. However, the comments from the PoA showed a lack of direction, consistency, and coordination. To show this, a few of the responses from the open-ended comments in the PoA are listed below:

- "Teachers fear this."

- "Everyone is different."

- "This needs to become systematic."

The last question from the Academic Elements section dealt with the theme of the identification of skills and progress. From the PrA, 83\% of responses were HFR: 50\%sometimes, 33\%-often, and 17\%-hardly ever were LFR. From the PoA, the HFR decreased to $18 \%$-sometimes, and the LFR increased to $83 \%$ : $12 \%$-never and $71 \%$-hardly ever.

There were no open-ended comments from the PrA and only one comment from the PoA relating to the identification of skills and progress. One respondent commented that this happens, "Just within our teams."

The responses, both summative and formative, pertaining to the Academic Elements contain interesting data and comments. The summative data clearly shows an overwhelming decrease in HFR in every question and an increase in LFR. In just four questions the HFR decreased from $100 \%$ to $76 \%, 100 \%$ to $29 \%, 100 \%$ to $12 \%$, and $100 \%$ 
to $18 \%$. The formative responses show a lack of coordination, collaboration, and systematic approach within this section. As with the aforementioned section, the participants showed a discovery of information and clearly connected the information from the guidebook to their own sites. Therefore, the data collected in the PrA and the PoA on the Academic Elements revealed a presumed growth of knowledge after participants went through the workshop and guidebook.

Social elements. On both assessments, questions 14-18 fell under the Social Elements section of the guidebook. Question 14 dealt with the inclusion of parents and staff in the educational planning. In the PrA, $83 \%$ were HFR: $61 \%$-sometimes, $22 \%$ often. After the workshop the HFR decreased to 24\%-sometimes while the LFR increased from $17 \%$-hardly ever to $77 \%$-hardly ever.

There were no open-ended comments from the PrA and only two comments from the PoA relating to the inclusion of parents and staff in the educational planning. Both responses were different on the role of including these stakeholders with educational planning. One respondent commented, "Not enough collaborating with parents." Another stated, "We are not ready for this."

The next question dealt with building the academic behaviors of students. In the PrA, 78\% were HFR: 34\%-sometimes, 44\%-often, while 17\%-hardly ever were LFR. After the workshop the HFR decreased to $24 \%$-sometimes while the LFR increased from $17 \%$-hardly ever to $76 \%$-hardly ever. 
There were no open-ended comments from the PrA and the comments from the PoA showed a split in approaches to this theme of building academic behaviors. One respondent replied, "Yes, at the elementary level." Another echoed this comment, "Mostly at the elementary level." A third related to this by saying, "Not at the secondary level. A last comment summed all of these comments up, "Elementary does a better job with this."

Questions 16-18 all relate to the transitions from one level to another including: elementary to middle, middle to high, and high to college. In the PrA there were 53\%, $65 \%$, and $82 \%$ HFR with the elementary transition being the lowest followed by the middle school transition and then the high school to college as the highest percentage. The LFR were $41 \%, 35 \%$, and $18 \%$. In the PoA these percentages reduced to $18 \%, 13 \%$, and $65 \%$. The LFR increased to $82 \%, 88 \%$, and $35 \%$.

Once again, there were not any comments from the open-ended questions in the PrA. In the PoA, respondents claimed that there were too many gaps, and that the secondary levels do better with this. One respondent noted, "We should survey parents on this."

Guidebook knowledge. As noted in step 4 of this study, this section of questions from the PrA and PoA required a change in analysis from questions 1-18. To show a presumed growth of knowledge after participating in the workshop and reviewing the guidebook, I assumed from the results that a growth of knowledge occurred with questions $19-20$ in the following instances: 
1. When data percentages decreased from LFR in the PrA to a data percentage increase of HFR; or a data percentage decreased from a lower LFR to a greater increase in a higher LFR (100\%-never in PrA to $100 \%$-hardly ever in PoA); or a data percentage increase from a lower HFR to a greater increase in a higher HFR (100\%-sometimes in PrA to 100\%-always in PoA).

I was eager to collect and analyze the data from these two questions because the preliminary data showed positive results. I wanted to see the data from a larger sample size to see if the results from the main field test matched the preliminary field test.

Question 19 related to participants knowledge on how to implement a comprehensive approach to postsecondary readiness. This gave me direct data on one aspect of the usefulness of the guidebook. In the PrA $87 \%$ of the responses were LFR: 35\%-never, and 52\%-hardly ever while 6\%-sometimes marked HFR. From the PoA the HFR increased to 100\%: 12\%-sometimes, 53\%-often, and 35\%-always. This showed a 94\% jump in HFR responses. This pattern echoed true of question 20 relating to the resources of the guidebook. In the PrA $65 \%$ of the responses were LFR: 12\%-never, and 53\%-hardly ever while 35\% were HFR: $29 \%$-sometimes and 6\%-often. From the PoA the HFR increased to 100\%: 17\%-sometimes, 77\%-often, and 6\%-always. This showed a $65 \%$ jump in HFR responses.

There were no open-ended comments from the PrA and the comments from the PoA were quite positive. The comments about the guidebook were:

- "I've never seen an approach like this."

- "I hope our leaders adopt this approach to unite all levels toward postsecondary options."

- Thanks for the organized approach 
- This guidebook/workshop gave me direction and an awareness of how to approach this

- Your approach enlightened me to this process

The comments on the resources were:

- Thanks for refocusing us on the important concepts

- I wish this occurred at the beginning of the year

- Thanks for the tools

- Thanks for the help

The PrA and PoA provided me rich summative and formative data on the guidebook and its usefulness. I believe that the purpose of the assessments was achieved because the data revealed that participants discovered new information and practices from the guidebook and they connected this information to their own sites.

Interviews on postsecondary readiness. Throughout my research, the summative data were rich and gave me insight to the efficacy of the guidebook. However, I found the formative data captured information and improved the guidebook (Bridges \& Hallinger, 1995). This section discusses this information and the results of this formative data. The interview data were collected throughout the week during the main field test. I interviewed two administrators, two secondary level teachers, and two elementary teachers. I used an office, a conference room and classrooms that were conductive to collecting data for the interviews. I updated my interview protocols and research questions (Appendix L) to capture data pertaining to the individual sections of the 
guidebook. This would help me gather specific data relating to the content and approach of the guidebook, its resources and application.

The first interviewee was John (see Table 40). He was the gatekeeper for my field test, and he had more than 10 years of experience in education. A gatekeeper is an individual who has inside status with a group and serves as the initial contact for the researcher and leads the researcher to other participants (Creswell, 2007). I was able to meet with him after our first workshop on The Problem of the guidebook. We met in his office and along with my research questions, I also used the interview protocol one (Appendix M). The second person I interviewed was James. He is a secondary team leader and taught Humanities at the high school level. I met with him after our second workshop together. The interview focused on the on the workshop and Academic Elements of the guidebook. We met in his classroom and along with my research questions, I used the interview protocol two (Appendix N). The next interview was with Pete. He is an elementary administrator of the school and had been there the last 8 years. I met with him after our second workshop together. The interview focused on the workshop on Structural Elements of the guidebook. We met in the conference room and along with my research questions, I used the interview protocol three (Appendix O). My next interview was with Kathy. She is a middle school science teacher. I met with him after our third workshop together. The interview focused on the workshop and on the Application section of the guidebook. We met in her classroom and along with my research questions, I used the interview protocol four (Appendix P). The next interviewee 
was Paula. She was a team leader and a sixth grade teacher and I interviewed her after our second workshop together. The interview focused on the workshop on Social Elements of the guidebook. We met in her classroom and along with my research questions, I used the interview protocol five (Appendix Q). My last interview was with Eric. He was a team leader and taught fifth grade. I met with him after first and only workshop together. The interview focused on the workshop on The Problem section of the guidebook. We met in his classroom and along with my research questions, I used the interview protocol one (Appendix M).

Table 40

Main Field Test: Educational Leaders Interview Demographics

\begin{tabular}{|c|c|c|c|c|}
\hline Participant & Role & Ethnicity & Team & $\begin{array}{c}\text { Experience in } \\
\text { Education }\end{array}$ \\
\hline Pete & $\begin{array}{l}\text { Elementary } \\
\text { School Principal }\end{array}$ & Caucasian & $\begin{array}{l}\text { Administrative } \\
\text { Team }\end{array}$ & 8 years \\
\hline John & $\begin{array}{l}\text { Middle School } \\
\text { Principal and } \\
\text { Special Education } \\
\text { Coordinator and } \\
\text { Gatekeeper }\end{array}$ & Caucasian & $\begin{array}{l}\text { Administrative } \\
\text { Team }\end{array}$ & $11+$ years \\
\hline James & $\begin{array}{l}\text { High School } \\
\text { Humanities } \\
\text { Teacher }\end{array}$ & Caucasian & Secondary Team & 6 years \\
\hline Kathy & $\begin{array}{l}\text { Middle School } \\
\text { Science Teacher }\end{array}$ & Other/Multicultural & Secondary Team & 2 years \\
\hline Paula & $\begin{array}{l}\text { Sixth Grade } \\
\text { Teacher }\end{array}$ & Pacific Islander & Elementary Team & 2 years \\
\hline Eric & $\begin{array}{l}\text { Fifth Grade } \\
\text { Teacher }\end{array}$ & Caucasian & Elementary Team & 8 years \\
\hline
\end{tabular}

Note. Pseudonyms were used to protect participants' identities. 
Results of interviews on postsecondary readiness. Data were analyzed using inductive coding, facesheet coding, and enumeration. I transcribed the data from the interviews and coded them into key, descriptive words that characterized the themes and segments of the data. I used facesheet coding to identify the educational roles of individuals. This was helpful to disaggregate the data based on levels of respondents. Facesheet coding applies to a complete document, and I used this throughout the study (Johnson \& Christensen, 2007).

After inductive coding, the main source of data analysis I used was enumeration. This took the themes and revealed frequency of the data collected. Table 41 reveals the data collected and coded from six interviews on postsecondary readiness.

Following the interview protocols on my research questions and the guidebook, I generated and enumerated the following codes from the interviews: systematic approach (46), leadership (36), communication (34), consistency (32), and common language (29). The interviewees responded the most to the guidebook's systematic approach. They felt the importance of using it as a whole staff including different levels to bring one consistent approach to their school. They also realized the importance of leadership to this process. They felt this would be a great leadership tool for their teams. To pull these top two results together, they recognized communication as a critical component. Once again they thought the guidebook could help "immensely" with communication. All participants voiced a need for consistency as echoed with the comments on a systematic approach. To wrap up the top five coded themes was common language. The teachers 
interviewed really stressed the importance of this. A common language helps them move forward as a team, and they thought the guidebook and its components provide this

Table 41

Main Field Test: Key Themes From Six Coded Interviews

\begin{tabular}{|l|c|}
\hline \multicolumn{1}{|c|}{ Themes } & Number of Pieces of Information Coded \\
\hline Consistency & 32 \\
\hline Systematic Approach & 46 \\
\hline Communication & 34 \\
\hline Reflections & 24 \\
\hline Leadership & 36 \\
\hline Equity & 21 \\
\hline Common Language & 29 \\
\hline Standards & 18 \\
\hline Targets & 16 \\
\hline Recommendations & 23 \\
\hline Design & 13 \\
\hline Collaboration & 22 \\
\hline Professional Development & 26 \\
\hline Alignment & 19 \\
\hline Comprehensive & 28 \\
\hline Action Plan & 26 \\
\hline
\end{tabular}


Table 42

Main Field Test: Formative Interview Feedback

\begin{tabular}{|l|l|}
\hline Participants & \multicolumn{1}{c|}{ Preliminary Guidebook Advice/Components } \\
\hline John & - We need this type of tool at our site for consistency \\
- The organization of the workshop and guidebook helped in the understanding of \\
the concepts \\
- We need a K-12 College Readiness Alignment \& Plan \\
- This is directly linked to our accreditation process \\
- We are lacking a systematic approach and this will help us get there \\
- I would create an assessment rubric at the end of each section \\
- The Problem was evident in your guidebook and it is evident at our school \\
- I think the action plan needs to be teased out a bit, but if we get leadership to buy \\
into this, I believe the action plan can walk us through our issues \\
- This is a communication tool
\end{tabular}


Table 42 (continued)

\begin{tabular}{|l|l|}
\hline Participants & \multicolumn{1}{|c|}{ Preliminary Guidebook Advice/Components } \\
\hline Paula & $\begin{array}{l}\text { - This can help unite our advisory from one level to another } \\
\text { - This will help to prepare our sixth grader for the next level } \\
\text { - This provides a common language for all educators } \\
\text { - The leadership needs to take this approach and help build a systematic approach } \\
\end{array}$ \\
\hline - Students need an awareness of college in younger grades. \\
- More specific reflection questions could help provide context for each teacher's \\
response.
\end{tabular}

Note. Pseudonyms were used to protect participants' identities.

After the six interviews with the participants, I was able to gather and analyze the formative data (Table 42). The six interviews with different individuals from various levels and roles throughout the school gave me formative feedback on both the workshop and guidebook. As stated above this feedback proved to be the most helpful of all for the improvement of the guidebook. Often times the participants were candid and as they got to know me they really became interested in helping me improve the product. John told me, "We need this type of tool at our site for consistency." He told me that this would not be more work, "This is directly linked to our accreditation process." He liked the systematic approach to bring together all of his staff toward a common mission and vision. "We are lacking a systematic approach and this will help us get there." John concluded the interview with a compliment for the workshop, the guidebook and their approach, and stated, "We need a K-12 college readiness alignment and plan." I began 
the interview with James and he stated, "I already knew the problem. So it was like preaching to the choir. However, I wanted relevant solutions." After showing him the roadmap for the other workshop session, he changed his tune and replied, "Your tools and resources look like they would be very helpful." He gave me constructive advice on improving the assessment section of the guidebook, "The assessment section should be more clear and descriptive." He also mentioned that, "Your recommendations need to be a bigger part of your workshop and guidebook." Pete an elementary administrator first stated, "Schools need to have a plan in place for preparing students for college. All teachers need to be aware of the plan." He then replied, "This guidebook will help with some of our communication issues." He also thought the guidebook could bring together the levels of his school together, "This can help with our alignment and connect our levels." Kathy and Eric thought the leadership should use the guidebook to help their schools. Kathy stated, "Change comes from top down and that is where it needs to start first. This can provide consistency and communication. Our leadership needs to buy into something like this." Eric said, "Our leadership needs to sit down and think of how to approach this." Paula, a sixth grade teacher noted, "Students need an awareness of college in younger grades." She thought it could play a critical role in the elementary and school-wide advisory. "This can help unite our advisory from one level to another." She also commented on the leadership role with this guidebook, "The leadership needs to take this approach and help build a systematic approach." She also provided constructive feedback about the guidebook, "More specific reflection questions could help provide 
context for each teacher's response.” After one workshop session, Eric commented, "It made me more frustrated that our school and admin needed to do work. To be honest, I was a little frustrated that this session was a little long and there was no solution out of it."

The main field test was another important step for revising and refining the workshop and guidebook. It gave me additional information from a larger group of educational leaders from the same school. It was a richer experience because I saw how educational leaders from different levels interact with the guidebook. I received rich, specific formative and summative feedback to allow me to move toward operational product revision. Through my experience with the small-scale testing, the preliminary field test, and the main field test, I had the necessary data to close out steps 1-6 of the R\&D cycle.

\section{Summative Evaluation of Results}

\section{Demographic Data Results}

The demographic data from the main field test offered a variety of data based on gender, role and ethnicity of educational leaders. During the week long workshop, there were 26 participants. Out of the 26 participants, 13 were female and 13 were male. Since this was a split in gender of participants, I did not use this as a criterion for data review or data analysis. The ethnicity of the participants was mixed. Half of the overall participants were Caucasian, seven were Pacific Islanders, two were Latino/Hispanic, two were African American, one was Asian, and one was listed as multicultural. I did not use 
ethnicity as a factor in the review and analysis of data. The role of educational leader was the category I focused on in this study. I facesheet coded the roles in this study because the responses of educational leaders in different contents, areas and levels were extremely helpful in my study to measure the usefulness of the workshop and guidebook. Three participants were administrators, 11 were from the secondary team, five were from the sixth grade team, and seven were from the fifth grade team. I thought this sampling was a great one with which to collect and analyze data on postsecondary readiness. Since this process begins in elementary school, I was pleased to have participants from all levels.

\section{Workshop Survey Results}

The overall results from the workshop was positive. The areas of the workshop that were evaluated were: Workshop Content, Workshop Design, Workshop Facilitator, Workshop Results, and Workshop Delivery. An overwhelming number of participants responded that they agreed or strongly agreed on the each area of the workshop. Participants strongly agreed on $51 \%$ of the comments relating to all areas of the workshop. Respondents agreed on 35\% of the comments on the workshop. Only $14 \%$ of the comments were marked neutral with none of the categories labeled strongly disagree or disagree marked. The strongest components of the workshop were the Workshop Facilitator and Workshop Design. The Workshop Facilitator section had 64\% of respondents marking strongly agree and less than $1 \%$ of respondents marking neutral. The Workshop Design section had 56\% of respondents marking strongly agree and less than $1 \%$ of respondents marking neutral. The components of the workshop that were in 
need of improvement were the Workshop Content and Workshop Delivery. Only one section of Workshop Content was concerning. The greatest amount of neutral responses came with the comment on the content being relevant to participants' jobs. The percentage of respondents that marked neutral was $24 \%$. This was due to the fifth grade participants who felt disconnected with the topic of postsecondary readiness. Workshop Delivery had $32 \%$ of comments falling under neutral, while $36 \%$ of comments were agree, and $32 \%$ of comments were strongly agree. These results were concerning to me because the indicator was whether the workshop was a good way for participants to learn this content. I address this data in the operational product revisions later in this chapter.

\section{Guidebook Survey Results}

This section categorizes the evaluation of the guidebook's usability, applicability, and accessibility. The choices for responses were either yes or no with an overwhelming number of respondents marking yes (90\%). Only $10 \%$ of the comments were marked no. The strongest component of the guidebook was the Usability. The Usability section had $95 \%$ of respondents marking yes and $5 \%$ of respondents marking no. The component of the workshop that was in need of improvement was Applicability. Only one section of Applicability was concerning. The greatest number of no responses came in response to the comment of whether the guidebook takes into account the time and motivation available to the K-12 educational leader. The percentage of respondents that marked no was $53 \%$ as opposed to $47 \%$ that marked yes. Another area of concern fell under Accessibility. The comment dealt with respondents being able to list the six sections of 
the PRG. The percentage of respondents that marked no was $65 \%$ as opposed to $35 \%$ that marked yes. I address this data in the operational product revisions later in this chapter.

\section{Knowledge of Postsecondary Readiness Results}

The purpose of the PrA and PoAs was twofold: (a) to discover information and practices from the guidebook, and (b) to connect the information from the guidebook to their own sites. The comments from these assessments are categorized into the sections of the guidebook. These sections are: The Problem, Structural Elements, Academic Elements, Social Elements, Application, and Resources. I categorized the perceived growth of knowledge prior to the implementation of the workshop and guidebook to after

the implementation of the workshop and guidebook. This perceived growth of knowledge can be characterized as an implementation dip due to the guidebook's innovative approach that requires new skills and understanding (Fullan, 2001). The choices for responses were never, hardly ever, sometimes, often and always. The greatest perceived growth of knowledge was calculated from the decline in percentage of HFR in the PrA to the PoA. The sections with comments that showed the greatest perceived growth of knowledge were: Structural Elements, and Academic Elements. The comment under the Structural Elements dealt with a mission and vision created through shared values and beliefs. There was an $83 \%$ drop in HFR from PrA to PoA after the implementation of the workshop and guidebook. The comment under the Academic Elements dealt with the consistent application of quality instructional practices in each class. There was an $88 \%$ drop in HFR from PrA to PoA after the implementation of the workshop and guidebook. 
The comment on implementing a comprehensive approach to postsecondary readiness went from $6 \%$ HFR to $100 \%$ HFR which showed the most perceived growth of knowledge. The least perceived growth of knowledge was calculated from the least amount of decline in percentage of HFR) in the PrA to the PoA. The section with comments that showed the least perceived growth of knowledge was the Structural Elements. One of the comments under the Structural Elements dealt with the alignment of standards, curriculum, and assessments to college readiness expectations only decreased 18\% HFR from PrA to PoA. The other comment under the Structural Elements dealt with having partnerships with postsecondary institutions only decreased 18\% HFR from PrA to PoA.

\section{Demographic Data Results of Interview Participants}

The demographic data from the interviews offered another variety of data based on role, ethnicity, team, and experience in education. I interviewed six participants. Four participants were Caucasian, one was Pacific Islander, and one was Multicultural. Two participants were from the administrative team, two were from the secondary team, and two were from the elementary team. Their experience varied from 2 to plus 11 years. The demographic data I focused on with the participants was the team category. These data allowed me to measure the usefulness of the workshop and guidebook with educational leaders at different levels. 


\section{Formative Evaluation of Results}

\section{Workshop Results}

The formative results from the workshop were valuable and positive. The most valuable aspect of the workshop included its organized, systematic approach. Six respondents listed this as the most valuable aspect. The other valuable aspect participants listed was the topic, concepts, best practices and resources. Another six respondents listed this as the most valuable aspect. The third most valuable aspect on the workshop was the approach on communication and vertical alignment. Three respondents recognized this as a valuable aspect. Respondents listed that they would improve the workshop by allowing more time for the workshop. The percentage of respondents marking this for improvement was $88 \%$. The area for improvement that related to allowing more time and reinforced the timing issue was the time of day and time of year in which the workshop was presented. Nine respondents marked this as the least valuable aspect of the workshop. Two respondents thought that more workshop sessions were needed. The concerns about the workshop will be addressed in the operational product revision later in this chapter.

\section{Guidebook Functionality Results}

As with the summative results section on the guidebook, this section categorizes the evaluation of the guidebook's usability, and applicability through open-ended responses. The overwhelming majority of respondents (100\%) identified the following groups for which the guidebook was written: district administrator, building 
administrator, teacher, community college representative, university representative, and policy maker. The other choices were: community member (42\%) and parent (35\%). Under the Applicability of the guidebook, five people identified that the guidebook would be used for advisory improvements. Four members would use it to build academic behavioral skills, while another four members would use it to implement quality instructional practices. Only one participant would use it to redraft the mission statement. Participants provided open-ended comments on what they liked about the guidebook. Seven respondents liked that it provided an organized comprehensive and systematic approach. Three participants thought liked that it provided an approach to vertical alignment with programs. Participants also provided open-ended comments on what they found difficult about the guidebook. Six respondents thought the assessment section was vague and confusing and needed to be more specific. Five participants were weary of adding another approach to their school load. The improvements from this section will be discussed later in this chapter.

\section{Guidebook Results (Knowledge)}

The data from this section were used to back-up the data from summative results on the PrA and PoAs. The comments were taken from the open-ended responses to the responses. The purpose of the PrA and PoAs was twofold: (a) to discover information and practices from the guidebook, and (b) to connect the information from the guidebook to their own sites. The comments from these assessments are categorized into the sections of the guidebook. These sections are: The Problem, Structural Elements, Academic 
Elements, Social Elements, Application, and Resources. For this section on formative results from the assessments, I focused on the greatest perceived growth of knowledge to reinforce the summative results. The open-ended comments I focused on fell under the Structural Elements, and Academic Elements. The data under the Structural Elements dealt with a mission and vision created through shared values and beliefs. The openended comments that reinforced the summative results are:

- "We need to revisit this."

- "I've never been part of this."

- "We haven't looked at our mission in 4 years."

- "We don't look at our mission statement ever."

The open-ended comments that fell under the Academic Elements dealt with the consistent application of quality instructional practices in each class. The open-ended comments that reinforced the summative results are:

- "This should happen."

- "Teachers fear this."

- "Everyone is different."

- "This needs to become systematic."

The least perceived growth of knowledge from the open-ended formative results also were used to reinforce the summative results. The open-ended comments that showed the least perceived growth of knowledge was from the Structural Elements section. The open-ended comments under the Structural Elements dealt with the alignment of 
standards, curriculum, and assessments to college readiness expectations. Two participants gave credit for their knowledge to the CCSS. The other open-ended comments under the Structural Elements dealt with the having partnerships with postsecondary institutions. Comments on this ranged from: "I don't know" to "I believe so." Two other comments noted that this was done through their college and career center. The improvements to the guidebook from this data will be discussed later in this chapter.

\section{Interview Data Results}

Through the interviews with the six educational leaders, I coded themes that came up in our conversations. Specifically for each workshop and section of the guidebook, I interviewed participants about the process and received feedback on improvements (Table 43).

The themes that were the most prevalent were: systematic approach (46), leadership (36), communication (34), consistency (32), and common language (29). The themes that were mentioned the least were: design (13), targets (16), standards (18), professional development (19), and equity (21). The improvements this data will be discussed later in this chapter. 
Table 43

Interview Data Results: Formative Interview Feedback

\begin{tabular}{|l|l|}
\hline \multicolumn{1}{|c|}{ Section } & \multicolumn{1}{c|}{ Feedback on Suggested Improvements } \\
\hline The Problem & $\begin{array}{l}\text { - Teachers need to be taught/trained on how to do this } \\
\text { - Skills/strategies to implant the importance of college for our students } \\
\text { - More specific outcomes that can help drive forward practice and } \\
\text { instruction in the classroom }\end{array}$ \\
\hline Structural Elements & $\begin{array}{l}\text { - How do I assess my college-going culture? A tool or continuum would be } \\
\text { very helpful }\end{array}$ \\
\hline Academic Elements & $\begin{array}{l}\text { - Tools to support me in evaluating the current effectiveness of my } \\
\text { instruction? }\end{array}$ \\
\hline Social Elements & $\begin{array}{l}\text { - Include an evaluative tool } \\
\text { - More resources please }\end{array}$ \\
\hline Application & $\begin{array}{l}\text { - This sections seems a little overwhelming An application checklist might } \\
\text { make it feel less cumbersome }\end{array}$ \\
\hline Resources & $\begin{array}{l}\text { - More resources. A web based resource link that can be added to by users } \\
\text { would be amazing }\end{array}$ \\
\hline Overall Guidebook & $\begin{array}{l}\text { The format of the guide book makes it difficult to use as an ongoing } \\
\text { process. The continum could review initiation through sustainability. }\end{array}$ \\
\hline
\end{tabular}

\section{Product Development}

Through my experience in education I have seen four things happen to high school graduates as they looked to pursue a postsecondary education: (a) they do not get accepted into postsecondary institutions, (b) they get accepted but have to take remedial classes because they lack in skills, (c) they take entry level college courses for which they are unprepared for and receive a failing grade, and (d) they become frustrated due to the lack of preparation and drop-out. Because I have seen these things happen year after year, I realized that it is not just the responsibility of the student for this lack of progression. 
Many high school graduates are not ready for a postsecondary education. Schools from across the nation have tried to address this problem in many ways. These approaches provide some measure of support to students, but many graduates still live through the aforementioned scenarios. To provide the full level of support to students, I wrote: Bridging the Future to Postsecondary Readiness. It provides a comprehensive, systematic approach based on best practices from school across the country that have some level of success of preparing students for postsecondary success. To go with this educational tool, I created a workshop that allows educational leaders to navigate successfully through the guidebook.

The survey results from the knowledge acquired through the workshop and engagement with the guidebook support its usefulness to educational leaders. Participants provided feedback on the usability, applicability, and accessibility of the guidebook along with comments on how to improve both the workshop and guidebook. The process began with a preliminary form of the product that was tested and revised according to analysis of the data; then tested again, followed by another revision to further improve the guidebook. The next sections discuss the development of the product through the operational product revisions.

\section{Initial Template}

The initial draft or template of the guidebook began as a concept out of the review of literature on college and career readiness. After reading about many approaches successful schools use to prepare high school students for postsecondary success, I began 
to plan a comprehensive, systematic approach that would maximize the educational goals for our students. First, I had to conceptualize the ideas and best practices into something that would be manageable for school practitioners. I created a postsecondary readiness framework from which to base my guidebook. This became the basis for my initial draft or template.

With the initial template, I continued to create sections based on the postsecondary readiness framework. Since the framework consisted of three elements: Structural Elements, Academic Elements, and Social Elements, the template would contain at least three sections. Next, I wanted to have a section where many of the best practices were applied in a secondary school setting (Application Section). This would allow users to see how the framework applies in an actual school. To add to this, I wanted to provide a Resource Section for the users so that they could continue their journey toward postsecondary readiness with their leadership teams. This would also ensure that the product would serve as a guide and introduce educational leaders to the framework, best practices and concepts toward postsecondary readiness. The application of these would be carried out by the educational leaders and their teams at their sites/schools. I knew at this point that the product I was creating would be a guidebook.

I came up with the design of the guidebook because I wanted to make something that looked modern and applicable. I used a stock photo of a young female in a cap and gown smiling with the word "community" in the background. This was to symbolize a person elated from her individual hard work teamed with the support and guidance of the 
community. It also stresses the importance of a degree. I focused on the colors of green and blue to capture a natural earthy tone. The greens and blues were lighter in color to lighten the mood of the user while guiding them through such a complex process. The greens and blues were used throughout the guidebook for lines, shapes and lettering.

The title of the guidebook evolved over time. I began with the simple title:

Preparing Students for College and Careers. As I continued collecting information on this process, I realized that college and career could be contracted to postsecondary. I also wanted a stronger verb than preparing, so I came up with the word bridging. I settled on this word because I felt the metaphor fit better with the purpose of the guidebook. If the guidebook worked for educational leaders then a bridge would be built for students to get them successfully from high school to postsecondary options. I also wanted the guidebook to have an impact on educational leaders and students for years to come, so I added the word future. I then played on these words until I came up with the next version: Bridging the Future to Postsecondary Readiness.

\section{Preliminary Form of the Product}

After creating the template of the guidebook to educational leaders around the country, I was able to gather more information about how they perceived this product. I discussed my ideas and concepts that were generated out of step 1 of the R\&D cycle with educational leaders from all levels and all types of schools aimed at preparing students for postsecondary success. They gave me valuable feedback on the initial template and based on this feedback I revised the template to include: an introduction, a section on the 
problem, the three sections from the postsecondary readiness framework, and a section of resources. I also added activities and assessments into each section to make the guidebook more interactive. The last piece I added to my guidebook was a workshop on how to use the guidebook. Feedback from the small-scale testing advised me that I could not assume that users would be able to go through it without some direction. By going through the first three steps of the R\&D process, the preliminary form of my guidebook had form and more structure to achieve its purpose.

\section{Main Product Revision}

The formative and summative feedback from the preliminary field tests was rich and helped me through the main product revision step of the R\&D cycle. I used the summative data on the workshop to rethink how I would present this in the future. The data clearly showed that it was too short to cover the concepts, so I changed the concept of the workshop during this step. The original workshop presented during the preliminary field test was created to give an introduction to the guidebook and discuss its components. The revised workshop would be presented with each section of the guidebook and serve to facilitate educational leaders through the guidebook. The interview data also helped to improve the workshop because it reiterated the need for longer sessions to help users navigate the guidebook successfully. The other feedback to improve the workshop was to implement activities to connect users with the guidebook to make it more interactive. By connecting the workshop sessions to every section and using them to facilitate learning, the new design of the workshop should connect users to the 
materials in an interactive way through the Activity Circles. The guidebook was refined to include feedback about implementing recommendations from my experience as a leader of a high school to college transitional school along with the information collected on the way about postsecondary readiness. I used this feedback to include recommendations in each section of the postsecondary readiness framework. Another way I took the feedback on the guidebook to make improvements was by adding an aspect to each section called, Reflections on Current Practice. This gave users another opportunity to interact with the guidebook by discussing what they currently do at their own site as it pertains to the elements in each section. Comments from the preliminary field test interview directed me to add more specific direction and purpose to each section. With this I added Design Questions to connect users to each section of the framework and provide guidance. Within each design question I also added targets or themes which serve to help readers reflect on current practices as well as to assess current knowledge. I invited participants go through the guidebook during the preliminary field test and felt like they gained a lot of knowledge, but they left frustrated due to the fact that there was no part of the guidebook that helped them with next steps. For the main product revision I added action templates at the end of each section to help users create a culture of postsecondary readiness for each element of the postsecondary readiness framework. This completed the revisions to the guidebook so I could move to the main field test with confidence that a quality product was created. 


\section{Operational Product Revision}

The operational product revision entailed the feedback and data from the main field test. Although the product was: created from an initial template, developed into a preliminary form of the product, tested in a preliminary field test, refined, and tested in a main field test, the operational product revision is the last step I completed for the purposes of this study. During step 7 of Borg and Gall's (1989) R\&D cycle, both summative and formative data were collected and analyzed from the main field test (Bridges \& Hallinger, 1995). These data were used to assess the workshop and guidebook for operational product revision. These assessments were based on the following research questions:

1. In what ways can schools better prepare students for postsecondary success?

2. In what ways is the PRG useful in helping educational leaders prepare students for postsecondary success?

3. What improvements and changes to the PRG are needed to help educational leaders?

4. What is the perceived impression of the guidebook's usability, applicability, and accessibility?

5. In what ways is the workshop useful in helping educational leaders navigate through the PRG?

This section addresses the five revisions that I made to the workshop and guidebook supported by data collected from the field tests. Table 44 shows the first revision and applies to the workshop supported by formative data. 
Table 44

Operational Product Revision 1: Supported by Data

\begin{tabular}{|c|l|l|}
\hline Product & \multicolumn{1}{|c|}{ Revision 1 } & \multicolumn{1}{c|}{ Data to Support Revision } \\
\hline Workshop & $\begin{array}{l}\text { - Reformatted the workshop to include } \\
\text { sessions with every section of the } \\
\text { guidebook. }\end{array}$ & $\begin{array}{l}\text { "The workshop could be longer to help } \\
\text { take us through each section of the } \\
\text { guidebook." } \\
\text { "Too short." }\end{array}$ \\
& $\begin{array}{l}\text { Sessions would include interactive } \\
\text { exercises and activities to plan next } \\
\text { steps toward implementation. } \\
\text { "This workshop could be a week long to } \\
\text { Timing of the workshop to run with } \\
\text { the beginning of the school year to } \\
\text { be integrated into professional } \\
\text { development for participating sites. } \\
\text { All participants must attend all } \\
\text { workshop sessions. }\end{array}$ & $\begin{array}{l}\text { "We just scratched the surface." } \\
\text { "I wish this occurred at the beginning of } \\
\text { the year." } \\
\text { Can you list the six sections of the } \\
\text { Postsecondary Readiness Guidebook? } \\
\text { 65\%-No, 35\%-Yes }\end{array}$ \\
\hline
\end{tabular}

Revision one. The first revision was to the workshop. The biggest change to the workshop came with the restructuring of the format. One participant stated, "The workshop could be longer to help take us through each section of the guidebook." Another responded that the workshop was, "Too short." I changed the workshop to include a session with each section. These session would take the participants through the exercises and activities and help them plan next steps toward implementation. This would help address another respondent's concern, “This workshop could be a week long to take us through the guidebook." It would also address another concern relating to the depth of the topic, "We just scratched the surface." Other participants thought the timing could be better noting, "I wish this occurred at the beginning of the year." The workshop will primarily be available at the beginning of the school year and integrated into professional 
development for participating sites. These improvements address the feedback from the field tests and make the workshop more useful.

The next section addresses revision two and applies to the workshop (Table 45) supported by formative and summative data.

Table 45

Operational Product Revision 2: Supported by Data

\begin{tabular}{|c|l|l|}
\hline Product & \multicolumn{1}{|c|}{ Revision 2 } & \multicolumn{1}{c|}{ Data to Support Revision } \\
\hline Workshop & $\begin{array}{l}\text { Inclusion of content to connect } \\
\text { each level and educator with the } \\
\text { guidebook and the postsecondary } \\
\text { readiness process. }\end{array}$ & $\begin{array}{l}\text { Does the guidebook take into account the time and } \\
\text { motivation available to the K-12 educational } \\
\text { leader? 53\%-No, 47\%-Yes } \\
\text { Does the guidebook take into account the time and } \\
\text { motivation available to the K-12 educational }\end{array}$ \\
& $\begin{array}{l}\text { Inclusion of timeline connected } \\
\text { to action plan template at the end } \\
\text { of each section to maximize the } \\
\text { efficiency and professional } \\
\text { development opportunities for }\end{array}$ & $\begin{array}{l}\text { leader? 53\%-No, 47\%-Yes } \\
\text { 100\% of participants recognized the following as } \\
\text { the audience for the guidebook: district } \\
\text { administrator, building administrator, teacher, } \\
\text { each participating site. }\end{array}$ \\
$\begin{array}{l}\text { Inclusion of content to include } \\
\text { audience for the guidebook. } \\
\text { Inclusion of content showing the } \\
\text { comprehensive approach toward } \\
\text { continuous school improvement. }\end{array}$ & $\begin{array}{l}\text { maker } \\
\text { 42\% of participants recognized a community } \\
\text { member as the audience for the guidebook } \\
\text { 35\% of participants recognized parent as the } \\
\text { audience for the guidebook }\end{array}$ \\
\hline
\end{tabular}

Revision two. This revision was also for the workshop. I created a slide to include how each level would connect to the guidebook and the postsecondary readiness process. This would connect to educational leaders from all levels. The summative data revealed that some participants felt neutral toward how relevant postsecondary readiness was to their jobs. As the workshop revisions included a change in format to integrate it into each section of the guidebook, these sessions would also have a timeline included for participants that is connected to the action plan to maximize the efficiency and 
professional development opportunities for each participating site. This addressed the data on the guidebook's applicability from the main field test. To address the guidebook's usability, I would add a component to the workshop that included the audience for the guidebook. Summative data on this showed that only $42 \%$ of respondents identified community members, and 35\% identified parents as an audience for the guidebook, and these stakeholders play a critical role in postsecondary readiness for students. The last component added to the workshop addressed teacher workloads. One respondent commented, "I am weary of adding another approach to our school load." The workshop has a component that links the systematic, comprehensive approach to postsecondary readiness complements school improvement plans and accreditation goals. These changes to the workshop based on the data strengthened both the workshop and the guidebook's usefulness.

The next section addresses revision three and applies to the guidebook (Table 46) supported by formative data.

Table 46

Operational Product Revision 3: Supported by Data

\begin{tabular}{|c|l|l|}
\hline Product & \multicolumn{1}{|c|}{ Revision 3 } & \multicolumn{1}{c|}{ Data to Support Revision } \\
\hline Guidebook & $\begin{array}{l}\text { Restructuring of the guidebook } \\
\text { to include: Assessing Current } \\
\text { Knowledge, at the beginning of } \\
\text { each section, and rubric on } \\
\text { elements from each section to } \\
\text { measure participating schools' } \\
\text { postsecondary readiness }\end{array}$ & $\begin{array}{l}\text { "How do I assess my college-going culture? A tool } \\
\text { or continum would be very helpful." } \\
\text { "The format of the guide book makes it difficult to } \\
\text { use as an ongoing resource. A rubric or continumm } \\
\text { to evaluate implementation would help guide the } \\
\text { process and provide a yard stick for where my } \\
\text { school is at in the process. The continuum could } \\
\text { review initiation through sustainability." }\end{array}$ \\
\hline
\end{tabular}


Revision three. This revision was for the guidebook. Originally I had a section called Assessing Current Knowledge, where users could measure their understanding on specific elements within each section of the guidebook. I moved this to the beginning of each section, but I wanted to address the data from the field tests. James asked, "How do I assess my college-going culture? A tool or continuum would be very helpful.” John, an administrator, commented, "The format of the guide book makes it difficult to use as an ongoing resource. A rubric or continuum to evaluate implementation would help guide the process and provide a yard stick for where my school is at in the process. The continuum could review initiation through sustainability." To address these comments, I put a rubric for each element of the postsecondary readiness framework at the end of each section. This gives educational leader the opportunity to measure their school's progress toward postsecondary readiness.

The next section addresses revision four and applies to the guidebook (Table 47) supported by formative data.

Table 47

Operational Product Revision 4: Supported by Data

\begin{tabular}{|c|l|l|}
\hline Product & \multicolumn{1}{|c|}{ Revision 4 } & \multicolumn{1}{c|}{ Data to Support Revision } \\
\hline Guidebook & $\begin{array}{l}\text { - Inclusion of a checklist to } \\
\text { contain the essential components } \\
\text { and activities from each section } \\
\text { to guide users throughout the } \\
\text { book. }\end{array}$ & $\begin{array}{l}\text { "The guide book is full of powerful information; I } \\
\text { had a difficult going back and finding resources or } \\
\text { info without rereading entire sections." } \\
\text { "These sections seem a little overwhelming." } \\
\text { "A checklist might make it feel less cumbersome." }\end{array}$ \\
\hline
\end{tabular}


Revision four. Providing a comprehensive approach to postsecondary readiness was daunting for many participants of the field tests. Paula a sixth grade teacher noted, "The guide book is full of powerful information, I had a difficult going back and finding resources or info without rereading entire sections." Eric a fifth grade teacher said, "These sections seem a little overwhelming." To address this data, I added a checklist for every section to help users navigate such a large topic. I came up with this idea from one participant who stated, “A checklist might make it feel less cumbersome.” This checklist contained the essential components and activities from each section to guide users throughout the book.

The next section addresses revision five and applies to the guidebook (Table 48) supported by formative data.

Table 48

Operational Product Revision 5: Supported by Data

\begin{tabular}{|c|l|l|}
\hline \multicolumn{1}{|c|}{ Product } & \multicolumn{1}{|c|}{ Revision 5 } & \multicolumn{1}{c|}{ Data to Support Revision } \\
\hline Guidebook & $\begin{array}{l}\text { - Inclusion of thoughts and quotes from } \\
\text { educational leaders with experience of } \\
\text { working with the Postsecondary } \\
\text { Readiness Guidebook. Each section } \\
\text { would have these "words of wisdom" to } \\
\text { give the users confidence with the } \\
\text { approaches from the guidebook. }\end{array}$ & $\begin{array}{l}\text { "Students need an awareness of college } \\
\text { "The problem is we are probably doing } \\
\text { things that are relevant, but we have no } \\
\text { formal guidance." } \\
\text { "We need to strengthen our partnerships } \\
\text { with our local colleges." }\end{array}$ \\
\hline
\end{tabular}

Revision five. The final revisions were small but powerful additions. I felt it necessary to capture thoughts from educational leaders who had experience with the PRG. This was important because in my experience, educators will experiment with 
different approaches if other educators have tried these approaches before them. I included quotes in sections of the guidebook dealing with college awareness such as, "Students need an awareness of college in younger grades." I included this quote in the sections dealing with a systematic approach to college readiness, "The problem is we are probably doing things that are relevant, but we have no formal guidance." In the Structural Elements section I included, "We need to strengthen our partnerships with our local colleges." Each section would have these "words of wisdom" to give the users confidence with the approaches from the guidebook.

\section{Field Testing Issues and Challenges}

The issues and challenges from the field tests hindered my ability to run the workshop and go through the guidebook effectively. I broke these down into six main categories. In this section I list the categories from my observations, discuss how they affected the study, list some examples from the field tests, and discuss what I would do differently in future studies to overcome these issues. Both issues and challenges are synonymous and interchangeable in this section.

\section{Accessibility}

One of the main categories of issues from the field tests was accessibility. Getting access to the people for my field tests proved to be difficult. They all had full-time jobs, and in the case of my preliminary field test, worked in locations far away from each other. In my main field test, school was in session and getting access to all of the participants at once was impossible. This affected my study because having to present 
different workshops and different sections of the guidebook at different times to different educational leaders provides inconsistent data. An example from the main field test was not having the director of the school present for the introductory workshop to support my study. I also had to present this introductory workshop four different times to an audience consisting of different levels from elementary to high school. In the future, I would present this in conjunction with the beginning of the year professional development sessions tied to school improvement plans.

\section{Commitment}

Another category of issues that hindered my study was commitment. Once the site committed to my study, I needed the participants to buy-in and commit to the process. In my preliminary field test this was difficult because I presented the guidebook to educational leaders affiliated with a community college. They were committed to the idea, but not the language. It was hard for them to buy-in to the entire process. In the main field test, I had participants attend my workshop sessions, but many failed to read the necessary sections prior to each workshop. This wasted a lot of time because I had to revisit concepts from the reading and could not dive into the reflection, assessment or activity sections as much as I would have liked. The time wasted minimized the usefulness of the workshop and guidebook review. An example of this from the main field test was when participants showed up late to one session because the gatekeeper did not communicate effectively to them and they did not fully commit to the process. Once they arrived, most of them did not read the section prior to the workshop. They were able 
to get a few things from the workshop and guidebook, but they missed much of the purpose. I would overcome this in the future through constant communications with the administrative team. This administrative team would get the buy-in and do work prior to my arrival. They would also tie this to their mission, vision and school improvement plans. This would increase commitment and the usefulness of the workshop and guidebook.

\section{Time}

The next major category that proved to be a challenge was time. In education, this seems to always be an issue. In the preliminary field test, I had to work with the participants' location and schedule, thus severely cutting down on the necessary time to present the workshop and review the guidebook. In the main field test time proved to be a factor because school was in session, and the only times I could work with the participants was during lunch. This hindered the usefulness of my workshop and guidebook because I needed a specific amount of time to go through each section. Time also affected the main field test because of the time of year I conducted the main field test. It was after they had begun their term, and their planning had already occurred. I would overcome this in the future by planning and presenting the workshop and guidebook in conjunction with the beginning of the year professional development sessions tied to school improvement plans. 


\section{Knowledge}

Knowledge ended up being a major issue in my study. I assumed that after the workshop and presentation they would increase their knowledge. However, I underestimated their knowledge on postsecondary readiness from the beginning. During the preliminary field test, many of the participants were interested in the topic and preparing students for postsecondary success, but their knowledge of secondary education was lacking. I believe that in order to effectively educate and prepare students for postsecondary success, that both the secondary school system and the postsecondary school system must have operational and academic knowledge of how the other works. During the main field test, the concepts I used with Oasis Academy seemed to be just beyond the level of understanding. I felt that they understood the basic concepts, but were in the dark about the big picture of making it happen. An example of this was when I introduced the concept of mission and vision. The results of the study clearly show that there was an outdated mission and vision built without shared values and beliefs, but they were not committed to making it happen. In the future, I can overcome the knowledge challenge by having administrators on site offering a basic level of knowledge and understanding related to postsecondary readiness and this comprehensive approach.

\section{External Factors}

The last issue from this study is the external factors. These are factors I cannot control, but need to be mentioned as they had an impact on the study. One of the external factors in the main field test was the leadership of the school. Prior to my arrival, the 
director of the school resigned but continued throughout the remainder of the school year. The leadership seemed to be fragmented. I believe that some of the leadership supported my study and some did not fully support it. This trickled down to some of the staff of the school and affected their attitude and commitment to the project. The other external factor was the school culture. The school I worked with in the main field test was in need of improvement. They had received money for school improvement, and during my visit there were many consultants working with staff on many things throughout the school. At the time of my visit, this school needed simplification and structure, not resources and consultants. There was too much going on with too many people. The last challenge was that of motivation. Each person I worked with had a personal motivation. Often times these would be political and initiated long before my arrival. This had an impact on how participants interacted with my study, but the measure of this impact is difficult to tell. All of these external factors had a role in my study, although measuring them would prove to be difficult.

\section{Summary}

Bridging the Future to Postsecondary Readiness is a guidebook developed for educational leaders to help prepare students for postsecondary success. The purpose of this study is to determine how useful the guidebook is in building the capacity and confidence of educational leaders to successfully facilitate student transitions from secondary to postsecondary education. The research method and design structure that I used to address my research problem is a PBL approach that uses the (R\&D process. This 
chapter followed Borg and Gall's (1989) R\&D cycle. The R\&D cycle involved steps of inquiry that allowed me to develop, test and validate my educational product (Bridges \& Hallinger, 1995).

In step 1, I collected information relating to the problem of students graduating from high school unprepared for a postsecondary education. I looked into approaches, programs and schools that addressed this problem, and came up with a template or tool based on the conceptual postsecondary readiness framework to provide a solution to the issue.

In step 2, I planned objectives and developed learning activities from the postsecondary readiness framework as I small-scale tested the template developed in step 1. This step was critical to develop a preliminary form of my guidebook. I took the template from step 1, and interviewed educational leaders who are focused on postsecondary readiness. These educational leaders were from all over the country and gave me insight on my approach and tool.

With step 3, I took the information collected from step 2 with educational leaders and began to develop a preliminary form of my guidebook. This made the template come alive through structure and purpose. I organized the guidebook around the postsecondary readiness framework to make it more helpful for educational leaders to use and implement with their schools. In this step I also created a workshop that would make it easier for the readers to navigate through the guidebook. 
In step 4, I conducted a preliminary field test with the guidebook. I presented a workshop with the guidebook with educational leaders. They participated in a workshop where they completed an assessment of knowledge on postsecondary readiness and previewed the guidebook. Participants navigated through the guidebook individually on their own time. I interviewed participants to gain insight on the workshop and guidebook's usefulness. Lastly, I administered a PoA of knowledge on postsecondary readiness after participants experienced the workshop and guidebook.

Step 5 allowed me to make improvements in the workshop and guidebook. The interview and assessment data were used for product revision. These data were used to create a product that would be tested in a main field test. The usefulness of the guidebook improved through this step of the R\&D cycle.

In step 6, I conducted a main field test. I offered workshops on the sections of the guidebook to help educational leaders develop a comprehensive approach to postsecondary readiness. Prior to the main field test, I surveyed participants on their knowledge of postsecondary readiness. After their experience with the workshop and guidebook, I surveyed them to capture the guidebook's efficacy. Another survey was administered on the usability, applicability, and accessibility of the guidebook. Lastly, I conducted interviews to collect data to improve the guidebook. I used this data from step 6 for the final edit of the guidebook which was step 7 of the R\&D cycle.

This chapter covered seven of the steps of the R\&D cycle through the creation, development, field testing, and revisions of the guidebook: Bridging the Future to 
Postsecondary Readiness. Chapter 4 reviewed the research questions and goals that helped guide my research. It then provided an analysis of the experience through six steps of the R\&D cycle. Next, it captured the summative and formative data from the results of the field tests which lead to the operational product revision or step 7 of the R\&D cycle. Lastly, it focused on field testing issues and challenges that came up during the field tests.

In chapter 5, I discuss the conclusions on my overall research experience along with the assessment of the experience through reflections on the research study. I also go into depth on the challenges during my field tests. Next, I answer my research questions and address the goals of the study. Lastly, I cover speculations about further development and use of the workshop and guidebook. I close with recommendations for school leadership. 


\section{CHAPTER 5}

\section{CONCLUSIONS, SPECULATIONS, AND RECOMMENDATIONS FOR LEADERSHIP}

\section{Overview}

Statistics show that $40 \%$ of admitted and enrolled postsecondary students take at least on remedial course, which reduces their chance of graduating and costs and estimated \$1 billion or more per year (Conley, 2012a). The problem that many high school graduates are not ready for a postsecondary education is real and should be addressed with a systematic approach. Many secondary schools try to address areas of this problem; however, high school graduates are still entering postsecondary education with a lack of skills. I developed the guidebook: Bridging the Future to Postsecondary Readiness to help educational leaders provide a systematic and comprehensive approach to the problem. Educational leaders intent on running programs to prepare students for postsecondary success need a tool and strategies to accomplish this mission.

Twenty-six educational leaders of a K-12 public charter school focused on preparing all of its students for postsecondary success took part in a main field test to measure the efficacy and usefulness of a PRG. I used the formative and summative data collected during the field test to analyze and improve the guidebook. The summative data were collected through surveys and evaluated the guidebook's efficacy, while the 
formative data were collected through interviews and helped point out ways the guidebook could be improved (Bridges \& Hallinger, 1995).

During step 6 of the R\&D cycle, participants of the study received a PrA of knowledge. The PrA served two purposes: (a) discover information and practices from the guidebook, and (b) connect the information from the guidebook to their own sites. After participating in a workshop and engaging with the guidebook, participants took a PoA with the same questions as the PrA: to measure a perceived growth of knowledge on postsecondary readiness. During the main field test and after the workshop, participants also received a survey on the functionality of the guidebook. Throughout the main field test, participants were interviewed about the workshop, guidebook and postsecondary readiness process. These evaluations during the main field test provided summative and formative feedback on the guidebook's efficacy and gave me insight as to what needed to be improved during the operational product revision step of the R\&D cycle.

This chapter looks into the conclusions of my overall study of the guidebook: Bridging the Future to Postsecondary Readiness. I provide an assessment of the experience of the development of my product through reflections on the process. I also discuss the events of my main field test and give an in-depth reflection of the challenges I faced while collecting data on my guidebook. In spite of these challenges, I was able to collect a lot of useful data from school practitioners which helped me draw conclusions about the research experience. I discuss these findings as well. Next, I speculate about steps 8-10 of the R\&D cycle, and I conclude with recommendations for leadership. 


\section{Assessment of the Experience}

As I look back on the development of my guidebook, the process really took off when I took my initial template, which was created from my literature review, and visited schools and talked with educational leaders about my ideas. Returning from these school visits gave me the necessary information to add objectives and learning activities to my postsecondary readiness framework along with best practices to each section of my product. As I did this, I was relieved to see my initial template take on its preliminary form. I decided then that this product would work best as a guidebook. I wanted it to guide educational leaders through the postsecondary readiness process. My main priority became completing the draft of the preliminary form of the guidebook. I also created a workshop based on the feedback from the small-scale testing to help educational leaders navigate successfully through the guidebook. Because it was in its preliminary form, I knew I needed to add more to make it more useful to educational leaders. I was ecstatic that I would be field testing the guidebook through a workshop to gain more insight into how I could improve its usefulness.

Even though I looked forward to the preliminary field test to improve the guidebook and workshop, securing participants was another worry. I wanted to get input from participants outside of secondary education and broaden the audience for the guidebook. This sounded great in theory, but it added some stress to the process. Once I was able to get a commitment from participants, the stress became less, but scheduling the preliminary field test was the biggest barrier due to different scheduling and location 
issues. To overcome this, I had to present the workshop three times to accommodate the participants and conduct interviews over the phone. Although it was difficult to overcome the logistics of the preliminary field test, I was pleased with the feedback and data during this step of the R\&D cycle.

I was really excited to take the feedback from the preliminary field test and improve the usefulness of the workshop and guidebook during the main product revision. I was able to instill more life into the guidebook through the addition of recommendations and assessments to each section of the guidebook, and more resources to the resource section. I also improved the workshop to include sessions on every section. I was proud of this accomplishment and experience because my guidebook was developing through each step of this process. It was difficult to hear criticisms, but I put my feelings aside as I knew the feedback would improve the guidebook and workshop.

Once again I was excited but nervous to proceed with the main field test. My concern was securing a site that would be receptive to a workshop and a guidebook centering on a comprehensive approach to postsecondary readiness. This was a big concept, and the idea of an outsider coming in to collect research could be daunting to the site. I had made contact with an educational leader who was interested in the prospect of me working with his school and staff. I submitted to him and his fellow administrators a letter of introduction to my research study along with consent forms 6 months prior to my visit. It was agonizing to wait for the site to approve my visit, but one month prior to my scheduled visit, they approved it and I was ready to go. I was a bit nervous about the 
main field test because I was participating with another school site that did not know me. Even though I sent a letter of introduction to the research study, I was not sure how it would be received. My agenda was created for a five day visit. I planned for five, one hour workshops to take participants through the guidebook and its components. I assumed that the agenda I sent would suffice for the participants so I could effectively introduce my product and collect the data I needed.

Prior to the first day I sent out a PrA of knowledge on postsecondary readiness. I wanted to assess the participants' knowledge before the implementation of the workshop and guidebook, and see how postsecondary readiness applied to their school. I also sent an electronic version to the participants and advised them to read the first section before I began with the workshop. I was under the assumption that I would be able to work with all teams for 1 hour every day during the field test. This way I could take them through The Problem on day one, Structural Elements on day two, Academic Elements on day three, Structural Elements on day four, and go through the application of the concepts, review the resources, and take them through the action plan on the last day of my visit.

The first day of my visit, however, I realized quickly that I would have to adjust my agenda to accommodate all of the participants. Since school was in session, I had planned to meet with all of the teams after school had ended. However, instead of my workshop including all of the participants from elementary, middle and high school, it just included the administrative team. The gatekeeper during my visit was not able to gain the participation of all of the participants, so I continued with a workshop on The 
Problem with three participants of the administrative team. They had completed the PrA of knowledge, and even though I only had one hour with them, I was able to take them through all of the components of the first section of the guidebook. After the workshop session, I was informed that the teams had limited availability to meet. I would not be able to meet with all of the teams after school as I had planned, but I would have to meet with them voluntarily during their prep periods and during lunch. Their contract stated that they were not to participate in meetings after school. To accomplish my goals and objectives for the field test, I modified the agenda to include workshop sessions pertinent to each team (Table 35). The revised agenda (Appendix $\mathbf{J}$ ) was set up to optimize both the participants' and my time. Because of the last minute changes, the secondary and administrative teams became my primary focus. Both of them would take part in four workshops. My next priority became the sixth grade team. They participated in three workshops. Lastly, the fifth grade team participated in only one workshop. This was due to the fact that many in this team felt disconnected with the topic. Every team participated in a workshop on The Problem.

Other obstacles that made it difficult for me to present and collect data on my product was the instability of leadership at the school and scheduling conflicts with outside resources. Oasis Academy was identified as a school in need of intervention (transformation model) during the 2011-2012 school year. A transformation model is one where the school must: replace the principal, replace no more than 50\%of staff, implement financial sustainability strategies, provide staff with professional development 
opportunities, use data for growth, adopt a new governance structure, increase learning time, and provide social and community oriented support for students (U.S. Department of Education, 2009). Even though my field visit was 3 years after the time they were designated as a school in need, the interim director had resigned just before I arrived for my field test. She was allowed to complete the school year during which my visit occurred. Because of this, the culture of the school was chaotic. I was not sure of the commitment to their current director or administrative staff. Upon the first meeting, I felt the buy-in to my workshop and guidebook was limited due to their partnerships with other competing educational interests and their involvement with too many educational initiatives. Another reason for this was the fact that the school had scheduled another visit from educational consultants to help the school align its curriculum. There were a lot of consultants on campus during my visit and some of their meetings conflicted with my workshops. I was not aware of this until the time of my visit.

Because of the aforementioned issues and challenges during the field test, it was difficult to guard against researcher bias. I was occupied with scheduling and collecting the necessary data, and I became desensitized to most of the negative comments about the workshop and guidebook. This was something I had not thought of prior to my study, but having gone through these types of issues, I would mandate that specific conditions exist during the research study to avoid or minimize researcher bias during the study.

In spite of the many obstacles during the main field test, I collected important data on the workshop and guidebook. I was able to gain the participants' trust with every 
interaction, and by the time I left the school, I felt that the buy-in to my workshop and guidebook had improved. One secondary participant stated, "For the first time our elementary teams have contacted us to align our practices in order to create a systematic approach to getting our students to college." My main focus during the field test was to collect data through the delivery of the workshop and implementation of the guidebook. Even though the field test was difficult and the conditions not ideal, I returned with important information to help refine my product.

As I worked through the obstacles of my main field test, I was excited to analyze the feedback. I was excited for two reasons. One reason was that I had a much larger sample size, and the other reason was that I collected data from elementary, middle and high school educational leaders. I knew I had great data, however, I was frustrated that the field test was not more fluid. I felt confident in the revisions to my guidebook because they answered my research questions and really added a new dimension to my guidebook.

\section{Conclusions}

The data I collected during the field tests helped me answer my research questions. My data revealed that alignment from one grade to another is significant to prepare students for postsecondary success. Effective communication along with a mission and vision created through shared values and beliefs organize educators toward a common goal. This goal for many schools is to prepare students for postsecondary success. The data showed that the guidebook provided opportunities and direction for this 
alignment and communication to occur. It gave them common language from which to improve their practices and apply them consistently throughout all grades and subject matter.

The feedback collected during the field tests gave me pertinent information on how to improve the workshop and guidebook. To help educational leaders, the workshop and guidebook need to be implemented under the proper conditions. The workshop has to be scheduled into the professional development of each participating site prior to the beginning of the school year. The workshop and guidebook must be integrated into the school improvement plan of the participating sites. This would create buy-in and commitment from the participating sites and maximize the time and motivation of the practitioner. It is necessary that the workshop include an eight hour training for the implementation, discussion, activities, assessment, and action steps. It must include all levels for maximum efficiency. The other condition for the further development of the guidebook is for administrators to include preparation sessions on postsecondary readiness with their staff prior to the workshop. This would give everyone a basic level of knowledge on the topic. After all of the above steps have been taken, then I feel the workshop and guidebook would help educational leaders.

Other items that could be added to the guidebook to help educational leaders would be to include evaluation tools for each element within the guidebook. For example for quality instructional practices under the Academic Elements section, an assessment for teachers to evaluate the current effectiveness of their instruction would be included. I 
would also translate the workshop and guidebook to an online resource for educational leaders all over the country. This would be included as a resource link for users to participate in online discussions and learning.

The goal of this study was to look at the problem that many high school graduates are not ready for postsecondary education, and address it with a field-tested guidebook for educational leaders. The guidebook provided these leaders with essential knowledge, tools and a comprehensive approach to prepare all students for postsecondary success. The second goal of this study provided educational leaders with workshop sessions on a comprehensive approach to postsecondary readiness. These sessions showed how this approach could impact their leadership, school and students. Both of these goals were accomplished. By going through the PBL and R\&D process, I generated a tested product that should be used to address postsecondary readiness.

\section{Speculations on Future Research}

During this research project I did not complete steps 8-10 of the R\&D cycle because the process for doctoral students of education is completed after step 7. However, I will speculate about future research on the subject of postsecondary readiness and next steps to potentially implement the guidebook with other educational leaders. The Operational field testing could occur nationally or statewide. I address each in this section. 


\section{National Conferences}

Now that I completed the operational product revisions, I have an opportunity to present my guidebook at the $10^{\text {th }}$ Annual Peer Learning Conference in Boston, Massachusetts. The Peer Learning Conference is a unique opportunity for practitioners, administrators, and students to share innovative strategies for educating and supporting disconnected youth in college-based programs. I was invited by the participants of my preliminary field test to present at this conference because of the approach and themes of my guidebook. The conference audience is primarily college-based programs, and although my workshop and guidebook may not be a perfect match for this audience, I could adapt my approach to fit the guidelines. Presenting at the Peer Learning Conference also allowed me to connect with representatives from community colleges and put into practice the elements from my guidebook.

Another national conference I could present my workshop and guidebook at is the National Charter School Conference during the beginning of each summer. The National Alliance for Public Charter Schools puts on this conference once a year where over 4,000 participants from around the country learn, connect, and share ideas about how to support charter schools. This would be a great audience to expose my guidebook to since I am the leader of a charter school and have more than 10 years of experience working in charter schools. I have been to eight of these conferences in the past, and this would be an excellent experience for me both personally and professionally. Unfortunately, I missed 
the deadline for this year's conference, but plan to submit a proposal in the fall for next year's conference.

One organization that I am looking into joining is the Middle College National Consortium. The members of this organization believe that authentic school reform grows out of sustained collaboration among practitioners. It is a data driven network and serves districts, community colleges, universities, and public charter schools around the country. They host conferences throughout the year, and I am looking into submitting a proposal to present at their annual Winter Leadership Conference next February. The MCNC receives donations from the Ford Foundation, Bill and Melinda Gates Foundation, the Carnegie Corporation of New York, and the W.K. Kellogg Foundation. I learned about this organization in my review of literature in chapter 2.

\section{State-Level Conferences}

I could present my workshop and guidebook to educational leaders at state-level conferences such as Confederation of Oregon School Administrators, Oregon School Boards Association (OSBA), or the League of Oregon Charter Schools. I could take an active role in program development within the state to help educational leaders prepare students for postsecondary success.

The Confederation of Oregon School Administrators hosts a conference at Seaside, Oregon in June of every year. I am looking to submit a proposal for next year's conference in January 2015. Preference at this conference will be given to proposals that include activities and trainings regarding aspects of Oregon's “40-40-20” plan which 
will: (a) ensure that at least $40 \%$ of adult Oregonians have earned a bachelor's degree or higher; (b) ensure that at least $40 \%$ of adult Oregonians have earned an associate's degree or postsecondary credential as their highest level of educational attainment; and (c) ensure that the remaining $20 \%$ or less of all adult Oregonians have earned a high school diploma, an extended or modified high school diploma, or the equivalent of a high school diploma as their highest level of educational attainment (Mission of Education Beyond High School, 2011). My workshop and guidebook fit perfectly with this plan and it would appear I would have a good chance at getting accepted to present.

I am planning on hosting and presenting at The League of Oregon Charter Schools Annual Conference late in the summer. I recently met with organizers and they were interested in having me present my guidebook and host the conference at my school. The League of Oregon Charter Schools supports Oregon charter schools and is committed to individual charter schools, as well as the "movement" as a whole. It serves as a clearinghouse for information and resources, to provide mentorship and support, to advocate for the charter school movement. This approach would give the workshop and guidebook more of a local audience and allow me to make progress toward postsecondary readiness locally and within the Oregon.

\section{Final Product Revision}

By presenting my workshop and guidebook at one or more of the aforementioned conferences, I would be able to collect valuable feedback on a bigger scale. This feedback will help to further refine and improve my workshop and guidebook. The data 
will lead to a final revision of the guidebook. I believe I would be able to present the workshop and guidebook in its current form locally and at the state-level. However, I would need to revise the guidebook to include a broader audience if I were to present at the national level. The current audience is for the K-12 educational leader, and the language is specific to this audience. I would need to work with college and university representatives to include language that would fit with these practitioners. One college representative during the preliminary field test stated, "The guidebook uses an excellent approach to building postsecondary readiness skills among K-12 educators, but the language is specific to the K-12 audience."

\section{Dissemination and Implementation}

Bridges and Hallinger (1995) pointed out that students implement step 10 at their own discretion. The final step of the R\&D cycle allows the researcher to implement the product on a larger scale for greater awareness. I would be able to do this through presentations at workshops and conferences. I would also be able to accomplish this through the publication of articles relating to postsecondary readiness, or ultimately through the publication of the guidebook: Bridging the Future to Postsecondary Readiness. My short-term goal is to become involved in activities around the state to promote postsecondary readiness. I would like to work with school districts, community colleges and universities to help Oregon achieve the "40-40-20" plan. A participant of my preliminary field test is a state-level Oregon educational policy advisor, and she would be able to help me become involved in this process state-wide. A long-term goal includes 
publishing my guidebook for all school practitioners to prepare students for postsecondary success. I believe that my short-term goal will give me the knowledge, experience and connections to publish a successful guidebook for educational leaders. Ultimately, I would like to become an educational consultant to help all schools implement a comprehensive approach to postsecondary readiness.

\section{Recommendations for Leadership}

For leaders in the field, there are many approaches toward improving schools. With all of these approaches, administrators get bombarded with too many educational approaches and become numb to the notion of implementing new ideas. It is with this in mind that I carefully consider recommendations for leadership.

The Postsecondary Readiness Workshop and Guidebook is an educational tool that builds the capacity and confidence of educational leaders to successfully facilitate student transitions from secondary to postsecondary education. As the principal of a middle college who implements this approach in my own school, I would recommend that other educational leaders begin to look at this approach for the benefit of our future students, communities and the nation.

Through my experience in education, I have seen schools that lack systematic approaches. This guidebook gives not only a comprehensive approach, but it also gives educational leaders a systematic approach to running their school. Participants of the workshop on the guidebook stated the need for this. One participant stated, "Students need an awareness of college in younger grades." Another commented, "There should be 
continuity between all grade levels and schools." In the K-12 school in which I field tested the workshop and guidebook, a teacher responded, "I learned that a K-12 program needs to be put in place at our school." The workshop and guidebook address this thinking and unites all educational leaders to work toward the same goal under a mission and vision created through shared values and beliefs. Because of the workshop and guidebook, one respondent replied, "Our school needs to continue to develop infrastructure to support postsecondary readiness from the bottom up." When educators realize this from the workshop and guidebook, then you have fertile ground for postsecondary readiness.

For too long educators from different levels in K-12 and higher education have separated themselves from each other. This makes no sense and our children and future citizens are greatly impacted from this thinking. We are investing in the same thing, children! These investments continue to grow through our systems and levels of education. Our approaches to educating these investments should be carefully collaborative, and communicated and implemented among educational leaders and schools across the nation.

Bridging the Future to Postsecondary Readiness is a guidebook that provides the educational leader with the tools to prepare students for postsecondary success. It puts into place a comprehensive, systematic approach to capture elements within a postsecondary readiness framework. I recommend that school leaders use the guidebook's rubrics to measure their school's progress within the three elements of the 
postsecondary readiness framework. By having staff reflect on current practices and beliefs, school leaders can assess the knowledge of their staff on postsecondary readiness elements. Leadership should engage in activities throughout the guidebook with staff for in-depth discussions about postsecondary readiness approaches. Educational leaders get a window into the processes of their schools. Next, school leadership should put into motion all of the work and discussions created from working with the guidebook into an action plan detailing stakeholder involvement, quick wins, moderate undertakings, and major tasks. Finally, I would advise leadership to look into the resources of the guidebook to further improve their practices toward a comprehensive, systematic approach to postsecondary readiness.

I would recommend that educational leaders implement this workshop and guidebook with their staff to build a foundation of postsecondary preparation. They need to integrate the concepts from the guidebook into their school improvement plans and through the accreditation process. By doing this, they create buy-in and commitment from their staff and create knowledge through the process. This should be implemented at the beginning of the year and built into the professional development opportunities prior to the start of school. Staff would participate in discussions, reflections, assessments, activities, and action steps. This creates the foundation for the systematic approach to postsecondary readiness. The action steps would continue throughout the year and involve teams of educational leaders for sustainability. This process would be evaluated at the end of the year. Plans for improvement would be created to begin the following 
year. In time, a comprehensive approach to postsecondary readiness would be created and students graduating would be prepared for a postsecondary education.

\section{Summary}

Many students graduating from high school are not prepared for a postsecondary education. This is something that can be addressed to help our students, communities and nation. Students from low-income families and some ethnic and racial minority groups are most dependent on the ability of their high school to prepare them properly for college success (Conley, 2010). Because many families rely on our public educational system, our schools need to do a better job of preparing students for college and careers. Schools try to address this problem, but the approaches are not systematic and comprehensive. Because of this narrow approach, high school graduates are still entering postsecondary education with a lack of skills. I developed the guidebook: Bridging the Future to Postsecondary Readiness to help educational leaders provide a systematic and comprehensive approach to the problem. Educational leaders intent on running programs to prepare students for postsecondary success need a tool and strategies to accomplish this mission.

I developed Bridging the Future to Postsecondary Readiness through the R\&D cycle and test it with a broad audience of: an educational policy advisor, representatives from a community college, and 26 educational leaders of a K-12 public charter school focused on preparing all of its students for postsecondary success. Following the development of this product was a point of pride during my research. I saw my 
guidebook grow from a concept, to a template, to a preliminary product, to a guidebook. My sample size grew and I was able to test the guidebook with a K-12 public charter school focused on preparing students for college and careers. I felt confident in my product and organized with my interview protocols, surveys, and assessments. I had refined my research questions throughout each step, and I felt great with the direction of my study.

When I conducted the main field test, I ran into some issues and challenges. I had to present my workshop and guidebook throughout the week while school was in session. This became a juggling act, and it had me revising my schedule, my workshop sessions, my interviews, surveys and assessments. I was intent on collecting the data to test the perceived usefulness of the guidebook and workshop.

I learned that for this study to be optimal, participants must have a base level of knowledge on the topic prior to the implementation of the workshop and guidebook. I also learned that the gatekeeper has to develop buy-in from the participants prior to the researcher arriving. The gatekeeper must be organized and coordinate the times and groups needed to conduct a successful field test. If the aforementioned aspects are not achieved, then the consistency of the data could be affected.

I also learned a great deal in the role of participant-as -observer. The more time I spent with each team, the more they opened up to me and gave important feedback to improve the workshop and guidebook. The relationship factor was critical to obtain rich and useful data. 
The feedback from the main field test revealed that the workshop and guidebook builds the capacity and confidence of participants to successfully facilitate student transitions from secondary to postsecondary education. I would definitely use this guidebook with my own school. It is now up to me to take this useful product and continue my journey toward helping other educational leaders set the foundation for postsecondary success for all students. 


\section{REFERENCES}

ACT, Inc. (2006). Ready for college and ready for work: Same or different? Retrieved from http://www.act.org/research/policymakers/pdf/ReadinessBrief.pdf

ACT, Inc. (2008). The forgotten middle: Ensuring that all students are on target for college-and career readiness before high school. Retrieved from http://www.act.org/research/policymakers/reports/ForgottenMiddle.html

ACT, Inc. (2009). Connecting college readiness standards to the classroom. Retrieved from http://www.act.org/standard/guides/act/pdf/ACT_Admin.pdf

Astin, A.W. (1984). Student involvement: A developmental theory for higher education. Journal of college student personnel, 25(4), 297-308.

Astin, A. W. (1985). Achieving educational excellence. San Francisco, CA: Jossey-Bass.

Benson, L., Harkavy, I. R., Harkavy, I., \& Puckett, J. L. (2007). Dewey’s dream: universities and democracies in an age of education reform: civil society, public schools, and democratic citizenship. Philadelphia, PA: Temple University Press.

Berger, A. R., Cole, S., Melton, J., Safran, S., Vogel, T., Walton, L., ... SRI International, A. (2005). Early college high school initiative: Evaluation year end report 2003-2004). American Institutes for Research. Retrieved from http://stats.lib.pdx.edu.proxy.lib.pdx.edu/proxy.php?url=http://search.ebscohost.c om/login.aspx $?$ direct=true $\& \mathrm{db}=$ eric $\& A N=E D 494921 \&$ site=ehost-live

Bernhardt, V. L. (2002). The school portfolio toolkit: A planning, implementation, and evaluation guide for continuous school improvement. Larchmont, NY: Eye on Education.

Bill and Melinda Gates Foundation. (2009). College-ready for all: Preparing students for success. Retrieved from http://www.gatesfoundation.org/What-We-Do/USProgram/College-Ready-Education

Bloom, T. (2011). College and career readiness: A systemic P-20 response. Retrieved from ttp://64.58.86.235/uploads/documents/hobsons_industryreport_ collegeandcareerreadiness_p20response.pdf 
Bolman, L. G., \& Deal, T. E. (2008). Reframing organizations: Artistry, choice, and leadership. San Francisco, CA: Jossey-Bass.

Borg, W. R., \& Gall, M. D. (1989). Educational Research. White Plains. NY: Longman.

Born, T. (2006). Middle and early college high schools: Providing multilevel support and accelerated learning. New Directions for Community Colleges, 2006(135), 49-58. doi:10.1002/cc.247

Boyer, E. L. (1983). High school: A report on secondary education in America. New York, NY: Harper \& Row.

Bridges, E. M., \& Hallinger, P. (1995). Implementing problem based learning in leadership development. Eugene, OR: University of Oregon, ERIC Clearinghouse on Educational Management.

Cabrera, A. F., \& La Nasa, S. M. (2000). Understanding the college-choice process. New Directions for Institutional Research, 2000(107), 5-22.

Carey, K. (2004). A matter of degrees: Improving graduation rates in four-year colleges and universities. Retrieved January 16, 2007, from http://www2.edtrust.org/NR/ rdonlyres/11B4283F-104E-4511-B0CA-1D3023231157/0/highered.pdf

Carnevale, A. P., Smith, N., \& Strohl, J. (2010). Help wanted: Projections of jobs and education requirements through 2018 (p. 122). Washington, DC: Georgetown University.

Casillas, A., Allen, J., Kuo, Y., Pappas, S., Hanson, M. A., \& Robbins, S. (2011). Development and validation of ENGAGE grades 6-9 (ACT Research Report Series, 2011-1). Iowa City, IA: ACT, Inc. Retrieved from http://www.act.org/research/researchers/reports/pdf/ACT_RR2011-1.pdf

Chenoweth, T. G., \& Everhart, R. B. (2002). Navigating comprehensive school change: A guide for the perplexed. Larchmont, NY: Eye On Education, Inc.

Conley, D. (2007). Redefining college readiness. Educational Policy Improvement Center, 3. Retrieved from http://inside.redwoods.edu/basicskills/documents/ 1.RedefiningCR_Vol3_Copy.pdf

Conley, D. (2010). College and career ready: Helping all students succeed beyond high school. San Francisco, CA: Jossey-Bass. 
Conley, D. (2012a). A complete definition of college and career readiness. Educational Policy Improvement Center. Retrieved from http://69.43.173.105/dl/ eve_natcon/nc12_four_keys_handout2.pdf

Conley, D. (2012b, May 22). Making more students college and career ready. Presentation at the Advisory Committee on Student Financial Assistance Symposium, Portland, Oregon.

Conley, D., Drummond, K. V., de Gonzalez, A., Rooseboom, J., \& Stout, O. (2011). Reaching the goal: The applicability and importance of the common. Retrieved from https://www.epiconline.org/files/pdf/ReachingtheGoal-Chapters1-6.pdf

Conley, D., \& McGaughy, C. (2012). College and career readiness: Same or different? Educational Leadership, 69(7), 28-34.

Corwin, Z. B., \& Tierney, W. G. (2007). Getting there-and beyond: Building a culture of college-going in high schools. Los Angeles, CA: University of Southern California, Center for Higher Education Policy Analysis. Retrieved from http://www.eric.ed.gov/ERICWebPortal/recordDetail?accno=ED498731

Cota-Robles, E. H., \& Gordan, E. W. (1999). Reaching the top: A report of the national task force on minority high achievement. New York, NY: The College Board.

Creswell, J. W. (2007). Qualitative inquiry and research design: Choosing among five approaches. Thousand Oaks, CA: Sage.

.Edmunds, J. (2010). A better 9th grade: Early results from an experimental study of the early college high school model. Retrieved from http://www.serve.org/FileLibraryDetails.aspx?id=179

Educators for Social Responsibility. (2012). Advisory programs help improve academic performance and postsecondary planning. Retrieved February 12, 2013, from http://esrnational.org/2012/02/advisory/

Folmer, H. R., Moynihan,M. N., \& Schothorst, P. M. (n.d.).Testing and evaluating manuals. Amsterdam, Netherlands: Royal Tropical Institute. Retrieved from http://www.nrsp.org.uk/pdfs/resources/CPG/17_Testing\%20\&\%20evaluating\%20 manuals.pdf.

Ford, S., Alukonis, D., Avallone, A., Easton, J., Gordon, D., King, K., ... Weiser, E. (2006). The future of 12th grade NAEP. Baltimore, MD: National Assessment Governing Board. 
Fullan, M. (2001). Leading in a culture of change (1st ed.). San Francisco, CA: JosseyBass.

Greene, J. C., Caracelli, V. J., \& Graham, W. F. (1989). Toward a conceptual framework for mixed-method evaluation designs. Educational evaluation and policy analysis, 11(3), 255.

Griffiths, M. (1998). The discourses of social justice in schools. British Educational Research Journal, 24(3), 301-316.

Guba, E. G., \& Lincoln, Y. S. (1994). Competing paradigms in qualitative research. In. N. K. Denzin \& Y. S. Lincoln (Eds.), Handbook of qualitative research (pp. 104117). Thousand Oaks, CA: Sage.

Guion, L. A. (2011, August 10). Triangulation: Establishing the validity of qualitative studies. Retrieved March 7, 2014, from http://edis.ifas.ufl.edu/fy394

Haycock, K., Barth, P., Mitchell, R., \& Wilkins, A. (1999). Ticket to nowhere: The gap between leaving high school and entering college and high-performance jobs.

Thinking $K-16,3,34$.

Hoffman, N., \& Vargas, J. (2005). Integrating grades 9 through 14: State policies to support and sustain early college high schools. Early College High School Initiative. Retrieved from http://stats.lib.pdx.edu.proxy.lib.pdx.edu/ proxy.php?url=http://search.ebscohost.com/login.aspx?direct=true \&db=eric\&AN $=$ ED486161\&site $=$ ehost-live

Hoffman, N., \& Vargas, J. (2010, October). A policymaker's guide to early college designs: Expanding a strategy for achieving college readiness for all. Retrieved April 19, 2011, from http://www.jff.org/publications/education/ policymaker\%E2\%80\%99s-guide-early-college-design/1141

Ingels, S. J., Curtin, T. R., Kaufman, P., Alt, M. N., \& Chen, X. (2002). Coming of age: 12 years later. Editorial Note, 4(2), 7.

Institute of Education Sciences. (2009). Middle college high school. (2009, March 17). Retrieved November 11, 2009, from http://nces.ed.gov/pubsearch/pubsinfo.asp?pubid=WWCIRDPMC09

Jobs for the Future. (2009). A portrait in numbers: Early college high school initiative. Retrieved from http://stats.lib.pdx.edu.proxy.lib.pdx.edu/proxy.php?url=http://search.ebscohost.c om/login.aspx $?$ direct=true $\& \mathrm{db}=$ eric $\& A N=E D 504745 \&$ site=ehost-live 
Johnson, B., \& Christensen, L. B. (2007). Educational research: Quantitative, qualitative, and mixed approaches. Thousand Oaks, CA: Sage.

Kitzhaber, J. (2011). Amended Executive Order No. 11-02 Oregon Education Investment Team. Retrieved from http://www.oregon.gov/gov/docs/ executive_orders/eo_1102.pdf

Lee, V. E., \& Smith, J. B. (1995). Effects of high school restructuring and size on early gains in achievement and engagement. Sociology of Education, 68(4), 241-270.

Manning, M. L., \& Saddlemire, R. (1998). High school advisory programs: The Roosevelt Roads experience. The Clearing House, 71(4), 239-241.

McAlister, S., Mevs, P., Lee, J., Rodriguez, E., \& Kim, H. (2012). ABOUT GATES COLLEGE READINESS INDICATOR SYSTEMS. Retrieved from http://www.smarteducationsystems.org/sites/default/files/CRIS_Guide.pdf

Middle college high school. (2009, March 17). Retrieved November 11, 2009, from http://nces.ed.gov/pubsearch/pubsinfo.asp?pubid=WWCIRDPMC09

Miles, M. B., \& Huberman, A. M. (1994). Qualitative data analysis: An expanded sourcebook. Thousand Oaks, CA: Sage. Retrieved from http://books.google.com.proxy.lib.pdx.edu/books?hl=en\&lr=\&id=U4lU_wJ5QEC\&oi=fnd\&pg=PR12\&dq=miles+and+huberman\%2B1994\&ots=kC-DHMSZO\&sig=R1jeAMUp6-71AV_KazVvcADaYL8

Mission of education beyond high school, Oregon $\S 351.009$ (2011). Retrieved from http://www.leg.state.or.us/ors/351.html

Nugent, S. A., \& Karnes, F. A. (2002). The Advanced Placement program and the International Baccalaureate Programme: A history and update. Gifted Child Today, 25(1), 30-39.

Oregon Education Investment Board. (2011, August). Building a system to ensure each student receives a high quality education. Retrieved from http://education.oregon.gov/Pages/default.aspx

Oregon Senate Bill 1581, Pub. L. No. 1581 (2012). Retrieved from http://www.oregon.gov/gov/oeib/docs/sb1581.pdf

Orfield, G. (2004). Losing our future: How minority youth are being left behind by the graduation rate crisis. Retrieved from http://www.urban.org/Template.cfm?Section=Home\&NavMenuID=75\&template $=/$ TaggedContent $/$ ViewPublication.cfm\&PublicationID $=8756$ 
Pascarella, E. T., \& Terenzini, P. T. (1991). How college affects students. San Francisco, CA: Jossey-Bass.

Poelzer, G. H., \& Feldhusen, J. F. (1997). The International Baccalaureate: A program for gifted secondary students. Roeper Review, 19(3), 168-171.

Powell, A. G., Farrar, E., \& Cohen, D. K. (1985). The shopping mall high school: Winners and losers in the educational marketplace. NASSP Bulletin, 69(483), 40-51.

Robbins, S. B., Lauver, K., Le, H., Davis, D., Langley, R., \& Carlstrom, A. (2004). Do psychosocial and study skill factors predict college outcomes? A meta-analysis. Psychological Bulletin, 130(2), 261.

Singh, K., \& Granville, M. (1999). Factors that affect enrollment in eighth grade algebra for African-American students. Research in Middle Level Education Quarterly, 22(2), 57-73.

Tashakkori, A., \& Teddlie, C. (1998). Mixed methodology: Combining qualitative and quantitative approaches. Thousand Oaks, CA: Sage.

Terenzini, P. T., Rendon, L. I., Lee Upcraft, M., Millar, S. B., Allison, K. W., Gregg, P. L., \& Jalomo, R. (1994). The transition to college: Diverse students, diverse stories. Research in Higher Education, 35(1), 57-73. doi:10.1007/BF02496662

Thurmond, V. A. (2001). The point of triangulation. Journal of Nursing Scholarship, $33(3), 253-258$.

Tough, P. (2009). Whatever it takes: Geoffrey Canada's quest to change Harlem and America. Mariner Books. Retrieved from http://books.google.com.proxy.lib.pdx.edu/books?hl=en\&lr=\&id=qNevESIWhh0 $\mathrm{C} \&$ oi $=\mathrm{fnd} \& \mathrm{pg}=\mathrm{PA} 1 \& \mathrm{dq}=$ whatever $+\mathrm{it}+$ takes$\% 2 \mathrm{Btough} \&$ ots $=\mathrm{N} 3 \mathrm{bu} 53 \mathrm{XW}$ 6r\&sig $=-\mathrm{NNy} 9 \mathrm{qiTW}$ c5rYXHOJT2cpe7fCgM

United States Department of Labor, Bureau of Labor Statistics. (2014). Employment Projections: Earnings and unemployment rates by educational attainment. Retrieved March 26, 2014, from http://www.bls.gov/emp/ep_chart_001.htm

United States Department of Education. (2009, November). Race to the Top program: Executive summary. Retrieved from http://www2.ed.gov/programs/racetothetop/executive-summary.pdf 
Waters, M. R., \& Williams, J. M. (2011). College and career readiness. In S Redding, M. Murphy, \& P. Sheley (Eds.), Handbook on family and community engagement (pp. 93-96). Lincoln, IL: Academic Development Institute, Center on Innovation and Improvement.

Wimberly, G. L., \& Noeth, R. J. (2005). College readiness begins in middle school. Iowa City, IA: ACT.

Wolk, R. A. (2005). It's kind of different: Student experiences in two early college high schools. Retrieved from http://highschool.ccsso.org/alfresco/d/d/workspace/ SpacesStore/d50a6ced-c8dd-11dc-a45b-f7a084f7893a/ECHS_different.pdf 


\section{APPENDIX A}

WORKSHOP POWERPOINT PRESENTATION: PRELIMINARY FIELD TESTING 


\section{Bridging the Future}

7

\section{Postsecondary Readiness for Public Schools}

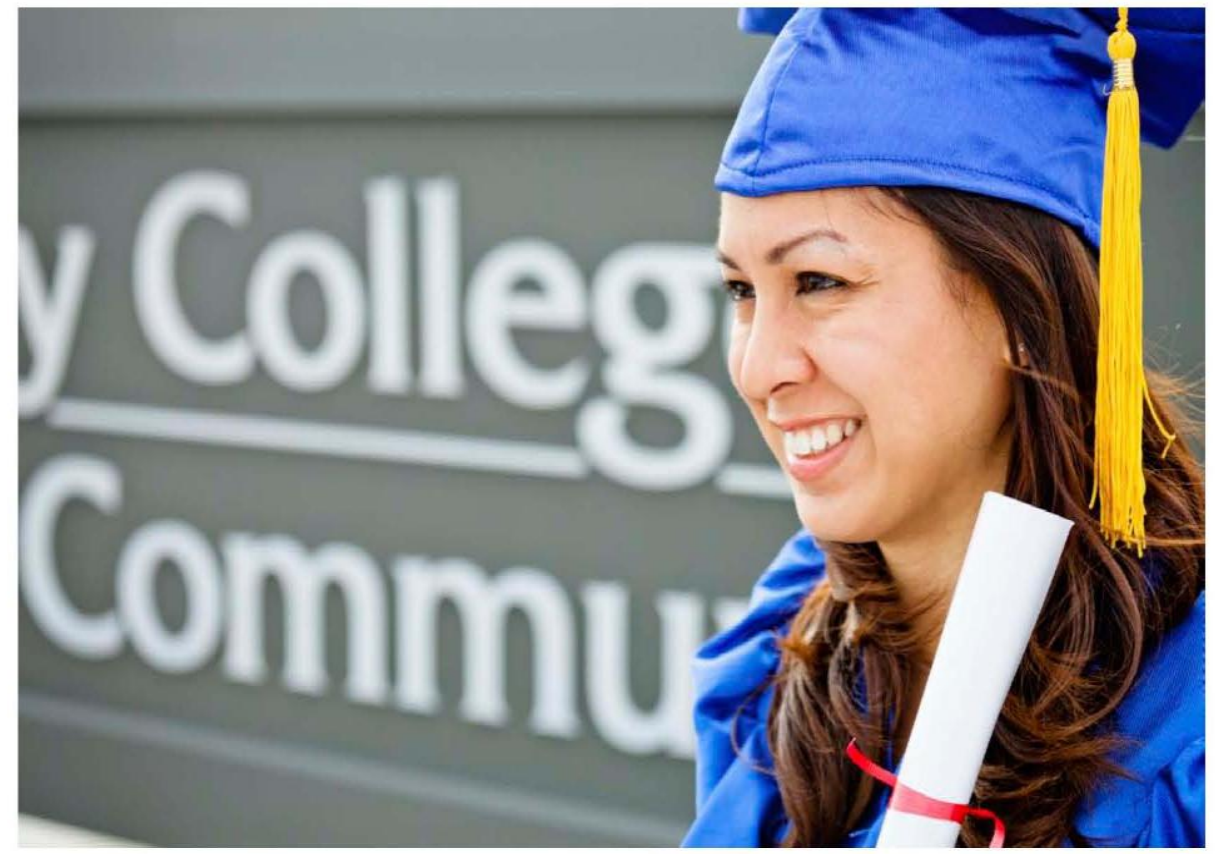




\section{Goals for this session}

1. Collect data on your understanding of postsecondary readiness

2. Help you navigate through the guidebook

3. Understand the components of postsecondary readiness

4. Become more familiar with a comprehensive approach to postsecondary readiness

5. Collect data on the usefulness of the workshop

\section{Agenda}

- Take the pre-assessment on postsecondary readiness (15 min)

- Receive a copy of the Postsecondary Readiness Guidebook and go through the workshop (30 min)

- Participate in a question and answer session for clarification (10 min)

Take the workshop evaluation survey (5 min) 


\section{How to use the guidebook}

Contents

Section 1: The Problem- Supported by Research and Data

Section 2: Structural Elements

Section 3: Academic Elements

Section 4: Social Elements

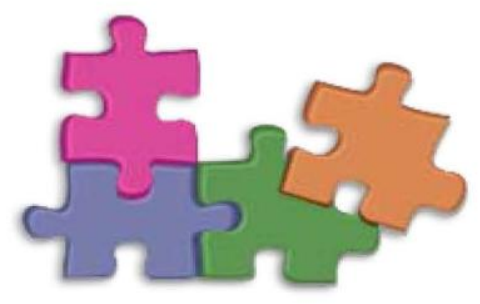

The Problem

Many Students Graduating from High School Aren't Ready for a Postsecondary Education!

Postsecondary Readiness Framework

1. Structural Elements

2. Academic Elements

3. Social Elements

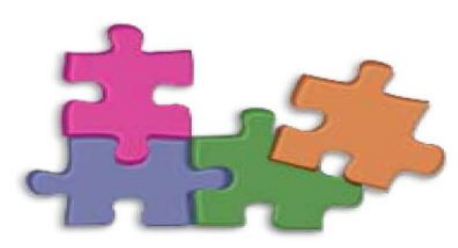




\section{Postsecondary Readiness Framework}

\section{$\pi$}

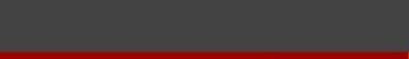

\begin{tabular}{|c|c|c|}
\hline \multicolumn{3}{|c|}{ POSTSECONDARY READINESS FRAMEWORK } \\
\hline $\begin{array}{l}\text { Structural Elements } \\
\text { 1. the mission/vision of schools } \\
\text { 2. transitions and } \\
\text { infrastructure } \\
\text { a. academic } \\
\text { preparedness } \\
\text { b. academic tenacity } \\
\text { 3. developing college } \\
\text { knowledge } \\
\text { a. college-going } \\
\text { culture } \\
\text { b. developing a } \\
\text { partnerships }\end{array}$ & $\begin{array}{l}\text { 1. } \begin{array}{l}\text { Academic Elements } \\
\text { curriculum a rigorous }\end{array} \\
\text { 2. college and career } \\
\text { readiness standards and } \\
\text { practices }\end{array}$ & $\begin{array}{l}\text { 1. } \begin{array}{l}\text { Social Elements } \\
\text { school staff in educational } \\
\text { planning }\end{array} \\
\text { 2. identifying and building } \\
\text { academic behaviors of } \\
\text { students }\end{array}$ \\
\hline
\end{tabular}

Components of guidebook continued...

Activity Circles- Gives guidebook users the opportunity to discuss, reflect, and react to information presented.

Example: How is your district/state working with the federal government to help prepare students for postsecondary success?

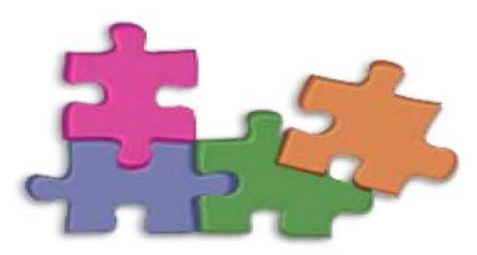


Components of guidebook continued...

\section{Assessing Current Knowledge- Provides a brief summary of the target content, and measures the understanding and comfort level regarding key strategies and processes presented within each target.}

4=I understand the current research, and already use this data to create/improve programs aimed to address and help solve the problem.

$3=I$ understand the current research, but I need to use the data to create/improve programs aimed to address and help solve the problem.

$2=$ I can explain the current research, but I am not fully confident that I can use the data to create/improve programs aimed to address and help solve the problem. $1=$ I do not understand the current research, and I do not currently use the data in my school.

1. Clearly articulating my state's, district's, and school's approach to preparing students for postsecondary success Based on my rating, I may need to revisit the following:

\section{Other important components}

Section 5: Application of Postsecondary Readiness

Section 6: Postsecondary Readiness Resources

Section 7: Postsecondary Readiness Guidebook Assessment

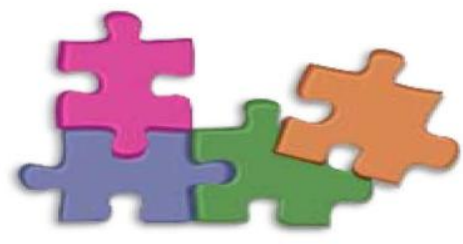


APPENDIX B

PARTICIPANTS' CONSENT FORM 


\section{Participants' Consent Form (Small Scale and Preliminary Field Testing)}

You are invited to participate in a research study conducted by Brian Sien from Portland State University, Educational Administration Doctoral Program. The researcher hopes to learn about a workshop and guidebook as it relates to postsecondary readiness. The study is being conducted in partial fulfillment of the requirements for a doctoral degree through PSU. You were selected as a participant in this study because of your experience and knowledge in preparing students for postsecondary success.

If you decide to participate, you will be asked to undergo one 45 minute to 1 hour interview where you will be asked about your experience and knowledge with the postsecondary readiness workshop and guidebook. While participating in this study, it is possible that you may feel uncomfortable with some of the questions as they probe into the depth of your job as an educational leader and I will give you a general idea to the themes of the questions before the interview. You may not receive any direct benefit from taking part in this study, but the study may help to increase knowledge which may help others in the future.

Any information that is obtained in connection with this study and that can be linked to you or identify you will be kept confidential. This information will be kept confidential by using a pseudonym instead of your actual identity.

Your participation is voluntary. You do not have to take part in this study, and it will not affect your relationship with Portland State University or the researcher conducting the interview. You may also withdraw from this study at any time without affecting your relationship with Portland State University or the researcher conducting the interviews.

If you have concerns or problems about your participation in this study or your rights as a research subject, please contact the Human Subjects Research Review Committee, Office of Research and Sponsored Projects, 600 Unitus Bldg., Portland State University, (503) 725-4288 / 1-877-480-4400. If you have questions about the study itself, contact Brian Sien at 12021 SE 82nd Avenue, Happy Valley, Oregon, 97086, (503) 518-5925.

Your signature indicates that you have read and understand the above information and agree to take part in this study. Please understand that you may withdraw your consent at any time without penalty, and that, by signing, you are not waiving any legal claims, rights or remedies. The researcher will provide you with a copy of this form for your own records. 


\section{APPENDIX C}

INTERVIEW PROTOCOL: SMALL-SCALE TESTING 
Interview Protocol: Small Scale Testing

Time of interview:

Date:

Place:

Interviewer:

Interviewee:

Position of interviewee:

(Briefly describe the project)

\section{Preliminary Research Questions}

1. How do you and your school better prepare high school students for postsecondary success?

2. Would a postsecondary readiness guidebook be effective in helping educational leaders prepare students for postsecondary success?

\section{Guiding Questions}

3. In your educational structure, what do you do to successfully prepare students for a postsecondary education?

4. What standards exist to help you and your team prepare students for a postsecondary education?

5. What do programs do you have to help students make a successful transition from high school to postsecondary education? 


\section{APPENDIX D}

OBSERVATIONAL PROTOCOL: SMALL-SCALE TESTING 
Observational Protocol-Small Scale Testing

\begin{tabular}{|l|l|}
\hline \multicolumn{1}{|c|}{ Site and Date: } & \\
\hline Length of Observation: & \\
\hline Context: & \\
\hline Room layout: & \\
\hline Obsective Notes \\
\hline \\
\hline Observation: & \\
\hline & \\
\hline Observation: & \\
\hline
\end{tabular}




\section{APPENDIX E}

POSTSECONDARY READINESS GUIDEBOOK WORKSHOP QUESTIONNAIRE 
Postsecondary Readiness Guidebook Workshop Questionnaire

Workshop Name:

Location:

Date:

Job Title:

Years in present position:

\section{INSTRUCTIONS}

Please circle your response to the items. Rate aspects of the workshop on a 1 to 5 scale:

1=Strongly Disagree 2=Disagree 3= Neutral 4=Agree 5=Strongly agree N/A=Not applicable

WORKSHOP CONTENT (Circle your response to each item.)

1. I was well informed about the goals and objectives of this workshop.

2. This workshop lived up to my expectations.

3. The content is relevant to my job.

WORKSHOP DESIGN (Circle your response to each item.)

4. The workshop objectives were clear to me.

5. The workshop activities stimulated my learning.

6. The activities in this workshop gave me sufficient practice and feedback.

7. The difficulty level of this workshop was appropriate.

8. The pace of this workshop was appropriate.

WORKSHOP INSTRUCTOR (FACILITATOR) (Circle your response to each item.)

9. The instructor was well prepared.

10. The instructor was helpful. 
WORKSHOP RESULTS (Circle your response to each item.)

11. I accomplished the objectives of this workshop.

12. I will be able to use what I learned in this workshop.

SELF-PACED DELIVERY (Circle your response to each item.)

13. The workshop was a good way for me to learn this content.

14. How would you improve this workshop? (Check all that apply.)

Provide better information before the workshop.

Clarify the workshop objectives.

Reduce the content covered in the workshop.

Increase the content covered in the workshop.

Update the content covered in the workshop.

Improve the instructional methods.

Make workshop activities more stimulating.

Improve workshop organization.

Make the workshop less difficult.

Make the workshop more difficult.

Slow down the pace of the workshop.

Speed up the pace of the workshop.

Allot more time for the workshop.

Shorten the time for the workshop.

Improve the tests used in the workshop.

Add more video to the workshop.

1. What is least valuable about this workshop?

2. What is most valuable about this workshop? 


\section{APPENDIX F}

PrA AND PoA ON POSTSECONDARY READINESS 
Pre- and Post-Assessments on Postsecondary Readiness

Location:

Date:

Job Title:

Years in present position:

\section{1-Never 2-Hardly ever 3-Sometimes 4-Often 5-Always}

1. We prepare students for postsecondary options at my school.

2. Preparing students for postsecondary options is a top priority for our school.

3. Our mission and vision was created through shared values and beliefs of all stakeholders involved with the school.

4. Data is used to create and drive postsecondary readiness programs and policies.

5. Standards, curriculum and assessments are aligned to college readiness expectations.

6. Interventions are in place at my school to keep students on track for postsecondary success.

7. Tenacity-building activities are systematic and implemented across all grade levels.

8. My school has developed a college-going culture.

9. My school has developed partnerships with local colleges and universities.

10. Curriculum at my school is rigorous.

11. Our teachers and school align curriculum, instruction, assessment, and programs to college and career readiness standards.

12. Quality instructional practices are consistently integrated into each class offered at my school. 
13. There is a structure set up at my school for the systematic identification of skills and progress.

14. Parents and school staff are included in educational planning.

15. There is a structure/program set up at my school for identifying and building academic behaviors of students.

16. Systematically, my school improves both students' and parents' transition knowledge and skills with regard to the transition from elementary to middle school.

17. Systematically, my school improves both students' and parents' transition knowledge and skills with regard to the transition from middle school to high school.

18. Systematically, my school improves both students' and parents' transition knowledge and skills with regard to the transition from high school to college.

19. I know how to implement a comprehensive approach to postsecondary readiness at my school.

20. I am aware of resources to help improve our process of postsecondary preparedness. 
APPENDIX G

INTERVIEW PROTOCOL: PRELIMINARY FIELD TESTING 


\section{Interview Protocol: Preliminary Field Testing}

Time of interview:

Date:

Place:

Interviewer:

Interviewee:

Position of interviewee:

(Briefly describe the project)

1. How can educational leaders better prepare high school students for postsecondary success?

2. Is the Postsecondary Readiness Guidebook effective in helping educational leaders prepare students for postsecondary success?

3. Is the Postsecondary Readiness Workshop effective in helping educational leaders navigate through the Postsecondary Readiness Guidebook?

4. In what ways is the guidebook/workshop helpful?

5. What are some things that should be changed about the guidebook/workshop?

6. In what ways can the guidebook help educational leaders prepare students for a postsecondary education?

7. Are the approaches in the guidebook helpful for educational leaders to prepare students for a postsecondary education?

8. In what ways does the guidebook bring awareness to postsecondary awareness in secondary schools? 
APPENDIX $\mathrm{H}$

LETTER OF INTRODUCTION (MAIN FIELD TESTING) 


\section{Letter of Introduction (Main Field Testing)}

October 18, 2013

Educational Leaders,

As the leader of a school whose mission is to prepare students for college and career success, I want to take this opportunity to share, and invite you to utilize an educational tool I have created to help school leaders better prepare students for postsecondary options.

Helping students navigate the transition between the public school system, the community college and university systems, and the workplace is a passion of mine. This transition begins long before students exit the public school system, and I have begun a journey to identify best practices and programs aimed at helping students acquire college and career readiness skills to succeed in postsecondary options. This journey is grounded in research conducted as part of my dissertation to complete my doctoral degree in educational administration along with over 17 years of experience in education and educational leadership. It is through this journey that I am eager and willing to build a network of collaboration between educational institutions that are intent on preparing students for postsecondary success.

The foundation of this collaboration centers on a comprehensive approach to postsecondary preparedness that is described in detail in a Postsecondary Readiness Guidebook. The guidebook was created through a "postsecondary readiness framework" which focuses on three key elements: structural, academic, and social elements. The guidebook is grounded in current research and educational experience to maximize the experience for the user.

Through collaboration and the use of the guidebook, the learning outcome is to: familiarize the user with current research, best practices, and resources in the field on preparing students for postsecondary success. The objectives to support this learning outcome are:

- Given the Postsecondary Readiness Guidebook, the user will be able to identify the best practices and resources to implement in his/her own educational institution.

- Given the opportunity to collaborate with other educational leaders intent on preparing students for postsecondary success, the user will be able to implement best practices and utilize the resources of the Postsecondary Readiness Guidebook. 
I am reaching out to you in the hope of forming a collaborative partnership to help students achieve postsecondary success. If this is something you are eager and willing to pursue, I have the following option on how we can begin this partnership.

1. Participate in a main field test of the guidebook-Based on the feedback during a preliminary field test, the guidebook will be revised and improved to be used for the main field test. I will provide a workshop on the use of the guidebook with you and your team. I will obtain feedback through field notes, observations, interviews, and questionnaires/surveys. The data collected will help me to further revise and improve the guidebook.

I want to thank you for your time and willingness to think about collaborating in a process aimed at helping students successfully navigate the transition from high school to college. I am confident that taking part in this option listed above will help to bring awareness to current research, best practices, and resources in the field, as well as to begin the process of implementation of these best practices to prepare students for postsecondary success.

I look forward to hearing from you in the near future in hopes of collaboration.

Sincerely,

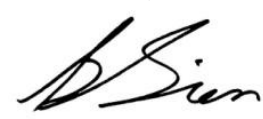

Brian Sien 


\section{APPENDIX I}

PARTICIPANTS' CONSENT FORM (MAIN FIELD TESTING) 


\section{Participants' Consent Form (Main Field Testing)}

You are invited to participate in a research study conducted by Brian Sien from Portland State University, Educational Administration Doctoral Program. The researcher hopes to learn about the postsecondary readiness process as it relates to qualitative research. The study is being conducted in partial fulfillment of the requirements for a doctoral degree through PSU. You were selected as a participant in this study because of your experience and knowledge in a K-12 Public Charter School.

If you decide to participate, you will be asked to undergo a week long workshop which includes: how to use the Postsecondary Readiness Guidebook along with its exercises and activities. This workshop will include interviews, observations and questionnaires relating to postsecondary readiness in your school. While participating in this study, if you would like, I will give you a general idea to the themes of the questions before each interview. You may not receive any direct benefit from taking part in this study, but the study is intended to help increase knowledge of the subject and to help with your school's accreditation process.

Any information that is obtained in connection with this study and that can be linked to you or identify you will be kept confidential. The school's identity and any information obtained will also be kept confidential. This information will be kept confidential by using pseudonyms of the school and actual people.

Your participation is voluntary. You do not have to take part in this study, and it will not affect your relationship with Portland State University or the researcher conducting the data collection. You may also withdraw from this study at any time without affecting your relationship with Portland State University or the researcher conducting the interviews.

If you have concerns or problems about your participation in this study or your rights as a research subject, please contact the Human Subjects Research Review Committee, Office of Research and Sponsored Projects, 600 Unitus Bldg., Portland State University, (503) 725-4288 / 1-877-480-4400. If you have questions about the study itself, contact Brian Sien at 12021 SE 82 ${ }^{\text {nd }}$ Avenue, Happy Valley, Oregon, 97086, (503) 518-5925.

Your signature indicates that you have read and understand the above information and agree to take part in this study. Please understand that you may withdraw your consent at any time without penalty, and that, by signing, you are not waiving any legal claims, rights or remedies. The researcher will provide you with a copy of this form for your own records. 
APPENDIX J

WORKSHOP POWERPOINT PRESENTATION:

MAIN FIELD TESTING 
Bridging the Future

$\lambda$

Postsecondary Readiness for Public Schools

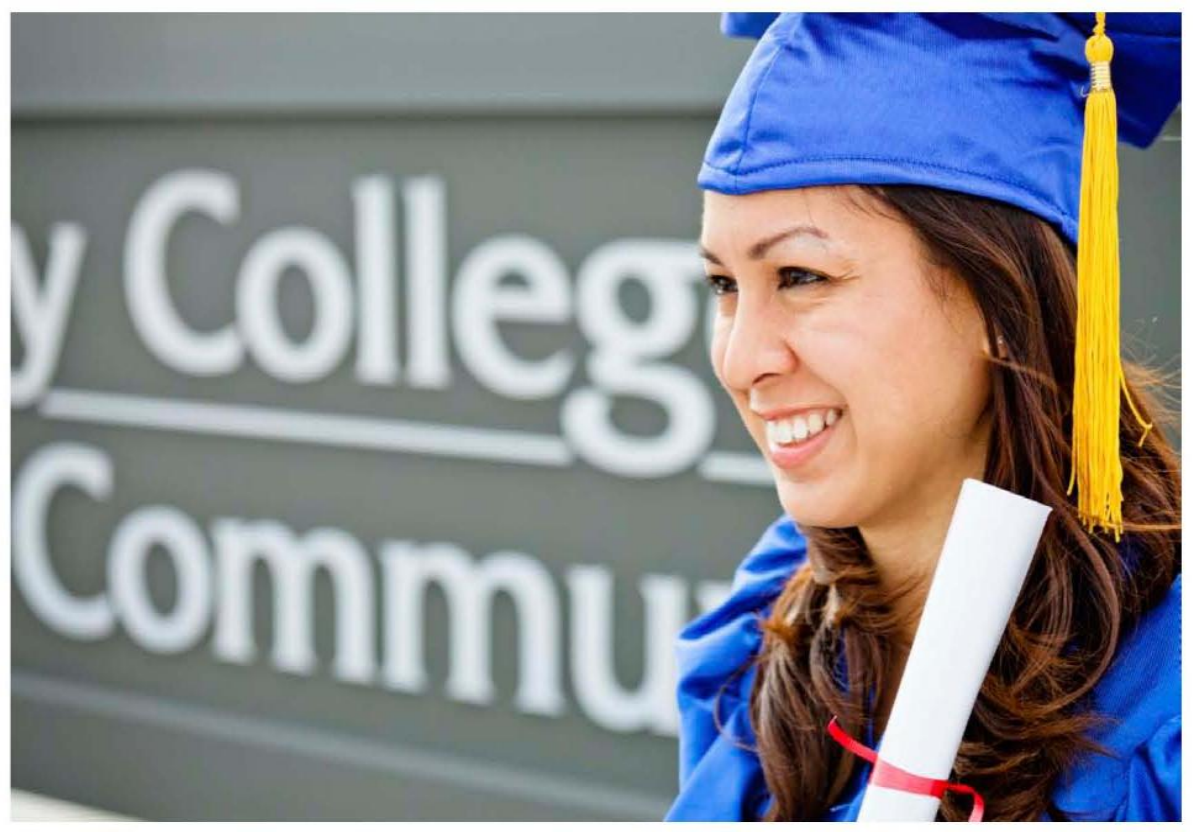




\section{Goals for the week}

1. Familiarize teams with current research, best practices, and resources on postsecondary readiness

2. Collect data on the usefulness of the workshop and guidebook

\section{Objectives for the week}

1. Given the Postsecondary Readiness Guidebook, the user will be able to identify the best practices and resources to implement in his/her own educational institution.

2. Given the opportunity to collaborate with other educational leaders intent on preparing students for postsecondary success, the user will be able to implement best practices and utilize the resources of the Postsecondary Readiness Guidebook. 


\section{Agenda}

\section{Prior to Monday-2/3/2014}

- Participants will complete a pre-assessment on knowledge and application of postsecondary readiness framework

- Participants will receive an electronic version of the guidebook

- Admin . Team will have read Section 1

\section{Monday-2/3/2014}

- Participants will take part in a workshop on how to use the guidebook

- Admin. Team will go through Section 1 of the guidebook

- Secondary Team will read Section 2 of the guidebook by Tuesday$2 / 4 / 2014$ 


\section{Agenda}

\section{Tuesday-2/4/2014}

- Participants will take part in a workshop on how to use the guidebook

- Secondary Team will go through Section 2 of the guidebook

- Admin. Team will read Section 2 of the guidebook by Wednesday-2/5/2014

- Secondary Team will read Section 3 of the guidebook by Wednesday-2/5/2014

- Sixth Grade Team will read Section 1 of the guidebook by Wednesday-2/5/2014

\section{Wednesday-2/5/2014}

- Participants will take part in a workshop on how to use the guidebook

- Admin. Team will go through Section 2 of the guidebook

- Secondary Team will go through Section 3 of the guidebook

- Sixth Grade Team will go through Section 1 of the guidebook

- Participants will read Section 4 and 5 of the guidebook by Thursday-2/6/2014

\section{Agenda}

\section{Thursday-2/6/2014}

- Participants will take part in a workshop on how to use the guidebook

- Admin. Team will go through Section 5 of the guidebook

- Secondary Team will go through Section 5 of the guidebook

- Sixth Grade Team will go through Section 4 of the guidebook

- Participants will read Section 1 and 6 of the guidebook by Thursday-2/7/2014

\section{Friday-2/7/2014}

- Participants will take part in a workshop on how to use the guidebook

- Participants will go through Section 1 and 6 of the guidebook

- Participants will be able to plan for next steps on how to implement a comprehensive approach to postsecondary readiness 


\section{Data Collection}

- Throughout this session and for our next meeting, participants will take part in surveys and individual interviews and aimed to measure the usefulness of the work shop and the guidebook.

- This data will be collected through questionnaires and through observational field-notes.

\section{How to use the guidebook}

Contents

Section 1: The Problem- Supported by Research and Data

Section 2: Structural Elements

Section 3: Academic Elements

Section 4: Social Elements

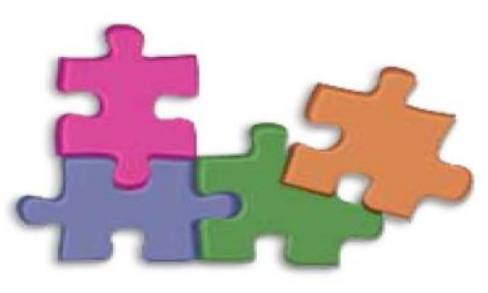


The Problem

Many Students Graduating from High School Aren't Ready for a Postsecondary Education!

\section{Postsecondary Readiness Framework}

\section{Structural Elements}

\section{Academic Elements}

\section{Social Elements}

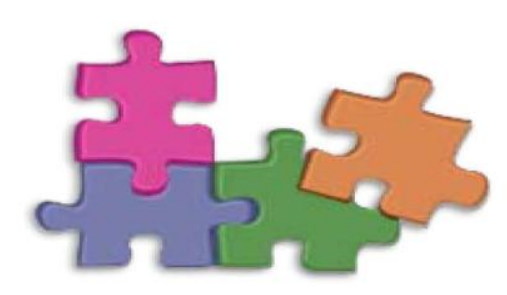

\section{Postsecondary Readiness Framework}

\section{$\pi$} Postsecondary

\section{POSTSECONDARY READINESS FRAMEWORK}

1. the $\frac{\text { Structural Elements }}{\text { mission/vision of schools }}$

2. transitions and

infrastructure

a. academic preparedness

b. academic tenacity

3. developing college knowledge
a. college-going culture
b. developing a partnerships

1. Academic Elements

creating a rigorous curriculum

2. college and career readiness standards and practices

3. quality instructional practices

4. identification of skills and progress
Social Elements

1. including parents and school staff in educational planning

2. identifying and building academic behaviors of students

3. improving both students, and parents 'transition knowledge and skills 
Components of guidebook

Targets- Identify and describe the problem and elements of the postsecondary readiness framework

Example: Many students graduating from high school aren't ready for a postsecondary education!

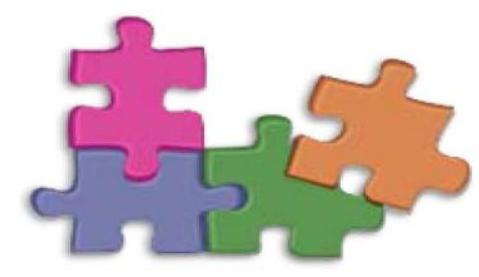

Components of guidebook continued...

Design questions- Are used to connect the practices and programs in your school to the targets

Example: How is your school preparing all students for postsecondary success?

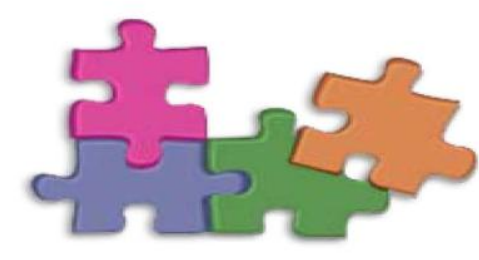


Components of guidebook continued...

Reflecting on Your Current Beliefs and Practices- Help to identify what is being done in your school and is connected to the Target

Example: How clear are you on your school's programs and best practices of addressing postsecondary preparedness?

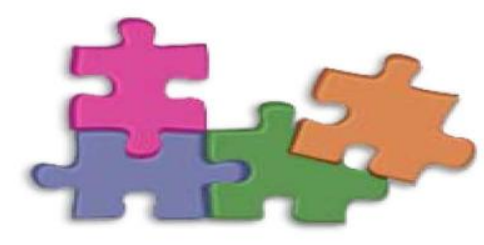

Components of guidebook continued...

Recommendations- Provide direction on how to address the problem

Example: Administer perception surveys of students, staff and parents to measure effectiveness of current practices aimed at preparing students for postsecondary success.

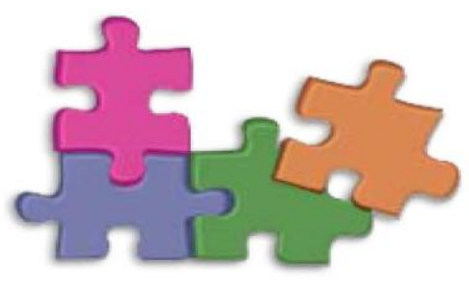




\title{
Components of guidebook continued...
}

\begin{abstract}
Activity Circles- Gives guidebook users the opportunity to discuss, reflect, and react to information presented.
\end{abstract}

Example: How is your district/state working with the federal government to help prepare students for postsecondary success?

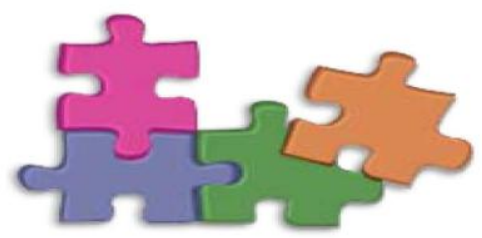

Components of guidebook continued...

Assessing Current Knowledge- Provides a brief summary of the target content, and measures the understanding and comfort level regarding key strategies and processes presented within each target.

4= I understand the current research, and already use this data to create/improve programs aimed to address and help solve the problem.

$3=I$ understand the current research, but I need to use the data to create/improve programs aimed to address and help solve the problem.

$2=$ I can explain the current research, but I am not fully confident that I can use the data to create/improve programs aimed to address and help solve the problem. $1=I$ do not understand the current research, and I do not currently use the data in my school.

1. Clearly articulating my state's, district's, and school's approach to preparing students for postsecondary success Based on my rating, I may need to revisit the following: 
Components of guidebook continued...

Action Templates- Aimed to help schools create a culture of postsecondary readiness specific to each element of the postsecondary readiness framework.

Example:

1. Quick wins-actions that can be implemented this semester or this school year

2. Moderately difficult undertakings-actions that need summer planning, professional development, or both

3. Major tasks-actions that will need two years or more for full implementation and may include quick wins and moderately difficult undertakings.

\section{Other important components}

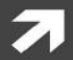

Section 5: Application of Postsecondary Readiness

Section 6: Postsecondary Readiness Resources

Section 7: Postsecondary Readiness Guidebook Assessment

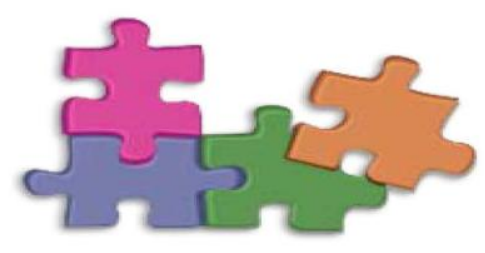


APPENDIX K

\section{GUIDEBOOK FUNCTIONALITY EVALUATION}




\section{Guidebook Functionality Evaluation}

\section{Demographics}

For each item, please select the description that applies to you. Demographic data, which is used for summary analysis, will not be reported if individuals can be identified.

\section{Ethnicity:}

(fill in all that apply)

$\bigcirc$ American Indian

O Asian

Black (African-American)

Filipino

Hispanic/Latino

$\bigcirc$ Middle Eastern

$\bigcirc$ Pacific Islander

$\bigcirc$ Other

\section{Gender:}

$\bigcirc$ Female

$\bigcirc$ Male

\section{Role:}

$\bigcirc$ District Administrator

$\bigcirc$ Building Administrator

$\bigcirc$ Teacher

$\bigcirc$ Parent

$\bigcirc$ Community Member

Community College Representative

$\bigcirc$ University Representative

$\bigcirc$ Policy Maker

$\bigcirc$ Other 


\section{I have been in education for:}

O 1-3 years

O 4-6 years

O 7-10 years

O 11 or more years

Below is a questionnaire designed to evaluate the Postsecondary Readiness Guidebook. The questionnaire is not a test of you; it is a test of the guidebook!

1. Look at the cover of this manual, and read the Table of Contents and Introduction. For which group(s) was this manual written? (usability)

2. Did the cover, Table of Contents and Introduction encourage you to read further? (usability)

O Yes

O No

3. Are the views, opinions and theories based on the best and most up to date information/research? (usability)

O Yes

O No

4. Is the guidebook free of hidden values or attitudes? (usability)

O Yes

O No

5. Do you have sufficient existing knowledge to make sense of the new information given? (usability)

O Yes

No

6. Does the guidebook help you understand how the elements of the postsecondary readiness framework will help your school? (applicability) 
7. Does the guidebook take into account the knowledge and skills available to the K-12 educational leader? (applicability)

$\bigcirc$ Yes

$\mathrm{ONo}$

8. Does the guidebook take into account the time and motivation available to the K-12 educational leader? (applicability)

$\bigcirc$ Yes

No

9. Does the workshop on the sections, application and resources of the guidebook help you understand how to use the guidebook? (applicability)

$\bigcirc$ Yes

$\mathrm{ONo}$

10. Please write one example of how you might apply the contents of this guidebook. (applicability)

11. Is the information well structured and easy to find? (accessibility)

$\bigcirc$ Yes

O No

12. Is the text readable? (accessibility)

$\mathrm{O}$ Yes

O No

13. Are the colors used well? (accessibility)

$\bigcirc$ Yes

No

14. Can you list the six sections of the Postsecondary Readiness Guidebook? (accessibility)

$\bigcirc$ Yes

$\mathrm{ONo}$ 
15. Can you list the three elements of the Postsecondary Readiness Framework? (accessibility)

$\bigcirc$ Yes

O No

16. Without looking it up, can you explain in your own words what the guidebook means when it talks about 'the problem'? (accessibility)

$\bigcirc$ Yes

$\bigcirc$ No

17. Do the components of the guidebook (design questions, targets, activity circles, recommendations etc.) really help you gain information and skills on the topic? (accessibility)

$\bigcirc$ Yes

O No

18. Is the reader given a way to assess his or her progress toward postsecondary readiness elements? (accessibility)

$\mathrm{O}$ Yes

$\mathrm{ONo}$

19. Please comment: what did you like about the guidebook?

20. Please comment: What parts, if any, did you find difficult? 
APPENDIX L

INTERVIEW PROTOCOL: MAIN FIELD TESTING 


\section{Interview Protocol: Main Field Testing}

Time of interview:

Date:

Place:

Interviewer:

Interviewee:

Position of interviewee:

(Briefly describe the project)

\section{Research Question}

1. In what ways can schools better prepare students for postsecondary success?

2. In what ways is the PRG useful in helping educational leaders prepare students for postsecondary success?

3. What improvements and changes to the PRG are needed to help educational leaders?

4. What is the perceived impression of the guidebook's usability, applicability, and accessibility?

5. In what ways is the workshop useful in helping educational leaders navigate through the PRG? 


\section{APPENDIX M}

INTERVIEW PROTOCOL 1: MAIN FIELD TESTING 


\section{Interview Protocol 1-Main Field Testing}

Purpose of Preliminary Field Test: A group of educational leaders will participate in a workshop, review the components of the guidebook and provide feedback on:

- the learning activities

- recommendations

- assessments

- resources

- usefulness of the guidebook

\section{Introduction}

1. To what extent does the Introduction of the guidebook help you understand its purpose and organization?

a. What aspects are effective with the purpose and organization?

b. What aspects need improvement?

\section{Section 1-The Problem}

1. How well does Section 1 (The Problem) help to frame the importance of the guidebook?
a. In what ways?

2. To what extent do the Reflecting on Your Current Beliefs and Practices and Activity Circles in Section 1 bring focus to your program's/school's approach to postsecondary preparedness relating to The Problem?

a. What questions are effective?

3. In what ways are the recommendations in this section helpful?

a. How can the recommendations be improved to help with your program's/school's approach to postsecondary preparedness?

4. How well does Assessing Current Knowledge in Section 1 identify current needs and improvements relating to The Problem?

a. Explain what can be improved with Assessing Current Knowledge in this section? 


\section{APPENDIX N}

INTERVIEW PROTOCOL 2: MAIN FIELD TESTING 


\section{Interview Protocol 2-Main Field Testing}

Purpose of Preliminary Field Test: A group of educational leaders will participate in a workshop, review the components of the guidebook and provide feedback on:

- the learning activities

- recommendations

- assessments

- resources

- usefulness of the guidebook

\section{Section 2-Structural Elements}

1. How well does Section 2 (Structural Components) address the organizational makeup of a school?

a. What structural components do you feel are the most beneficial to your program/school? Explain

b. What structural components do you feel are the least effective? Explain

2. To what extent do the Reflecting on Your Current Beliefs and Practices and Activity Circles in Section 2 bring focus to your program's/school's approach to postsecondary preparedness relating to Structure?

a. What questions are effective?

b. What questions need revision?

3. In what ways are the recommendations in this section helpful?

a. How can the recommendations be improved to help with your program's/school's approach to postsecondary preparedness?

4. How well does Assessing Current Knowledge in Section 2 identify current needs and improvements relating to Structure?

a. Explain what can be improved with Assessing Current Knowledge in this section? 
APPENDIX O

INTERVIEW PROTOCOL 3: MAIN FIELD TESTING 


\section{Interview Protocol 3-Main Field Testing}

Purpose of Preliminary Field Test: A group of educational leaders will participate in a workshop, review the components of the guidebook and provide feedback on:

- the learning activities

- recommendations

- assessments

- resources

- usefulness of the guidebook

\section{Section 3-Academic Elements}

1. How well does Section 3 (Academic Elements) address standards, practices, and assessments?

a. What academic elements do you feel are the most beneficial to your program/school? Explain

b. What academic elements do you feel are the least effective? Explain

2. To what extent do the Reflecting on Your Current Beliefs and Practices and Activity Circles in Section 3 bring focus to your program's/school's approach to postsecondary preparedness relating to Academic Elements?

a. What questions are effective?

b. What questions need revision?

3. In what ways are the recommendations in this section helpful?

a. How can the recommendations be improved to help with your program's/school's approach to postsecondary preparedness?

4. How well does Assessing Current Knowledge in Section 3 identify current needs and improvements relating to Academic Elements?

a. Explain what can be improved with Assessing Current Knowledge in this section? 


\section{APPENDIX P}

INTERVIEW PROTOCOL 4: MAIN FIELD TESTING 


\section{Interview Protocol 4-Main Field Testing}

Purpose of Preliminary Field Test: A group of educational leaders will participate in a workshop, review the components of the guidebook and provide feedback on:

- the learning activities

- recommendations

- assessments

- resources

- usefulness of the guidebook

\section{Section 4-Social Elements}

1. How well does Section 4 (Social Elements) address family involvement, academic behaviors, and education of transitional knowledge and skills?

a. What social elements do you feel are the most beneficial to your program/school? Explain

b. What social elements do you feel are the least effective? Explain

2. To what extent do the Reflecting on Your Current Beliefs and Practices and Activity Circles in Section 4 bring focus to your program's/school's approach to postsecondary preparedness relating to Social Elements?

a. What questions are effective?

b. What questions need revision?

3. In what ways are the recommendations in this section helpful?

a. How can the recommendations be improved to help with your program's/school's approach to postsecondary preparedness?

4. How well does Assessing Current Knowledge in Section 4 identify current needs and improvements relating to Social Elements?

a. Explain what can be improved with Assessing Current Knowledge in this section? 
APPENDIX Q

INTERVIEW PROTOCOL 5: MAIN FIELD TESTING 


\section{Interview Protocol 5-Main Field Testing}

Purpose of Preliminary Field Test: A group of educational leaders will participate in a workshop, review the components of the guidebook and provide feedback on:

- the learning activities

- recommendations

- assessments

- resources

- usefulness of the guidebook

\section{Section 5-Application of Postsecondary Readiness}

1. How well does Section 5 (Application of Postsecondary Readiness) show the implementation of a comprehensive approach to postsecondary readiness in a high school model? Explain

2. To what extent does the Application of Postsecondary Readiness in Section $\mathbf{5}$ help conceptualize these ideas at your school?

a. What elements are effective?

b. What elements need further explanation?

3. In what ways do the Other Best Practice at Clackamas Middle College provide insight to further postsecondary preparedness?

4. Explain what can be improved in this section to help conceptualize and implement this approach in your program/school?

\section{Section 6-Postsecondary Readiness Resources}

1. How useful are the resources in this section?

2. To what extent does the format (Target Users, When to Use These Resources, Focus of These Resources etc...) help to identify which resources will be used in your program/school?

a. How can this format be improved?

3. To what extent did the Action Templates at the end of each section help organize actions toward postsecondary preparedness?

a. What was effective with the Action Template?

b. What could be improved with the Action Template?

4. How well did the Action Templates-Professional Development and Communication Planning at the end of each section help identify people who can lead the implementation for postsecondary preparedness?

a. What was effective with the Action Template-Development and Communication Planning?

b. What could be improved with the Action Template-Development and Communication Planning? 
APPENDIX R

POSTSECONDARY READINESS GUIDEBOOK 

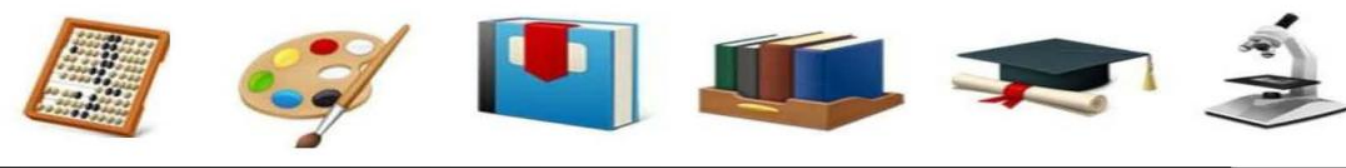

A Guidebook for Educational Leaders

\section{Bridging the Future to Postsecondary Readiness}

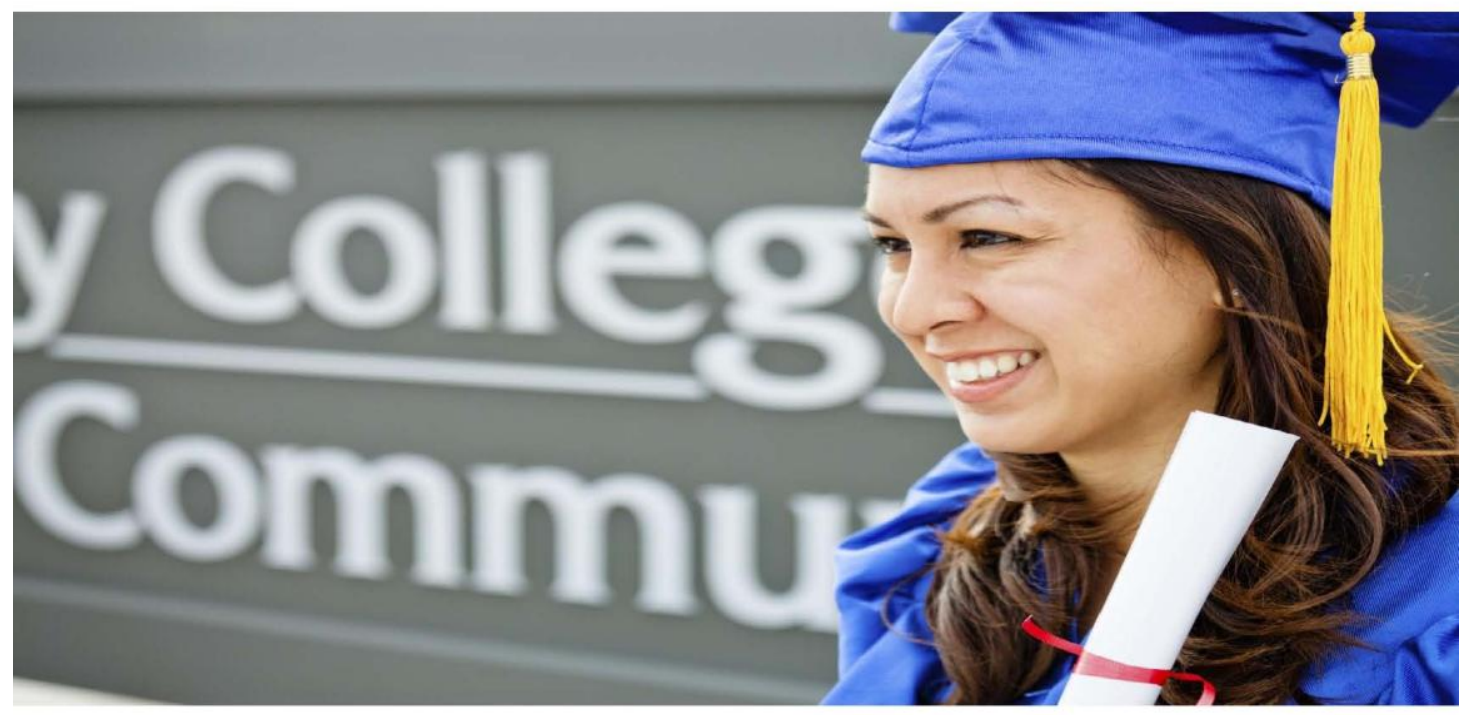

Graduate School of Education:

Bridging the Future:

Postsecondary Readiness for

Public Schools

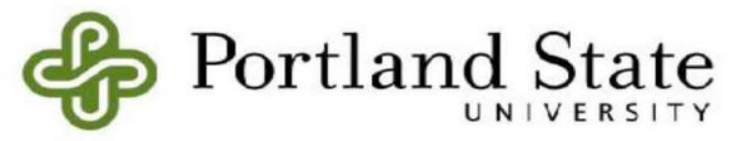

May 5, 2014 । Portland, Oregon 


\section{Contents}

INTRODUCTION $\ldots \ldots \ldots \ldots \ldots \ldots \ldots \ldots \ldots \ldots \ldots \ldots \ldots \ldots \ldots \ldots \ldots \ldots \ldots 1$

SECTION 1: THE PROBLEM-SUPPORTED

BY RESEARCH AND DATA ..................................

SECTION 2: STRUCTURAL ELEMENTS.

.23

SECTION 3: ACADEMIC ELEMENTS.

.43

SECTION 4: SOCIAL ELEMENTS

SECTION 5: APPLICATION OF POSTSECONDARY READINESS.

SECTION 6: POSTSECONDARY READINESS

RESOURCES 


\section{Introduction}

\section{WHY THIS GUIDEBOOK}

As an educator, I have had the opportunity to travel around the country to visit different

educational models. I do this because I believe that there are many ways to approach education, and I don't have the market cornered on excellence. I also do this because I believe that any opportunity to collaborate will greatly help our educational process. This is no more evident than in the quote by Nelson Mandela, "Education is the most powerful weapon which you can use to change the world."

I am the principal of a middle college and wanted to research best practices from around the country and apply them to my school. While traveling to Texas to visit a school model similar to ours, I was hoping to return with new, unique and innovative approaches to education. Upon my return, I had the opportunity to reflect on what I had learned. While the intent of my visit was to gain knowledge on how to best serve students transitioning to postsecondary options, which I was able to do, I also realized that educational systems that share similar missions can be disconnected and lack successful best practices and approaches in preparing their students for postsecondary success.

When I first arrived for my visit, I was welcomed by the principal who was in his first year with the school. As soon as I was greeted, the first thing he asked me was: "Why are you here?" I responded that our two schools were similar in their mission and that I wanted to see what they were doing that was effective, and what obstacles they have encountered along the way. $\mathrm{He}$ seemed surprised.

His reaction to my presence was disappointing. If the culture of education in our country was collaborative and connected, his response to my visit would have been different. He would have welcomed me, and our two schools would have formed a professional partnership. We would have shared our obstacles and best practices in order to best serve our students.

1 Bridging the Future to Postsecondary Readiness 
While walking away from my visit, I began to think about how I could maximize my work and experience in education. I realized that I have a great deal to share with this principal, and I am confident that by creating a guidebook for educational leaders, avenues will open up between educational institutions that are interested in preparing students for postsecondary success.

It is through this work toward my dissertation that I am eager and willing to build a network of collaboration between educational institutions that are intent on preparing students for postsecondary success. This can begin through the creation of a postsecondary readiness guidebook that will help school leaders prepare students for postsecondary success through a comprehensive approach. Through the creation of this guidebook, I can begin to lay a foundation of collaboration. Hopefully, through my work, I can help to build a systematic sharing of knowledge among schools aimed at successfully helping transition students from secondary schools to postsecondary options. It is through this work that I am committed and motivated toward helping other educational leaders.

\section{AUDIENCE}

The audience for this guidebook is large. When I field tested this guidebook, an elementary educator replied: "I learned that a K-12 postsecondary readiness program needs to be put in place at our school." Educating students is complex and because of this many people need to be involved in this process. If you are a district or building administrator, teacher, parent, community member, community college or university representative, or serve in an educational role at the state level; this guidebook is for you. Another participant of the field test stated, "Students need an awareness of college in younger grades." The information in this guidebook is pertinent to teachers of all levels in our educational system. We all have a role to play in preparing our student for postsecondary success.

\section{WHAT IS POSTSECONDARY READINESS and POSTSECONDARY FRAMEWORK}

As one can imagine, the research on preparing students for postsecondary success is complex and comprehensive. Because of this, the school system must have a structure and mechanisms

2 Bridging the Future to Postsecondary Readiness 
put in place where students can understand and/or become integrated into both the academic and social systems of postsecondary options.

For this guidebook, the term postsecondary readiness is synonymous with the term "college and career readiness". It is defined as: the completion of entry-level or core courses at a proficient level that allows students to take the next course in the sequence or the next level course in the subject area, or completion of the certificate (Conley, 2010).

In order to prepare all students for postsecondary education, schools must look to a postsecondary readiness framework in order to provide academic and social mechanisms to help all students transition successfully to postsecondary options. Within this framework, there are many aspects that must be addressed to help students make this transition successful. The following framework was created from research in order to help educators successfully prepare students for postsecondary success. The postsecondary readiness framework centers on three key elements: (1) structural elements, (2) academic elements, and (3) social elements.

As the transition from secondary schools to college is a complex one for many students, schools would better serve students if they looked into improving current systems or creating systems that address structural, academic, and social elements aimed at addressing this transition for students. Creating a postsecondary readiness framework would ensure a systematic process to successfully prepare students for postsecondary options.

\section{THE STRUCTURE OF THIS GUIDEBOOK}

This guidebook contains sections which address a fundamental problem to postsecondary preparedness along with data supporting the problem. After the problem has been presented, the guidebook focuses on the postsecondary readiness framework aimed at helping solve this fundamental problem. The framework is broken down into three key elements: (1) structural elements, (2) academic elements, and (3) social elements. Table 1 below reflects the components within the three key elements.

3 Bridging the Future to Postsecondary Readiness 
Table 1-Postsecondary Readiness Framework Elements

\begin{tabular}{|c|c|c|}
\hline \multicolumn{3}{|c|}{ POSTSECONDARY READINESS FRAMEWORK } \\
\hline $\begin{array}{l}\text { Structural Elements } \\
\text { 1. the mission/vision of schools } \\
\text { 2. transitions and } \\
\text { infrastructure } \\
\text { a. academic } \\
\text { preparedness } \\
\text { b. academic tenacity } \\
\text { 3. developing college } \\
\text { knowledge } \\
\text { a. college-going } \\
\text { b. culture developing a } \\
\text { partnerships }\end{array}$ & $\begin{array}{l}\text { Academic Elements } \\
\text { 1. creating a rigorous } \\
\text { curriculum } \\
\text { 2. college and career } \\
\text { readiness standards and } \\
\text { practices } \\
\text { 3. quality instructional } \\
\text { practices } \\
\text { 4. identification of skills and } \\
\text { progress }\end{array}$ & $\begin{array}{l}\text { 1. } \begin{array}{l}\text { Social Elements } \\
\text { school staff in educational } \\
\text { planning }\end{array} \\
\text { 2. identifying and building } \\
\text { academic behaviors of } \\
\text { students } \\
\text { 3. improving both students' } \\
\text { and parents' transition } \\
\text { knowledge and skills }\end{array}$ \\
\hline
\end{tabular}

Each section is guided by a design question related to above framework. For example: What structures are currently in place to successfully prepare students for postsecondary success? Within each design question there are targets or themes which serve to help readers reflect on current practices as well as to assess current knowledge. Assessing Current Knowledge (survey) will provide a brief summary of the target content, and understanding and comfort level regarding key strategies and processes presented within each target. The targets in each section present information in small manageable paragraphs. Robert Marzano (2007) refers to these as "chunks." Presenting the information in chunks keep with the basic principle of effective teaching to help readers effectively interact with new knowledge (Marzano, 2007). Each chunk of information is attached to an activity circle that asks readers to react to the information that has been presented, or to describe how readers use this information in their practice. These activity circles (discussion/reflection exercises) help guide and reform current practice. Reflecting on Current Practices will help to review what background knowledge and practices are used related to the target, but also to frame the material presented in each target. At the end of every section, there is checklist of recommendations to put the reader on the right path toward postsecondary readiness along with a rubric for the reader to assess progress toward each element within the postsecondary readiness framework. After the rubric there is an action template from National Association of Secondary School Principals (NASSP) aimed to help

4 Bridging the Future to Postsecondary Readiness 
schools create a culture of postsecondary readiness specific to each element of the postsecondary readiness framework.

This guidebook also contains an opportunity to see the application of the postsecondary readiness framework in a middle college, as well as resources, programs and websites aimed at preparing all students for postsecondary success.

\section{HOW TO USE THIS GUIDEBOOK}

The guidebook is designed to be used by educational leaders in schools that are preparing students for postsecondary success. A team or committee should be formed to review this guidebook and reflect on current practices aimed at improving postsecondary preparation in school. To maximize the time and effort of the team, the guidebook should be introduced to coincide with professional development opportunities and integrated into the continuous school improvement plan. When these conditions are met, this guidebook can be used to plan and improve programs throughout the school year, or be broken down into sections to address current needs.

This guidebook is broken down by the following categories:

- Section 1 provides research and data addressing the problem that many students graduating from secondary schools aren't prepared for postsecondary success. This will help to show the significance and purpose of the guidebook aimed to provide educational leaders a comprehensive approach in preparing students for postsecondary success.

- Section 2 describes the structural elements of the postsecondary readiness framework schools must have in place to help students move systematically toward college and career options.

- Section 3 describes the academic elements of the postsecondary readiness framework schools must have in place to align rigorous academic standards with postsecondary institutions.

- Section 4 describes the social elements of the postsecondary readiness framework schools must have in place to create a culture focused on a sense of caring, cultural

5 Bridging the Future to Postsecondary Readiness 
awareness, social and academic validation and support, and involvement of all stakeholders (students, staff members, parents, and community).

- Section 5 describes best practices of a middle college within the postsecondary readiness framework.

- Section 6 provides resources and programs focused on preparing students for postsecondary success.

\section{PURPOSE OF THIS GUIDEBOOK}

There are several types of promising programs that appear to help address the problem of students not being prepared to transition from secondary schools to postsecondary options. These are The Advanced Placement Program (AP), Advancement Via Individual Determination (AVID), The International Baccalaureate Programme (IB), and Early and Middle College High Schools. During the 2002-03 school year, 1.2 million students were enrolled in courses that awarded dual high school and college credit, 1.8 million students were enrolled in AP courses, and 165,000 students were enrolled in IB courses (Hoffman \& Vargas, 2010). Some of these approaches increase the chances of postsecondary student success. These programs can exist within high schools, or they can be individual schools.

This guidebook was created to point out the significance and address the problem of high school graduates not being prepared for postsecondary success. It also informs school leaders of their current postsecondary readiness culture, and provides elements aimed to create an integrated system that provides postsecondary information to students in a progressive, developmentally appropriate fashion so that they have a continuous sense of how well they are being preparedand are preparing themselves- for postsecondary success (Conley, 2007). This, according to David Conley, is considered the "holy grail" of college readiness.

6 Bridging the Future to Postsecondary Readiness 
SECTION 1:

THE PROBLEM - SUPPORTED BY RESEARCH AND DATA

"The problem is we are doing things that are relevant, but we have no formal guidance."

-James (High School Humanities Teacher)

"Schools need to have a plan in place for preparing students for college. All teachers need to be aware of the plan."

- Kathy (Middle School Science Teacher) 


\section{Design Question 1}

How is your school preparing all students for postsecondary success?

\section{Target 1}

\section{$(1$}

\section{The Problem: Many Students Graduating from Secondary} Schools Aren't Ready for a Postsecondary Education!

- First year of college is the most important in regard to degree completion ○ $25 \%$ of these students drop out their freshman year

Carey, 2004

- Some two-year colleges see $80 \%$ of their students taking remedial classes

- Nationally, only $17 \%$ of students who must take remedial readin 8 receive a bachelor's degree or higher

This target deals with the problem that many students graduating from secondary schools aren't ready for a postsecondary education. Target 1 begins with the statement of the problem central to this guidebook, followed by an assessment of current knowledge, understanding and comfort level pertaining to the problem. Readers then have the opportunity to reflect on current beliefs and practices around the problem. After reflection, research is presented to give context and to support the problem. In this research there is a look into past practices, current practices, the problem, its significance, along with ways to help prepare students for postsecondary success. Finally, this section ends with a rubric for the reader to assess progress toward each element within the postsecondary readiness framework, along with an action plan template for next steps.

8 Bridging the Future to Postsecondary Readiness 


\section{Assessing Current Knowledge}

Use the following rating scale to assess your current knowledge, understanding and comfort level regarding background information and research presented in this target.

4= I understand the current research, and already use this data to create/improve programs aimed to address and help solve the problem.

$3=$ I understand the current research, but I need to use the data to create/improve programs aimed to address and help solve the problem.

$2=$ I can explain the current research, but I am not fully confident that I can use the data to create/improve programs aimed to address and help solve the problem.

$1=\mathrm{I}$ do not understand the current research, and I do not currently use the data in my school.

1. I can clearly articulate research on my state's, district's, and school's approach to preparing students for postsecondary success

Based on my rating, I may need to revisit the following:

2. I look at research on the past and current context of education Based on my rating, I may need to revisit the following:

3. I realize the problem and its significance in today's society Based on my rating, I may need to revisit the following:

4. I can refine the direction and approaches of postsecondary preparedness in my district/school

Based on my rating, I may need to revisit the following:

9 Bridging the Future to Postsecondary Readiness 
Reflecting on Your Current Beliefs and Practices

Before examining the research, take some time to look at your current beliefs and practices by answering the following questions:

1. What knowledge do you have on the current research, along with federal and state involvement in helping schools prepare all students for postsecondary success? Where do you get your information/research/data pertaining to the aforementioned problem?

2. How clear are you on your school's programs and best practices of addressing postsecondary preparedness? List all of the approaches your school uses to address the aforementioned problem.

3. To what extent are you involved in these programs/best practices aimed at preparing students for postsecondary success? What systems are set up for all staff members to become involved in these programs/best practices?

4. To what extent are the details of the programs/best practices aimed at preparing students for postsecondary success communicated regularly to the staff at your school? How often are these programs/best practices refined/modified with current research to best serve all students?

10 Bridging the Future to Postsecondary Readiness 


\section{Recommendations}

This target addresses the following best practices for Design Question 1:

- Form a study group to review and analyze the issue/data of postsecondary preparedness, along with schools and programs looking to help prepare student for postsecondary success.

- List current programs/best practices in your school/district for postsecondary preparedness.

- Administer perception surveys of students, staff and parents to measure effectiveness of current practices aimed at preparing students for postsecondary success.

\section{Introduction to the Research}

In November of 2009, President Barack Obama stated the necessity of making education America's national mission (U.S. Department of Education, 2009). During tough economic times, education plays a critical role in helping our citizens obtain the necessary skills to become contributing members of the work force. The state of Oregon is realizing the importance of education and is committed to a "40-40-20" plan in which the state will: (1) ensure that at least 40 percent of adult Oregonians have earned a bachelor's degree or higher; (2) ensure that at least 40 percent of adult Oregonians have earned an associate's degree or post-secondary credential as their highest level of educational attainment; and (3) ensure that the remaining 20 percent or less of all adult Oregonians have earned a high school diploma, an extended or modified high school diploma or the equivalent of a high school diploma as their highest level of educational attainment (State of Oregon, 2011).

Unfortunately, in our educational system, many students graduating from secondary schools aren't ready for a postsecondary education, therefore making them unqualified to join the work force. Today, the goals of our educational system need to align with the goals of our society. We need to provide our students successful programs and schools that prepare them for a postsecondary education so that they can meet the demands of a global economy. Now more than ever, education must be the fabric for which the greatness of our country is defined.

This guidebook was created on the assumption that a postsecondary education will prepare students for the work force. A postsecondary education includes: community colleges (career certificates, associate's degrees), universities (bachelor's, master's, professional, and doctoral degree).

\footnotetext{
11 Bridging the Future to Postsecondary Readiness
} 
*For the Activity Circles, engage in a conversation with your team around the topic to help connect your knowledge to practice. This is will help build context and improve understanding of each topic or theme.

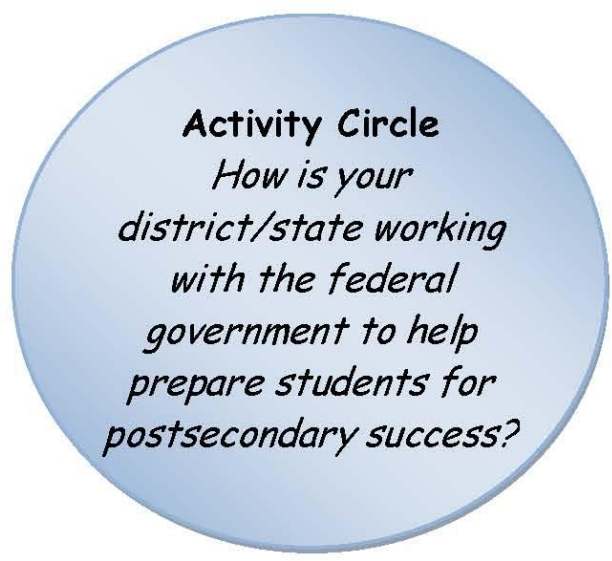

\section{A Picture of the Past}

When looking at transitioning students from secondary schools to postsecondary options, it is necessary to first look at the public school system. The evolution of secondary schools in our society is linked directly with the growth of our nation. Secondary schooling was developed from traditional village schools in the late $19^{\text {th }}$ and early $20^{\text {th }}$ centuries and was linked to the success of our country's economic and political future (Lee \& Smith, 1995). Large high schools were created for efficiency, differentiation, specialization, and standardization. This was done to prepare high school graduates to be productive members of the workforce, and was a successful model of the production of human capital until the late 1960's (Lee \& Smith, 1995). As students earn their high school diploma, their unemployment rates go down and their median weekly earnings go up compared to students who don't earn a high school diploma. The more education one receives, the lower the unemployment rate and the higher the earnings, putting a greater importance on postsecondary education (Figure 1).

12 Bridging the Future to Postsecondary Readiness 
Figure 1

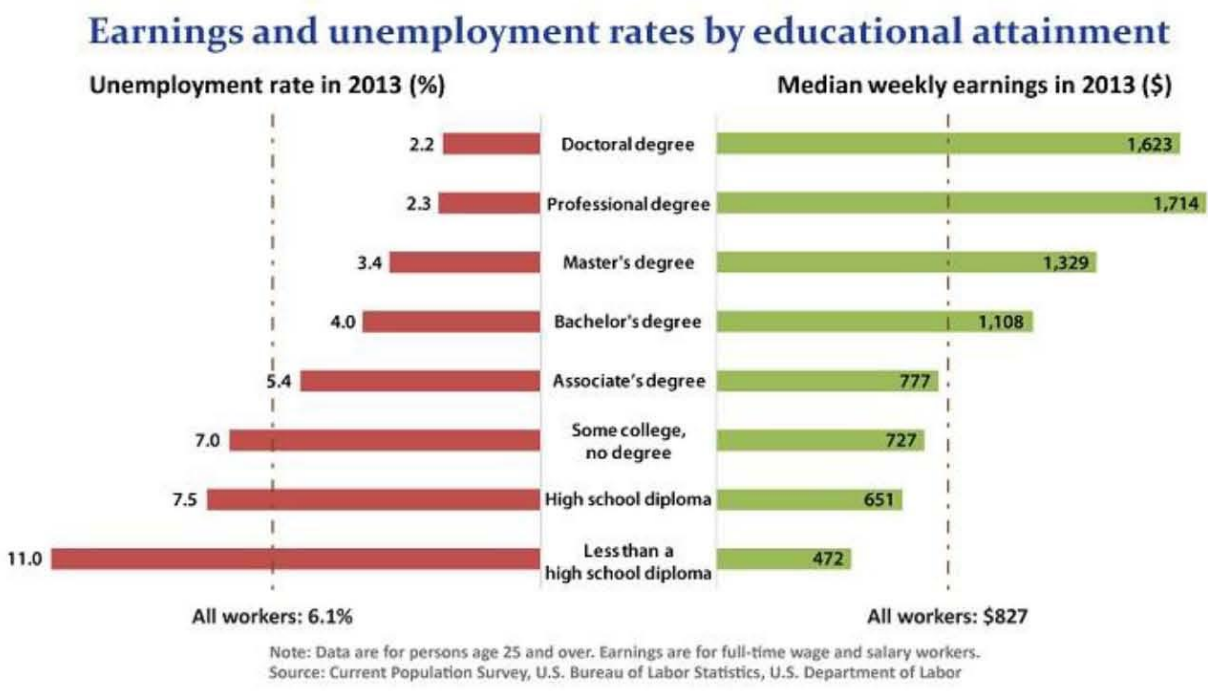

\section{Current Practice}

In secondary schools today, there are many students who aren't learning the necessary skills to succeed after their public schooling. It is easy to avoid learning in today's secondary schools and still graduate believing that one has learned (Powell \& others, 1985). Students from lowincome families and some ethnic and racial minority groups are most dependent on the ability of their secondary schools to prepare them properly for college success (D. T. Conley, 2010). Conley (2010), states that while many high school graduates exceed expectations, many do not, and there is no real way to know the minimal level of skill that all diploma recipients have attained. Secondary schools have continued to operate under older bureaucratic designs even though our society and workforce have placed a greater importance on postsecondary education. High schools should be directly connected to elementary and middle schools, higher education, industry and business, state and federal government and to their communities that surround them (Boyer, 1983). In reality, high schools often become independent educational institutions that are isolated from the aforementioned stakeholders. There needs to be a bridge to connect the systems of education so our children won't suffer in the transition from one system to the next.

Because many students graduating secondary schools aren't ready for college, the following questions need to be answered: What can be done to our educational structure so that it

\section{Bridging the Future to Postsecondary Readiness}


successfully prepares students for a postsecondary education? What standards exist to help states, districts, schools and educators prepare students for a postsecondary education? What program/schools currently exist to help students make a successful transition from secondary schools to postsecondary education? It is up to educators to prepare public school students with the skills necessary to make a successful transition from secondary schools to postsecondary education. By doing so, students will be able to reflect on their public school experience as constructive and positive tow ard helping them grow as individuals in our society. By answering the aforementioned questions, we begin to make education (America's national mission) a reality.

*Take some time and engage in a conversation with your team around the following question

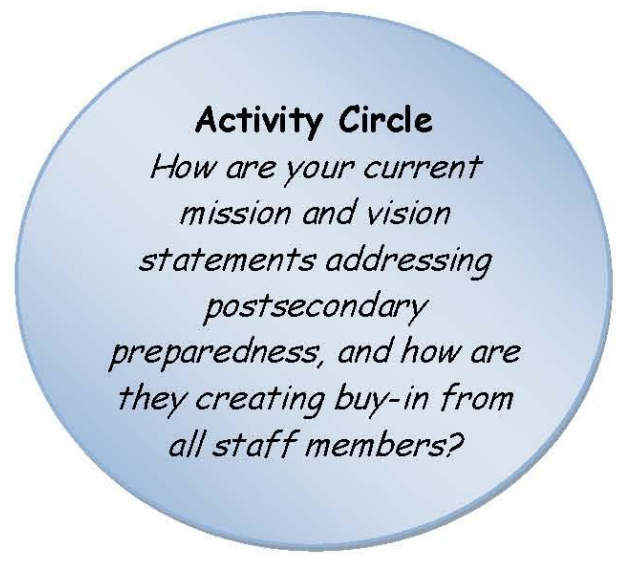

\section{The Problem}

In these uncertain economic times, parents from all racial, ethnic and economic backgrounds are looking to secondary schools more than ever to prepare their sons and daughters well for life after public schooling. Many parents are hoping that this life after public school entails a successful entry into an institution of higher education to ensure that their sons/daughters can live a life of happiness and prosperity. Studies show that students who earn a bachelor's degree are $33 \%$ more likely to become employed over students who earn a high school diploma (Pascarella \& Terenzini, 1991). Pascarella and Terenzini (1991), also show that students obtaining an associate degree have a $9-17 \%$ advantage of employment over students with a high school diploma.

\section{Bridging the Future to Postsecondary Readiness}


Research confirms that many students graduating from secondary schools aren't ready for postsecondary education. In our educational system secondary schools aren't adequately preparing students for postsecondary education. This lack of preparation requires remediation and can be attributed to the lack of alignment between secondary schooling and college regarding academic standards, communication and collaboration. Some two-year colleges see $80 \%$ of their students taking remedial classes. Moreover, only $17 \%$ of students who must take remedial reading receive a bachelor's degree or higher (D. T. Conley, 2010). Better efforts must be made to transition students from secondary schools to colleges and universities. The first year of college is the most important in regard to degree completion; 25 percent of these students drop out their freshman year (Carey, 2004).

In my experience as a middle college principal, it has become a necessity for my high school to work closely with our local community college to provide a seamless transition from secondary to postsecondary education to ensure student success. Both educational institutions have an investment in these students who will determine the future development and prosperity of our country.

\section{Significance of the Problem}

While all students who finish high school don't go to college, nearly 70 percent will actually enroll in colleges or universities within two years of high school graduation (Haycock, Barth, Mitchell, \& Wilkins, 1999). As more and more students and families realize the importance of a postsecondary education, efforts must be made by both secondary schools and colleges to work on transitioning students successfully from one system to another.

In order to facilitate this transition, the Bill \& Melinda Gates Foundation has invested nearly $\$ 4$ billion to transform the levels of college-readiness and success for America's young people, particularly for low-income and minority youth. This foundation has helped demonstrate that with the right opportunities, all young people can achieve at high levels (Bill and Melinda Gates Foundation, 2009). Because educational leaders aren't emphasizing skills students need to be successful in college, it makes it difficult for students to make the transition from the public

15 Bridging the Future to Postsecondary Readiness 
educational system (P-12) to the higher educational system (13-20).

The financial and economic implications of the current educational situation are difficult to ignore. The next decade will bring an economy where more than $60 \%$ of jobs will require a college degree, and in the state of Oregon, only about a third of students will enter college the fall after graduating, and only about $10 \%$ will earn a degree within 4 years (Carnevale, Smith, \& Strohl, 2010). Because secondary schools and postsecondary institutions aren't aligned, students aren't acquiring the necessary skills to move from one system to another. When looking at students who are admitted and enrolled into postsecondary institutions, $40 \%$ of them take at least one remedial course costing $\$ 1$ billion or more per year (D. T. Conley, 2010). An effective transition for these students would provide savings to states and families and provide economic stability for the country.

Culturally, issues of social justice arise when we look at serving all members of our society within the current system. Social justice can be defined as a dynamic state of affairs which is good for the common interest; this includes the good of each and all, in an acknowledgement that one depends on the other. The good depends on a right distribution of benefits and responsibilities (Griffiths, 1998, p. 302). It is important, when referring to the aforementioned definition, to acknowledge that all students should have access to a postsecondary education. Conley (2010), reports that only $60 \%$ of students from minority groups and low-income families can expect to graduate from high school, only one in three will enroll in college, and only one in seven will earn a bachelor's degree.

In 2005, the nation's governors held an educational summit to discuss the failure of secondary schooling to educate all students (Wolk \& Jobs for the Future, 2005). In this summit, some alarming statistics were addressed. According to Wolk and Jobs (2005):

- Almost a third of students who start the ninth grade fail to graduate and two-thirds are not prepared for college; only half of African-American, Latino, and NativeAmerican youth earn a high school diploma;

- A solid majority of high school seniors are not proficient in reading, math, or science, and their scores decline from fourth to twelfth grade; U.S. students usually rank in the bottom half along with underdeveloped nations;

16 Bridging the Future to Postsecondary Readiness 
- $75 \%$ of high school graduates enroll in college, more than a third need remedial courses, a third never make it to the sophomore year, and more than half do not complete the work necessary to earn a degree;

- $18 \%$ of African Americans and 10 percent of Latinos complete a four-year college degree by the time they are 29, compared to 34 percent of whites;

- The percentage of U.S. students who earn a college degree is the same as it was 30 years ago $(2005$, p. 2).

\section{What Now?}

It is clear from the research above, that a big representation of students moving to postsecondary education either aren't ready, or there are specific groups of students who either never make it or are underrepresented in higher education. Leaders at the federal and state level are beginning to see the importance of creating an educational structure that successfully transitions students from secondary schools to college and/or careers, and that it is directly aligned to the growth of our country.

In February 2009, President Obama signed into law the American Recovery and Reinvestment Act of 2009 (ARRA). This federal legislation was created to help stimulate the economy, support job creation, and invest in critical sectors, including education (U.S. Department of Education, 2009). The U.S. Department of Education (2009), created ARRA to move educational reform toward supporting investments in innovative strategies that will lead to improved student results, long-term gains in school and educational system capacity, and increased productivity and effectiveness. ARRA provided $\$ 4.35$ billion to create the Race to the Top Fund. This was a competitive grant program for States to reward and encourage innovation in education. This innovation addressed the following conditions: achieving significant improvement in student outcomes, including making substantial gains in student achievement, closing achievement gaps, improving high school graduation rates, and ensuring student preparation for success in college and careers; and implementing ambitious plans toward educational reform (U.S. Department of Education, 2009).

To prepare students for success in postsecondary education, Race to the Top encouraged the adoption of standards and assessments that prepared students to succeed and to compete in the global economy. Race to the Top was based on six priorities to improve the quality of education

17 Bridging the Future to Postsecondary Readiness 
in our country. Priority one and five addressed the successful transition from secondary schools to postsecondary education. Priority one, the Absolute Priority focused on a comprehensive approach to educational reform where the Local Educational Agencies (LEAs) or school districts will use the funds from Race to the Top to increase stake holder involvement and the rates at which students graduate from secondary schools prepared for postsecondary education (U.S. Department of Education, 2009). Priority five, the Invitational Priority focuses on early preschool-through-graduate school (P-20) coordination, vertical and horizontal alignment. Priority five stresses the importance of vertical alignment where a transition occurs (K-12 and postsecondary/careers) to ensure that students leaving one level are prepared for success, without remediation, in the next (U.S. Department of Education, 2009). While the federal government takes more of an active role in public education to improve the quality of education, it is working with states to set unifying educational guidelines and curriculum.

In the state of Oregon, the state legislature created the Oregon Education Investment Board (OEIB), an initiative and priority of Governor John Kitzhaber. The OEIB chaired by the governor is tasked with overseeing the effort to create a "seamless, unified system for investing in and delivering public education from early childhood through high school and college so that all Oregonians are well prepared for careers in our global economy" (Oregon.gov, 2011). The goals of OEIB are as follows: $100 \%$ of Oregonians will earn a high school diploma or equivalent- $40 \%$ of Oregonians will obtain an associate's degree or postsecondary credential, $40 \%$ of Oregonians will obtain a bachelor's degree or higher, and $20 \%$ will obtain a high school diploma, an extended or modified high school diploma or the equivalent of a high school diploma (Figure 2).

Figure 2
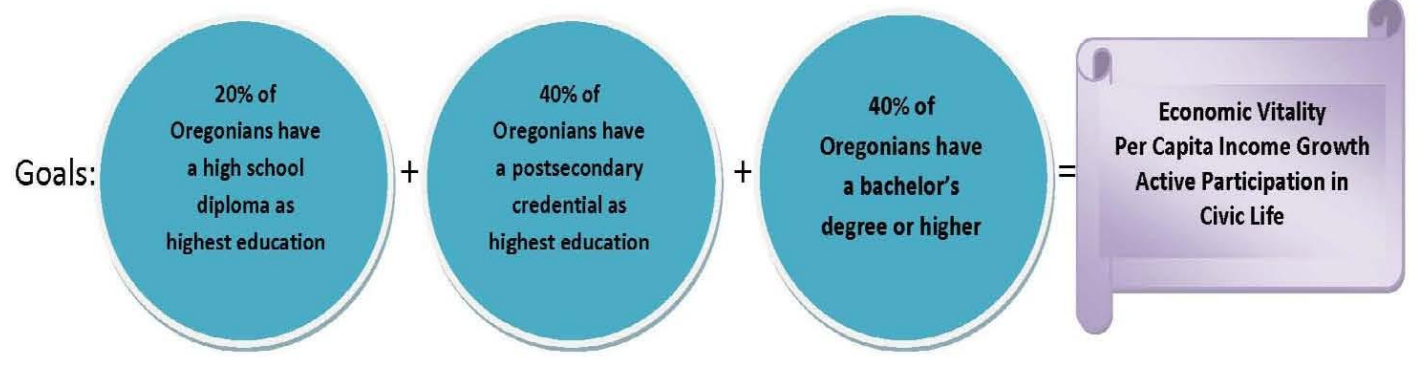

18 Bridging the Future to Postsecondary Readiness 
The process for achieving these goals will be achieved through a process of collecting, reviewing and evaluating the efforts of groups with expertise in the areas of early learning, educational finance, and increasing K-12 efficiencies (Kitzhaber, 2011).

Today, both the federal and state governments are taking active roles in addressing a successful transition from secondary schools to college. The policies at both levels should help to reduce remediation and successfully prepare students for a postsecondary education through the creation of a seamless educational system.

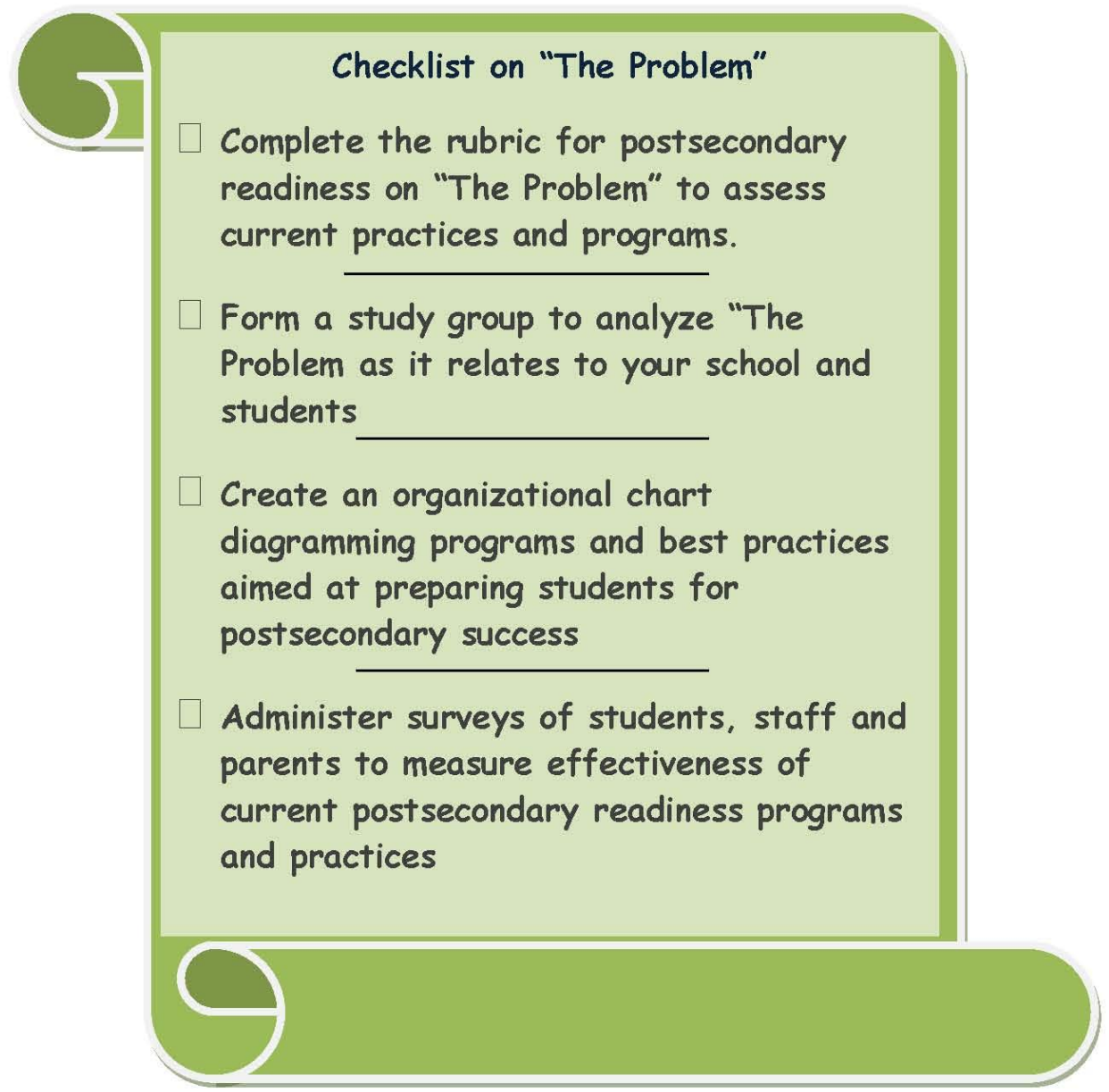

19 Bridging the Future to Postsecondary Readiness 


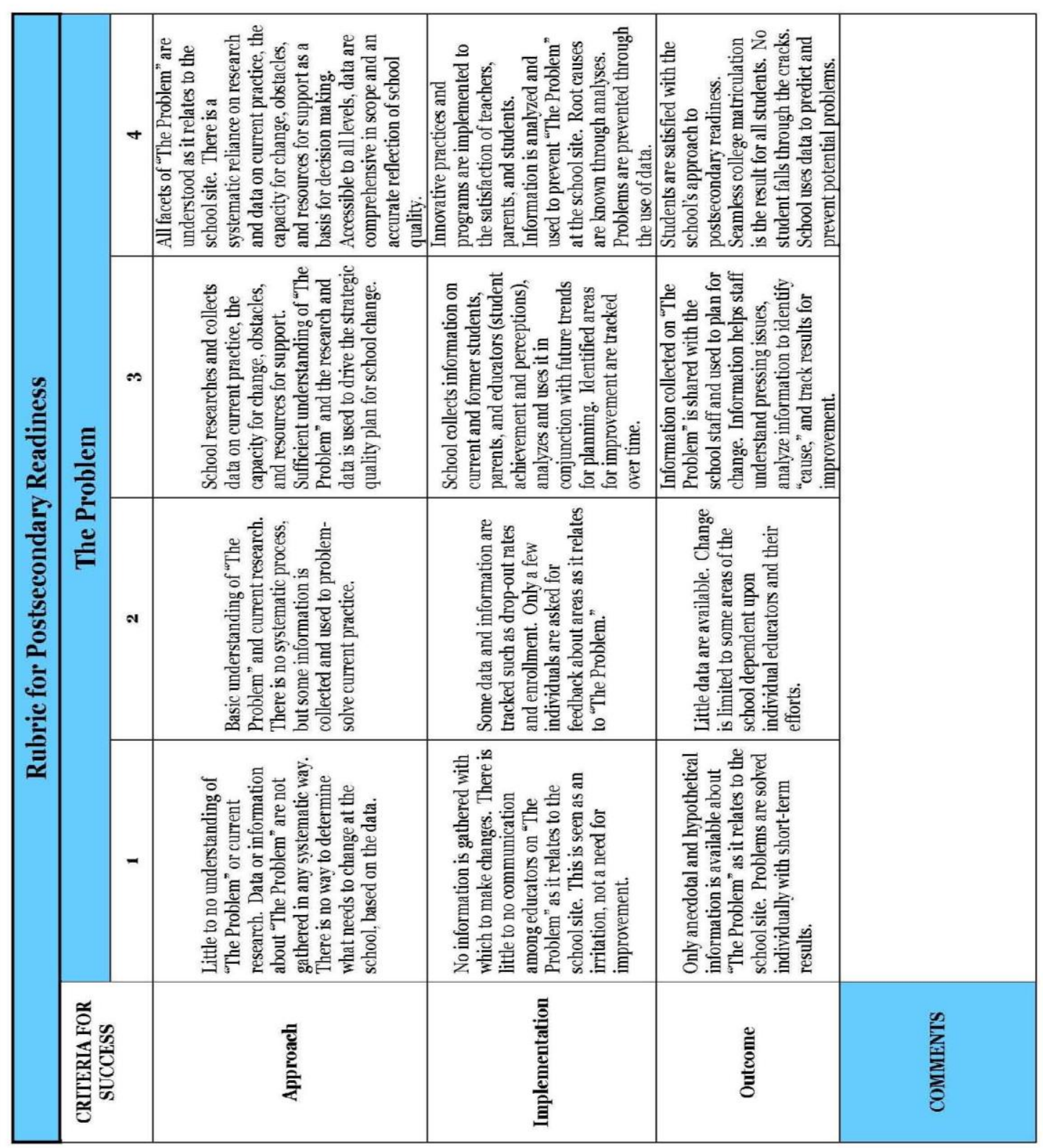

20 Bridging the Future to Postsecondary Readiness 


\section{Action Template $\sum_{\text {Advocacy \& Policy Center }}^{e}$}

Organize any new actions being considered for implementation at your school with this implementation template. Consider all general actions, those already begun as well as new ones, and then categorize them according to:

1. Quick wins-actions that can be implemented this semester or this school year

2. Moderately difficult undertakings-actions that need summer planning, professional development, or both

3. Major tasks-actions that will need two years or more for full implementation and may include quick wins and moderately difficult undertakings.

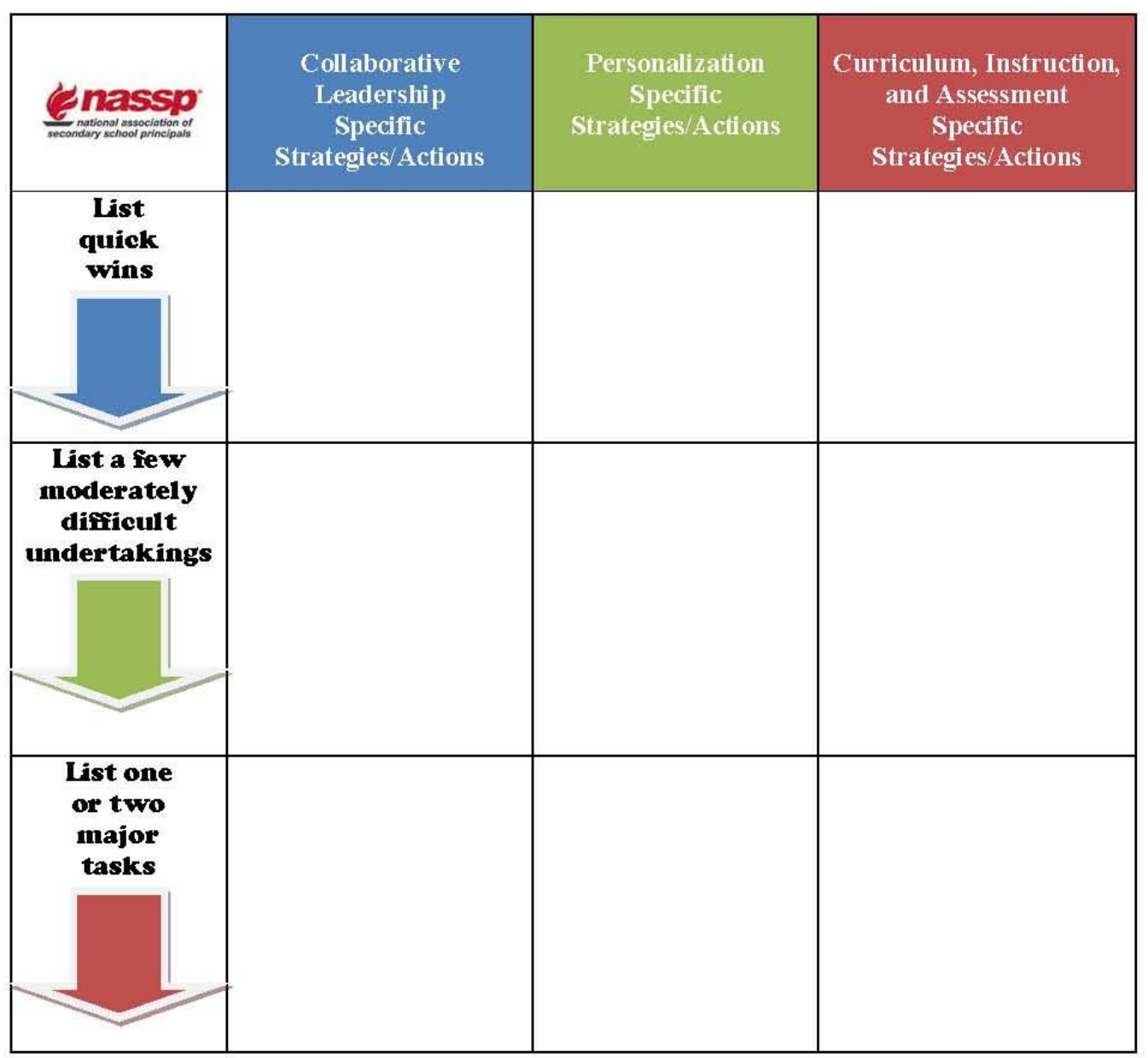

21 Bridging the Future to Postsecondary Readines's 


\section{Action Template $\sum_{\text {Advocacy \& Policy Center }}^{\ell}$}

Professional Development and Communication Planning

Consider your planned school improvement actions and strategies. Identify the teams and team members who will lead the implementation and the development of knowledge, skills, and attitudes needed for success. Discuss and list specific steps and actions that school staff members will take to develop the knowledge, skills, and attitudes of each group below

\begin{tabular}{|c|c|c|c|}
\hline 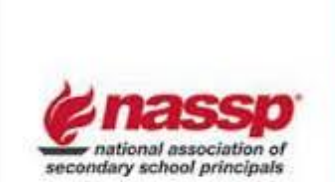 & $\begin{array}{l}\text { Actions to develop } \\
\text { the requisite } \\
\text { knowledge for } \\
\text { success }\end{array}$ & $\begin{array}{l}\text { Actions to practice } \\
\text { the requisite } \\
\text { skills for success }\end{array}$ & $\begin{array}{l}\text { Actions to develop } \\
\text { the requisite } \\
\text { attitudes for success }\end{array}$ \\
\hline $\begin{array}{l}\text { Leadership team/ } \\
\text { Steering committee }\end{array}$ & & & \\
\hline Faculty colleagues & & & \\
\hline District personnel & & & \\
\hline Parents & & & \\
\hline Students & & & \\
\hline Community leaders & & & \\
\hline $\begin{array}{c}\text { Others } \\
\text { (list them) }\end{array}$ & & & \\
\hline
\end{tabular}

22 Bridging the Future to Postsecondary Readiness 
SECTION 2:

POSTSECONDARY READINESS FRAMEWORK - STRUCTURAL ELEMENTS

\section{"The section nicely outlines} key structural areas for schools to implement to prepare students for postsecondary success."

-John (Special Education Coordinator)

\section{"We need to} strengthen our partnerships with

our local colleges." 


\section{Design Question 2}

What structures are currently in place to successfully prepare students for postsecondary success?

\section{Target 2}

(

\section{Postsecondary Readiness Framework: Structure}

- $70 \%$ of students will actually enroll in colleges or universities within two years of high school graduation

- More than a third need remedial courses, a third never make it to the sophomore year, and more than half do not complete the work necessary to earn a degree

Haycock, Barth, Mitchell, \& Wilkins, 1999

\footnotetext{
To prepare students for postsecondary success, educational leaders must look at the structural makeup of their schools to address successful transitions for every secondary school student to postsecondary options. This target focuses on putting the proper structure in place to prepare students for postsecondary success. For the purposes of this guidebook, structure is defined as the organizational makeup of a school. It must be noted that strategy and goals shape structure, but the process is often complex and subtle (Bolman \& Deal, 2008). The elements of this structure address: the mission/vision of schools, transitions and infrastructure, and the development of college knowledge. This target begins with an assessment of current knowledge, understanding and comfort level pertaining to the problem. Readers then have the opportunity to reflect on current beliefs and practices around the problem.
}

24 Bridging the Future to Postsecondary Readiness 


\section{Assessing Current Knowledge}

Use the following rating scale to assess your current knowledge, understanding and comfort level regarding structural elements presented in this target.

4= I understand this structural element, and it is fully implemented in my school.

$3=\mathrm{I}$ understand this structural element, but it isn't fully implemented in my school.

$2=I$ can explain this structural element, but I am not fully confident that it can be implemented in my school.

$1=\mathrm{I}$ do not understand this structural element, and it is not being implemented in my school.

1. Building the school's mission and vision on shared core values and beliefs of the staff Based on my rating, I may need to revisit the following:

2. Looking at sufficient data of all students to identify students showing proficiency or mastery of standards, along with students needing extra supports

Based on my rating, I may need to revisit the following:

3. Realizing the infrastructure of my school is built around strategies within the dimensions of academic preparedness and tenacity

Based on my rating, I may need to revisit the following:

4. Developing a sufficient partnership with a partnering postsecondary institution to prepare all students for postsecondary success

Based on my rating, I may need to revisit the following:

25 Bridging the Future to Postsecondary Readiness 


\section{Reflecting on Current Beliefs and Practices}

Before examining this target, take some time to look at your current beliefs and practices by answering the following questions:

1. Explain how the mission, vision and goals of the school were created? To what extent are these related to postsecondary preparedness?

2. How well do you know the organizational structure of your school/district? Describe it to the best of your current knowledge.

3. How clear are you about the process of how students transition in and out of your school/district; out of programs within your school? List what you know of these processes (Try to address the how, why, where, when and who).

4. What resources and partnerships are currently in place to support a postsecondary readiness culture?

5. Describe the data infrastructure that is currently in place for continuous school improvement.

26 Bridging the Future to Postsecondary Readiness 


\section{Recommendations}

This target addresses the following best practices for Design Question 2:

- Form a committee around the structural elements of the postsecondary readiness framework to review, analyze, and plan for a seamless approach to postsecondary preparedness.

- Create an organizational chart containing all of the programs/best practices in your school along with the person in charge of each program. These programs/best practices should be aimed to prepare all students for postsecondary success, and include an action plan for evaluation and review.

- Create a mission/vision statement along with school goals for your school based on collective shared values and beliefs of all staff members. These statements should include a systematic approach to prepare students for postsecondary success.

\section{Mission/Vision}

Shared visions emerge from personal visions. This is how they derive their energy

and how they foster commitment ... If people don't have their own vision, all they can do is

"sign up" for someone else's. The result is compliance, never commitment. (Senge, 1997)

To help prepare students for postsecondary success, one of the main structural elements is to embed the goals and expectations of college and career readiness for all students into the mission and vision of the school. The mission and vision should be shared and created around individual values and beliefs of all staff members. These individual values and beliefs should be integrated into the core values and beliefs for the school. Once the core values and beliefs are agreed upon, then the purpose for the school is created. The purpose of the school should include the goals and expectations of college and career readiness for all students. This purpose is important for creating a mission statement that everyone see, knows, and uses (Bernhardt, 2002). Creating a shared mission and vision is important for a healthy "college-going" culture and is necessary to prepare students for postsecondary success. Everything that is done in an organization should be aligned to its guiding principles. Guiding principles help to build a system of fundamental motivating assumptions, principles, values, and tenets that leads to a tangible vision (Figure 3 ).

\section{Bridging the Future to Postsecondary Readiness}




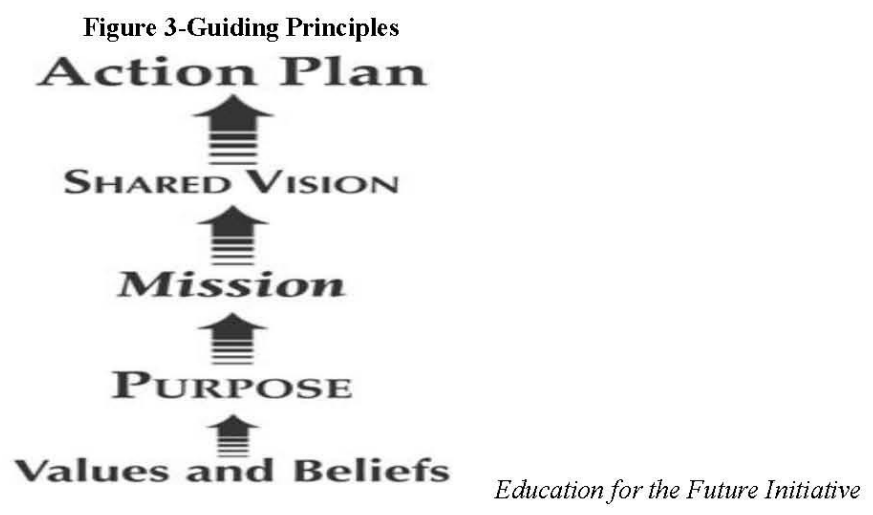

\section{Transitions and Creating the Infrastructure}

Research suggests that the major transition points in the educational continuum present students with particular social and academic challenges that can throw students off course (Bloom, 2011). ACT (2008) reports the transition from elementary to middle school is important and challenging especially with regard to behavior. This same study suggests that eighth grade is the most advantageous in a student's academic achievement and progress toward college and career readiness than any measure of high school achievement (ACT, Inc., 2008). Schools must address the social and academic elements of these key transitions and integrate them into the structure of the school so that students can navigate these transitions successfully throughout their educational experience.

When students get to secondary schools, the social and academic elements for success should be ingrained. However, there are many students who don't have these elements in place for success in secondary schools. Because of this there must be an infrastructure in place to address the transition from middle school to high school. At the same time, this infrastructure must exist for students who are proficient and show mastery of the social and academic elements of high school, and are ready to begin the transition to postsecondary options. Careful focus must be placed on the process of transitioning students to high school from earlier grades and/or schools, as well as transitioning students to college from high school programs aimed at preparing them for postsecondary success. Setting the infrastructure for postsecondary success should follow current research and best practices, and requires commitment and buy-in from all staff members.

28 Bridging the Future to Postsecondary Readiness 
From fall 2010 through summer 2011, the Annenberg Institute for School Reform received a three year grant from the Bill and Melinda Gates Foundation to develop the College Readiness Indicator System (CRIS). This initiative researched and collected indicators that measure the dimensions of college readiness. It helped districts develop supports connected to these indicators (McAlister, Mevs, Lee, Rodriguez, \& Kim, 2012).

Using CRIS as a guide to build an infrastructure, Table 2 below shows strategies and dimensions aimed at addressing postsecondary success.

Table 2-Setting the Infrastructure

\begin{tabular}{|l|l|}
\hline \multicolumn{1}{|c|}{ Dimension } & \multicolumn{1}{c|}{ Strategies } \\
\hline Academic Preparedness & $\begin{array}{l}\text { Use data to drive postsecondary readiness } \\
\text { policies }\end{array}$ \\
& $\begin{array}{l}\text { Align standards, curricula, and assessments } \\
\text { to college-ready expectations }\end{array}$ \\
& $\begin{array}{l}\text { Intervene early to keep students on a } \\
\text { college-ready track }\end{array}$ \\
\hline Academic Tenacity & $\begin{array}{l}\text { Expose students to tenacity-building } \\
\text { activities } \\
\text { Provide accelerated learning opportunities } \\
\text { that promote persistence and attainment } \\
\text { Restructure schools into personalized } \\
\text { learning communities }\end{array}$ \\
\hline
\end{tabular}

(McAlister et al., 2012)

Infrastructure: Academic Preparedness

\section{Diagnostics and Data}

"Schools that gather, analyze, and use information about their school communities make better decisions, not only about what to change but also about how to institutionalize systemic change." (Bernhardt, 2005, p. 2)

Bloom (2011) states that schools need to be able to identify students who are struggling and who lack the necessary skills as early as possible to provide targeted and research-based interventions.

29 Bridging the Future to Postsecondary Readiness 
I assume that when this mechanism is put into place in every secondary school, and the structure is aligned to the goals and expectations of college and career readiness for all students, then remediation will be less frequent and the transition to postsecondary options will be more successful.

In order to prepare students for a successful transition to postsecondary options, schools need to embrace diagnostics (assessments) and data. For this to happen, a data system needs to be created or adopted to understand multiple measures of school data. As Bernhardt (2005) states, using multiple methods of assessment allows students to show both social and academic growth. A school must gather multiple measures of data to not only improve, but to show if it is achieving its mission, vision, purpose and goals. Figure 4 on the next page illustrates the different types of information along with the levels of analysis that can be gained from the intersection of the data.

The next step would be to form a data committee. One person should be in charge of collecting the data (data collector), and one person in should be responsible for presenting it to the committee (educational leader). Both the data collector and educational leader must coordinate and collaborate to collect and present information pertinent to the mission, vision, purpose and goals of the school.

Here is an example of what this would look like. A data committee is formed prior to the beginning of the school year. When students enter secondary schools (at any grade), diagnostics are administered to see the skill level of each student. This data is collected by the data collector and recorded in a data system. This data is shared between the data collector and educational leader. The educational leader then analyzes the data and meets (regularly) with the data committee and uses the data for skill development toward postsecondary success?

30 Bridging the Future to Postsecondary Readiness 
Figure 4-Multiple Measures of Data

\section{Multiple Measures of Data}

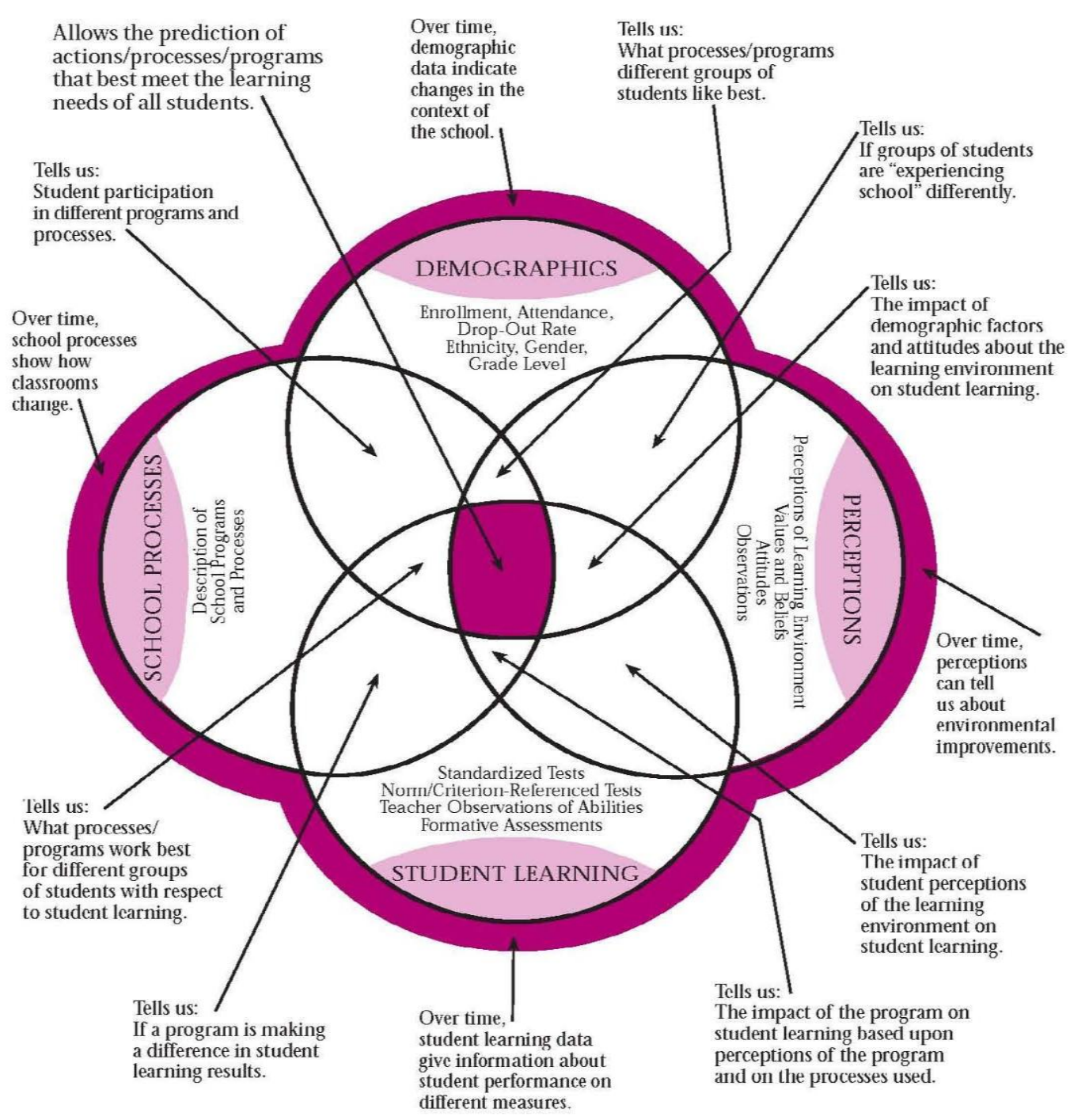

Copyright $\odot$ 1991-2009 Education for the Future Initiative, Chico, CA.

31 Bridging the Future to Postsecondary Readiness 
*For the Activity Circles, engage in a conversation with your team around the topic to help connect your knowledge to practice. This is will help build context and improve understanding of each topic or theme.

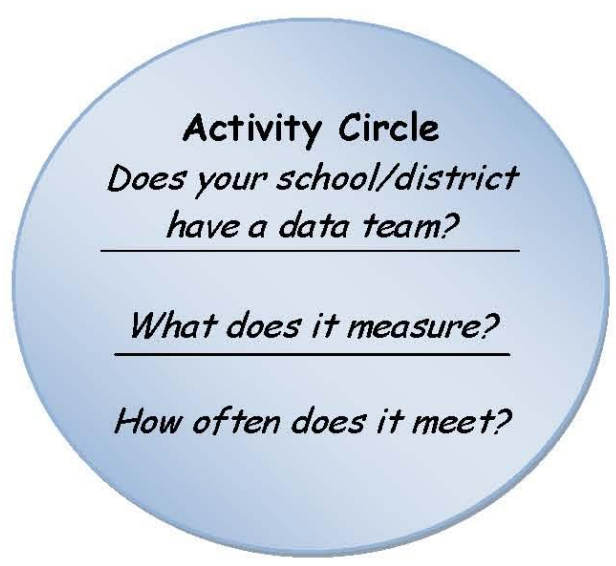

\section{Standards and Expectations}

Teachers need to look at their lessons and align them to standards aimed at helping students with postsecondary readiness. Schools and teachers, who are serious about preparing students for postsecondary success, must also coordinate and align their lessons with standards used at colleges and universities. Teachers must align the aforementioned standards in the areas of curriculum, instruction and assessment. For example: Produce clear and coherent writing in which the development, organization, and style are appropriate to task, purpose, and audience. Identifying this standard is step one, but after the identifying process, planning must begin for pre-assessments, assessments, and post-assessments to measure progress. Once these assessments are created, then standards must be integrated into the curriculum, and must directly influence instruction. Curriculum, instruction and assessment must always be linked when creating and planning lessons. A more in-depth look at standards will be addressed again in Section 3 of this guidebook.

\section{Bridging the Future to Postsecondary Readiness}


*Take some time and engage in a conversation with your team around the following question(s)

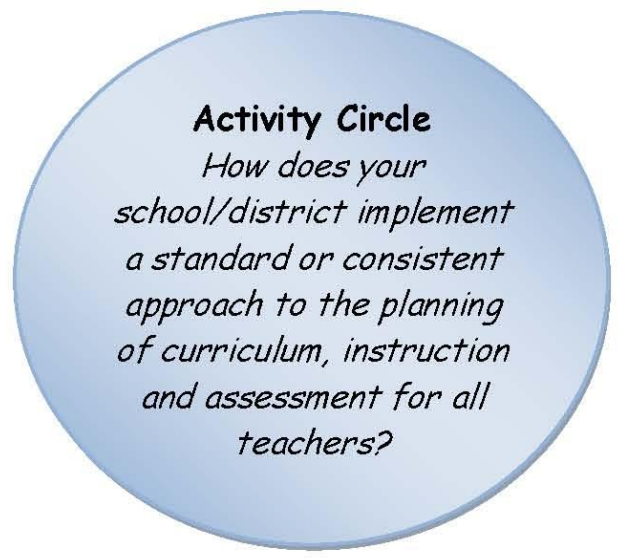

\section{Interventions and Support}

Once students' skills are identified, then programs must be implemented to help students build their skills and keep them on track for postsecondary success. These interventions and support must be identified and applied early so that gaps don't develop in learning. Coordination with learning and language specialists is key to providing struggling students the extra support they need to keep them on-track. Some examples of these interventions and support include but may not be limited to: learning centers, resource rooms, individual or group tutoring, mentoring etc...

*Take some time and engage in a conversation with your team around the following question(s)

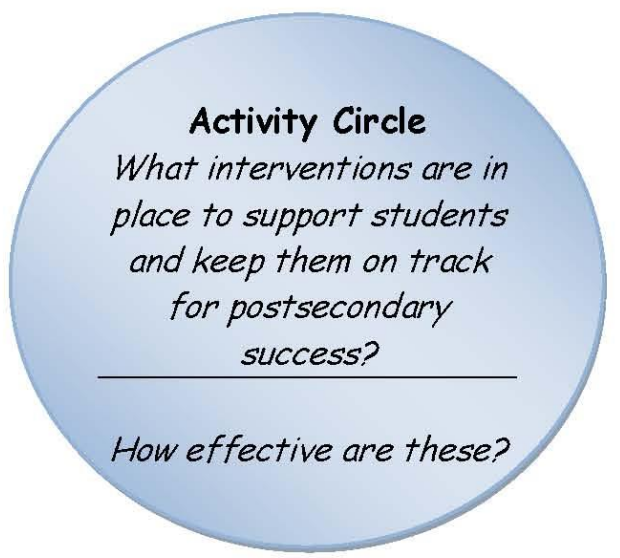

33 Bridging the Future to Postsecondary Readiness 


\section{Infrastructure: Academic Tenacity}

\section{Tenacity-Building Activities}

Academic tenacity is defined as the mindsets and skills that allow students to look beyond shortterm concerns to longer-term or higher-order goals, and to withstand challenges and setbacks to persevere toward these goals (Shechtman, DeBarger, Dornsif, Rosier, \& Yarnall, 2013). There are three types of approaches used in schools today: the "character education" model, "projectbased learning" model, and support for school-wide improvement.

Shechtman et al., explains the "character education" model as explicit articulation of learning goals for targeted competencies, clear and regular assessment and feedback of student progress, intensive teacher professional development, and discourse about these competencies throughout the school culture.

The "project-based learning" model is where students develop competencies through engagement in long-term, challenging, and/or real-world problems that require planning, monitoring, feedback, and iteration. Projects are often aligned with students' interests and passions.

The third type of approach is through support for school-wide improvement. This includes but is not limited to teacher professional development, networks of school communities, and strategies to improve school organizational structure.

*Take some time and engage in a conversation with your team around the following question(s)

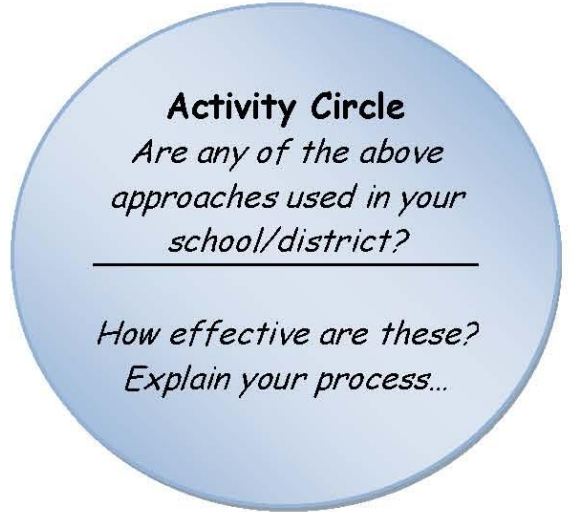

34 Bridging the Future to Postsecondary Readiness 


\section{Accelerated Learning Opportunities}

As students show proficiency or mastery in content areas, they must have the opportunity to advance both socially and academically in their learning. Academically, this can occur through advanced placement programs, or through International Baccalaureate Programs (IB). To maximize advanced learning opportunities, however, schools and programs must not only address the academic growth of students, but also, the social growth.

In most early and middle colleges, matriculation is the expectation for all students. An example of this would be where groups of students, who show social and academic proficiency or mastery of high school culture and content, are allowed to take prescribed entry level college courses together in a cohort. When they become proficient or show mastery of these entry level courses, they then matriculate toward a college degree or certificate of their choice. It must be noted that schools/programs should give all students the opportunity to advance both socially and academically in their learning toward postsecondary opportunities.

*Take some time and engage in a conversation with your team around the following question(s)

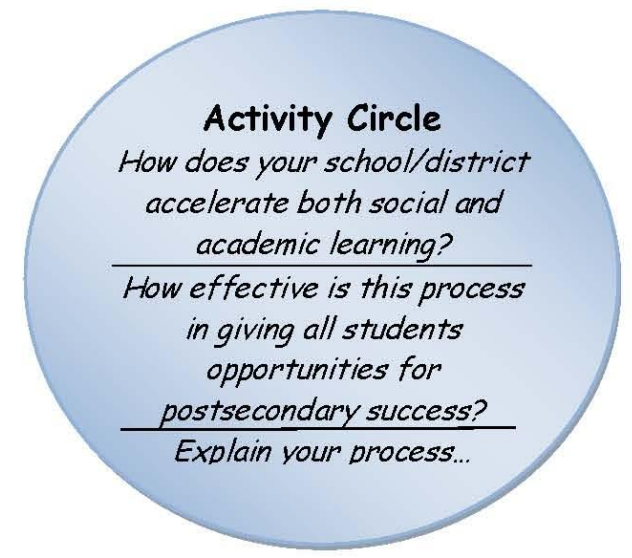

\section{Personalized Learning Communities}

This strategy requires schools to break down large learning environments into small, personalized learning communities. These communities have a small group of staff members who focus on student success around a framework of postsecondary preparedness. These staff

\footnotetext{
35 Bridging the Future to Postsecondary Readiness
} 
members use data to inform them of student progress in the areas of culture and environment, curriculum, instruction, and assessment. This data is also used to help staff members collaborate to improve their own practices in curriculum, instruction, assessment and helping set the culture and environment for their small communities. In schools, these small, personalized learning communities are often called: academies, houses, teams etc... They can be organized in different ways such as: by grade, by content area, career interests, themes etc... This sets up an educational environment and culture that is more personalized, and allows for better support for each individual student and staff member.

*Take some time and engage in a conversation with your team around the following question(s)

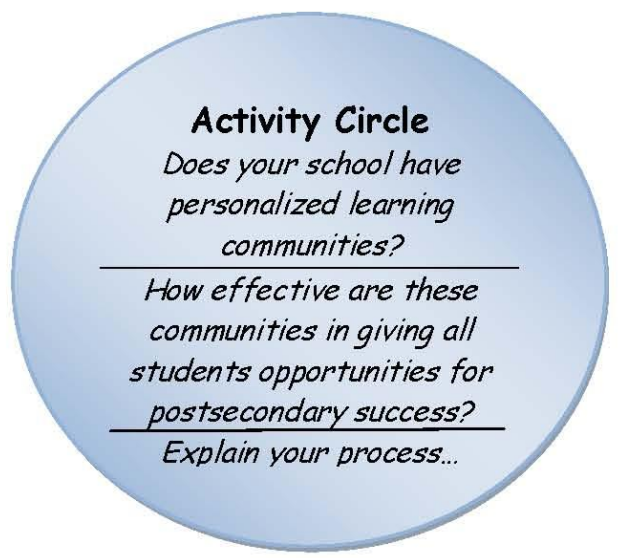

\section{College Knowledge: College-Going Culture}

\section{Creating the Culture}

David Conley (2007, p. 22) notes: "Many students fail to apply to college simply because the process seems so daunting, and they feel intimidates or overwhelmed by all of the requirements and activities associated with the application process." In order to create this "college-going" culture, schools must go through a process of "reculturing." Reculturing is defined as challenging current practices, patterns, and norms by examining them and implementing change when it is appropriate for the success of all students. Schools serious about creating significant changes that will positively impact student achievement and direction, especially in getting students ready for the postsecondary transition must go through this process (Chenoweth \& Everhart, 2002).

\section{Bridging the Future to Postsecondary Readiness}


A college-going culture should be visible and alive in each school. After creating the mission, vision and goals of the school around a shared set of core values and beliefs, then the table is set for high expectations and college-going culture. The next steps in creating a college-going culture in any school include but may not be limited to: setting high expectations for all students, measuring college skills, and credit/degree attainment, and setting a college awareness environment.

The goal for creating this culture is to raise the bar both academically and socially for all students. For example, in high school, students have the opportunity to take college courses on the high school campus to help students understand the rigor and structure of a college course. Supports are in place to help students who are placed in these classes to make their experience challenging, yet positive. All students must systematically focus on: short-term goals to help build college skills in each class, medium-term goals to plan out their path to college, and longterm goals to connect their skills with both a postsecondary education, and ultimately to a career.

Once a data system is in place, diagnostics or assessments must be able to measure the attainment of college-ready skills of all students. This not only helps to advance students who are proficient or master set standards, but to provide supports to students who need them. Data must also measure college credit and degree attainment. This data should be the focal point of school-wide improvement, awareness for current students and families, marketing for future students and families, and celebrations of student and school achievement.

Setting the environment for college or postsecondary awareness should be deliberate and systematic. Before entering the school, all students must take the partnering college or university placement exam in reading, writing and math. This is a powerful tool in setting the expectation of college. Once new students enter the school for the first time during the academic year, a visit to the partnering college or university is another great way of reinforcing the college-going culture. This helps to stress the importance of where their hard work and skills will take them during or after their public school journey.

37 Bridging the Future to Postsecondary Readiness 
Some easy, but effective ways of helping reinforce the college-going culture at a school is through visuals and displays. One idea that successful schools use is to post the mission, vision, and goals around the school which contain postsecondary preparedness messages. Another idea is to display the college or university pennant or banner of each staff member outside of or in each classroom. These gets students to see that we have gone through this process and are advocates in helping them get through their journey.

Creating a college-going culture will also be addressed later in Section 4. Specifically, the strategies of supporting students through the college planning process, along with engaging families in learning about and supporting the college-going process fall under the Social Elements of the Postsecondary Framework section.

*Take some time and engage in a conversation with your team around the following question(s)

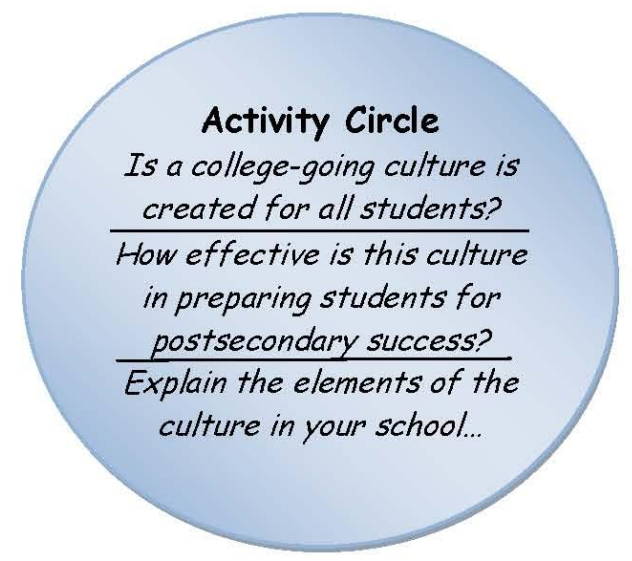

\section{College Knowledge: Developing Partnerships}

One of the most important elements in the structural section of the postsecondary readiness framework is to develop a partnership with the local college or university. Because the process of preparing students for postsecondary success is a complex one, secondary schools can't do it alone. This partnership or relationship with local postsecondary institutions is a must. It gives schools an opportunity to offer its students college-like experiences such as: senior seminars on college readiness, college placement tests, advanced placement classes, college campus visits,

38 Bridging the Future to Postsecondary Readiness 
and summer bridge programs to help prepare students for the transition (Conley \& McGaughy, 2012). The partnership also allows schools to offer dual enrollment programs to students. This gives high schools an opportunity to align courses offered with college course expectations, and to share data for continuous school improvement.

*Take some time and engage in a conversation with your team around the following question(s)

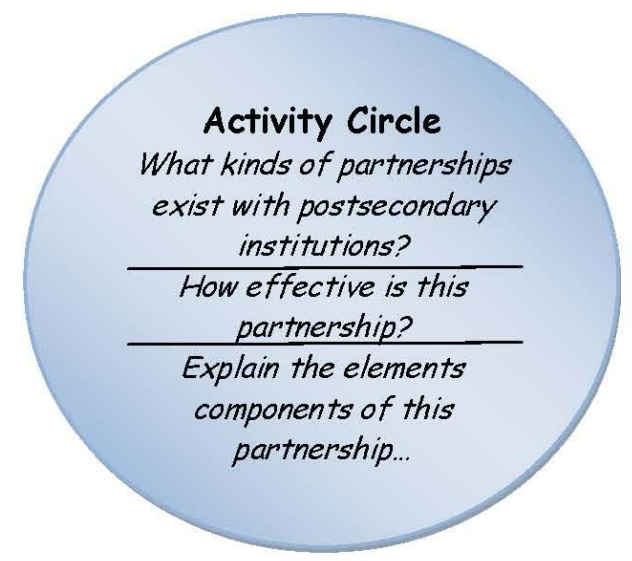

\section{Checklist for Structural Elements}

$\square$ Complete the rubric for postsecondary readiness on Structural Elements to assess current practices and programs.

$\square$ Form a committee to focus on the Structural Elements to review, analyze, and plan for a seamless approach to postsecondary readiness.

$\square$ Create an organizational chart outlining programs within the Structural Elements section. These programs should include an action plan for evaluation and review.

$\square$ Create a mission/vision statement along with school goals based on collective shared values and beliefs of all staff members.

39 Bridging the Future to Postsecondary Readiness 


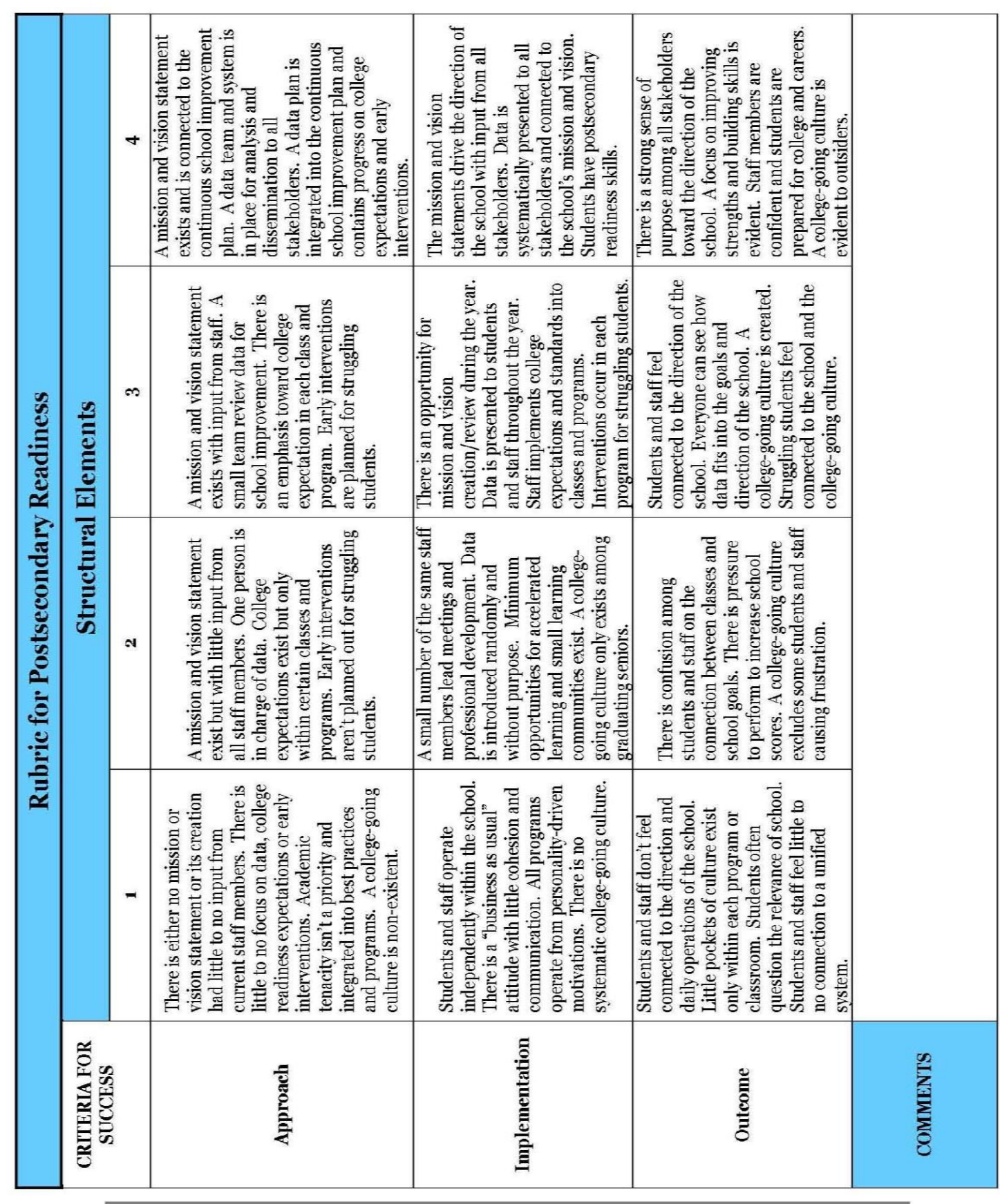

40 Bridging the Future to Postsecondary Readiness 


\section{Action Template $\sum_{\text {Advocacy \& Policy Center }}^{e}$}

Organize any new actions being considered for implementation at your school with this implementation template. Consider all general actions, those already begun as well as new ones, and then categorize them according to:

1. Ouick wins-actions that can be implemented this semester or this school year

2. Moderately difficult undertakings-actions that need summer planning, professional development, or both

3. Major tasks-actions that will need two years or more for full implementation and may include quick wins and moderately difficult undertakings.

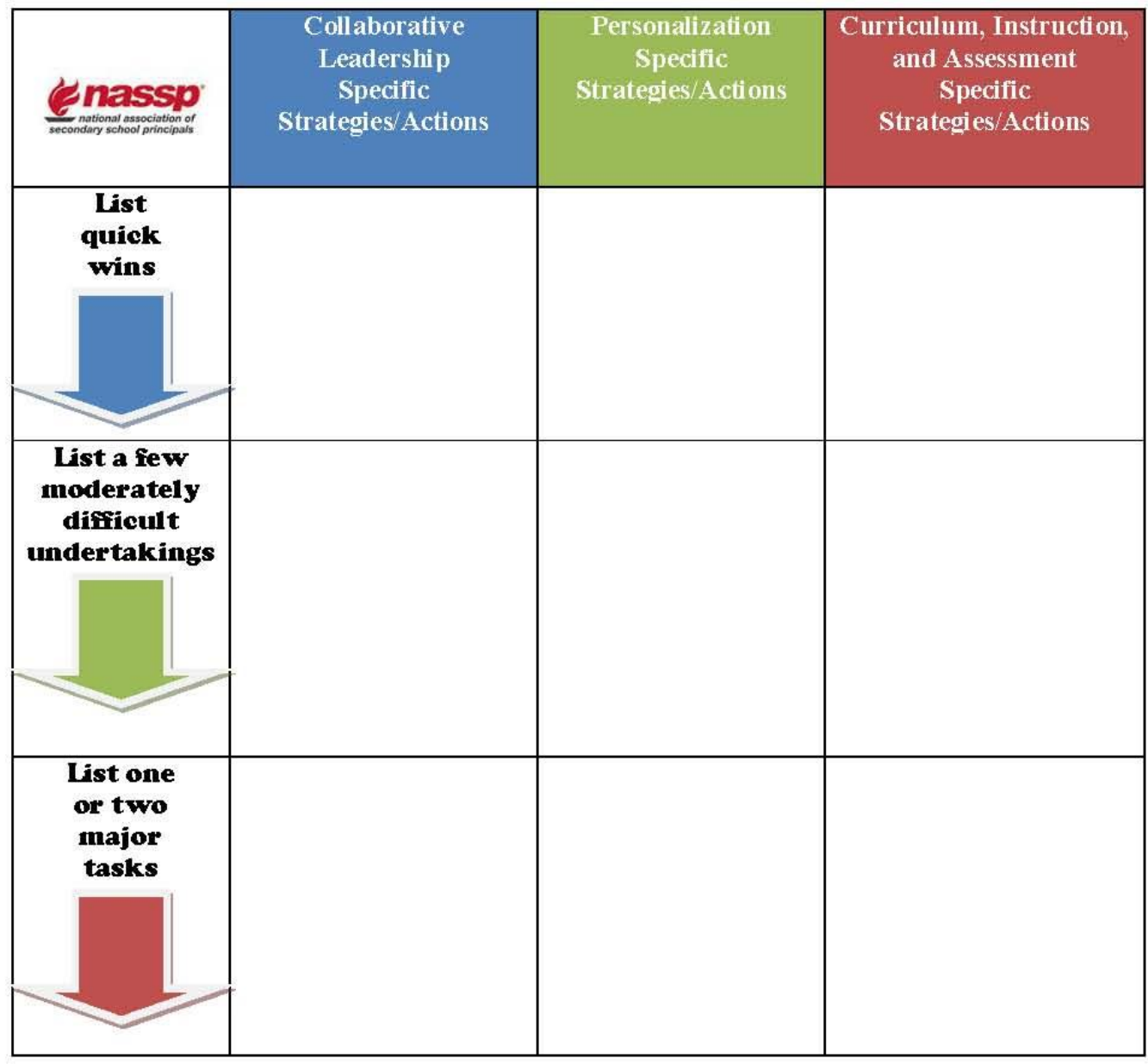

41 Bridging the Future to Postsecondary Readines's 


\section{Action Template $\int_{\text {Advocacy \& Policy Center }}^{e}$}

Professional Development and Communication Planning

Consider your planned school improvement actions and strategies. Identify the teams and team members who will lead the implementation and the development of knowledge, skills, and

attitudes needed for success. Discuss and list specific steps and actions that school staff members will take to devel op the knowledge, skills, and attitudes of each group below.

\begin{tabular}{|c|c|c|c|}
\hline 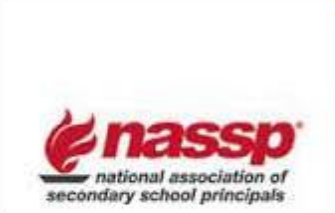 & $\begin{array}{l}\text { Actions to develop } \\
\text { the requisite } \\
\text { knowledge for } \\
\text { success }\end{array}$ & $\begin{array}{l}\text { Actions to practice } \\
\text { the requisite } \\
\text { skills for success }\end{array}$ & $\begin{array}{l}\text { Actions to develop } \\
\text { the requisite } \\
\text { attitudes for success }\end{array}$ \\
\hline $\begin{array}{l}\text { Leadership team/ } \\
\text { Steering committee }\end{array}$ & & & \\
\hline Faculty colleagues & & & \\
\hline District personnel & & & \\
\hline Parents & & & \\
\hline Students & & & \\
\hline Community leaders & & & \\
\hline $\begin{array}{l}\text { Others } \\
\text { (list them) }\end{array}$ & & & \\
\hline
\end{tabular}

42 Bridging the Future to Postsecondary Readiness 
"Bridging the Future to Postsecondary

Readiness is set up as a guidebook, and that allows teams to apply relevant concepts and best practices to their schools at their own pace."

-Linda (Program Director)

SECTION 3:

POSTSECONDARY READINESS FRAMEWORK - ACADEMIC ELEMENTS

43 Bridging the Future to Postsecondary Readiness 


\section{Design Question 3}

What academic guidelines exist to help educators prepare students for a postsecondary education?

\section{Target 3}

\section{-}

\section{Postsecondary Readiness Framework: Academic Elements}

- The next decade will bring an economy where more than $60 \%$ of jobs will require a college degree

- In Orezon only about a third of students will enter college the fall after graduatinf, and only about $10 \%$ will earn a degree within 4 years

Carnevale, N. Smith, \& Strohl, 2010

- Forty percent of students enrolled into postsecondary institutions will take at least one remedial course costing $\$ 1$ billion or more per year

$$
\text { Conley, } 2010
$$

One of the most important aspects of the postsecondary readiness framework focuses on academics. In order for students to be prepared for postsecondary options, secondary schools must identify rigorous academic standards and align them with skills/standards students need at postsecondary institutions. If this is not done, then it is unlikely that the curriculum will be rigorous enough to prepare students for a successful transition. Once this is in place, then instruction and assessment must also be aligned in order to impact student learning and outcomes (Bloom, 2011). This target will focus on academic elements and practices that secondary schools can use to successfully transition students to postsecondary options. The academic elements center on rigorous secondary school standards, college and career readiness standards, quality instructional practices, and assessments to identify academic skill level.

44 Bridging the Future to Postsecondary Readiness 


\section{Assessing Current Knowledge}

Use the following rating scale to assess your current knowledge, understanding and comfort level regarding background information and research presented in this target.

4= I understand this academic element, and it is fully implemented at my school.

$3=\mathrm{I}$ understand this academic element, but it isn't fully implemented in my school.

$2=I$ can explain this academic element, but I am not fully confident that it can be implemented in my school.

$1=\mathrm{I}$ do not understand this academic element, and it is not being implemented in my school.

1. All courses offered at my school are aligned to Common Core State Standards or College Readiness Standards

Based on my rating, I may need to revisit the following:

2. All teachers design instruction with the same components consistently throughout the year

Based on my rating, I may need to revisit the following:

3. All teachers implement the same components of a lesson consistently throughout the school year

Based on my rating, I may need to revisit the following:

4. Summative assessments are used to identify student skill prior to enrolling and are used consistently throughout the school year to gauge student development

Based on my rating, I may need to revisit the following:

45 Bridging the Future to Postsecondary Readiness 


\section{Reflecting on Current Beliefs and Practices}

Before examining this target, take some time to look at your current beliefs and practices by answering the following questions:

1. What standards are currently being used to determine student learning in your school/district/state? How are teachers using these in their classrooms? Are these standards being integrated into each classroom consistently? Describe this process to the best of your current knowledge (Try to address the how, why, where, when and who).

2. To what extent do your school and teachers implement college readiness standards? Are these college readiness standards aligned to current secondary school standards? What does this process look like (Try to address the how, why, where, when and who)?

3. Explain how instruction is tailored around academic standards at your school? Is instruction consistent across content areas? Explain instructional practices at your school?

4. What types of assessments do your school and teachers use to identify the academic skill level of each student? To what extent is the use of assessments in your school applied consistently across content areas? How well are assessments used to inform instructional practices?

46 Bridging the Future to Postsecondary Readiness 


\section{Recommendations}

This target addresses the following best practices for Design Question 3:

- Form a committee around the academic elements of the postsecondary readiness framework to review, analyze, and plan for a seamless approach to postsecondary preparedness.

- Identify elements of effective instructional practice at your school. These elements should address consistent application of rigorous standards, assessment methods, and data collection and analysis to inform and improve instruction.

\section{Common Core State Standards (CCSS)}

In most states around the nation, teachers are aligning their lessons to Common Core State Standards (CCSS) which aim to provide a consistent, clear understanding of what students are expected to learn. They are focused on literacy in each content area, math standards, and postsecondary readiness. They are designed to help teachers and parents support students in their educational journey. The CCSS are intended to be rigorous, relevant and reflect the knowledge and skills that students need for success in college and careers.

CCSS provide goals and benchmarks to ensure students are achieving certain skills and knowledge by the end of each year; help colleges and professional development programs better prepare teachers; provide the opportunity for teachers to be involved in the development of assessments linked to these top-quality standards; allow states to develop and provide better assessments that more accurately measure whether or not students have learned what was taught; and guide educators toward curricula and teaching strategies that will give students a deep understanding of the subject and the skills they need to apply their knowledge.

As teachers look to align their curriculum to CCSS, it is important to note that these standards can be complex and demonstrate many different skills students need to show in order to be prepared for college, careers, and citizenship. In order to navigate these standards and apply them to coursework and instruction, former administrator, educator turned author, Michael Schmoker identifies how educators must prioritize standards using the following criteria:

\section{Endurance}

a. Will the standard provide students with knowledge and skills beyond a single test date?

47 Bridging the Future to Postsecondary Readiness 


\section{Leverage}

a. Will the standard provide knowledge and skills that are of value in multiple disciplines?

\section{Readiness for the Next Level}

a. Will the standard provide students with essential knowledge and skills that are necessary for their success in the next grade level?

*For the Activity Circles, engage in a conversation with your team around the topic to help connect your knowledge to practice. This is will help build context and improve understanding of each topic or theme.

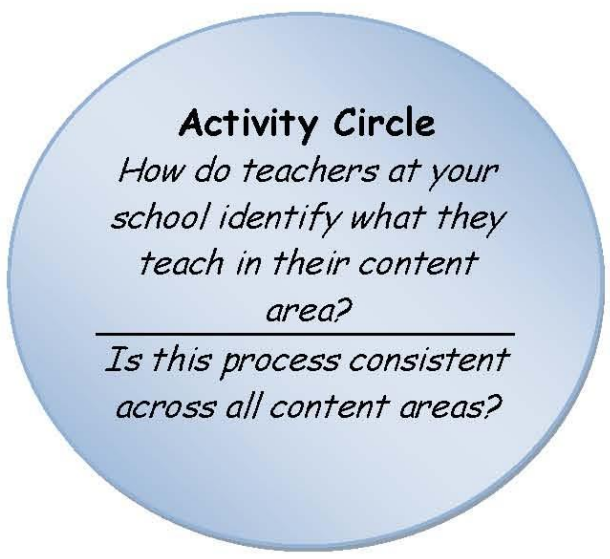

College and Career Readiness Standards (CCR)

After years of studying faculty members in many subject areas at two- and four year postsecondary institutions across the country, the Educational Policy Improvement Center, or EPIC, has developed four keys to college and career readiness. While all of these keys are interrelated, two of the four keys (key cognitive strategies and key content knowledge) fall primarily within the academic elements of the postsecondary readiness framework. The key transition knowledge and skills, and the key learning skills and techniques fit and are explained below in the social elements section of the postsecondary readiness framework and will be discussed at length in Section 4. As students move toward mastery in each of these keys, the

48 Bridging the Future to Postsecondary Readiness 
more likely students will be postsecondary ready (D. T. Conley, 2012). Table 3 below shows these keys.

Table 3-Keys to College and Career Readiness

\begin{tabular}{|c|c|c|c|}
\hline \multicolumn{4}{|c|}{ College and Career Readiness } \\
\hline $\begin{array}{l}\text { Key Content Knowledge } \\
\text { Structure of Knowledge } \\
\text { 1. Facts } \\
\text { 2. Key terms } \\
\text { 3. Linking ideas } \\
\text { 4. Organizing concepts } \\
\text { Student Relation to Content } \\
\text { 1. Attribution } \\
\text { 2. Effort vs. Aptitude } \\
\text { 3. Academic Value } \\
\text { 4. } \\
\text { Challenge }\end{array}$ & $\begin{array}{ll} & \frac{\text { Key Cognitive }}{\text { Strategies }} \\
\text { 1. } & \text { Problem } \\
\text { Formulation } \\
\text { 2. } & \text { Research } \\
\text { 3. Interpretation } \\
\text { 4. } & \text { Communication } \\
\text { 5. } & \text { Precision and } \\
& \text { Accuracy }\end{array}$ & $\begin{array}{l}\frac{\text { Key Learning Skills }}{\text { and Techniques }} \\
\text { 1. Ownership of } \\
\text { Learning } \\
\text { 2. Learning } \\
\text { Techniques }\end{array}$ & \begin{tabular}{ll}
\multicolumn{2}{l}{ Key Transition Knowledge } \\
1. & Postsecond Skills \\
2. & Postsecondary Awareness \\
3. & Matriculation \\
4. & Career Awareness \\
5. Role and Identity \\
6. Self-advocacy
\end{tabular} \\
\hline
\end{tabular}

(D. Conley, 2012a)

Each one of these keys contains skills which college-level students need to have in order to complete college-level work. These keys should serve as a guide or compass for educators to use in order to prepare students for postsecondary success.

\section{Key Content Knowledge}

Teaming the Key Content Knowledge with the CCSS will help to develop college and career readiness standards for all students. All students need to be provided with a credible curriculum that links knowledge and critical thinking. Critical thinking is highly dependent on content knowledge. To ensure critical thinking by students through content knowledge, educators must: link texts to relevant issues, develop good questions with each text, and write research papers and make presentations to display critical thinking skills in each content area.

Key Content Knowledge involves the conceptual ideas from core subjects. Teachers focus on key terms, factual information, linking ideas, and organizing concepts within their curriculum. For students to retain this information, however, connections must be created with their prior knowledge to build a structure of new knowledge (D. Conley, 2012b). Teachers associate emotions, positive or negative, with the knowledge being presented. They must use the knowledge in a variety of authentic situations, and receive timely feedback to effectively use this knowledge for growth. In this key, students should link core subject knowledge with career

\section{Bridging the Future to Postsecondary Readiness}


aspirations to give relevance to each subject matter. Table 4 below shows an example of an authentic situation for learning.

Table 4-Authentic Assessment to Build New Knowledge

Geometry City
You have just taken your dream job of becoming an engineer and your boss has just given you your
first project. You have been asked to build a three-dimensional model of a city. You can be as
creative as you want and you may choose the materials you will use to build your city (clay, paper,
etc.).
In this city you should include at least 10 building and at least 5 streets. Within these 1o buildings,
there must be clear representations of two similar figures, two congruent figures, and two
geometric transformations. You are required to use a straight edge when constructing your city
streets.
You must be able to describe the streets using the terms parallel, perpendicular, and intersecting.
You are also required to determine the surface area of each building that you create. Along with
this three-dimensional model of your city, you must also create a two-dimensional representation of
your city.
This representation should be drawn to scale. You must also include a 1-2 page write-up the will
include your process of creating both representations of your city, a description of what buildings
represent what geometric concepts by using the ratio factor and the surface areas to prove that the
buildings are similar, the city name, description of the streets (include street names), the
advantages and disadvantages of two- and three- dimensional representation.
You will complete this project individually and you will have 2 weeks to complete the assignment.
On the day that the projects are due, every student will present their project to the class explaining
what they have created. Once everyone has presented, we will discuss the advantages and
disadvantages of each type of representation.

It also must be noted that the two academic skills that are identified for college success are reading and writing. These important skills are also focal points with the CCSS. Students must be able to identify and understand different formats and different types of written materials. For example, students must be able to distinguish between an editorial and an informative article. High importance should be placed on decoding, identification of key elements and concepts, and interpretation. Students should be able to build up persistence as they reread passages to connect to deeper meanings in each text. Writing is the format which students are evaluated and which student thinking is expressed and assessed most frequently. To prepare students best for postsecondary success, a focus on expository, descriptive, and persuasive writing must be stresses in all classes. The skills of prewriting, editing, and rewriting must be repeated to build college writing habits. Students should present arguments clearly, stressing each point, and be able to use resources and manuals to construct papers free of errors.

50 Bridging the Future to Postsecondary Readiness 
*Take some time and engage in a conversation with your team around the following question(s)

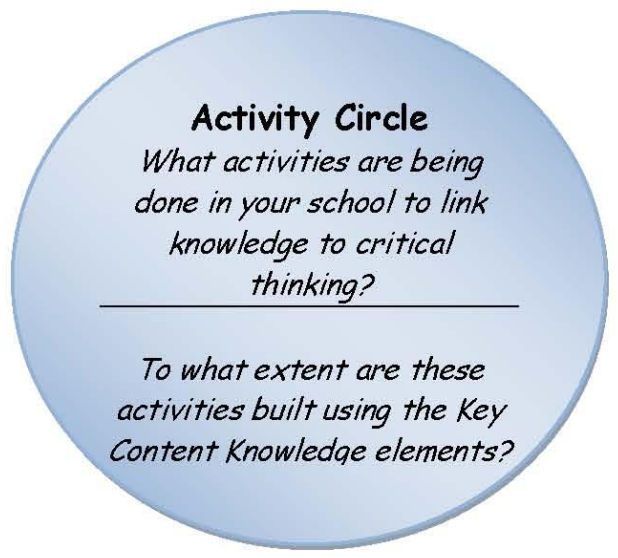

\section{Key Cognitive Strategies}

Key Cognitive Strategies involve skills around thinking. These skills involve formulating hypotheses, developing problem-solving strategies, identifying sources and collecting information. They also involve analyzing the findings or conflicting viewpoints, organizing and constructing work products in a variety of formats. Once this process is done, then students must confirm the precision and accuracy of all the work they produced (D. T. Conley, 2012).

EPIC has done excellent work in identifying these strategies, and schools and teachers should develop skills within these strategies to prepare students for postsecondary success. The strategies and components teachers should focus on must be connected to Key Content Knowledge for optimal success.

Because the process of preparing students for postsecondary success is a complex one, assessing postsecondary readiness becomes more and more challenging. Conley (2012a) recognizes the complexity of postsecondary readiness and addresses it through the following thoughts and recommendations:

- No single test can gauge every standard needed for postsecondary readiness

- Test scores are appropriate at a system level, but become more error-prone and inappropriate at each sublevel- state, district, school, classroom, individuals

- Scores from a single measure of college and career readiness may be misused

51 Bridging the Future to Postsecondary Readiness 
- Systems of assessment need to be set up (rather than one test or score) to address- grades, student self-reports, complex curriculum-embedded performance tasks, behavioral assessments, non-content-based measures

To address some of the points listed above, EPIC, recommends that courses use embedded assessments tied to key cognitive strategies, key content knowledge and key learning skills and techniques. Examples of this include but aren't limited to extended essays, demonstrations and culminating projects, research papers, and inquiry-based experiments and investigations (D. T.

Conley, 2007)

*Take some time and engage in a conversation with your team around the following question(s)

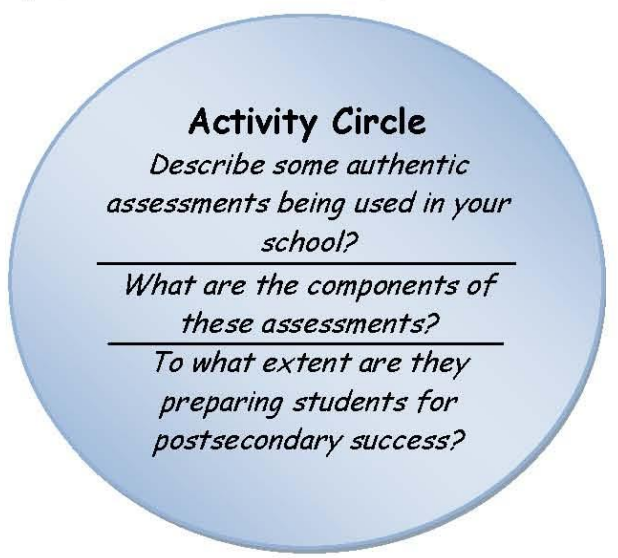

\section{Quality Instructional Practices}

Improved classroom instruction is the prime factor to improve student achievement gains.

(Odden \& Wallace, 2003)

Preparing students for postsecondary readiness requires quality instructional practices. This is a complex process which requires teachers to think deliberately about how to build and develop skills so that students are prepared for a successful transition to postsecondary options. The following aspects categorize quality instructional practices and help teachers and students work together to maximize both teacher and student potential.

- Designing instruction- understanding and design

52 Bridging the Future to Postsecondary Readiness 
- Classroom practice- engagement, objectives, learning targets, teaching/modeling/demonstrating, guided practice (authentic literacy), and checks for understanding (formative assessment)

One of the most important factors to student success is designing instruction. This happens well before students enter the classroom. Extensive work by Grant Wiggins and Jay McTighe reveals best practices around understanding and design.

\section{Designing Instruction}

Understanding

In order to prepare students for postsecondary success, teachers must deepen and develop student understanding of important ideas and processes in each content area. Each big idea has an essential question that needs to be revealed. This is done when students apply their knowledge (old and new) through authentic assessments. To ensure student understanding in each class, Wiggins and McTighe list six indicators: (1) to explain, (2) interpret, (3) apply, (4) shift perspective, (5) empathize, and (6) self-assess. These overlap with the Key Cognitive Strategies and help to reinforce necessary skills in student development. Students need to go through this process to transfer their learning.

\section{Design}

Before instruction can happen, curriculum needs to be designed carefully to ensure student learning and skill development. Based on surveys of K-16 faculty throughout the world, the characteristics of the best learning designs contain the following components:

- Expectations

$$
\begin{aligned}
& \text { provide clear learning goals and performance expectations } \\
& \text { cast learning goals in terms of genuine/meaningful performance } \\
& \text { frame the work around genuine questions \& meaningful challenges } \\
& \text { show models/exemplars of expected performance }
\end{aligned}
$$

- Instruction

- the teacher serves as a facilitator/coach to support the learner

- targeted instruction and relevant resources are provided to "equip" students for expected performance

- the textbook serves as one resource among many (i.e., text is resource, not

\section{Bridging the Future to Postsecondary Readiness}


syllabus)

- the teacher "uncovers" important ideas/processes by exploring essential questions and genuine applications of knowledge and skills

- Learning Activities

- individual differences (e.g., learning styles, skill levels, interests) are accommodated through a variety of activities/methods

o there is variety in work, methods and students have some choice (e.g., opportunities for both group and individual work)

- learning is active/experiential to help students "construct meaning"

- cycles of model-try-feedback-refine anchor the learning

- Assessment

- there is no mystery as to performance goals or standards

- diagnostic assessments check for prior knowledge, skill level, and misconceptions

- students demonstrate their understanding through "real world" applications (i.e., genuine use of knowledge and skills, tangible product, target audience)

- assessment methods are matched to achievement targets

o on-going, timely, and descriptive feedback is provided.

learners have opportunities for trial and error, reflection and revision

- self-assessment is expected

- Sequence \& Coherence

- start with a "hook", immerse the learner in a genuine problem/issue/challenge move back and forth from whole to part, with increasing complexity scaffold learning in "do-able" increments

teach as needed; don't over-teach all of the "basics" first

revisit ideas - have learners rethink and revise earlier ideas/work

are flexible (e.g., respond to student needs; revise plan to achieve goals)

(McTighe, 2010)

A very effective way to set up successful instruction and accomplish the aforementioned components is through a process known as "backward design," or Understanding by Design

(UbD). This process is used to plan single units, year-long courses, or an entire curriculum.

$\mathrm{UbD}$ must be linked to both CCSS and CRS in order to maximize postsecondary readiness. It is best to work collaboratively with other educators to share key findings and ideas.

Understanding by Design ( $U b D$ )

$\mathrm{UbD}$ is a three stage process which helps teachers in thinking about effective instruction through curriculum planning. It is a fluid process and not rigid or prescriptive. The goal of UbD is

54 Bridging the Future to Postsecondary Readiness 
student understanding. UbD is linked to CCSS and CRS and transforms these into relevant elements and assessments. This happens when students transfer their learning through authentic performance or assessment. Teachers coach understanding and support these experiences by adjusting any necessary components for optimal learning. For effectiveness, the planning must be done "backward" to align the desired results, evidence, and learning plan. UbD must be monitored and adjusted around curriculum designed and student performance. Below are the stages of backward design.

\section{Stage 1-Desired Results}

- What long-term transfer goals are sought?

- What meanings should students make in order to arrive at important understandings?

- What essential questions will students explore?

- What knowledge \& skill will students acquire?

- What established goals/Standards are targeted?

\section{Stage 2- Evidence}

- What performances and products will reveal evidence of meaning-making and transfer?

- By what criteria will performance be assessed, in light of Stage 1 desired results?

- What additional evidence will be collected for all Stage 1 Desired Results?

Stage 3-Learning Plan

- What activities, experiences, and lessons will lead to achievement of the desired results and success at the assessments?

- How will the learning plan help students of Acquisition, Meaning Making, and Transfer?

- How will the unit be sequenced and differentiated to optimize achievement for all learners?

- Are all three stages properly aligned?

As schools and educators strive to prepare students for postsecondary readiness, designing instruction must be an integral part of this process, and it should be linked to the previous academic elements listed above in this section (rigorous secondary school standards, and college readiness standards), along with the following aspects of quality instructional practices, as well as assessments to identify academic skill level.

55 Bridging the Future to Postsecondary Readiness 
*Take some time and engage in a conversation with your team around the following question(s)

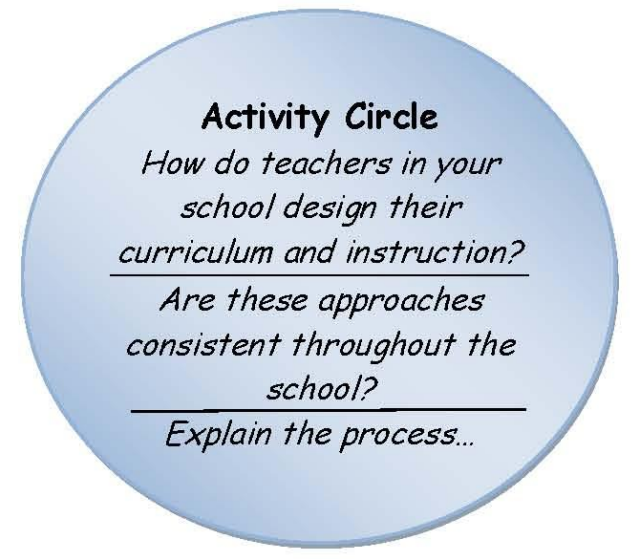

\section{Classroom Practice}

Engagement

In preparing students for postsecondary readiness, a consistent classroom approach must be used by all teachers. The goal of this classroom approach is to engage students to build and develop skills. Through my experience as a classroom teacher and as an administrator, engagement is observable and captures a learner's thinking through writing, reading, speaking and doing in the safety of an accepting school culture. Students should be engaged to make meaning out of intentional opportunities created by the classroom teacher. Some examples of what engagement looks like in a college readiness classroom are listed below:

\section{Students are:}

- Reading, critically, annotating text with pen/pencil in hand

- Writing to learn, creating, planning, problem-solving, discussing, debating, asking questions

- Constructing new knowledge and skills by building on their current knowledge and skills

- Presenting, performing, inquiring, exploring, explaining, evaluating, experimenting

- Interacting with other students, doing, moving, gesturing

- Involved in the assessment cycle

56 Bridging the Future to Postsecondary Readiness 
Clear Learning Objectives

Because classroom practice can be a complex and difficult thing to master, it is important to go back to the basics of teaching as it will help to simplify the practice and ensure effective lessons and quality teaching. Mike Schmoker refers to this as "How We Teach" (Schmoker, 2006).

One of the most fundamental aspects of classroom preparation is to create learning objectives. However, these learning objectives must be clear and organized. As Schmoker (2006) points out, a clear learning objective allows teachers to link their lessons to a specific skill while providing background knowledge to create student interest in the topic. It must be pointed out that learning objectives are clear, carefully worded, and guide teachers through lessons. Each learning objective is a small step in what the learner is supposed to know or be able to do.

Objectives should: (1) define specific outcomes with regard to skill development and content mastery, (2) help develop and design instruction materials, (3) aid in assessing instructional goals, and (4) give students a framework from which to organize their learning. Some examples of clear learning objectives are listed below:

- Solve first-degree polynomial problems.

- Write an effective introductory paragraph for an argument.

- Make inferences/draw conclusions about a character (literary or historical).

- Compare and contrast meiosis and mitosis.

(Schmoker, 2006)

Learning Targets

A learning target is a learning outcome that answers the question, "What is the specific goal of today's instruction?" In other words, a target states what each student will be able to understand or be able to do at the end of a lesson or a series of lessons. These need to be shared with students daily. Targets are not only posted but are also explicitly stated on student work and students can accurately discuss targets when prompted.

A learning target is not an instructional objective. An instructional objective connects a series of lessons. A target guides the lesson for today and connects this learning to tomorrow and future lessons. A target is the formative assessment for each class. Some examples of clear learning targets are listed on the next page.

57 Bridging the Future to Postsecondary Readiness 
Learning Targets (continued...)

- Students will be able to construct a bar graph.

- Students will be able to read aloud with fluency and expression.

- Students will be able to distinguish between historical fact and opinion.

- Students will be able to identify metaphors and similes.

Table 5 shows the difference between a learning target and an instructional objective.

Table 5-Differentiating Targets and Objectives

\begin{tabular}{|c|c|}
\hline Learning Target & Instructional Objectives \\
\hline $\begin{array}{l}\text { - Guides learning } \\
\text { - Written from the student point of view } \\
\text { - Provides a common focus for teaching } \\
\text { - Directly connects to the formative } \\
\text { assessment for today, which impacts } \\
\text { instruction for tomorrow }\end{array}$ & $\begin{array}{l}\text { - Guides instruction } \\
\text { - Unifies outcome over a series of related } \\
\text { lessons } \\
\text { - Written from the teacher's point of view }\end{array}$ \\
\hline
\end{tabular}

\section{Teaching/Modeling/Demonstrating}

Dissemination of information is another important aspect of classroom practice. This dissemination should be differentiated to accommodate all learning styles. Teachers should use what Schmoker refers to as an "anticipatory set," which is a hook or a question that will create interest into the information that will be disseminated (Schmoker, 2006). This helps lead to active student engagement.

Schmoker points to two effective ways to disseminate information in the classroom. They are through the following learning templates:

\section{Two Learning Templates}

- Interactive lecture and direct teaching: Information throughout the lecture is broken down into "chunks" - the teacher talks for no more than five minutes before giving students an opportunity to process the information by talking, writing, or sharing. The teacher must ensure that every student is responding multiple times, to questions through the lecture.

- Literacy-based lessons: To have students read, talk, and write while focusing on any applicable text.

58 Bridging the Future to Postsecondary Readiness 
Schmoker emphasizes the importance of the teacher's role throughout both of these learning templates. Teachers should circulate when students write, underline, take notes, or quick write. Classroom discussion should connect directly to learning goals and targets. While students write or discuss, they should always reference a text.

(Schmoker, 2006)

\section{Guided Practice}

In my experience as an educator, Guided Practice is best defined as purposeful reading, writing, and discussing/analyzing with high quality texts in all subject areas. Guided Practice is a necessary classroom tool which allows students to practice or apply what has been taught or modeled. The teacher must observe and guide student work and blend perfectly with the aforementioned practice of teaching modeling and demonstrating, as well as with the following practice of checking for understanding. Schmoker (2006) points out that teachers should allow opportunities for students to work in pairs and occasionally in groups. Guided Practice lets students process what they have learned, and allows teachers the opportunity to assess both class as well as student progress. A form of Guided Practice is that of Authentic Literacy in which the following is done throughout all subject areas:

\section{Authentic Literacy}

(1) Task-The purpose for the reading

(2) Text- The pages from the textbook that support the task

(3) Talk- Discussion about what was read

(Schmoker, 2006)

\section{Checks for Understanding/Formative Assessment}

The last piece of Classroom Practice that best prepares students for postsecondary readiness is to repeatedly check to see if students are progressing toward the learning targets. Once again, this concept isn't new but needs to be completed with fidelity. Schmoker (2006) refers to this step as Checks for Understanding/Formative Assessment. This can best be categorized as "the practice" portion of the unit. Students should be afforded many opportunities to practice in order to become proficient or master the learning targets. Once these targets are have been developed by students, then students should be prepared for "the game" portion of the unit, or the Summative

\section{Bridging the Future to Postsecondary Readiness}


Assessment. This step also allows teachers to use information gathered to inform instruction and instructional pace. Below are some common forms for checking for understanding:

\section{Checking for Understanding}

- Circulate, observe, and listen as students work in pairs

- Call on a sampling of students or pairs randomly between each step (not calling on students who raise their hands)

- Have students signal their understanding: thumbs up or down; red, green, yellow Popsicle sticks

- Have students hold up dry-erase boards with answers/solutions

- Exit slips/Quick writes that demonstrate student learning

(Schmoker, 2006)

*Take some time and engage in a conversation with your team around the following question(s)

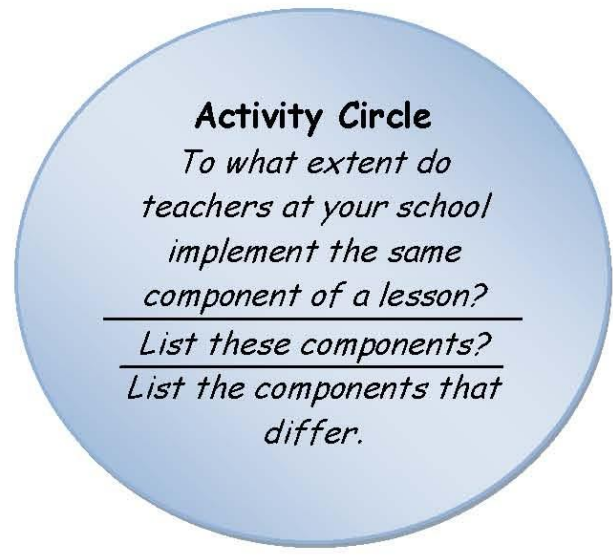

\section{Assessments}

The Assessments component of the Academic Elements section focuses on standardized summative assessments which measure individual college readiness skills. This section doesn't focus on designing and using specific classroom formative assessments. For the purposes of this guidebook, it is assumed that implementing the aforementioned quality instructional practices will build and develop college readiness skills through classroom formative assessments. Resources on designing and using formative assessments in the classroom are found later in section six.

60 Bridging the Future to Postsecondary Readiness 
As students enter school (at any level), they should be assessed as to their readiness for each particular level. Schools need to look at sources of information to identify student skills, and track progress along the way for promotion or additional support. Secondary schools across the nation aimed at preparing students for postsecondary success use standardized assessments such as EXPLORE, PLAN and ACT as part of the educational planning. The three instruments are administered at three separate points in a student's secondary educational experience. These assessments are part of ACT's Educational Planning and Assessment System (EPAS). EPAS reflects the essential skills and understandings being taught in classrooms nationwide (ACT, Inc, 2009). A description of these assessments can be found below and in Table 6 :

- EXPLORE: prepares eighth- and ninth-graders for their high school coursework and their post-high school choices. It includes four multiple-choice tests covering English, mathematics, reading, and science.

- PLAN: serves as the midpoint check of academic progress in high school. It is designed to improve students' preparation for education, training, and work after high school while they still have time to adjust their high school courses.

- $A C T$ : is America's most widely accepted college entrance exam. It assesses high school students' general educational development and their ability to complete college-level work. The multiple-choice tests cover four skill areas: English, mathematics, reading, and science. The Writing Test, which is optional, measures skills in planning and writing a short essay.

Table 6-What is the EXPLORE, PLAN and ACT?

\begin{tabular}{|c|c|c|c|}
\hline \multicolumn{4}{|c|}{ Overview of EXPLORE, PLAN, and the ACT } \\
\hline Testing Program & Target Grades & Components & Content Areas \\
\hline EXPLORE & $\begin{array}{l}\text { Transition to High School } \\
\text { Grades } 8 \text { or } 9\end{array}$ & $\begin{array}{ll} & \text { Student Planning } \\
\text { - } & \text { Assessment } \\
\text { - } & \text { Instructional Support } \\
\text { - Evaluation }\end{array}$ & $\begin{array}{ll}\text { - } & \text { English } \\
\text { - } & \text { Math } \\
\text { - } & \text { Reading } \\
\text { Science }\end{array}$ \\
\hline PLAN & $\begin{array}{l}\text { Midpoint High School Review } \\
\text { Grade } 10\end{array}$ & $\begin{array}{ll}\text { - } & \text { Student Planning } \\
\text { - } & \text { Assessment } \\
\text { - } & \text { Instructional Support } \\
\text { - } & \text { Evaluation }\end{array}$ & $\begin{array}{ll} & \text { English } \\
\text { - } & \text { Math } \\
\text { - } & \text { Reading } \\
\text { Science }\end{array}$ \\
\hline $\mathrm{ACT}$ & $\begin{array}{l}\text { Final Measure of High School } \\
\text { Outcomes } \\
\text { Transition to College } \\
\text { Grades } 11 \text { and/or } 12 \\
\end{array}$ & $\begin{array}{ll}\text { - } & \text { Student Planning } \\
\text { - } & \text { Assessment } \\
\text { - } & \text { Instructional Support } \\
\text { - } & \text { Evaluation }\end{array}$ & $\begin{array}{ll}\text { - } & \text { English } \\
\text { - } & \text { Math } \\
\text { - } & \text { Reading } \\
\text { - } & \text { Wrience } \\
\end{array}$ \\
\hline
\end{tabular}

61 Bridging the Future to Postsecondary Readiness 
By beginning to evaluate students' strengths and weaknesses early in Grades 8 and 9 and continuing to assess progress through Grade 12 , educators gain the information necessary to monitor and guide students as they prepare for their high school and postsecondary goals. EPAS provides schools, parents, and students with:

- a student planning component that looks at career and educational exploration and planning, and prepares students for life after secondary schooling

- an assessment component which measures knowledge in areas of English, Mathematics, Reading, and Science (and Writing in the ACT)

- an instructional support component that offers instructional support to teachers in each content area related to core subjects and college readiness standards

- an evaluation component which provides information that allows schools to research and monitor student performance over time and to assess the strengths and potential weaknesses of school programs

These assessments serve many purposes. Teachers and counselors use these assessments to identify academic strengths and areas needing improvement. They also help teachers to develop challenging curriculum for all students, and link assessment results with corresponding skills (Wimberly \& Noeth, 2005). Lastly, these assessments help to build student awareness of classes needed for diploma or degree completion. Most students (70\%) taking the aforementioned assessments indicated that information from these reports helped them identify necessary high school classes (Wimberly \& Noeth, 2005).

*Take some time and engage in a conversation with your team around the following question(s)

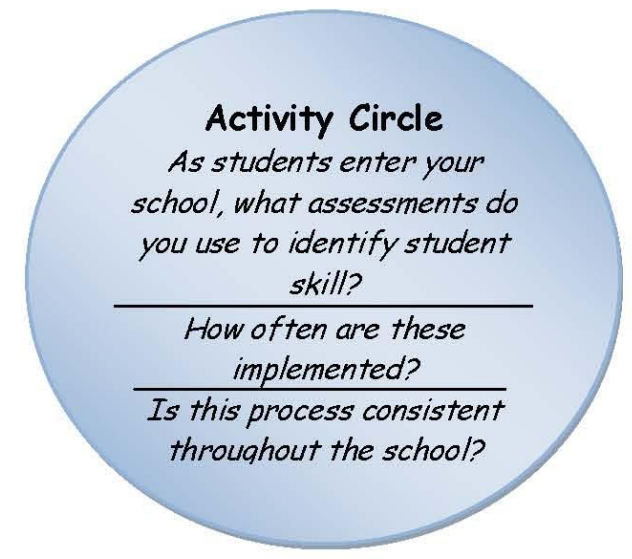

62 Bridging the Future to Postsecondary Readiness 


\section{Checklist for Academic Elements}

Complete the rubric for postsecondary readiness on Academic Elements to assess current practices and programs.

$\square$ Form a committee to focus on the Academic Elements to review, analyze, and plan for a seamless approach to postsecondary readiness.

Identify elements of effective instructional practice at your school. These elements should address consistent application of rigorous standards, assessment methods, and data collection and analysis to inform and improve instruction.

Schedule professional development around gaps in quality instructional practices and assessment.

Create a bank of tools/resources that capture aspects of quality instructional practices and assessment methods.

Focus on 1-2 of these per term for all teachers to integrate into their practice and classroom.

Allow professional development time to reflect and discuss the use of these practices along with the challenges and obstacles and next steps.
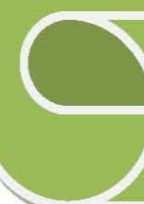

63 Bridging the Future to Postsecondary Readiness 


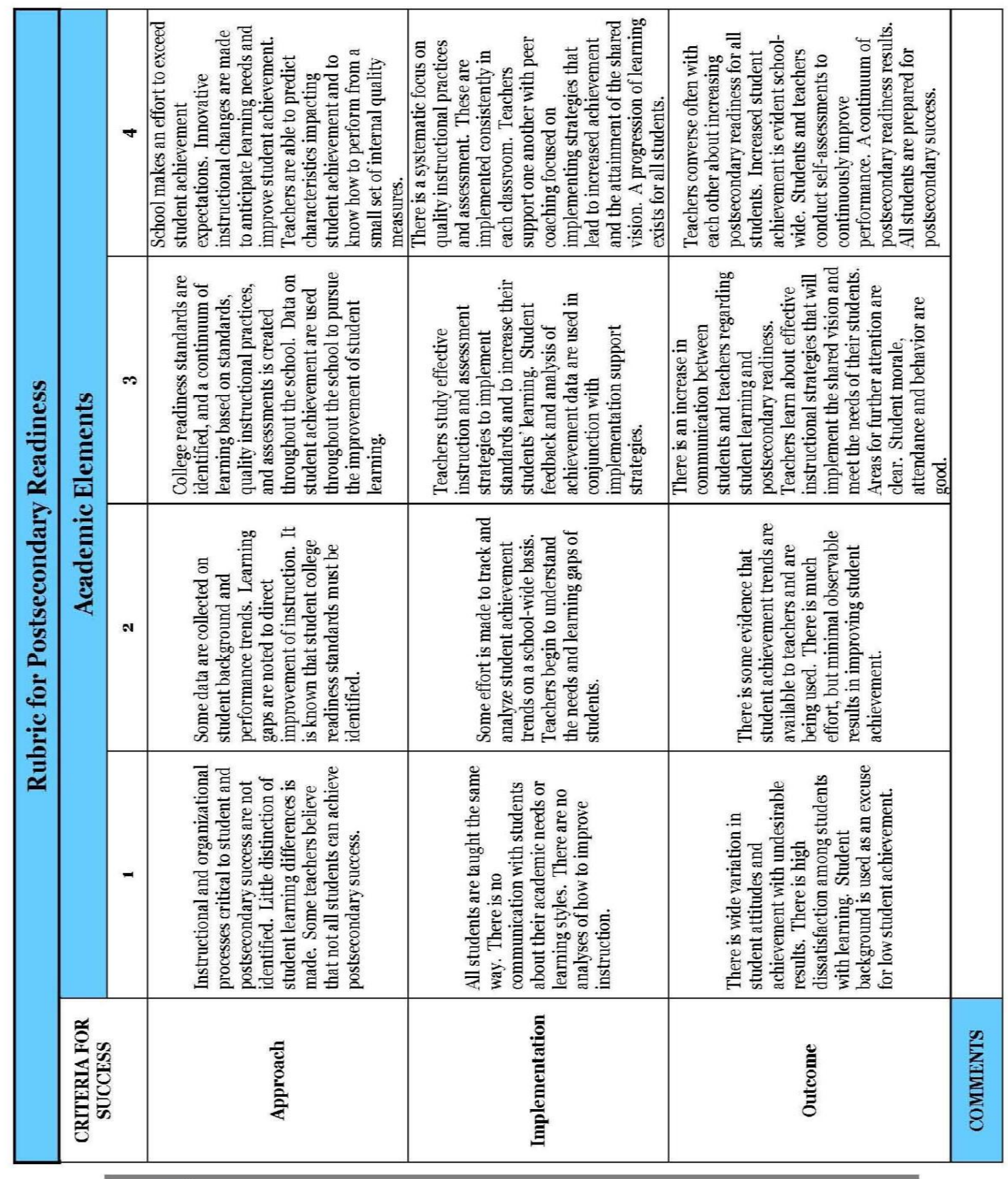

64 Bridging the Future to Postsecondary Readiness 


\section{Action Template ${ }_{\text {Advocacy \& Policy Center }}^{e}$}

Organize any new actions being considered for implementation at your school with this implementation template. Consider all general actions, those already begun as well as new ones, and then categorize them according to:

1. Quick wins-actions that can be implemented this semester or this school year

2. Moderatelv difficult undertakings-actions that need summer planning, professional development, or both

3. Major tasks-actions that will need two years or more for full implementation and may include quick wins and moderately difficult undertakings.

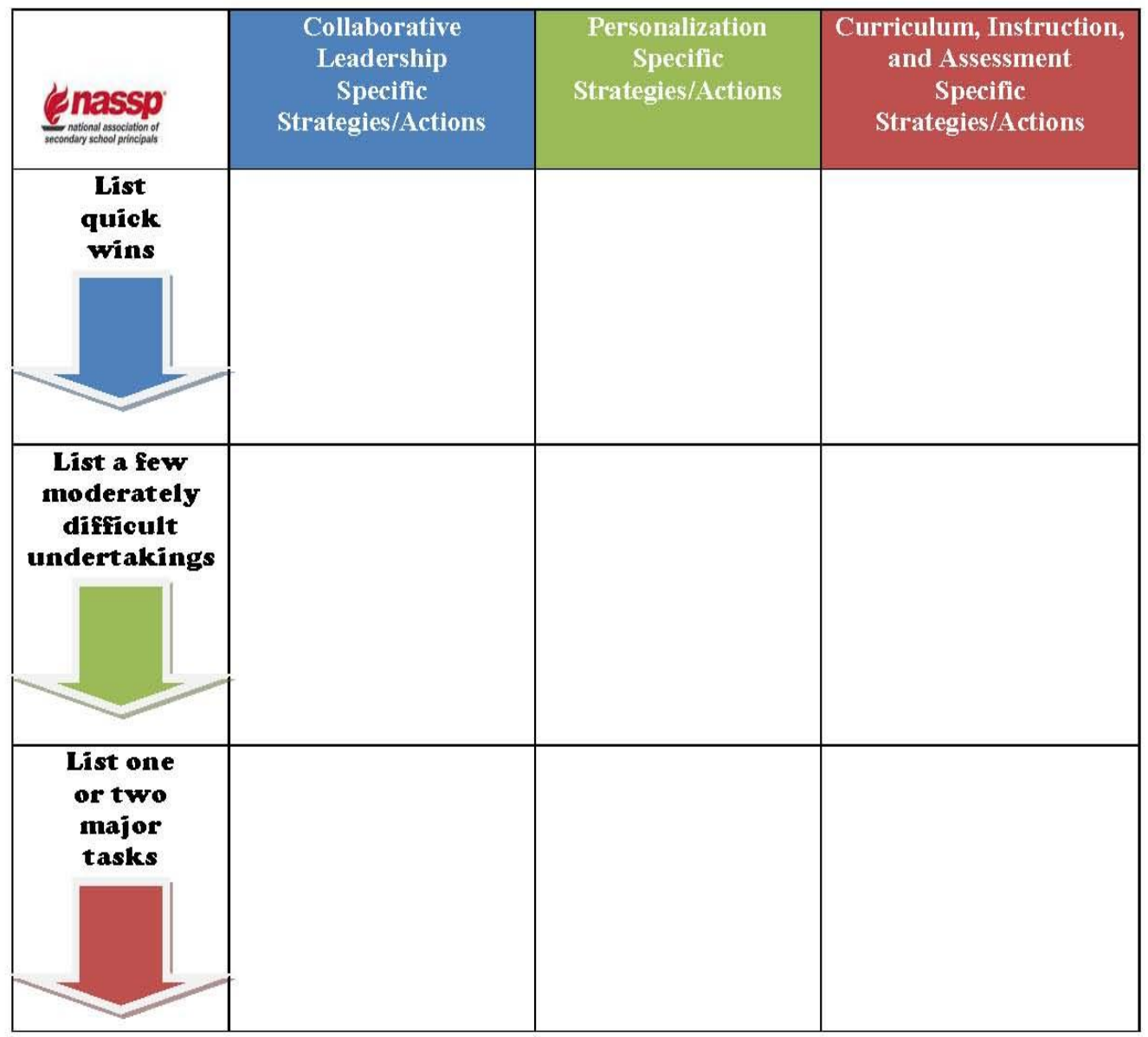

65 Bridging the Future to Postsecondary Readiness 


\section{Action Template $\int_{\text {Advocacy \& Policy Center }}^{e}$}

Professional Development and Communication Planning

Consider your planned school improvement actions and strategi es. Identify the teams and team members who will lead the implementation and the development of knowledge, skills, and attitudes needed for success. Discuss and list specific steps and actions that school staff members will take to devel op the knowledge, skills, and attitudes of each group below.

\begin{tabular}{|c|c|c|c|}
\hline 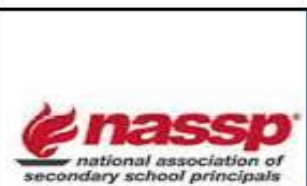 & $\begin{array}{l}\text { Actions to develop } \\
\text { the requisite } \\
\text { kn owled ge for } \\
\text { success }\end{array}$ & $\begin{array}{l}\text { Actions to practice } \\
\text { the requisite } \\
\text { skills for success }\end{array}$ & $\begin{array}{l}\text { Actions to develop } \\
\text { the requisite } \\
\text { attitud es for success }\end{array}$ \\
\hline $\begin{array}{l}\text { Leadership team/ } \\
\text { Steering } \\
\text { committee }\end{array}$ & & & \\
\hline $\begin{array}{l}\text { Faculty } \\
\text { colleagues }\end{array}$ & & & \\
\hline $\begin{array}{c}\text { Distriet } \\
\text { personnel }\end{array}$ & & & \\
\hline Parents & & & \\
\hline Students & & & \\
\hline $\begin{array}{l}\text { Community } \\
\text { leaders }\end{array}$ & & & \\
\hline $\begin{array}{c}\text { Others } \\
\text { (list them) }\end{array}$ & & & \\
\hline
\end{tabular}

66 Bridging the Future to Postsecondary Reodiness 


\section{POSTSECONDARY READINESS FRAMEWORK - SOCIAL} ELEMENTS

"One of the most valuable messages in this chapter touches on how this process needs to begin early on (middle school). Currently, our educational model focuses heavily on seniors and it is erratic and unrefined."

\section{-Mark (High School Science Teacher)}
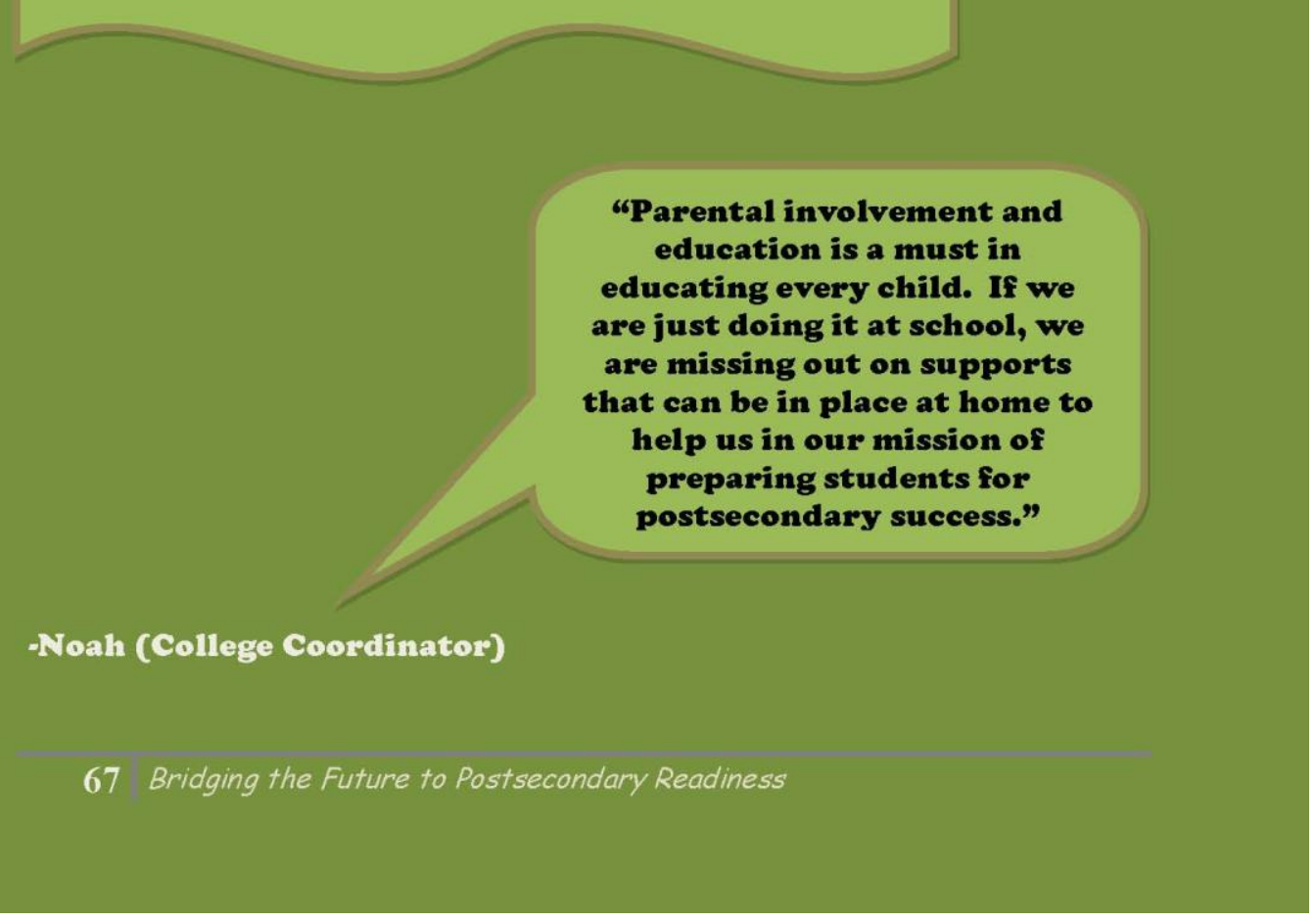


\section{Design Question 4}

What social elements exist in your school to prepare students for postsecondary success?

\section{Target 4}

-

\section{Postsecondary Readiness Framework: Social Elements}

- Only half of African-American, Latino, and Native-American youth earn a hish school diploma

- In Oreson only about a third of students will enter college the fall after 8 raduating, and only about $10 \%$ will earn a desree within 4 years

- Eishteen percent of African Americans and 10 percent of Latinos complete a four year college desree by the time they are 29, compared to 34 percent of whites

Wolk $\delta$ Jobs for the Future, 2005

This next target addresses social elements that need to be put in place to prepare students for postsecondary success. After putting structural pieces in place to set a foundation for postsecondary readiness, along with focusing on the academic elements that teachers/staff use to better prepare students for postsecondary success; social elements are the last pieces of the postsecondary readiness framework to create an integrated system that allows a school to provide a comprehensive approach to postsecondary preparation. The social elements consist of staff and family involvement, identifying and building academic behaviors of students, and improving students' and their families' transition knowledge and skills (academic awareness, college admission process, college and career culture, and tuition(financial aid) toward postsecondary success.

68 Bridging the Future to Postsecondary Readiness 


\section{Assessing Current Knowledge}

Use the following rating scale to assess your current knowledge, understanding and comfort level regarding background information and research presented in this target.

4= I understand this social element, and it is fully implemented at my school.

$3=\mathrm{I}$ understand this social element, but it isn't fully implemented in my school.

$2=$ I can explain this social element, but I am not fully confident that it can be implemented in my school.

$1=\mathrm{I}$ do not understand this social element, and it is not being implemented in my school.

1. Family involvement is systematic and creates a postsecondary readiness culture at my school

Based on my rating, I may need to revisit the following:

2. Staff involvement is systematic and creates a postsecondary readiness culture at my school

Based on my rating, I may need to revisit the following:

3. All staff is involved in identifying and building academic behaviors of students throughout the school year

Based on my rating, I may need to revisit the following:

4. Improving students' and their families' transition knowledge and skills toward postsecondary success is systematic and creates a postsecondary readiness culture at my school Based on my rating, I may need to revisit the following:

69 Bridging the Future to Postsecondary Readiness 


\section{Reflecting on Current Beliefs and Practices}

Before examining the research, take some time to look at your current beliefs and practices by answering the following questions:

1. What staff members are involved in systems/programs/classes of preparing students for postsecondary success? Describe what you know of this process (Try to address the how, why, where, when and who).

2. What systems/programs are in place to involve family members in the process of preparing students for postsecondary success? Describe the process currently in place at your school.

3. What systems are in place to identify and build academic behaviors in your school? Describe what you know of these behaviors, and if there is a process to identify and build skills in this area? (Try to address the how, why, where, when and who).

4. When focusing on key transition knowledge and skills (see above) what resources/systems/programs are available to support students and their families? Describe the process that is currently in place at your school. Are these skills being built in a systematic manner?

70 Bridging the Future to Postsecondary Readiness 


\section{Recommendations}

This target addresses the following best practices for Design Question 4:

- Form a committee around the social elements of the postsecondary readiness framework to review, analyze, and plan for a seamless approach to postsecondary preparedness. Make sure to include parents, students, and staff to maximize input and participation from all stakeholders.

- Create an organizational chart with all of the resources/programs/best practices involving the social elements at your school along with the person in charge of each program. These resources/programs/best practices should be aimed to prepare all students for postsecondary success, and include an action plan for evaluation and review.

\section{Staff Involvement}

The involvement of school personnel is a critical element to help students with postsecondary planning. Counselors, teachers, principals often influence students' educational goals and postsecondary planning. The National Association of Secondary School Principals (NASSP) recommends that every secondary school have an individual adult coach to help students through their educational journey and transitions. These adult mentors monitor student's academic progress and social development and guide them through the educational planning process.

As both economic and human resources are becoming increasingly limited in schools and school districts, it is necessary to use these resources in a different and unique manner. School counselors also play a significant role to develop educational goals, identify educational opportunities, and inform students and their parents about postsecondary options. Sometimes, however, counselors don't get involved in postsecondary planning until twelfth grade which may be too late to help students. Unfortunately, due to the high counselor-student ratio in our high schools, counselor roles and time are limited, so their duties often are unrelated to college and career advising. Another difficulty is that counselors often lack the training and resources necessary to provide college and career advising. Because of this, teachers often help students with educational planning activities. Teachers develop strong relationships with students and advise them to take specific, challenging courses and to set educational goals to succeed both in and out of the classroom. In order to provide the proper support and guidance to students, we must redefine how we use personnel in schools. Getting students ready for postsecondary options shouldn't rest on the counselors alone.

71 Bridging the Future to Postsecondary Readiness 


\section{Creating a Culture of Interdependence}

Because of the demands on school staff, the most effective way to prepare students for postsecondary success is to involve all personnel. How do you accomplish this with greater class/case loads, and increasing roles and responsibilities for all staff members? The answer lies in readjusting your view on education. Educators don't have to work harder to accomplish postsecondary readiness, they need to work smarter. All stakeholders in education and their jobs/duties should be connected and not separated. This process needs to be deliberate.

Educators need to embrace the concept of interdependence (a group of people/things depending on each other) and not independence. This creates connection from educator to another to best serve students' needs. This begs the question: How can schools create a culture of interdependence?

\section{Vision Compass}

One method that helps educators get through obstacles in education is to simplify processes as much as possible. For example, all schools are responsible for educating students. This task can be daunting. How does one approach such a mammoth endeavor? One way is to simplify the process. As a principal of a middle college, I break the educational process in my school into four components; (1) environment and culture, (2) curriculum, (3) instruction, and (4) assessment. These components set up a vision compass.

In Section Two, or the Structural Elements of the Postsecondary Readiness Framework of this guidebook, I touched on embedding the goals and expectations of college and career readiness for all students into the mission and vision of the school. I also mentioned that the mission and vision should be inclusive of all staff members input, and contain their shared values and beliefs. This is very important to do within the vision compass to empower staff and create ownership. Categories or indicators within the vision compass should be compiled into a vision statement to help guide the school throughout the school year.

Once a shared vision is created within the vision compass, guidelines for the school year have been set. When people from outside the building walk into the school and each classroom, they should see the indicators of the vision compass come to life. This process begins to create a

72 Bridging the Future to Postsecondary Readiness 
culture of interdependence with the staff as they are all striving to accomplish what they value and believe within the vision compass.

After the vision compass and vision statement have been created, the work toward interdependence is just beginning. The next important step is to create committees or vision panels containing all staff members in the school. All staff members are required to pick one or more of the vision components they would like to focus on for the year. For example, counselors may choose the environment and culture component, while a teacher may choose the instruction component. By doing this, the vision of the school should come to life and not just be a statement posted on a wall.

Once the vision panels are created, the process tow ard interdependence is underway. Vision panels should meet bi-monthly or as needed to prioritize indicators within the vision compass. After members prioritize the indicators, they then will create goals, an action plan, a timeline, and an assessment tool to measure the effectiveness of their work. Their work and progress will be presented to the staff for input throughout the year at staff meetings. At the end of the year, members of each vision panel will meet to reflect on their work and progress throughout the year. Each vision panel will present their findings and reflections to the staff. The staff will collectively look at all of the components of the vision compass and modify them as necessary. If any modification occurs, then the vision statement will be rewritten with all staff input. It is important to note that this culture of interdependency is ongoing and should change to always fit the needs of the school.

73 Bridging the Future to Postsecondary Readiness 
*For the Activity Circles, engage in a conversation with your team around the topic to help connect your knowledge to practice. This is will help build context and improve understanding of each topic or theme.

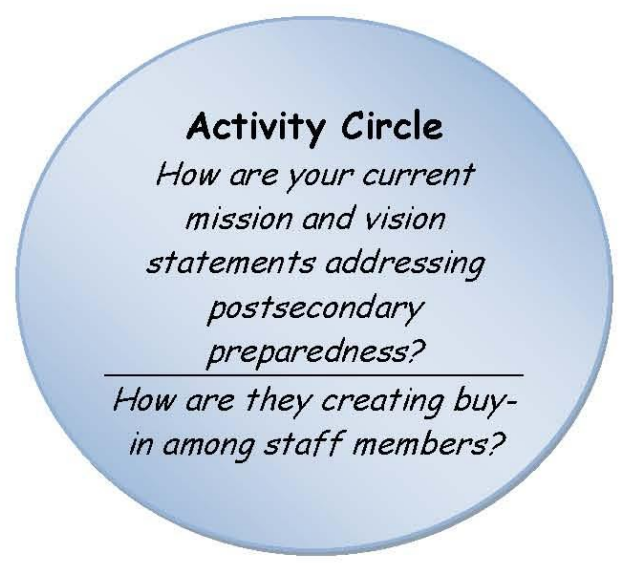

\section{Family Involvement}

The encouragement of parents is one of the strongest factors in helping students develop their educational plans (Cabrera \& La Nasa, 2000). Most parents expect their children to earn college degrees and enter rewarding careers (Wimberly \& Noeth, 2005). Parents are key when it comes to their children's college-going behaviors (McAlister, Mevs, Lee, Rodriguez, \& Kim, 2012). A study done in the late 1980 's shows that more than three quarters (78\%) of all parents surveyed expected their children to attend college and over half of them (58\%) expected them to finish (Ingels, Curtin, Kaufman, Alt, \& Chen, 2002). With this foundational piece in place, it is important to involve parents in the planning of the future of their child. Parents who have timely information about educational planning increase their child's school success, facilitate college planning, and increase the likelihood that their child will attend college (Cota-Robles \& Gordan, 1999).

The problem begins when students enter middle and high school. There is a disconnect between parents' educational expectations for their children and their postsecondary planning activities (Wimberly \& Noeth, 2005). This is especially true for parents who have not attended college. Wimberly and Noeth (2005) note that these parents may lack the necessary skills and resources

74 Bridging the Future to Postsecondary Readiness 
to assist their children with educational planning. Some parents are never or rarely informed or involved in educational decisions and as a result students have to rely on school personnel and peers to help them through this process of educational planning (Wimberly \& Noeth, 2005).

Schools today are beginning to realize that parental involvement is critical in the development of students and are taking steps to inform and involve parents. This is happening through informational nights where schools provide students and parents information about workplace and college admission requirements, secondary school classes, and postsecondary options (Wimberly \& Noeth, 2005).

While progress is being made to involve families in education, this process needs to become more inclusive with the educational system. Family involvement needs to be as important as classes required for graduation. To make this happen, educators need to realize that informational nights and newsletters are important, but shouldn't be the sole factors in family involvement. This process is complex and needs development and time to become a quality program within the school.

\section{Developing a Family Involvement Program}

As schools begin to plan for systematic family involvement, the group of leaders responsible for this process should understand the school's needs, and provide a framework for defining actions to address these needs. To begin with, each site should develop a logic model and needs assessment prior to any family involvement activities. As mentioned above, buy-in is critical to the success any program. This buy-in must include all stakeholders (including parents the program is intended to serve), as well as adequate time for implementation. Planning for successful family involvement requires selecting programs, activities and strategies that are effective, targeted and appropriate to the site and participants. Lastly, effective programming require both formative (periodic and ongoing) and summative (final or year-end) evaluation (Oregon Department of Education, 2006).

Getting Started-Preliminary Steps

The first step to improving parent, family, and community involvement in your school is to assemble a committee composed of:

75 Bridging the Future to Postsecondary Readiness 
- Parents who represent any major groups at the school

- Community members and agencies

- The principal

- Teachers

- Students

- District staff

The next step for the committee is to assess the situation. Data should be collected to inform the members of the committee about the status of partnerships. After the school has looked carefully at the information gathered, the committee will prioritize, assign tasks, and plan to evaluate the progress of the program. The data that is collected should address the following questions:

- Is this a school with a high percentage of single-parent homes?

- Is this a school with many English language learners?

- Is this a school with a high mobility rate?

- Are there many families where at least one parent is predominately in the home?

- Is there a high percentage of homes where violence, abuse, addiction, physical or mental illness is present?

- What educational goals do families have for their children?

After assessing data pertaining to the families of the school, the school's achievement data should be reviewed by the committee, and then it should be put into a clear, easy-to understand report. This report should be sent to family members for input on successes, improvements, and contributions they can make to help move the school in the right direction. Once this is completed, then the committee can move forward to look into the following questions:

- What are our school's goals for improving our school, family, and community partnerships over the next three years?

- How can we effectively involve families and the community in the decision-making process?

- Do decision-makers have the appropriate research and training to make informed decisions?

- Do materials need to be translated?

- Do translators need to be provided at meetings?

- Does childcare need to be provided while parents attend meetings or volunteer at school?

- Should school personnel be making home visits? If so, how?

- Is student attendance a problem?

- What kind of support do teachers need?

- What are the achievement trends?

- How can outreach to families and the community link to the academic needs of the school?

- What do parents say about past successful events?

76 Bridging the Future to Postsecondary Readiness 
- What activities do parents feel would be most beneficial?

- How can we most effectively use community resources?

Types of Family Involvement

After these preliminary steps have been taken, the foundation to family involvement is set, and now the committee can move forward and look deeper into the different types of family involvement. Table 7 shows the types of family involvement in schools.

Table 7-Types of Family Involvement

\begin{tabular}{|c|c|c|c|c|}
\hline $\begin{array}{c}\text { Family } \\
\text { Involvement }\end{array}$ & $\begin{array}{c}\text { Engaging } \\
\text { Parents of } \\
\text { Students With } \\
\text { Disabilities } \\
\end{array}$ & $\begin{array}{c}\text { Reaching Out to } \\
\text { Families }\end{array}$ & $\begin{array}{c}\text { Ongoing } \\
\text { Communications }\end{array}$ & $\begin{array}{l}\text { Special } \\
\text { Groups }\end{array}$ \\
\hline $\begin{array}{l}\text { - Communicating } \\
\text { With Families } \\
\text { - Volunteering } \\
\text { - Learning at } \\
\text { Home } \\
\text { - Increasing } \\
\text { Parents' } \\
\text { Participation in } \\
\text { Decision- } \\
\text { making and } \\
\text { Leadership } \\
\text { Roles } \\
\text { Collaborating } \\
\text { With the } \\
\text { Community }\end{array}$ & $\begin{array}{l}\text { - Create a } \\
\text { School or } \\
\text { District } \\
\text { Advisory } \\
\text { Council for } \\
\text { Special } \\
\text { Education } \\
\text { Create a } \\
\text { Mentor } \\
\text { Parent } \\
\text { Program } \\
\text { Create a } \\
\text { Parent } \\
\text { Transition } \\
\text { Program } \\
\text { Offer } \\
\text { Community } \\
\text { Education } \\
\text { Courses }\end{array}$ & $\begin{array}{ll}\text { - } & \text { Early Fall } \\
\text { - Hailings } \\
\text { Home-School } \\
\text { Handbooks } \\
\text { - } \text { Open House } \\
\text { Ppecial } \\
\text { Practices and } \\
\text { Programs } \\
\text { - Parent } \\
\text { Resource } \\
\text { Centers } \\
\text { Informal } \\
\text { School- } \\
\text { Family } \\
\text { Gatherings } \\
\text { Parent } \\
\text { Workshops } \\
\text { - Secondary } \\
\text { School } \\
\text { Strategies } \\
\text { Strategies for } \\
\text { Children With } \\
\text { Special Needs } \\
\text { Personal } \\
\text { Contacts } \\
\text { Parent- } \\
\text { Teacher } \\
\text { Conferences } \\
\text { Home Visits } \\
\text { Parent } \\
\text { Liaisons }\end{array}$ & $\begin{array}{l}\text { - Newsletters } \\
\text { - Positive Phone } \\
\text { Calls } \\
\text { - Homework and } \\
\text { Home } \\
\text { Learning }\end{array}$ & $\begin{array}{l}\text { - Involving } \\
\text { Parents } \\
\text { With } \\
\text { Limited } \\
\text { English } \\
\text { - Involving } \\
\text { Single and } \\
\text { Working } \\
\text { Parents } \\
\text { - Involving } \\
\text { Fathers } \\
\text { Developing } \\
\text { Parent } \\
\text { Leadership }\end{array}$ \\
\hline
\end{tabular}

77 Bridging the Future to Postsecondary Readiness 
*Take some time and engage in a conversation with your team around the following question(s)

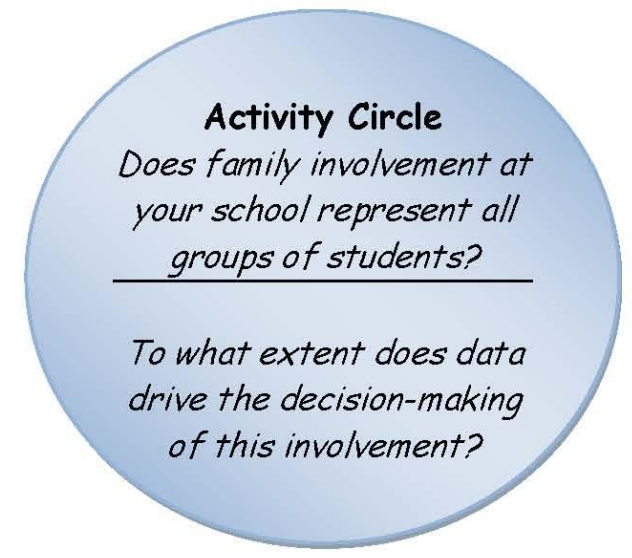

\section{Academic Behaviors}

Another social element important to postsecondary readiness focuses on academic behaviors. Academic behaviors can be defined as noncognitive skills or a set of qualities that includes persistence, self-control, curiosity, conscientiousness, grit and self-confidence (Tough, 2009). Casillas et al. (2011) state that these noncognitive factors include a range of attitudinal, behavioral, emotional, and personality characteristics that are necessary to function well in school and work. Conley (2012) includes these academic behaviors as one of his four keys to college and career readiness. He refers to them as key as learning skills and techniques. This key involves the ownership of learning (goal setting, persistence, self-awareness etc...) and specific learning techniques (time management, study skills, collaborative learning etc...). For the purposes of this guidebook, I will use the term "academic behavior" to categorize the full range of noncognitive factors.

Research shows that a combination of noncognitive factors, academic performance, and standardized achievement factors are predictive of first-year college academic success and retention (Robbins et al., 2004). The first step toward building academic behaviors in schools is to identify at-risk students and provide supports to assist them in their educational development.

78 Bridging the Future to Postsecondary Readiness 


\section{Assessing Academic Behaviors}

What happens when students come to school for the first time? How do educators know what behavioral skills they have acquired? Do schools have an educational profile of each student? These questions and more reveal that schools aren't prepared for the social development of each student. Many schools implement quality instructional practices, and in these practices, teachers assess student skill throughout the class period/term to indicate individual academic skill. These assessments inform instruction so that every student can grow in skill level. If this is true in many classrooms and considered a quality instructional practice, then why aren't we assessing academic behaviors of each student when they enroll, so we can measure the effectiveness of the school for student growth? One way of assessing academic behaviors is through ENGAGE.

ENGAGE

A tool has been developed to identify these academic behaviors and help educators to build these skills. Schools across the nation are using ENGAGE developed by ACT to identify youth who are at academic risk by supplementing standardized achievement testing with measures of important academic behaviors (Casillas et al., 2011). Casillas points out that ENGAGE is a lowstakes, self-report inventory organized into three categories shown to be indicators of academic performance and persistence (Robbins et al., 2004). The three categories are:

- Motivation includes personal characteristics that help students to succeed academically by focusing and maintaining energies on goal-directed activities.

- Social engagement includes interpersonal factors that influence students' successful integration into their environment.

- Self-regulation includes the thinking processes and emotional responses of students that govern how well they monitor, regulate, and control their behavior related to school and learning.

(Casillas et al., 2011)

ENGAGE is available for use with grades 6-9 and grades 10-12, and captures students' perceptions of themselves, their families' commitment to education, school-related factors, and important behavioral indicators (Casillas et al., 2011). Results from ENGAGE (grades 6-9) produces a report that provides an academic success index which estimates the probability that a student will be academically successful (defined as obtaining a high school GPA of 2.0 or above) (Casillas et al., 2011). Results from ENGAGE (grades 10-12) provides a report that offers an

79 Bridging the Future to Postsecondary Readiness 
academic success index which estimates the probability that a student will earn a college GPA greater than 2.0 and a retention index which estimates the probability of a student returning to college for a second year. Casillas et al (2011) note that with the student-level information provided by ENGAGE, educators can identify students who may be at-risk of experiencing academic difficulties and connect them to interventions based on their areas of need.

\section{Key Learning Skills and Techniques}

Conley realizes the importance of building academic behaviors to prepare students for postsecondary success. As noted above, he refers to these behaviors in his key learning skills and techniques. Conley breaks up key learning skills and techniques into two broad categories: student ownership of learning, which includes goal setting, persistence, self-awareness, motivation, progress monitoring, help seeking and self-efficacy; and learning techniques, such as time management, study skills, strategic reading, memorizing techniques, collaborative learning, technology skills, and self-monitoring (D. T. Conley, 2012). Postsecondary instructors at a wide range of two- and four-year institutions stress the importance of these key learning skills and techniques across subject areas and programs (D. . Conley \& McGaughy, 2012). Tables 8 and 9 below show this categorization of key learning skills and techniques.

Table 8-Key Learning Skills

\begin{tabular}{|l|}
\hline$\frac{\text { Know Yourself }}{\bullet \quad \text { Be self-aware-Find out your interests, passions, skills, and ambitions. }}$ \\
$\frac{\text { Set Goals }}{\bullet \quad \text { Know what you need to achieve based on self-awareness. }}$ \\
$\frac{\text { Be Motivated }}{\bullet \quad \text { Have the mindset to achieve your goals. }}$ \\
$\frac{\text { Persist }}{\bullet \quad \text { Don't give up, especially when something does not come as easily to you. }}$ \\
$\frac{\text { Monitor Performance }}{\bullet \quad \text { Know how well you are really doing. Gauge your true skill level. }}$ \\
$\frac{\text { Ask for Help }}{\bullet \quad \text { Know when you are stuck, then get help. Don't view this as a weakness. }}$ \\
$\frac{\text { Show self-efficacy }}{\bullet \quad \text { Learn how to control the things you can control. Then control them. }}$
\end{tabular}

(D. Conley, 2012)

80 Bridging the Future to Postsecondary Readiness 
Table 9-Key Learning Techniques

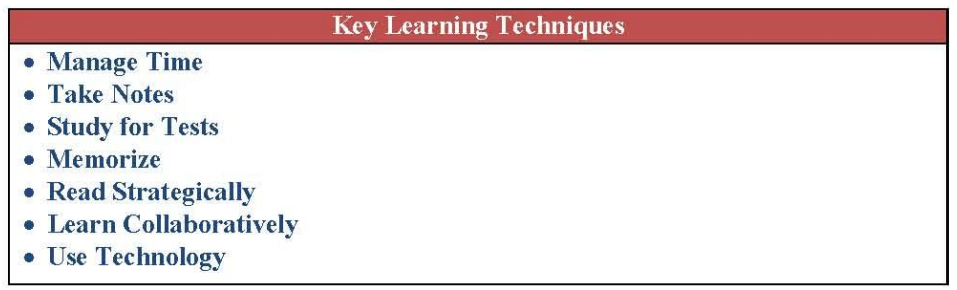

(D. Conley, 2012)

\section{Application}

The Academic Behaviors should be addressed at each school level from elementary through to college. These skills must be developed and refined every year in a systematic way. The most effective way to build these skills is to have a comprehensive approach toward building academic behaviors in both the classroom and throughout the school. Students who struggle in school not only have to build these skills in their classes, but they need to be reinforced through support classes and with support personnel such as learning specialists. If the approach to these academic behaviors in each classroom is limited, then programs must be created to address these skills with all staff buy-in and participation. An example of this would be a learning center where students with low academic and/or behavioral skills would receive extra support to help build these skills through: individual tutoring, guidance and support, small group mentoring, and by creating an awareness of student ownership, and explicitly practicing individual learning techniques.

*Take some time and engage in a conversation with your team around the following question(s)

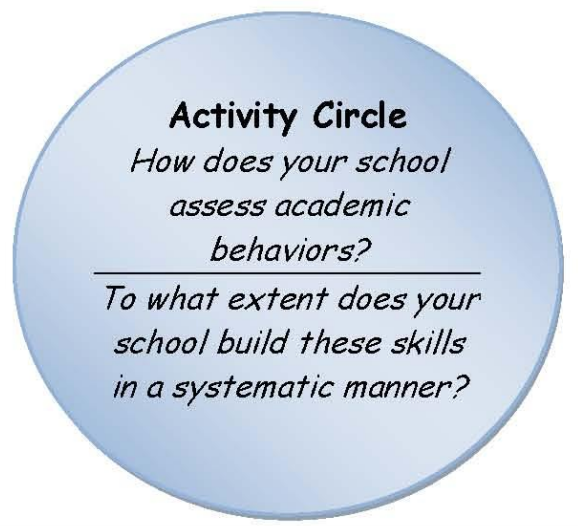

81 Bridging the Future to Postsecondary Readiness 


\section{Key Transition Knowledge and Skills}

The last aspect of social elements within the postsecondary readiness framework is working with parents and students to build knowledge and skills around the theme of life beyond high school. Conley (2012) refers to this as key transition knowledge and skills. This key is necessary to navigate the transition from secondary school to postsecondary institutions. This information is knowledge that isn't often accessible to all students (D. T. Conley, 2012). Families, which are often historically under-represented in higher education or certain career pathways, are who usually get left out of this knowledge. The themes within this key are: Academic Awareness, College Admissions Process, College and Career Culture, and Tuition and Financial Aid. Table 10 below shows these themes, their definitions and components.

Table 10- Key Transition Knowledge and Skills

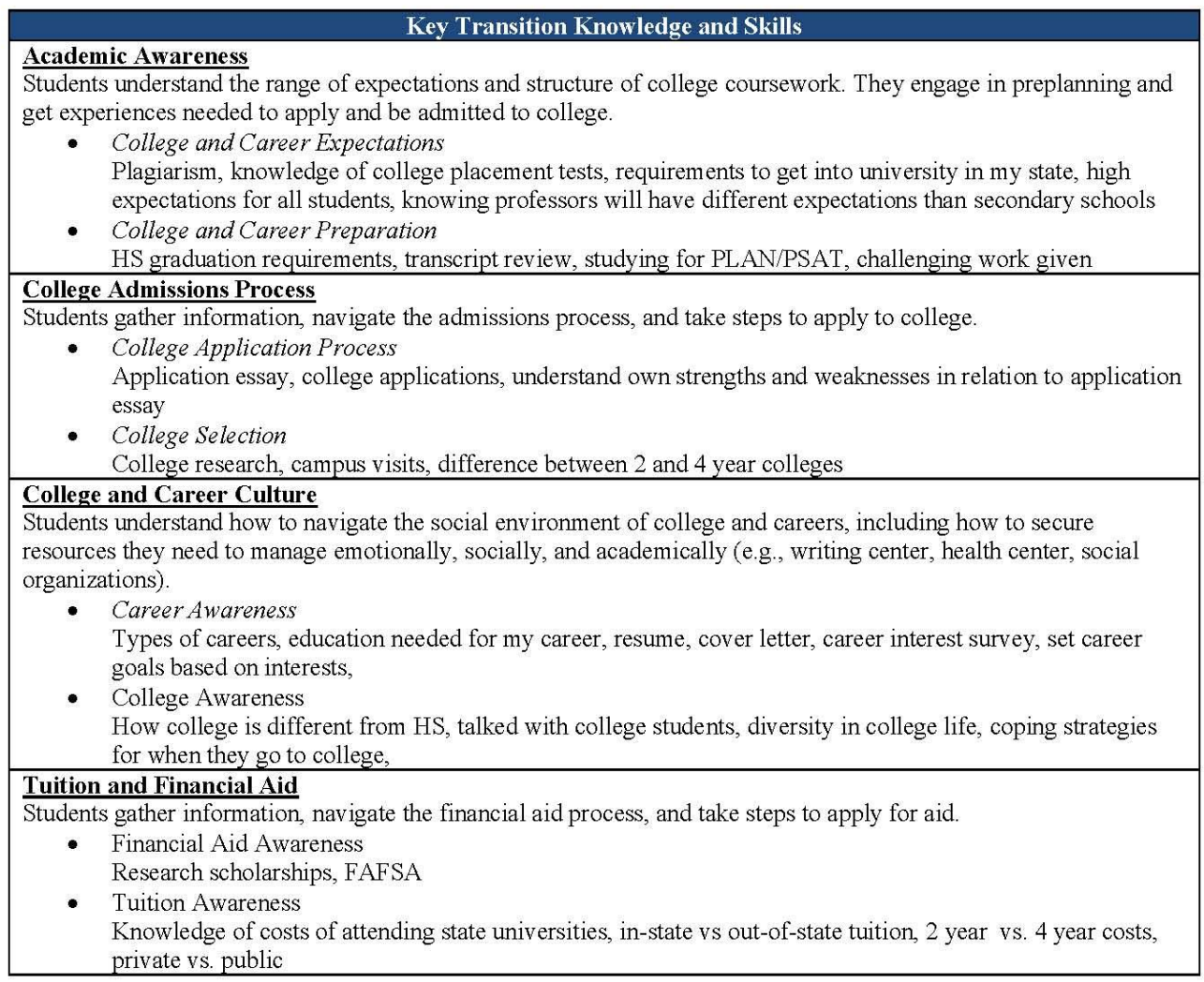

(D. Conley, 2012)

82 Bridging the Future to Postsecondary Readiness 


\section{Assessing Key Transition Knowledge and Skills}

What data do schools collect to measure Key Transition Knowledge and Skills? Is this data indicative of a systematic approach? How are the approaches to build these skills assessed? Are these assessments measuring some or all of the aforementioned knowledge and skills? These are questions that must be answered in order to create a postsecondary readiness culture. Due to limited resources, many schools provide a scattered approach toward building this knowledge and these skills. This scattered approach isn't woven into the fabric of the school and aligned with proper assessment methods to help inform the school of its effectiveness in preparing students for postsecondary success. This process should be researched and include all school personnel to create a culture of postsecondary success. One way of providing a comprehensive approach to assessing college readiness skills is through CampusReady.

CampusReady

CampusReady looks at skills needed for students to succeed in college. It helps schools identify areas of strength in addressing these skills, along with providing feedback to implement strategies not yet being used. CampusReady gives schools an opportunity to:

- Gain an understanding of what students do within the dimensions of college readiness.

- Learn what knowledge and skills associated with college readiness are currently part of the school's processes, practices, and curriculum.

- Identify specific ways to increase the alignment of the curriculum with the content and skills that students must know and be able to master for college success.

- Receive individualized, actionable recommendations to foster improvement, including connections to targeted resources.

- Obtain knowledge of how individual school's practices compare to the best practices identified in other schools nationwide.

- Provide faculty and staff with new ideas for developing college readiness among students as they respond to the diagnostic items, which were identified as effective practices in a nationwide study.

\section{Application}

Key Transition Knowledge and Skills are critical to build in schools, and are often left to the counselors. All school staff and parent involvement is necessary to the postsecondary success of every student. Schools must find systematic ways to include this involvement into its educational programs. These skills are as important as both academic and behavioral skills. If the approach to the transition knowledge and skills in schools is limited to volunteers in college

83 Bridging the Future to Postsecondary Readiness 
and career centers, informational nights, and counselor meetings, then programs must be created to address these skills with all staff buy-in and participation. An example of this would be an advisory program.

An advisory program is defined as an effort to ensure that all students have at least one adult who knows them well and that all students belong to a small interactive group (Manning \&

Saddlemire, 1998). In these advisory programs, Manning and Saddlemire (1998) point out that educators and counselors work collaboratively to improve the educational experiences and overall well-being of the students. Educators for Social Responsibility (ESR) have done work on designing and implementing effective secondary school programs. Advisory programs play an important role in a school's overall academic and student support services plan ("Advisory Programs," 2012). They help to create a personalized learning environment where all students are well known by at least one adult. ESR (2012) stresses the importance of how advisory provides a structure and a set of practices for monitoring and supporting students' academic progress and college and career readiness throughout their time in secondary schools. Advisory programs allow opportunities for parental involvement through student-led conferences, where the focus is on the student and his/her educational and postsecondary planning. When programs like this are implemented, then volunteers in college and career centers, informational nights, and counselor meetings help to enrich and supplement the growth of every student.

\section{Support Outside of School}

\section{Grants}

Grants are available to address the lack of knowledge and support (key transition knowledge and skills) some students have around applying for, funding, and enrolling in college. The U.S.

Department of Education launched the College Access Challenge Grant Program which aims to increase the number of low-income students who are ready for college (McAlister et al., 2012). McAlister et al. (2012) notes that other programs such as Project Grad USA and College Goal Sunday look to develop the college knowledge students and their families need for postsecondary success.

84 Bridging the Future to Postsecondary Readiness 
Community

Community-based organizations (CBOs) play an active role in supporting students with key transition knowledge and skills (McAlister et al., 2012). As McAlister et al. (2012) note, CBOs step in to bridge gaps in college knowledge for students in high-needs schools where few of their peers apply to college. The College Board also does a great job of addressing the key transition knowledge and skills by keeping parents informed and equipped to make college decisions (McAlister et al., 2012). Partnership between The College Board and the American Council on Education, and the Ad Council have developed the KnowHow2Go Initiative, which serves as a resource to help students and parents plan for postsecondary success (McAlister et al., 2012).

*Take some time and engage in a conversation with your team around the following question(s)

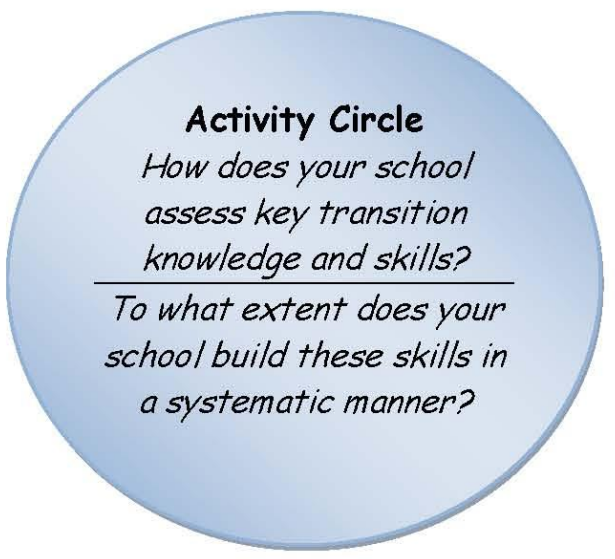

85 Bridging the Future to Postsecondary Readiness 


\section{Checklist for Social Elements}

- Complete the rubric for postsecondary readiness on Social Elements to assess current practices and programs.

1 Form a committee to focus on the Social Elements to review, analyze, and plan for a seamless approach to postsecondary readiness.

Create an organizational chart with all of the resources/programs/best practices involving the Social Elements at your school.

Identify staff members and their involvement with systems/programs/classes of preparing students for postsecondary success. Identify how other staff members can become involved in this process.

$\square$ Identify a parent(s) and community member(s) to serve on this committee to create a system involving families and community members.

$\square$ Prioritize a list of academic behaviors to focus on throughout the school year. Create a system for integration and evaluation of building these skills.
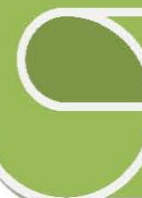

86 Bridging the Future to Postsecondary Readiness 


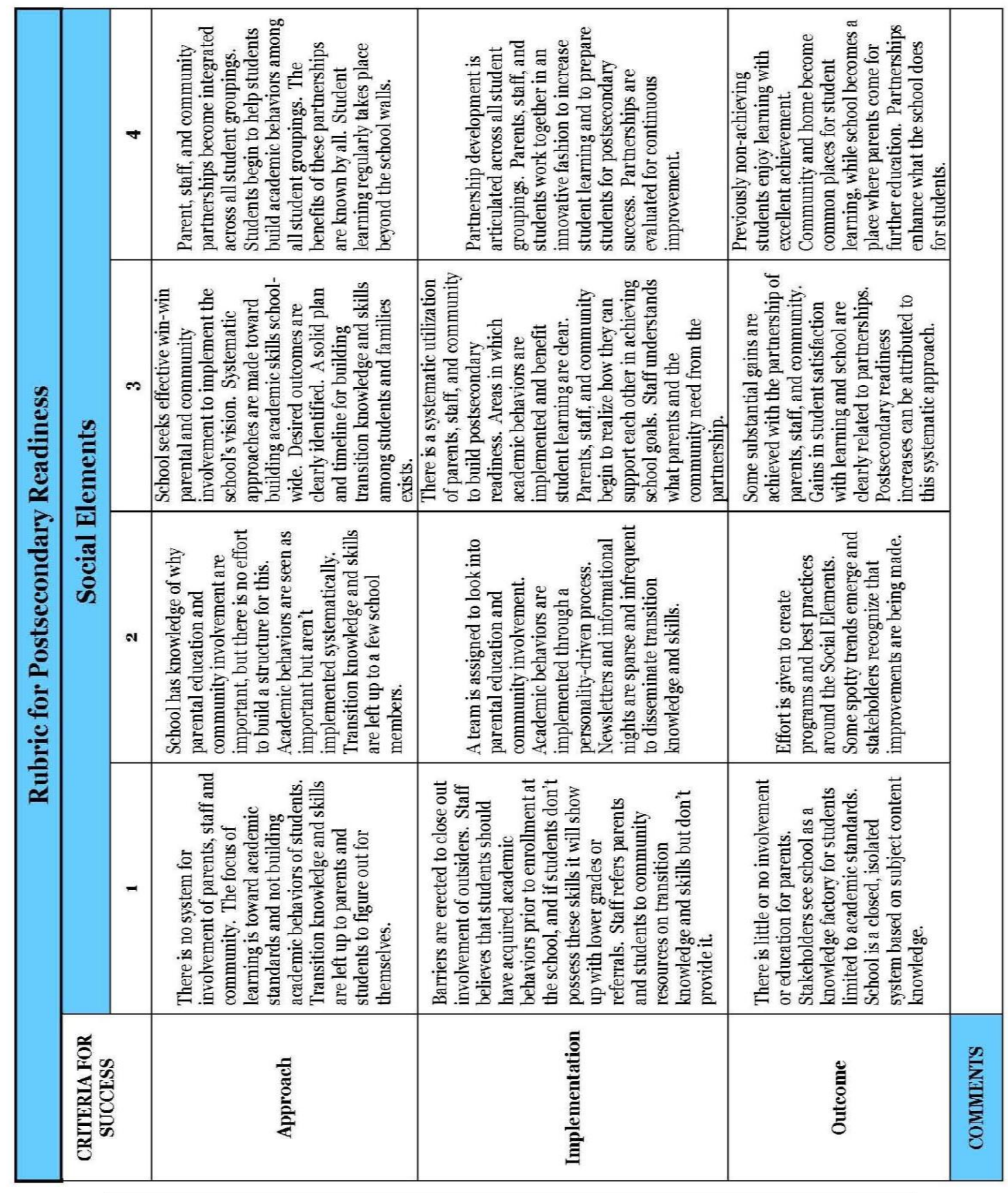

87 Bridging the Future to Postsecondary Readiness 


\section{Action Template $\tilde{S}_{\text {Advocacy \& Policy Center }}^{e}$}

Organize any new actions being considered for implementation at your school with this implementation template. Consider all general actions, those already begun as well as new ones, and then categorize them according to:

1. Ouick wins-actions that can be implemented this semester or this school year

2. Moderately difficult undertakings-actions that need summer planning, professional development, or both

3. Major tasks-actions that will need two years or more for full implementation and may include quick wins and moderately difficult undertakings.

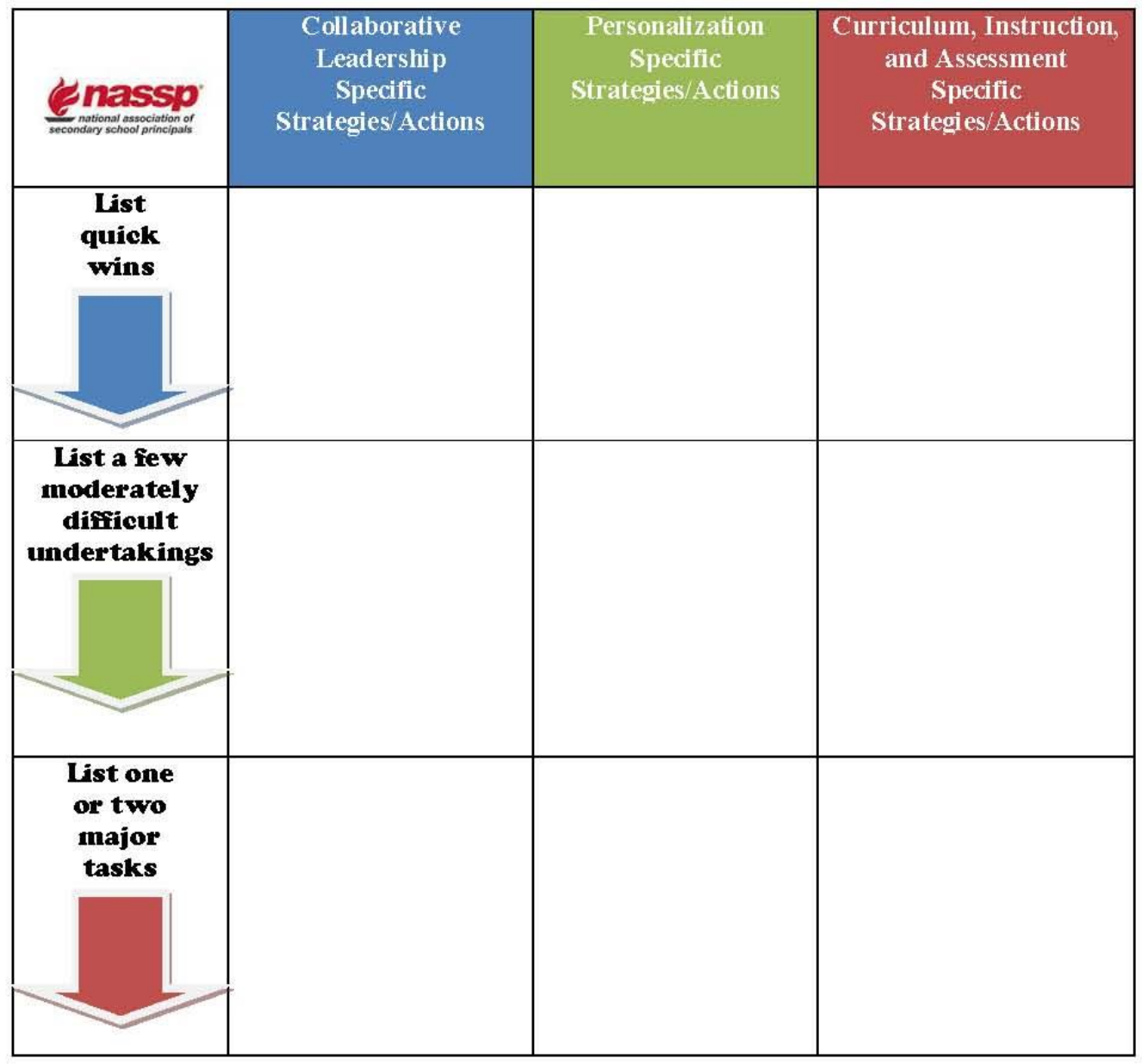

88 Bridging the Future to Postsecondary Readines's 


\section{Action Template $\sum_{\text {Advocacy \& Policy Center }}^{e}$}

\section{Professional Development and Communication Planning}

Consider your planned school improvement actions and strategies. Identify the teams and team members who will lead the implementation and the development of knowledge, skills, and

attitudes needed for success. Discuss and list specific steps and actions that school staff members will take to develop the knowledge, skills, and attitudes of each group below.

\begin{tabular}{|c|c|c|c|}
\hline 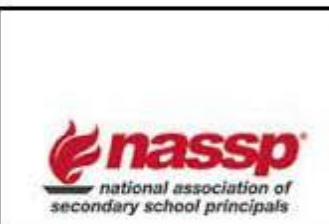 & $\begin{array}{l}\text { Actions to develop } \\
\text { the requisite } \\
\text { knowledge for } \\
\text { success }\end{array}$ & $\begin{array}{l}\text { Actions to practice } \\
\text { the requisite } \\
\text { slills for success }\end{array}$ & $\begin{array}{l}\text { Actions to develop } \\
\text { the requisite } \\
\text { attitudes for success }\end{array}$ \\
\hline $\begin{array}{l}\text { Leadership team/ } \\
\text { Steering committee }\end{array}$ & & & \\
\hline Faculty colleagues & & & \\
\hline District personnel & & & \\
\hline Parents & & & \\
\hline Students & & & \\
\hline Community leaders & & & \\
\hline $\begin{array}{l}\text { Others } \\
\text { (list them) }\end{array}$ & & & \\
\hline
\end{tabular}

89 Bridging the Future to Postsecondary Readiness 
SECTION 5:

\section{APPLICATION OF POSTSECONDARY READINESS}

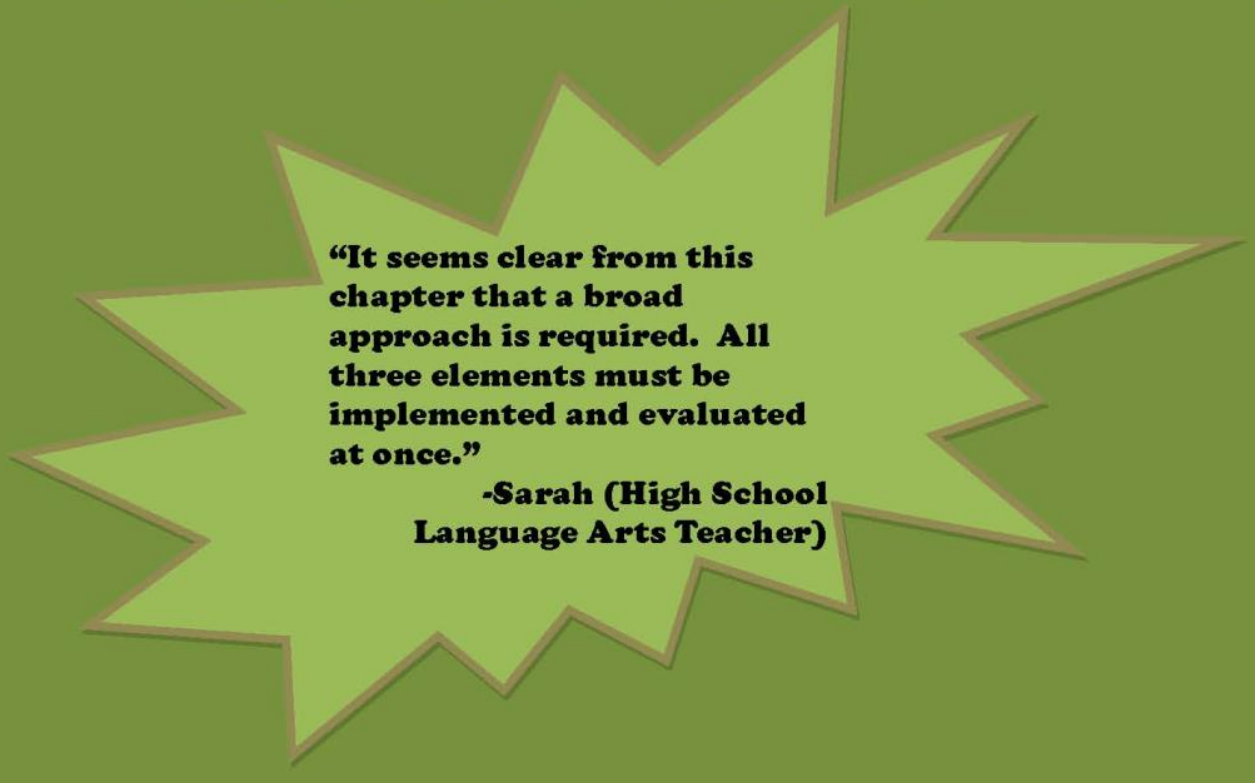

“Understanding by design!!!!”

-Amy (High School Math)

90 Bridging the Future to Postsecondary Readiness 


\section{Design Question 5}

What does a comprehensive approach to college and career readiness look like?

\section{$\underline{\text { Target } 5}$}

\section{-}

\section{Application of Postsecondary Readiness}

"The holy grail of college readiness would be an integrated system that provides all of this information to students in a progressive, developmentally appropriate fashion so that they have a sense a continuous sense of how well they are beins preparedand are preparing themselves for college."

This next target addresses the application of the three elements of the postsecondary readiness framework within a high school. This section gives the reader examples and ideas on how a high school provides a comprehensive approach to college and career readiness. Because a comprehensive approach to college and career readiness is complex, this section highlights the elements of the postsecondary readiness framework in one school that may or may not be applicable to other schools. However, if a school's mission is to prepare students for postsecondary options, many of the best practices in this section can transfer to any school regardless of the level or size.

This target is broken down into the three elements of the postsecondary readiness framework: structural, academic, and social. Within these elements, are best practices that a middle college implements to prepare students for postsecondary success. This section will provide readers the opportunity to see practical applications of the postsecondary readiness framework.

91 Bridging the Future to Postsecondary Readiness 


\section{Clackamas Middle College}

Clackamas Middle College (CMC) is a four-year high school college transition program enrolling 300 students in grades 9-12. It is accredited by AdvancED. CMC is designed to give students the opportunity to earn both high school and college credits simultaneously with the goal of earning a high school diploma, a transfer degree, or certificate of completion.

CMC students are diverse. Students enrolling in Clackamas Middle College are interested in success beyond high school. There is a personal interest in college or career-related programs while completing high school graduation requirements. Students know that when they leave our school, they will be prepared for post-secondary success. This is evident as all of our graduates leave with college transcripts, college credits and college transfer degrees or college certificates.

\section{Structural Element: Best Practices}

\section{Mission, Vision, Purpose, Goals, Shared Values and Beliefs}

Creating the mission and vision, along with determining the shared values and beliefs, and core purpose of the school is guided by Education for the Future (EFF), and Victoria Bernhardt's (Section 6) work on Continuous School Improvement. It is through this work and attendance at EFF's Summer Institute that guides CMC's direction.

Core Values

Prior to the first week of school for students, staff at the school participates in an activity that will set the course and direction for the school. Staff will begin to brainstorm and document personal values and beliefs about: What are the curriculum, instruction, assessment, and environment factors that support effective learning for Clackamas Middle College students? Once consensus around the core values and beliefs for the school is reached, then they should be documented.

Core Purpose

The next step in developing a mission and vision for the school is to identify the core purpose of the school. Staff should brainstorm and document personal ideas about the purpose of the school. Make sure to look for commonalties, reach consensus, and document the core purpose for the school.

Mission Statement

After the core values and beliefs, and the core purpose have been created by the staff, the next step is to create a mission statement for the school. The first thing to do is to review the current mission statement. The staff will use the core values and beliefs, and purpose to draft the mission of the

92 Bridging the Future to Postsecondary Readiness 
school. As long as the purpose is clear, the process can proceed without the mission statement completely written out. It is the purpose that is most important. Form a committee to write the actual mission statement. Once the statement is created, review it with the whole staff for buy-in.

\section{Vision Statement}

To create the vision statement, staff members brainstorm and document personal visions for the school in terms of what the school would look like, sound like, feel like if we were living our core values and beliefs, purpose, and mission. These visions should be broken down into the following components: curriculum, instruction, assessment, and culture and environment. Once these are listed, look for commonalties, reach consensus, and document the vision for each category. After this process is complete, someone will need to draft a shared vision statement for the school.

\section{School Goals}

Once the shared vision is completed, attention must be turned to school goals and the outcomes of the vision. For each school, there should only be two or three school goals. It is recommended to have an academic goal and a social goal. For example, CMC's goals are: (1) Every student feels emotionally and academically safe and is part of an accepting school culture. (2) Every student progresses academically toward college and career-related opportunities systematically throughout the year.

\section{Tips for Creating a Shared Vision}

In order to make the vision come to life in the school, make sure to document the shared vision and post it around the school. Make sure all staff members have a copy. A rubric or assessment tool needs to be developed that will describe the evolution and implementation of the vision in the school and in classrooms.

Develop a plan to implement the vision. Include an action plan along with professional development required to implement the vision, materials to purchase, and support mechanisms for implementation, such as peer coaching.

When integrating the shared vision into the curriculum and instruction of the school, grade level/subject area teams adapt the vision into real terms for each teacher. Check across grade level teams to ensure a continuum of learning that makes sense. Determine a structure and time for grade level meetings and across grade level meetings.

\section{Bridging the Future to Postsecondary Readiness}


School leaders need to determine a leadership structure to implement and monitor the vision. For example, at CMC, we have broken our vision into the four components of curriculum, instruction, assessment, and culture and environment. Each staff member in the school signs up to be part of at least one component. These groups are called vision panels and the members are responsible for monitoring and implementing the shared vision. They meet weekly and use the following questions to help guide their work:

- What professional development is needed and when?

- What materials are needed to implement the vision?

- What other things need to be done to implement the vision?

- How will the implementation of the vision be supported?

- How can progress be measured?

- How do we document changes in the vision from year to year?

\section{Diagnostics and Data}

The first week of school, all students take part in diagnostics/assessments to help identify each students' social and academic skills. All students participate in ACT's ENGAGE, EXPLORE, and PLAN to give staff an idea of student skill pertaining to academics, behavior, and transitional knowledge. This information is put into a student profile to help assess the growth of skills in their time at CMC. Every student at CMC has a profile and portfolio that marks not only the progress of their skills but their movement throughout our system. This data allows us to provide extra support for students struggling in specific areas, while recognizing the students who need to matriculate to college and career programs within our system. Figures 5-7 on the next page show examples of the ENGAGE and EXPLORE diagnostic used at CMC.

94 Bridging the Future to Postsecondary Readiness 


\section{Sample Student}

Tested on Auglist 30, 2011
$11^{\text {th }}$ Grade. ID 926096433

SAMPLE HIGH SCHOOL Class/section: 006

ENGAGE

Grades 10-12

ENGAGE Grades 10-12 measures persona|, behavioral, and academic skills critical to high school and college achievement. Low scores on ENGAGE represent areas that, when improved, may increase your grades and make it easier to focus on being successful as you transition into college. This report is designed to help you identify your strengths and weaknesses in order to ensure that you are successful in your academic career.

SCALE

Academic self-canficence

Commitment to college

Goal striving

Social activity

Steadiness

Social connection

Communication skills

Academic discipline

General determination

Study skills

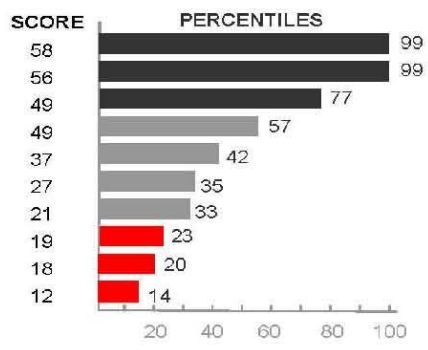

Figure 6-EXPLORE
ENGAGE INDICES

Probability estimates range from $\mathrm{O}$ to 1 ; indices do not appear on student reports.

\begin{tabular}{|c|c|}
\hline .49 & Academic Success Index \\
probability of college GPA $\supseteq 20$
\end{tabular}

.66 Retention Index

$27 \%$ ile prabability of returning secand year

STUDENT SELF REPORT

High school GPA: (C- to C) $1.5-1.9$

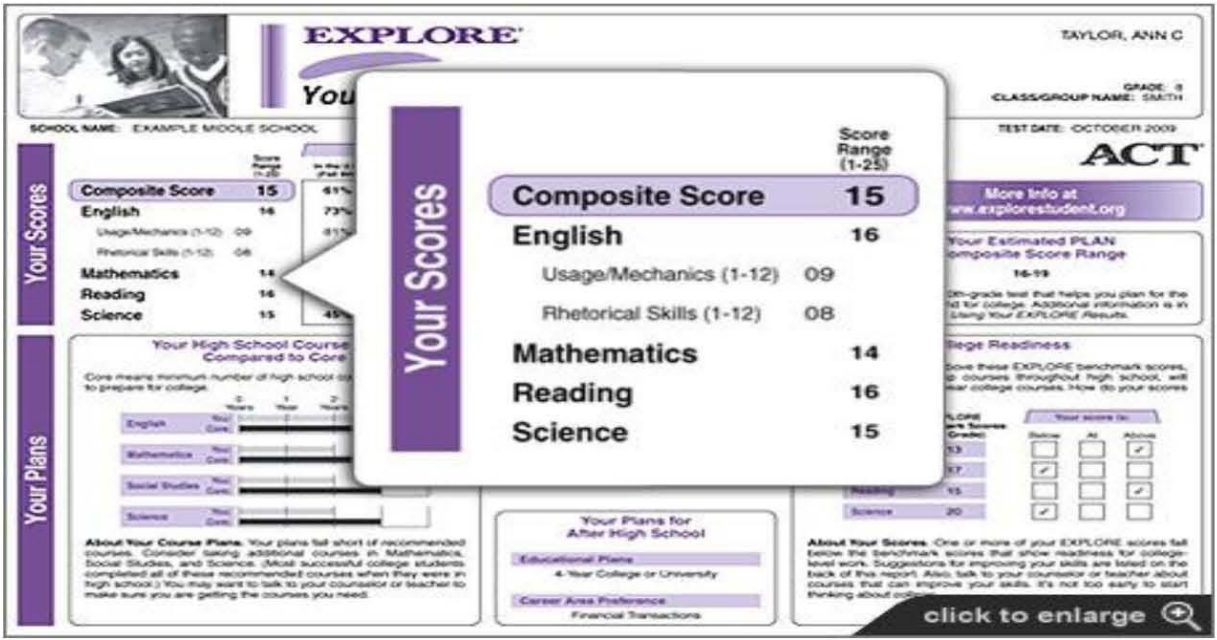

Figure 7-EXPLORE

\begin{tabular}{|c|c|c|c|c|c|c|c|c|c|c|}
\hline & \multirow{2}{*}{$\begin{array}{l}\text { Score } \\
\text { Range } \\
(1-25)\end{array}$} & \multicolumn{9}{|c|}{ Percent of students scoring at or below your score } \\
\hline & & $\begin{array}{l}\text { In the U.S. } \\
\text { (Fall Bun) }\end{array}$ & $1 \%$ & 105 & $25 \%$ & $30 \%$ & $75 \%$ & $90 \%$ & 89\% In Your School & In Your State \\
\hline Composite Score & 15 & $61 \%$ & I & & & & & & $60 \%$ & $63 \%$ \\
\hline English & 16 & $73 \%$ & & & & & & & $75 \%$ & $76 \%$ \\
\hline Usage/Mechanics (1-12) & 09 & $81 \%$ & & & & & & & $81 \%$ & $84 \%$ \\
\hline Rhetorical Skills $(1-12)$ & 08 & $75 \%$ & & & & & & & $84 \%$ & $77 \%$ \\
\hline Mathematics & 14 & $41 \%$ & & & & & & & $40 \%$ & $51 \%$ \\
\hline Reading & 16 & $79 \%$ & 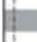 & & & & & & $78 \%$ & $77 \%$ \\
\hline Science & 15 & $45 \%$ & 14 & & & & & & $36 \%$ & $44 \%$ \\
\hline
\end{tabular}

95 Bridging the Future to Postsecondary Readiness 


\section{Learning Center}

After student skill has been initially identified at CMC, students who have been diagnosed with low social and academic skills are placed into a Learning Center for one hour a day for extra support and receive elective credit. The Learning Center was created to help students build and reinforce postsecondary readiness skills.

The Learning Center is staffed by an academic mentor who conducts lessons and discussions designed to help build college readiness skills and techniques. The mentor monitors and collects data on student grades, attendance, and homework completion. This information is analyzed weekly and presented to both students and staff of CMC. This data will inform any changes that need to occur in the structure and content of the Learning Center. To support each student, the mentor attends meetings involving students, parents, staff and learning specialists.

Lessons in Learning Center are student driven while the academic mentor provides prompts and facilitates discussion. Students should regularly utilize reflection. In general, the format should be:

- Mentor poses a question or topic.

- Students reflect on the topic through writing

- Students re-read their response, highlighting key information

- Students share with a partner or small group

- Pairs or groups share with the larger class

In the Learning Center, the academic mentor should model college readiness behavior. For example: reflecting students, and participating in student groups. This creates buy-in from participants in the Learning Center and personalizes the learning and skill building.

Goals of the Learning Center

The goals of the Learning Center are to develop key learning skills and techniques students need to be successful at the college level. These skills and techniques are listed on the following page in Table 11 and 12.

96 Bridging the Future to Postsecondary Readiness 
Table 11-Key Learning Skills

\begin{tabular}{|l|}
\hline$\frac{\text { Know Yourself }}{\bullet \quad \text { Be self-aware-Find out your interests, passions, skills, and ambitions. }}$ \\
$\frac{\text { Set Goals }}{\bullet \quad \text { Know what you need to achieve based on self-awareness. }}$ \\
$\frac{\text { Be Motivated }}{\bullet \quad \text { Have the mindset to achieve your goals. }}$ \\
$\frac{\text { Persist }}{\bullet \quad \text { Don't give up, especially when something does not come as easily to you. }}$ \\
$\frac{\text { Monitor Performance }}{\bullet \quad \text { Know how well you are really doing. Gauge your true skill level. }}$ \\
$\frac{\text { Ask for Help }}{\bullet \quad \text { Know when you are stuck, then get help. Don't view this as a weakness. }}$ \\
$\frac{\text { Show self-efficacy }}{\bullet \text { Learn how to control the things you can control. Then control them. }}$
\end{tabular}

(D. Conley, 2012)

Table 12-Key Learning Techniques

Key Learning Techniques

- Manage Time

- Take Notes

- Study for Tests

- Memorize

- Read Strategically

- Learn Collaboratively

- Use Technology

(D. Conley, 2012)

Assessments and Evaluations

Ongoing assessments will be used to properly monitor and assess the success of the Learning

Center. Daily, students fill out brief check-in forms. To encourage monitoring performance, students check their grades and attendance online and address the following:

- Classes enrolled

- Grades in classes

- Absences

- Missing assignments

Data from these check-in forms are shown to students the first day of the week. The academic mentor and students reflect on this data to continue progress or make any necessary changes.

The data also serves to measure whether the goals of the Learning Center are being met, to inform decisions for improvement, and to increase student performance.

97 Bridging the Future to Postsecondary Readiness 


\section{Academic Element: Best Practices}

\section{Understanding by Design (UbD)}

As mentioned in Section Three, designing lessons and units are at the heart of curriculum and instruction. A very effective way to set up successful instruction and accomplish the aforementioned components is through a process known as "backward design," or Understanding by Design (UbD). This process is used to plan single units, year-long courses, or an entire curriculum. UbD must be linked to both CCSS and CRS in order to maximize postsecondary readiness. It is best to work collaboratively with other educators to share key findings and ideas.

The design process involves teachers planning in three stages, each with a focusing question:

1. Stage 1- What is worthy and requiring of understanding?

2. Stage 2- What is evidence of understanding?

3. Stage 3- What learning experiences and teaching promote understanding, interest and excellence?

Figure 8 below is a tool used by staff at CMC to help guide teachers in creating a postsecondary readiness curriculum.

\section{Figure 8-Understanding by Design}

\begin{tabular}{|c|c|}
\hline \multicolumn{2}{|c|}{ Stage 1 - Desired Results } \\
\hline \multicolumn{2}{|c|}{$\begin{array}{l}\text { Established Goals: } \\
\text { - Whal relevant goals (e.g., comlent slandards, course or program objectives, learning oulcomes) will lhis design } \\
\text { address? }\end{array}$} \\
\hline $\begin{array}{l}\text { Understandings: } \\
\text { Students will understand that ... } \\
\text { What are the big ideas? } \\
\text { - What specific understandings about them are } \\
\text { desircd? } \\
\text { - What misunderstandings are predictable? }\end{array}$ & $\begin{array}{l}\text { Q Esscntial Questions: } \\
\text { - What provocalive questions will foster inquiry, } \\
\text { understanding, and transfer of learning? }\end{array}$ \\
\hline $\begin{array}{l}\text { Students will know... } \\
\text { - What kcy knowledge and skills will students } \\
\text { acquire as a result of this unit? } \\
\text { - What should they eventually be able to do as a } \\
\text { result of such knowledge and skills? }\end{array}$ & A $\quad$ Students will be able to... \\
\hline \multicolumn{2}{|c|}{ Stage 2-Assessment Evidence } \\
\hline $\begin{array}{l}\text { Performance Tasks: } \\
\text { - Through what authentic performance tasks will } \\
\text { students demonstrate the desired understandings? } \\
\text { By what criteria will performances of } \\
\text { understanding be judged? }\end{array}$ & $\begin{array}{l}\text { Other Evidence: } \\
\text { - Through what other evidence (c.g., quizzes, tests, } \\
\text { academic prompts, observations, homework, jour- } \\
\text { nals) will students demonstrate achievement of } \\
\text { the desired results? } \\
\text { - Ilow will students reflect upon and self-assess } \\
\text { their leurning? }\end{array}$ \\
\hline \multicolumn{2}{|c|}{ Stage 3 - Learning Plan } \\
\hline \multicolumn{2}{|c|}{$\begin{array}{l}\text { Learning } \Lambda \text { ctivities: } \\
\text { What learning experiences and instruction will enable students to achieve the desired results? I low will the } \\
\text { design: } \\
\text { W = Help the students know Where the unit is going and What is expected? Help the teacher know Where the } \\
\text { students are coming from (prior knowledge, interests)? } \\
\text { II = IIook all students and IIold their interest? } \\
\mathbf{E}=\text { Equip students, help them Experience the key ideas and Explore the issues? } \\
\mathbf{R}=\text { Provide opportunities to Rethink and Revise their understandings and work? } \\
\mathbf{E}=\text { Allow students to Evaluate their work and its implication's? } \\
\text { T = Be Tailored (personalized) to the different needs, interests, and abilities of learners? } \\
\mathbf{0}=\text { Be Organized to maximize initial and sustained engagement as well as effective learning? }\end{array}$} \\
\hline
\end{tabular}

(McTighe, 2010)

98 Bridging the Future to Postsecondary Readiness 


\section{Key Cognitive Strategies}

Below is a college ready task created by EPIC where students connect the Key Cognitive Strategies with Key Content Knowledge. Staff at Clackamas Middle College have taken authentic assessments like these and modified them to fit into their vision of curriculum, instruction and assessment.

\section{$\underline{\text { Task }}$}

Students will research adolescents' financial literacy and will identify one area of personal finance that adolescents should understand more clearly. Topics might include budgeting, saving for college, planning for taxes, or investing one's income wisely. Students will then conduct research to educate themselves about this topic and identify the most important knowledge and information to share with other adolescents. They will create a brochure designed for ninth graders at their school to educate them about this topic and will also write a speech to teach the ninth graders about it.

\section{Time Frame}

Plan about one to two weeks for students to complete the task. Schedule in-class time for students to complete their research and word process their book reviews. Other work may be in or out of class, at teacher discretion.

Common Core State Standards Addressed

\section{Standards for English Language Arts Practice}

\section{Grades 11-12, Reading Informational Text}

- Cite strong and thorough textual evidence to support analysis of what the text says explicitly as well as inferences drawn from the text, including determining where the text leaves matters uncertain.

- Determine two or more central ideas of a text and analyze their development over the course of the text, including how they interact and build on one another to provide a complex analysis; provide an objective summary of the text.

99 Bridging the Future to Postsecondary Readiness 


\section{Grades 11-12, Writing}

- Write informative/explanatory texts to examine and convey complex ideas, concepts, and information clearly and accurately through the effective selection, organization, and analysis of content.

\section{Grades 11-12, Speaking \& Listening}

- Present information, findings, and supporting evidence, conveying a clear and distinct perspective, such that listeners can follow the line of reasoning, alternative or opposing perspectives are addressed, and the organization, development, substance, and style are appropriate to purpose, audience, and a range of formal and informal tasks.

\section{Prerequisite English Language Arts Knowledge and Skills}

Use the following list of assumed knowledge and skills to determine the appropriateness of this task for your students, in order to make it a fair assessment.

- How to create a brochure (using page-layout software or physical cut-and-paste techniques)

- How to interpret data that is represented in graphs and charts

- How to identify relevant sources

- How to identify the main idea and most relevant pieces of information about a technical topic for a particular audience

Each authentic performance task is broken down into sections to help teachers and students chunk specific skills tow ard college readiness. As each student gradually moves throughout each task, they are consistently checking for precision and accuracy to ensure college ready skills through the final draft. The performance expectations to guide this task are as follows:

Problem Formulation

- Hypothesize

- Write a hypothesis that contains a cause-and-effect or thesis statement.

- Be sure that your hypothesis or thesis is written so that it might be able to solve the problem in the task.

- Be sure that your hypothesis or thesis makes sense and is complete.

- $\underline{\text { Strategize }}$

- Be sure that these strategies work with the subject area.

- Be sure that your strategy or strategies address the problem in the task.

Research

- Identify

- Decide on a method for searching for information that you think will work with the problem outlined in the task.

100 Bridging the Future to Postsecondary Readiness 
Be sure that all the sources you might use are related to the problem.

- $\underline{\text { Collect }}$

Be sure that you have chosen enough sources to address your hypothesis or thesis

- Decide on a method for searching for information that you think will work with the problem outlined in the task.

- Be sure that all the sources you might use are related to the problem.

Interpretation

- Be sure that you have chosen enough sources to address your hypothesis or thesis

- Analyze

- Be sure that your analysis method will work well with the problem outlined in the task.

- Use an analysis method you remember using or one you develop to complete this section.

- Evaluate

- Check that your analysis helps you support or challenge your hypothesis or thesis.

- Select your findings that you think will help you complete the task.

- Put your findings together in a way that you think will address your hypothesis or thesis.

- Be sure that you have enough findings to support or challenge your hypothesis or thesis. Describe any changes in your thinking and your reasons for them.

Communication

- $\underline{\text { Organize }}$

- Use a logical organizational structure to create your final work product.

- Make sure your work product is organized the same way throughout the product.

- Use formats and conventions that fit with the subject area, as you create your final work product.

- Construct

- Be sure that you use the results from Problem Formulation, Research, and Interpretation in your final product.

- Make sure that each of your drafts gets better with each version. Double check that you have considered all the feedback you received.

Precision and Accuracy

- Monitor

- Be sure that your work is precise and follows the rules and conventions.

- Properly record or document your references.

- $\underline{\text { Confirm }}$

Check for technical and grammatical accuracy.

- Double check that you have followed all directions.

101 Bridging the Future to Postsecondary Readiness 
To assess each task EPIC has developed a scoring guide to set expectations. The scoring guide is intended to develop student skill throughout high school to help students be college ready by the end of high school. The guide is based on a Novice-Expert scale. The following describes the indicators under each performance expectation.

Emerging Novice-1 Complete at least most of the work and make a good effort to follow directions.

Novice -2 Complete the task and follow directions and rules well. Make sure that the information you provide in your task is correct.

Accomplished Novice-3 Show that you really understand what you are being asked to do. Start to go beyond just following directions, and use your understanding of the topic to be more efficient in the way you complete the task. Start to use some of your own ideas on how to solve the task. Begin to link up the various parts and pieces of the task.

Emerging Strategic Thinker-4 Use the directions as a guide to complete the task, rather than following them literally. Use your solid understanding of the subject area to efficiently complete the task. Explain things correctly and start to add some of your own ideas. Produce work that reads well and makes sense, with the pieces all fitting together.

Strategic Thinker-5 Show that you understand the nature of the task so well that the directions just help you identify a more efficient and complete strategy. Show elements of originality in your approach, and connect all the parts of the task together to create a strong sense of the whole. Choose a strategy that yields a full and complete solution to the task.

Accomplished Strategic Thinker-6 Demonstrate a more intuitive use of subject-area rules to go beyond their literal application. Be very efficient and creative in how you approach the task, showing strong evidence of original ideas. Structure your work around a set of core concepts to explain findings and create a well-integrated and connected final product. Develop a cogent and coherent solution strategy.

Emerging Expert-7 Show strong evidence of an intuitive and insightful use of subject-area rules. Be extremely efficient and use novel or creative ideas. Consciously organize and explain findings

102 Bridging the Future to Postsecondary Readiness 
around a set of core concepts. Effectively integrate and connect all task elements. Provide a very cogent and coherent solution strategy.

The goals for the Novice-Expert scale to prepare them for college success is shown below in Table 13.

Table 13-Novice-Expert Goals

\begin{tabular}{|c|c|}
\hline Benchmark Level & Goal \\
\hline I & Novice-2 \\
\hline II & Accomplished Novice-3 \\
\hline III & Emerging Strategic Thinker-4 \\
\hline College Ready & Strategic Thinker-5 \\
\hline
\end{tabular}

\section{Quality Instructional Practice}

Clackamas Middle College belongs to The North Clackamas School District (NCSD), and uses NCSD's model for active engagement. One of the goals of NCSD is to focus on quality instructional practices through active engagement. Like the other tools in this section, staff at Clackamas Middle College have taken this instructional model and modified it to fit into their vision of curriculum, instruction and assessment.

\section{Instructional Model for Active Engagement}

Engagement at CMC and within the NCSD is defined as the observable evidence of a learner's thinking through intentional opportunities to write, read, speak and do in a safe and risk-free environment. Educators need to engage students in making meaning. In classrooms, engagement looks like:

Students are:

- Reading, critically, annotating text with pen/pencil in hand

- Writing to learn, creating, planning, problem-solving, discussing, debating, asking questions

- Constructing new knowledge and skills by building on their current knowledge and skills

- Presenting, performing, inquiring, exploring, explaining, evaluating, experimenting

- Interacting with other students, doing, moving, gesturing

- Involved in the assessment cycle

The following components of active engagement are implemented in classes at CMC.

- Shared Learning Targets/Learning Objectives

- What do we want students to learn?

103 Bridging the Future to Postsecondary Readiness 
- Build Academic Background Knowledge

- Through Direct Vocabulary Instruction

- Guided Practice to include:

- Purposeful Reading, Writing, and Discussing

- Check for understanding

- Formative Assessments to inform practice

- How will we know if they have learned it?

- What will we do if they have?

- What will we do if they haven't?

Learning Target

A learning target is a learning outcome that focuses on the specific goal of each day's

instruction. A target states what each student will be able to understand or be able to do at the

end of a lesson or a series of lessons. Targets are not only posted but are also explicitly stated on student work and students can accurately discuss targets when prompted.

A learning target is not an instructional objective. An instructional objective connects a series of lessons. A target guides the lesson for today and connects this learning to tomorrow and future lessons. A target is the formative assessment for today's meeting. The difference between a learning target and instructional objective is shown below.

Learning Target

- Guides learning

- Written from the student point of view

- Provides a common focus for teaching

- Directly connects to the formative assessment for today, which impacts instruction for tomorrow

Instructional Objective

- Guides instruction

- Unifies outcome over a series of related lessons

- Written from the teacher's point of view

Direct Vocabulary

Direct vocabulary instruction includes the practice of identifying a small number of student/level appropriate terms that are imperative for students to own prior to reading a text, engaging in lecture, or participating in a demonstration.

\section{Guided Practice}

Guided practice involves purposeful reading, writing, and discussing. It refers to targeted opportunities for students to consistently read, write, and discuss/analyze in all subjects. Classes

104 Bridging the Future to Postsecondary Readiness 
implementing guided practice use high quality texts and provide both student and professional writing exemplars.

Checking for Understanding

Checking for understanding allows teachers to formatively assess learning. Examples of this practice include:

- Circulate, observe, and listen as students work in pairs

- Call on a sampling of students or pairs randomly between each step (not calling on students who raise their hands)

- Have students signal their understanding: thumbs up or down; red, green, yellow Popsicle sticks

- Have students hold up dry-erase boards with answers/solutions

- Exit slips/Quick Writes that demonstrate student learning

- Other formative measures to be determined by individual PLCs within buildings

Figure 9 on the next page is a tool used by staff at CMC to help guide teachers for active engagement in the classroom.

105 Bridging the Future to Postsecondary Readiness 
Figure 9- Instructional Model for Active Engagement

\begin{tabular}{|c|c|}
\hline \multicolumn{2}{|c|}{ Instructional Model for Active Engagement } \\
\hline \multicolumn{2}{|c|}{ Lesson Tool } \\
\hline \multicolumn{2}{|l|}{ Target: } \\
\hline Teacher Modeling: & Reading: \\
\hline \multicolumn{2}{|l|}{ Vocabulary: } \\
\hline Writing: & Discussing/doing: \\
\hline \multicolumn{2}{|c|}{ CHECK FOR UNDERSTANDING: } \\
\hline Next Steps: (Notes) & \\
\hline
\end{tabular}

\section{Social Element: Best Practices}

\section{College Readiness Seminar}

To address many of the Social Elements of the Postsecondary Readiness Framework, Clackamas Middle College created an advisory program aimed to prepare students for postsecondary success. This advisory program is called College Readiness Seminar and focuses on two of Conley's (see Section Four) four keys to college and career readiness: Key Learning Skills and Techniques and Key Transitional Knowledge and Skills.

106 Bridging the Future to Postsecondary Readiness 
Purpose

The purpose of the CMC's College Readiness Seminar is to develop a positive school climate and prepare students for success in CMC Pathways, post-secondary opportunities and career development.

CMC's College Readiness Seminar is designed to:

- Provide peer mentoring and social support for a positive school climate and encourage a college-going school culture.

- Encourage student engagement by ensuring that every student has at least one adult, at school, who knows and cares about him/her. Research shows that student engagement is the best prevention against dropping out.

- Enhance student achievement by helping students evaluate and reflect on their own skills, interests, and accomplishments and then make plans to improve.

How it Works

All staff members will serve as advisors to students. The seminar will be sorted according to grade level $\left(9^{\text {th }}, 10^{\text {th }}, 11^{\text {th }}, 12^{\text {th }}\right)$. Advisors in the seminar will stay with students until they enter CMC's college programs.

CMC will conduct workshops for advisors before the College Readiness Seminar begins that will go over the role of College Readiness Seminar, along with monthly trainings on best practices. In addition, copies of articles and research on excellent advising and purpose-specific demonstrations (e.g., how to review ACT assessments) will be on-going and scheduled as needed. Advisors will participate in a bi-weekly check-in/reflection during CMC staff meetings.

Advisors will nominate one student from each College Readiness Seminar group to serve on CMC's Student College Readiness Seminar Panel that will meet with the principal monthly to provide student input on school climate.

Content

The curriculum will include online and classroom-based lessons through CollegeBoard, CMC specific lessons, ACT and EPIC developed lessons and assessments.

107 Bridging the Future to Postsecondary Readiness 


\section{Ninth Grade College Readiness Seminar}

Ninth grade advisories are designed to give students a positive start in their high school careers. Emphasis will be placed on familiarization with the school and its resources, creating a collegegoing culture, and educational planning.

\section{Tenth Grade College Readiness Seminar}

Tenth grade advisories are designed to make sure students stay on the right track and grow as students. Emphasis will be placed on creating college-going culture, Pathways awareness and educational planning.

\section{Eleventh Grade College Readiness Seminar}

Eleventh grade advisories are designed to help students develop college knowledge and skills. Emphasis will be placed on self-reflection, educational planning and setting goals for life after high school.

\section{Twelfth Grade College Readiness Seminar}

Twelfth grade College Readiness Seminar is designed to guide students toward graduation and prepare for life after high school. Emphasis will be placed on career and college research, selfreflection and post-secondary planning.

\section{Assessment}

Individual students/advisees will receive .25 credit for College Readiness Seminar on a Pass/No Pass basis. To receive a Pass, students must demonstrate:

- $90 \%$ Attendance;

- Completion of grade-level portfolio checklist

- Meeting passing requirements on CMC Student Participation Rubric.

- Students, Parents, and Advisors will complete an evaluation survey of the CMC College Readiness Seminar program at the end of the school year.

- CMC will implement EPIC's CampusReady assessment on an annual basis to determine student and staff perceptions of the school's culture for college and career readiness. Student's aspirations for college will also be assessed through this measure.

- CMC will assess long-term outcomes through by tracking annual changes in graduation rates, the number of students entering into college programs, the number of students completing an Associate's Degree, and the number of students applying to postsecondary education.

108 Bridging the Future to Postsecondary Readiness 


\section{Principal}

The principal, with the help of teachers in the school, is responsible for implementing the

College Readiness Seminar program. The principal will:

- Provide encouragement and support for the program.

- Serve as an advisor.

- Communicate the goals and expectations of the College Readiness Seminar program to the school community.

- Assign teachers to be advocates and arrange for changes in student-advocates matches if necessary, in accordance with policy procedures.

- Arrange for the training of advocates.

- Oversee the communication of information to parents and the arrangements for parental involvement.

- Conduct program reviews as required.

\section{Program Coordinator}

The Program Coordinator is responsible for coordinating the logistics of the College Readiness

Seminar program. The coordinator will:

- Provide support as needed.

- Provide supplemental curriculum, program materials and resources.

- Coordinate individual and team recognition, arrange for trainings and program evaluations.

- Create monthly parent newsletter to keep parents informed of College Readiness Seminar activities.

\section{Advisors}

Advisors' responsibilities fall into the three main areas listed below.

1) Assist students with their Annual and 4/5 Year Education Plans

- Help students set goals, develop action plans, and review their plans.

- Help students prepare for transitions to a new grade, college programs, or their postsecondary destination.

- Help students access a variety of information sources on post-secondary education and career options.

2) Monitor academic achievement

- Monitor the academic progress of their students closely and refer them to school counselors, other staff, or intervention programs if needed.

- Review grades of each student assigned to them.

- Help students make connections among academic progress, their annual educational plans, and their future goals.

- Attempt to know each student in the College Readiness Seminar group on a personal basis.

- Provide an environment for the College Readiness Seminar group that will facilitate a cohesive, supportive, peer group.

3) Parental Involvement

109 Bridging the Future to Postsecondary Readiness 
- Communicate with the parents of the students assigned to them at the start of each school year (letter to parents).

- Participate in student-led conferences each year with students and their parents.

- Refer parents to subject teacher, counselors, or the principal as appropriate.

\section{Students}

Students at CMC are responsible for:

- Attending regularly scheduled College Readiness Seminar sessions.

- Participating actively in College Readiness Seminar sessions.

- Developing and completing their student portfolios and online lessons.

- Participating in student-led conferences with their advisors and their parents each year.

\section{Parents}

Parental support is a key factor in students' academic success. Parents can help their children by:

- Supporting them in reviewing their annual education plans.

- Participating in reviews of their children's education plans each year by attending any scheduled conferences.

- Helping them identify their strengths, learning style, interests, talents, skills, and needs.

- Being supportive of their goals, pointing out their strengths and accomplishments, encouraging them to explore options for their future, and encouraging them to ask for help when they need it.

School Resources and Supports

\section{Counselors}

Advisors are encouraged to make referrals to the counselors as appropriate. Contact may be made with the counselor assigned to work with students in a specific grade or to any counselor individually. Seniors will also be assigned an Aspire Mentor that will meet with them regularly to help them complete senior internship requirements, college applications, etc.

\section{Student Achievement Planning (SAP)}

Advisors are encouraged to work with the other staff to make referrals to the Student Achievement Planning Program. An appropriate plan of action will be agreed upon. Interventions may include one or more of the following: modification or adaptations to the general education program, assessment, parental involvement, changes in behavior, monitoring, counseling, or community services. Advisors will bring the student's portfolio file to SAP meetings as necessary.

110 Bridging the Future to Postsecondary Readiness 
Other Structural, Academic, and Social Best Practices

This section was designed to provide a few concrete examples from a high school on how they are educating students within the structural, academic and social elements of a postsecondary readiness framework.

Staff at Clackamas Middle College measures their successes through student attainment of college credit, and college degree/certificates. When these are accomplished, then CMC is preparing students for postsecondary success. Graduates will leave CMC with a sense of purpose, identity, accomplishment, and connectedness to their future. It is through this connection between school and their future that postsecondary skills are built.

In addition to the best practices listed above in this section, other best practices are listed on the next page. These provide a comprehensive approach and help students, staff, and families at CMC establish a culture of postsecondary success.

111 Bridging the Future to Postsecondary Readiness 


\section{Other Best Practices at Clackamas Middle College}

\section{Structural Elements}

- School leaders are assigned to capture data, record it into a data system, and analyze it to help influence culture and environment, curriculum, instruction and assessment. This data should be reviewed by committees and staff members regularly throughout the year.

- The Pathways to College Program allows students (in cohorts) to accelerate their learning both socially and academically through entry level college courses.

- College courses are contracted with the partnering college to offer dual high school/college credit.

- All students graduate with a high school diploma along with a college degree/certificate and/or a college transcript.

\section{Academic Elements}

- A bi-monthly student achievement planning session is held with all staff to identify individual student need and support for improvement.

- A service learning class requiring service to the community allows juniors the opportunity to serve the community and participate in civic engagement.

- A internship experience allows seniors the opportunity to explore future career choices.

\section{Social Elements}

- New students take college entrance exams for enrollment, tour the partnering college campus, and attend an awareness session of school expectations.

- Credit and degree attainment is measured, collected and presented to current/future students and families, educational leaders, and community members.

- An "I Am College" wall is created to display the postsecondary programs each graduating senior will be attending.

- Student-led conferences allow students the opportunity to connect with family and share personal, academic and career goals.

112 Bridging the Future to Postsecondary Readiness 
SECTION 6:

\section{POSTSECONDARY READINESS RESOURCES}

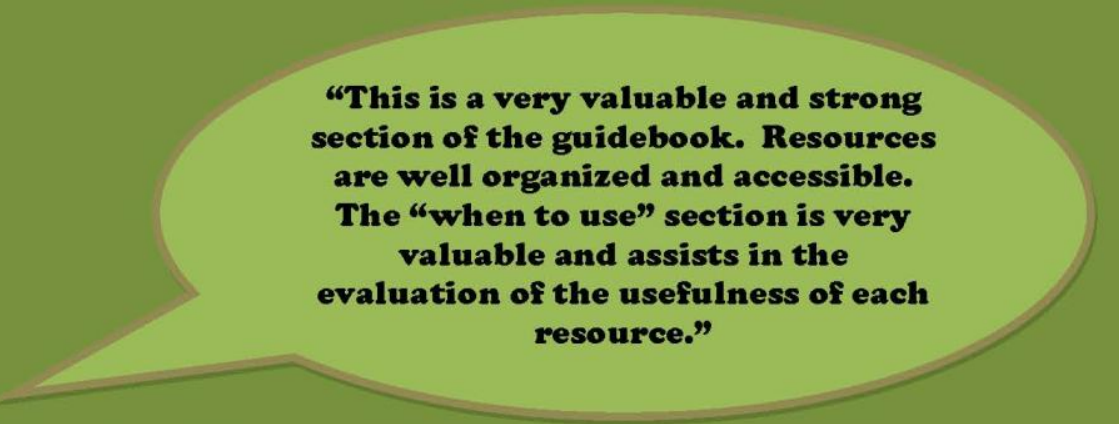

Leslie (Middle Sehool Language Arts)

"This guidebook definitely provides a comprehensive

framework around postsecondary readiness and gives educators a compass on how to navigate within this framework." 


\section{Design Question 6}

What are some resources that can help schools set up a culture of postsecondary readiness?

\section{Target 6}

\section{-}

\section{Postsecondary Readiness Resources}

This section is set up to help schools in their journey toward postsecondary readiness. After going through the first five sections of this guidebook, educational leaders may need further development of the elements within the postsecondary readiness framework. This section is to deepen the knowledge of the best practices within this framework. These resources were selected to support the learning, planning, and implementation of school programs and strategies required to prepare students for postsecondary success.

The collection responds to the structural, academic, and social elements listed in this guidebook. These components include:

- Smart use of data to address student needs and monitor progress

- A culture of postsecondary success for all at the school, district, and community level

- Adult learning and support, including professional learning and planning time

- Student learning and support for success in a rigorous, challenging curriculum

- Youth development supports to help connect aspirations to a plan

- Transition supports from secondary schooling to higher education

These resources will help school teams select tools most appropriate for their current work toward postsecondary preparedness. This section contains 13 descriptions of resources, lists the target users, and describes when to use the resource. Each description also contains, where appropriate, helpful tips and advice for using the resource. Please note that most of the descriptions are either paraphrased from or taken directly from the resource website.

114 Bridging the Future to Postsecondary Readiness 


\title{
Clackamas Middle College (CMC)
}

\author{
$\underline{\text { http://www.clackamasmiddlecollege.org/ }}$
}

Target Users

School leaders, teachers, and other practitioners, and district administrators

\section{When to Use These Resources}

Use this resource when looking at the creating a postsecondary readiness culture. This site provides the application of the structural, academic, and social elements within the postsecondary readiness framework discussed in this guidebook.

\section{Focus of These Resources}

Clackamas Middle College (CMC) is a four-year high school college transition program enrolling 300 students in grades 9-12. It is accredited by the Northwest Accreditation Commission. While CMC is sponsored by the North Clackamas School District, some of our students live in neighboring districts. Between 130-170 students are enrolled in our unique College Prep Program which prepares students for college classes. Around 35-50 students begin their transition to college classes in our Pathways to College Program. Over 115 of our students participate in our College Extended Options (CEO) program by enrolling in community college courses.

The school opened in September, 2003, and to this date, Clackamas Middle College has graduated over 400 students, all of which left us with college transcripts, college credits and college transfer degrees or college certificates.

CMC is designed to give students the opportunity to earn both high school and college credits simultaneously with the goal of earning a high school diploma, a transfer degree, or certificate of completion. Students begin their courses in our College Prep Program on our campus and transition to college classes through our Pathways to College (PTC) and College Extended Options (CEO) Programs at Clackamas Community College. Six on-campus teachers, two counselors, one school-to-careers coordinator, one administrator, and one secretary collaborate extensively with each other and our community college partners to maximize student success. Visiting instructors from Clackamas Community College come to the CMC campus daily and teach classes throughout the year. Other students take their courses exclusively at community colleges through our Pathways to College (PTC) and College Extended Options (CEO) Programs.

\section{Recommendations}

To maximize the potential of this resource, it is recommended that schools interested in CMC's approach to postsecondary preparedness contact school leadership for collaboration toward setting and maintaining a postsecondary readiness culture.

\footnotetext{
115 Bridging the Future to Postsecondary Readiness
} 


\title{
Education for the Future (EFF)
}

\author{
$\underline{\text { http://eff.csuchico.edu/html/home.html }}$
}

\section{Target Users}

School leaders, teachers, and other practitioners, and district administrators

\section{When to Use These Resources}

Use this resource when your school would like to gather, analyze, and use data to continuously improve teaching and learning. EFF provides educational leaders with a framework for school improvement.

\section{Focus of These Resources}

Education for the Future staff works with organizations as large as the U.S. Department of Education/International Education Ministries, and as small as rural schools to facilitate the use of school portfolios and the use of comprehensive data analysis for continuous school improvement.

One of the many ways EFF works with people in implementing systemic change and comprehensive data analyses that lead to increased student learning is by providing a variety of professional learning services.

Professional Learning content has evolved naturally from their research and is created together with the end users. The research is typically focused on data-driven work that incorporates systems theory and practice. Over time, professional learning opportunities have expanded into deeper content that fuels change and meets new and evolving needs of educators and students.

\section{Recommendations}

To maximize the potential of EFF, it is recommended that schools interested in these resources should attend EFF's Professional Learning Offerings such as:

Workshops

Data/School Improvement Institutes

$>$ Train The Trainers Sessions

$>$ Conference Sessions

$>$ International Work

$>$ Work With Universities

$>$ Questionnaire Support Services

$>$ General Consulting Services

116 Bridging the Future to Postsecondary Readiness 


\section{Education Policy and Improvement Center (EPIC)}

$>$ http://www.epiconline.org/

Target Users

School leaders, teachers, and other practitioners, students, and administrators

\section{When to Use These Resources}

EPIC has created tools and resources to increase school's capacity to prepare all students for higher education, based upon David Conley's four facets (Key Cognitive Strategies, Key Content Knowledge, Key Learning Skills and Techniques, and Key Transition Knowledge and Skills).

Through research, EPIC designed a system of tools designed to equip educators with what they need to prepare students for success beyond high school. The College and Career Readiness System is comprised of three distinct categories: Calibrate, Create, and Connect.

\section{CALIBRATED}

Diagnostics that measure college and career readiness with greater precision

ThinkReady- Developing thinking strategies for postsecondary success and lifelong learning.

$>$ CampusReady- Analyzing school programs and culture for college and career readiness.

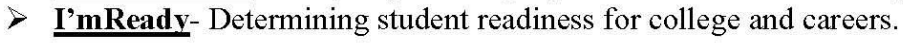

CREATE

Applications that increase college and career readiness through changes to courses

$>$ CourseCreate- Producing syllabi for college and career ready courses.

$>$ CourseAlion- Aligning courses to college and career readiness expectations.

$>$ CoursePathway- Creating school-wide course pathways aligned to college and career readiness.

CONNECT

Processes that strengthen linkages with postsecondary education

$>$ ReadinessBridge- Connecting secondary school coursework to college-level expectations.

$>$ ReadinessConnect- Connecting secondary school and college courses.

$>$ ReadinessPartner- Connecting secondary and postsecondary faculty and administrators to college and career readiness.

\section{Focus of These Resources}

These resources are based on the research of David Conley, the CEO of EPIC, and his numerous publications about preparing students for college and careers.

\section{Recommendations}

Schools will develop an extensive profile using these tools. It is important for teams of teachers to design a process for reviewing the data and for targeting areas of high need and for assigning responsibilities for moving forward. For example, who will organize professional development sessions or professional learning community work to improve weak areas identified?

117 Bridging the Future to Postsecondary Readiness 


\section{ACT (American College Test) \\ $>$ http://www.act.org/ \\ $>$ http:/www.act.org/engage/ \\ $>$ http://www.act.org/products/k-12-act-explore/ \\ $>$ http://www.act.org/products/k-12-act-plan/}

Target Users

Leadership teams, teachers, central office staff, and parents

\section{When to Use These Resources}

$>$ To help schools consider what programs are no longer useful or affordable, given their goals.

$>$ To measure student skills in various areas

$>$ To understand an instruction-centered approach for moving beyond the vision of the comprehensive high school as a model of excellence.

$>$ As background reading for stakeholders concerned with improving student learning and ensuring that each student graduates ready for postsecondary success.

\section{Focus of These Resources}

ACT's range of assessments and reporting systems have been developed with more than 50 years of experience behind them.

Most know this nonprofit organization as being responsible for the ACT test - the college admissions and placement test taken by more than 1.6 million high school graduates every year. In addition, they provide more than a hundred other assessment, research, information, and program management services for education and workforce development. They serve elementary and secondary schools, colleges, professional associations, businesses, and government agencies - nationally and internationally.

Currently, ACT is developing a next generation assessment system designed to provide students, parents, and educators with the actionable information they need to measure and improve student performance from the earliest grades. This system, ACT Aspire, will help students stay on target to reach their full potential throughout their educational journey.

\section{Recommendations}

Schools provide ACT diagnostics to measure student skills.

$>$ Results from these assessments should be included in advisory programs to help students match up their skills to their college and career choices.

$>$ Schools should critically examine the assessment results to provide a focal point for school improvement in curriculum, instruction and assessment.

\footnotetext{
118 Bridging the Future to Postsecondary Readiness
} 


\section{Professional Learning Communities (PLC's)}

http://www.allthingsplc.info/

Target Users

School leaders, teachers, counselors, and district administrators

\section{When to Use These Resources}

This site is a collaborative, objective resource for educators and administrators who are committed to enhancing student achievement. This site helps educators share their knowledge, ask questions, and get expert insight into the issues educators face each day in the classroom.

\section{Focus of These Resources}

The very essence of a learning community is a focus on and a commitment to the learning of each student. When a school or district functions as a PLC, educators within the organization embrace high levels of learning for all students as both the reason the organization exists and the fundamental responsibility of those who work within it. In order to achieve this purpose, the members of a PLC create and are guided by a clear and compelling vision of what the organization must become in order to help all students learn. They make collective commitments clarifying what each member will do to create such an organization, and they use results-oriented goals to mark their progress. Members work together to clarify exactly what each student must learn, monitor each student's learning on a timely basis, provide systematic interventions that ensure students receive additional time and support for learning when they struggle, and extend and enrich learning when students have already mastered the intended outcomes.

A corollary assumption is that if the organization is to become more effective in helping all students learn, the adults in the organization must also be continually learning. Therefore, structures are created to ensure staff members engage in job-embedded learning as part of their routine work practices.

There is no ambiguity or hedging regarding this commitment to learning. Whereas many schools operate as if their primary purpose is to ensure that children are taught, PLCs are dedicated to the idea that their organization exists to ensure that all students learn essential knowledge, skills, and dispositions. All the other characteristics of a PLC flow directly from this epic shift in assumptions about the purpose of the school.

(Source: AllThingsPLC website, cited above)

\section{Recommendations}

Educators should only use these resources if they are interested in the following:

Gathering evidence of current levels of student learning

$>$ Developing strategies and ideas to build on strengths and address weaknesses in that learning

$>$ Implementing those strategies and ideas

$>$ Analyzing the impact of the changes to discover what was effective and what was not

$>$ Applying new knowledge in the next cycle of continuous improvement

119 Bridging the Future to Postsecondary Readiness 


\title{
Common Core State Standards (CCSS)
}

\author{
$\underline{\text { http://www.corestandards.org/ }}$
}

Target Users

School leaders, teachers, and other practitioners, and district administrators

\section{When to Use These Resources}

Educators look to these resources when searching for a consistent, clear understanding of what students are expected to learn. This will help teachers and parents know what they need to do to help provide support to students. These standards are designed to be robust and relevant to the real world, reflecting the knowledge and skills that our young people need for success in college and careers. With American students fully prepared for the future, our communities will be best positioned to compete successfully in the global economy.

\section{Focus of These Resources}

Building on the excellent foundation of standards states have laid, the Common Core State Standards are the first step in providing our young people with a high-quality education. It should be clear to every student, parent, and teacher what the standards of success are in every school.

Teachers, parents and community leaders have all weighed in to help create the Common Core State Standards. The standards clearly communicate what is expected of students at each grade level. This will allow our teachers to be better equipped to know exactly what they need to help students learn and establish individualized benchmarks for them. The Common Core State Standards focus on core conceptual understandings and procedures starting in the early grades, thus enabling teachers to take the time needed to teach core concepts and procedures well - and to give students the opportunity to master them.

With students, parents and teachers all on the same page and working together for shared goals, we can ensure that students make progress each year and graduate from school prepared to succeed in college and in a modern workforce.

\section{Recommendations}

$>$ These resources: provide goals and benchmarks to ensure students are achieving certain skills and knowledge by the end of each year

$>$ These resources: help colleges and professional development programs better prepare teachers

$>$ These resources: providing the opportunity for teachers to be involved in the development of assessments linked to these top-quality standards

$>$ These resources: allow states to develop and provide better assessments that more accurately measure whether or not students have learned what was taught

$>$ These resources: guide educators toward curricula and teaching strategies that will give students a deep understanding of the subject and the skills they need to apply their knowledge

120 Bridging the Future to Postsecondary Readiness 


\title{
Authentic Education (UbD)
}

\author{
http://www.authenticeducation.org/
}

Target Users

Teachers, administrators, and students

\section{When to Use These Resources}

This site's aim is to provide a framework for improving student achievement through Understanding by Design (UbD). This site emphasizes the teacher's role as a designer of student learning. It helps teachers to clarify learning goals, devise revealing assessments of student understanding, and craft effective and engaging learning activities.

\section{Focus of These Resources}

The mission of Authentic Education is to make schools better by providing our clients with stateof-the-art educational thinking, tools, and training. They aim to leave educators equipped to tackle challenging issues. They empower educational leaders to make school more learningcentered and results focused. Capacity is built through providing services, products, and fresh ideas for helping schools make student performance the central focus of school.

Their mission is informed with the following four beliefs:

$>$ Excellence in schooling requires a vigilant focus on learning - and, specifically, learning for understanding.

$>$ All education is local.

$>$ Schooling needs to be grounded in more authentic forms of learning.

$>$ Education succeeds if and only if everyone in schools gets constant and powerful feedback, and is obligated to seek it and consider it.

(Source: Authentic Education website, cited above)

\section{Recommendations}

To maximize the potential of Authentic Education, it is recommended that schools interested in these resources attend Authentic Education's Professional Learning Offerings such as:

Consultations

$>$ Training

$>$ Workshops

$>$ Custom research and review of materials

$>$ Teleconferences and video conferences

\section{Bridging the Future to Postsecondary Readiness}




\title{
Learning Sciences Marzano Center
}

\author{
http://www.marzanocenter.com/
}

Target Users

School leaders, teachers, and district administrators

\section{When to Use These Resources}

This site's aim is to provide and develop next-generation teacher and leadership evaluation tools and training. It develops and disseminates cutting-edge resources in educational best practices. Their goal is to support teachers to be highly effective, lifelong learners, and in doing so, to significantly impact student growth and achievement over time.

\section{Focus of These Resources}

This site specializes in deep implementation of continuous-teacher-growth systems, focusing on best practices to support teachers in improving their daily instruction. These growth systems help ensure:

Better students through better teachers

$>$ Less underperforming teachers, improved morale and improved instruction

$>$ Teachers and students moving toward meeting local, state, and national standards

$>$ Specialization and support

$>$ Educators working toward the same goals, with a common language

$>$ A sustainable system through implementation

$>$ Maximum buy-in

\section{Recommendations}

To maximize the potential of Learning Sciences Marzano Center, it is recommended that schools form committees to research the best practices/literature involved in the continuous-teachergrowth systems. It is recommended that committees focus on the following literature to set a foundation of knowledge prior to implementation:

Transforming Classroom Grading

$>$ Designing \& Teaching Learning Goals \& Objectives

$>$ Leaders of Learning: How District, School, and Classroom Leaders Improve Student Achievement

$>$ District Leadership that Works: Striking the Right Balance

$>$ Classroom Management That Works: Research-Based Strategies for Every Teacher

$>$ The Art and Science of Teaching: A Comprehensive Framework for Effective Instruction

$>$ School Leadership That Works: From Research to Results

$>$ Classroom Assessment and Grading That Work

$>$ A Handbook for Classroom Management That Works

$>$ Effective Supervision: Supporting the Art and Science of Teaching

\section{Bridging the Future to Postsecondary Readiness}




\section{Focus (Dr. Mike Schmoker)}

$\underline{\text { http://mikeschmoker.com/ }}$

Target Users

Teachers, administrators, and students

When to Use These Resources

This site's aim is to help stakeholders in education who are straining under the weight of multiple initiatives, and who are frustrated with the latest movements in education. It helps them return to the basics of learning. The focal point of this site is Schmoker's book, Focus:

Elevating the Essentials to Radically Improve Student Learning.

The book helps new teachers focus on the essentials of curriculum and lessons, and will help veterans, weary of one solution to educating all, to rediscover the joy of teaching with purpose. The book also helps students who are depending on leaders and policymakers to listen to the evidence, and focus on learning.

\section{Focus of These Resources}

Schmoker helps to provide practical PLC tools and documents so that educators can better focus on learning. He provides resource within the following categories:

$>$ Administrative Team Protocols

$>$ Team Protocols and Norms - Lesson Plan Protocols

$>$ Tips and Recommendations to Write More and Grade Less

\section{Recommendations}

To maximize the potential of Dr. Schmoker's approach, it is recommended that educational leaders within schools read Focus: Elevating the Essentials to Radically Improve Student Learning. focus on learning Committees to research the best practices/literature involved in the continuous-teacher-growth systems. It is recommended that committees focus on the following literature to set a foundation of knowledge prior to implementation:

Focus: Elevating the Essentials to Radically Improve Student Learning

$>$ More Argument, Fewer Standards

$>$ When Pedagogic Fads Trump Priorities - Education Week

$>$ Planning for Failure? Or for School Success? - Education Week

$>$ The 'Crayola Curriculum' - Education Week

$>$ Tipping Point: From Feckless Reform to Substantive Instructional Improvement-Phi Delta Kappan

$>$ First Things First: Demystifying Data Analysis- Educational Leadership

$>$ Realizing the Promise of Standards-Based Education- Educational Leadership

123 Bridging the Future to Postsecondary Readiness 


\section{The College Board}

$>$ http://www.collegeboard.org/

Target Users

School leaders, teachers, counselors, and district administrators

\section{When to Use These Resources}

Educators looking to provide students with access to a high-quality education, and to prepare them for success in college. Their College Readiness initiatives promote curricula, assessment tools, district and guidance resources that help K-12 students prepare for the academic rigors of higher education.

\section{Focus of These Resources}

Educators looking to provide students with access to a high-quality education, and to prepare them for success in college. Their College Readiness initiatives promote curricula, assessment tools, district and guidance resources that help K-12 students prepare for the academic rigors of higher education. Their college readiness programs include:

$>$ Advisory Programs

$>$ Advanced Placement (AP)

$>$ SpringBoard

$>$ ReadiStep

$>$ CollegeEd

$>$ CLEP

$>\mathrm{PSAT} / \mathrm{NMSQT}$

$>$ EXCELerator

The College Board helps students connect with and successfully complete a high-quality college education. They provide resources, tools and services to students, parents, colleges and universities in the areas of college planning, recruitment and admissions, financial aid, and retention. The SAT and Student Search Service programs alone have helped millions of students of diverse backgrounds learn about colleges, apply and enroll. The College Connection and Success programs and resources comprise:

SAT, SAT Subject Tests and SAT Readiness Tools

$>$ Student Search Service

$>$ BigFuture (our college planning site)

$>$ College Search

$>$ CSS/Financial Aid PROFILE

$>$ Scholarship Search

\section{Recommendations}

To maximize the potential of The College Board, it is recommended that schools familiar with the programs and resources listed above form a committee to research the website prior to the implementation of any new programs.

124 Bridging the Future to Postsecondary Readiness 


\section{National Association of Secondary School Principals (NASSP) \\ $>$ http://www.principals.org/}

\section{Target Users}

Student leaders, school leaders, district administration, and policy makers

\section{When to Use These Resources}

This site's aim is to provide student leaders, school leaders and district administration with resources, professional development, and advocacy to prepare students for postsecondary learning opportunities.

\section{Focus of These Resources}

In existence since 1916, NASSP is the preeminent organization of and national voice for secondary school principals, assistant principals, and aspiring school leaders from across the United States and more than 45 countries around the world. The mission of NASSP is to promote excellence in school leadership.

School Leaders

NASSP provides members with the professional research-based and peer-tested resources, and practical tools and materials they need to serve as visionary school leaders.

Through award winning publications, professional development opportunities, ready access to relevant research, and persistence in advocating on behalf of school leaders, NASSP helps to advance secondary school education by:

Promoting high professional standards

$>$ Focusing attention on school leaders' challenges

$>$ Providing a "national voice" for school leaders

$>$ Building public confidence in education

$>$ Strengthening the role of the principal as instructional leader

$>$ Publicizing the issues and interests of our members in the news media

Student Leaders

NASSP also promotes the intellectual growth, academic achievement, character and leadership development, and physical well-being of youth. NASSP has founded the following student leadership programs:

$>$ National Honor Society and National Junior Honor Society

$>$ National Association of Student Councils

$>$ National Elementary Honor Society

(Source: Authentic Education website, cited above)

\section{Recommendations}

Membership into the NASSP provides resources and guidance for school and student leaders.

125 Bridging the Future to Postsecondary Readiness 


\section{American School Counselor Association (ASCA) \\ $>$ http://www.schoolcounselor.org/}

\section{Target Users}

Student leaders, school leaders, district administration, and parents

\section{When to Use These Resources}

This site's aim is to provide school counselors' efforts to help students focus on academic, personal/social and career development so they achieve success in school and are prepared to lead fulfilling lives as responsible members of society.

These resources should be used by student leaders, school leaders, district administration, and parents for professional development, publications and other resources, research and advocacy.

\section{Focus of These Resources}

The American School Counselor Association (ASCA) is the foundation that expands the image and influence of professional school counselors through advocacy, leadership, collaboration and systemic change. ASCA empowers professional school counselors with the knowledge, skills, linkages and resources to promote student success in the school, the home, the community and the world.

\section{ASCA's Mission}

The mission of ASCA is to represent professional school counselors and to promote professionalism and ethical practices.

ASCA's Goals and Objectives

$>$ Professional development opportunities in areas of critical need are made available to all professional school counselors.

$>$ Timely, relevant information exists to enhance professional school counselors' level of skill and professionalism.

$>$ Legislative policy exists that supports professional school counselors and child advocacy.

$>$ ASCA initiates and supports relevant research and evaluation in school counseling.

$>$ Professional and ethical standards articulate the code of conduct and professional behavior for professional school counselors.

$>$ Strategic partnerships with stakeholders exist to benefit professional school counselors and their students.

$>$ Leaders at local, state and national levels champion and lead change initiatives.

$>$ ASCA maintains an organizational structure and administrative functions that facilitate the accomplishment of the goals and objectives.

(Source: $A S C A$ website, cited above)

\section{Recommendations}

Membership into the ASCA provides resources and guidance for counselors and educational leaders.

126 Bridging the Future to Postsecondary Readiness 


\section{Gateway to College National Network \\ $>$ http://www.gatewaytocollege.org/}

\section{Target Users}

School and community college partners, and school counselors

\section{When to Use These Resources}

Use this resource when planning intervention strategies for high school dropouts and those at risk for dropping out so that these students may earn a diploma and get a jump-start on college credits. It could also prove very useful for schools and colleges trying to form effective partnerships to help at-risk students stay in and graduate from school.

\section{Focus of These Resources}

Portland Community College (Portland, Oregon) created the Gateway to College program in 2000 to help reconnect high school dropouts with their education. Through the program, students complete their high school diploma requirements at community and technical colleges while simultaneously earning college credits toward an associate's degree or certificate. The Bill and Melinda Gates Foundation funded the replication of Gateway to College as part of its Early College High School Initiative. Since 2003, Gateway to College has evolved from a single-site program into a national network of 43 colleges in 23 states partnering with more than 125 school districts.

In addition to the Gateway program, the site also includes information about Project Degree, which helps underprepared college students (ages 18-26) accelerate their progress through developmental education courses in college and to transfer successfully to full-credit college courses.

Gateway to College also helps:

$>$ Build partnerships that connect K-12 and higher education institutions and communities

$>$ Influence systems by creating change agents who are transforming instruction and student support practices from the inside out

$>$ Conduct research and share findings about how to successfully serve high school dropouts and academically underprepared college students

$>$ Effect policy and regulatory changes to ensure that Gateway to College and other alternative education models are available in every community that needs them

$>$ Provide customized consulting services to colleges and school districts

The National Network also provides ongoing training, technical assistance, and professional development opportunities to Gateway and Project Degree programs across the country.

\section{Recommendations}

To be effective, high schools need to form partnerships with their local community colleges and co-design an appropriate intervention strategy for re-capturing dropouts and re-engaging those at risk. Schools and communities need to accept ownership of these students and be committed to their educational success.

127 Bridging the Future to Postsecondary Readiness 


\section{About the Author}

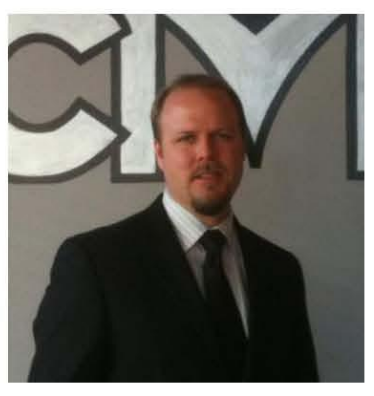

Brian Sien is the current principal of Clackamas Middle College outside of Portland, Oregon. He has over 18 years experience as an educator. During this time, Brian has worked in educational systems throughout three different states: Montana, Arizona, and Oregon. He has taught for ten years before going into administration. His experience is with both traditional and charter public schools. His passion is working with students, teachers, administrators and state leaders to help provide a seamless transition from K-12 education to postsecondary education for all stakeholders. He graduated with a Bachelor of Arts from the University of Montana with a major in English Education and a minor in Spanish. He earned a Master's of Science degree with a major in Curriculum and Instruction from Portland State University. He is currently finishing up a degree of Doctor of Education in Educational Leadership: Administration through Portland State University. 


\section{REFERENCES}

ACT, Inc. (2009). Connecting College Readiness Standards to the Classroom.

ACT, Inc. (2008). The forgotten middle: Ensuring that all students are on target for college-and career readiness before high school. Retrieved from http://www.act.org/research/policymakers/reports/ForgottenMiddle.html

Advisory Programs Help Improve Academic Performance and Postsecondary Planning. (2012, February 1). Retrieved February 12, 2013, from http://esrnational.org/2012/02/advisory/

Bernhardt, V. L. (2002). The school portfolio toolkit: A planning, implementation, and evaluation guide for continuous school improvement. Eye on Education.

Bernhardt, V. L. (2005). Using Data to Improve Student Learning in High Schools. Eye on Education, 320.

Bill and Melinda Gates Foundation. (2009). College-Ready For All: Preparing Students For Success.

Bloom, T. (2011). College and Career Readiness A Systemic P-20 Response. Retrieved from http://64.58.86.235/uploads/documents/hobsons_industryreport_collegeandcareerreadines s_p20response.pdf

Bolman, L. G., \& Deal, T. E. (2008). Reframing organizations: Artistry, choice, and leadership. Jossey-Bass Inc Pub.

Boyer, E. L. (1983). High school: A report on secondary education in America. Harper \& Row, Inc., 10 East 53rd Street, New York, NY 10022 (\$15.00).

Cabrera, A. F., \& La Nasa, S. M. (2000). Understanding the College-Choice Process. New Directions for Institutional Research, 2000(107), 5-22.

129 Bridging the Future to Postsecondary Readiness 
Carey, K. (2004). A matter of degrees: Improving graduation rates in four-year colleges and universities. The Education Trust. Retrieved January, 16, 2007.

Carnevale, A. P., Smith, N., \& Strohl, J. (2010). Help Wanted-Projections of Jobs and Education Requirements Through 2018 (p. 122). Georgetown University.

Casillas, A., Allen, J., Kuo, Y., Pappas, S., Hanson, M. A., \& Robbins, S. (2011). Development and validation of ENGAGE grades 6-9. ACT Research Report Series, 2011-1). Iowa City, IA: ACT, Inc. Retrieved from http:/www. act. org/research/researchers/reports/pdf/ACT_RR2011-1. pdf. Retrieved from http://myweb.uiowa.edu.proxy.lib.pdx.edu/yilkuo/ACT_RR2011-1.pdf

Chenoweth, T. G., \& Everhart, R. B. (2002). Navigating comprehensive school change: A guide for the perplexed. Eye On Education, Inc.

Conley, D. (2012a, May 22). Making More Students College and Career Ready. Symposium presented at the Advisory Committee on Student Financial Assistance Symposium, Portland, Oregon.

Conley, D. (2012b, May 22). Making More Students College and Career Ready. Symposium presented at the Advisory Committee on Student Financial Assistance (ACSFA) Symposium, Portland, Oregon.

Conley, D. ., \& McGaughy, C. (2012). College and Career Readiness: Same or Different? EDUCATIONAL LEADERSHIP, 69(7), 28-34.

Conley, D. T. (2007). Redefining college readiness. Educational Policy Improvement Center, 3. Retrieved from http://inside.redwoods.edu/basicskills/documents/1.RedefiningCR_Vol3_Copy.pdf

130 Bridging the Future to Postsecondary Readiness 
Conley, D. T. (2010). College and career ready: Helping all students succeed beyond high school. Jossey-Bass.

Conley, D. T. (2012). A Complete Definition of College and Career Readiness. Educational Policy Improvement Center. Retrieved from http://69.43.173.105/d1/eve_natcon/nc12_four_keys_handout2.pdf

Cota-Robles, E. H., \& Gordan, E. W. (1999). Reaching the top: A report of the national task force on minority high achievement. New York: The College Board.

Griffiths, M. (1998). The discourses of social justice in schools. British Educational Research Journal, 24(3), 301-316.

Haycock, K., Barth, P., Mitchell, R., \& Wilkins, A. (1999). Ticket to Nowhere: The Gap between Leaving High School and Entering College and High-Performance Jobs. Thinking $K-16,3,34$.

Ingels, S. J., Curtin, T. R., Kaufman, P., Alt, M. N., \& Chen, X. (2002). Coming of Age: 12 Years Later. EDITORIAL NOTE, 4(2), 7.

Kitzhaber, J. (2011, February 22). Amended Executive Order No. 11-02 Oregon Education Investment Team.

Lee, V. E., \& Smith, J. B. (1995). Effects of high school restructuring and size on early gains in achievement and engagement. Sociology of Education, 68(4), 241-270.

Manning, M. L., \& Saddlemire, R. (1998). High school advisory programs: The Roosevelt Roads experience. The Clearing House, 71(4), 239-241.

McAlister, S., Mevs, P., Lee, J., Rodriguez, E., \& Kim, H. (2012). ABOUT GATES COLLEGE READINESS INDICATOR SYSTEMS. Retrieved from http://www.smarteducationsystems.org/sites/default/files/CRIS_Guide.pdf

\footnotetext{
131 Bridging the Future to Postsecondary Readiness
} 
McTighe, J. (2010). Understanding by design. Retrieved from

http://rt3region7.ncdpi.wikispaces.net/file/view/Intro+to+UBD+Handouts.pdf

Odden, A., \& Wallace, M. (2003). Leveraging teacher pay: How we can raise student achievement through better systems of compensation. Education Week, 23, 64.

Oregon Department of Education. (2006, April). A Toolkit for Family Involvement in Education.

Oregon.gov. (2011, August). Oregon Education Investment Board. Governor John Kitzhaber. oregon.gov. Retrieved from

http:/www.oregon.gov/Gov/Pages/oeib/OregonEducationInvestmentBoard.aspx\#Oregon Education_Investment_Board_OEIB_

Pascarella, E. T., \& Terenzini, P. T. (1991). How college affects students. Jossey-Bass San Francisco, Cal.

Powell, A. G., \& others. (1985). The Shopping Mall High School. Winners and Losers in the Educational Marketplace. NASSP Bulletin, 69(483), 40-51.

Robbins, S. B., Lauver, K., Le, H., Davis, D., Langley, R., \& Carlstrom, A. (2004). Do psychosocial and study skill factors predict college outcomes? A meta-analysis. Psychological bulletin, 130(2), 261.

Schmoker, M. (2006). Results Now: How We Can Achieve Unprecedented Improvements in Teaching and Learning. Association for Supervision and Curriculum Development. 1703 North Beauregard Street, Alexandria, VA 22311-1714. Tel: 800-933-2723; Tel: 703-5789600; Fax: 703-575-5400; Web site: http://www. ased. org.

Senge, P. M. (1997). The fifth discipline. Measuring Business Excellence, 1(3), 46-51.

\footnotetext{
132 Bridging the Future to Postsecondary Readiness
} 
Shechtman, N., DeBarger, A. H., Dornsif, C., Rosier, S., \& Yarnall, L. (2013). Promoting Grit, Tenacity, and Perseverance: Critical Factors for Success in the 21 st Century. U.S. Department of Education.

State of Oregon. Mission of education beyond high school., Pub. L. No. Chapter 351 (2011). Retrieved from http://www.leg.state.or.us/ors/351.html

Tough, P. (2009). Whatever it takes: Geoffrey Canada's quest to change Harlem and America. Mariner Books. Retrieved from http://books.google.com.proxy.lib.pdx.edu/books?hl=en\&lr=\&id=qNevESIWhhOC\&oi=f nd\&pg $=$ PA1\&dq $=$ whatever + it + takes\%2Btough\&ots=N3bu53XW6r\&sig=NNy9qiTWc5rYXHOJT2cpe7fCgM

U.S. Department of Education. (2009, November). Race to the Top Program Executive Summary.

Wimberly, G. L., \& Noeth, R. J. (2005). College readiness begins in middle school. Iowa City, IA: $A C T$.

Wolk, R. A., \& Jobs for the Future, B. (2005). "It's Kind of Different": Student Experiences in Two Early College High Schools. Jobs for the Future. Retrieved from http://stats.lib.pdx.edu.proxy.lib.pdx.edu/proxy.php?url=http://search.ebscohost.com/logi n.aspx?direct $=$ true $\& \mathrm{db}=$ eric $\& A \mathrm{~N}=\mathrm{ED} 497811 \&$ site $=$ ehost-live

133 Bridging the Future to Postsecondary Readiness 